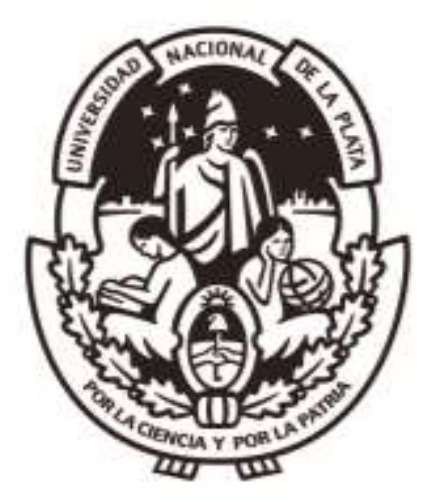

\title{
CONVERSIÓN DE BIOMASA EN PRODUCTOS QUÍMICOS VALIOSOS Y COMBUSTIBLES RENOVABLES POR VIIAS ENZIMÁTICAS Y QUIIMICAS
}

Tesis doctoral presentada por

\section{Juan José Musci}

Ante la Facultad de Ingeniería de la Universidad Nacional de La Plata para la obtención del Grado Académico de

\section{Doctor en Ingeniería}

Director

Dra. Mónica L. Casella

$$
\text { Co-Director }
$$

Dr. Guillermo J. Siri

Jurados

Dra. María Cristina Abello

Dr. Sergio de Miguel

Dr. Delia Beatriz Soria

La Plata, 22 de marzo de 2018 
Este libro está dedicado a:

Marta Rosario y Alberto Luján, mis padres. A mis hermanos: Marisa Silvana, Daniel Alberto y Juan Ignacio Luján. Por su cariño, su apoyo incondicional en todo momento y sus palabras de aliento.

A todos aquellos que me aman y a quienes amo. 
Ante todo mi más sincero agradecimiento a mis directores por ser personas de bien, maestros, guías y consejeros que no escatimaron esfuerzos:

Dra. Mónica L. Casella, por su afecto, dedicación y paciencia. Y porque gracias a su temperancia se pudo llevar a cabo este proyecto.

Dr. Guillermo J. Siri, por sus palabras señeras y sus certeros juicios.

Institucionalmente a la UNNOBA por haberme otorgado la beca de iniciación y brindarme el lugar y la infraestructura para llevar a cabo este proyecto.

Al CINDECA por permitirme utilizar sus instalaciones.

A la CIC por haberme otorgado la beca de estudios orientados que estimuló mi inquietud para lograr el doctorado.

Al CONICET por haberme otorgado la beca de finalización que me permitió aspirar a este doctorado.

Las investigadoras Dra. Andrea B. Merlo y Dra. María José Torres, quienes me brindaron toda su colaboración tanto en las tareas a desarrollar, como en las revisiones y consultas.

A mi grupo de trabajo: Claudia G. Caggiano, María Laura Faroppa y Daiana Latorre por su colaboración.

A mis compañeras becarias.

A mis familiares y amigos

A todos gracias por su apoyo, sus palabras de aliento y por haber confiado en mí. 


\section{ÍNDICE}

\section{CAPÍTULO 1: INTRODUCCIÓN}

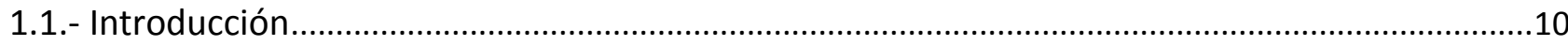

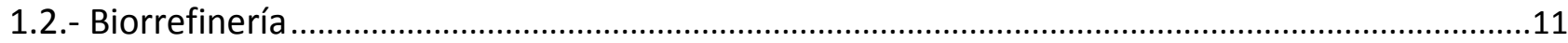

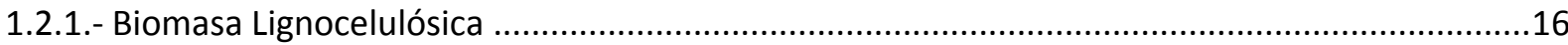

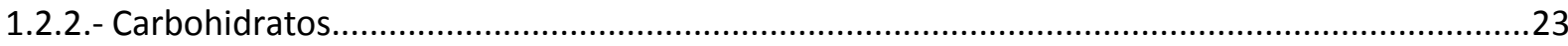

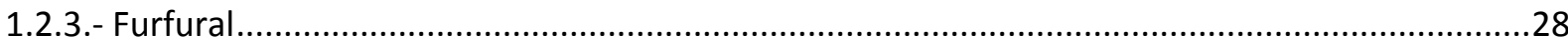

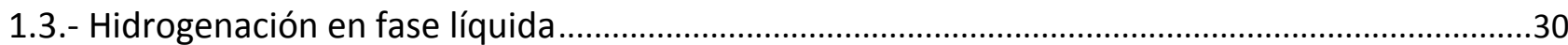

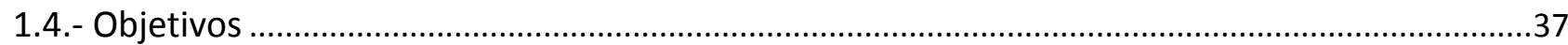

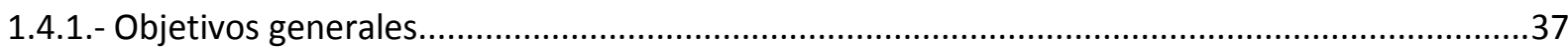

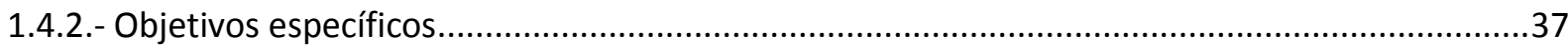

\section{CAPÍTULO 2: METODOLOGÍA EXPERIMENTAL}

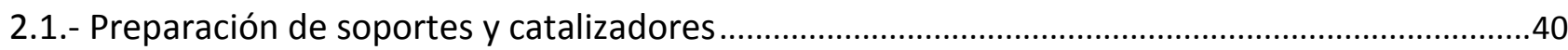

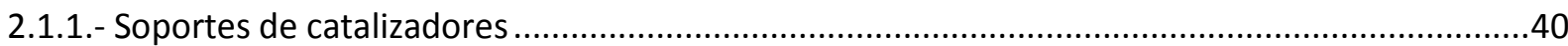

2.1.2.- Características generales de los soportes ............................................................................... 40

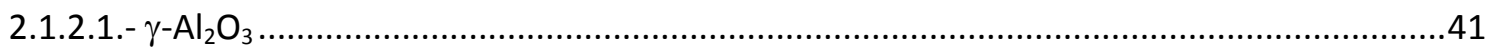

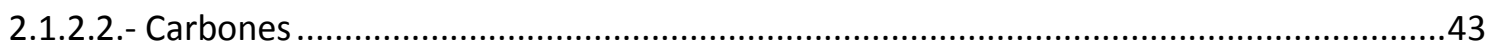

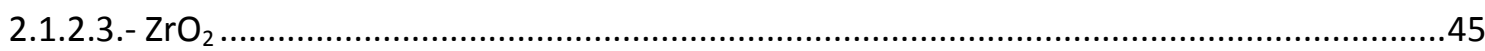

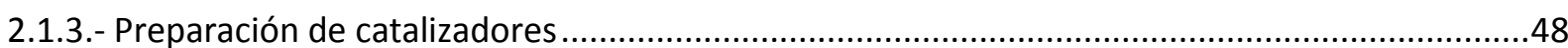

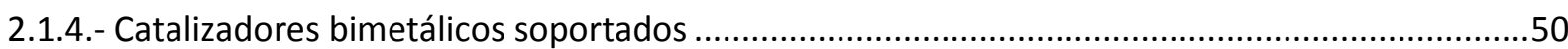

2.1.5.- Química Organometálica de Superficie sobre Metales ............................................................52

2.2.- Técnicas de caracterización de los sólidos ...................................................................................53

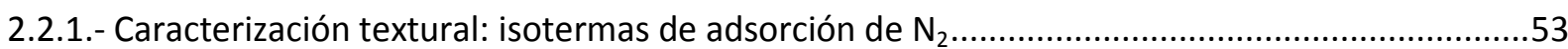

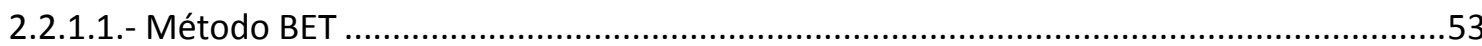

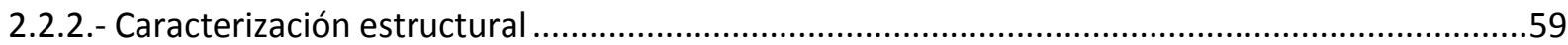

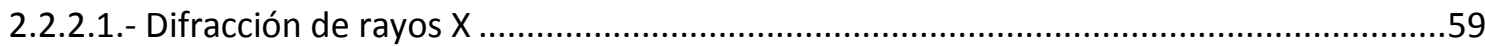

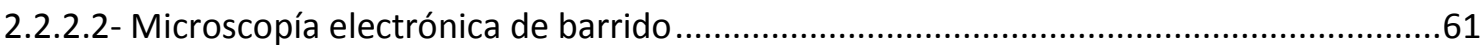

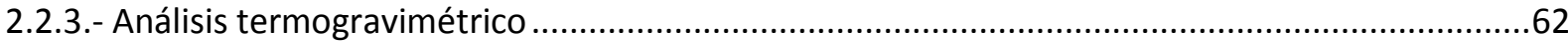

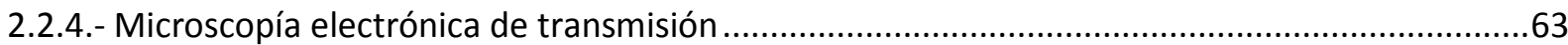

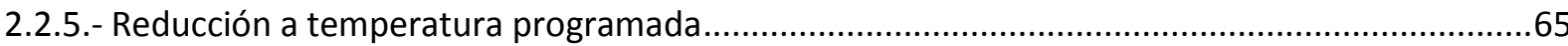


2.2.6.- Caracterización superficial .65

2.2.6.1.- Espectroscopia fotoelectrónica de rayos $X$. .65

2.3.- Medidas de actividad catalítica .68

2.3.1.- Descripción general del sistema de reacción utilizado .68

2.3.2.- Procedimiento de carga y operación del reactor. 71

2.3.3.- Procedimiento para la toma de muestras 72

2.3.4.- Análisis de la mezcla de reacción .72

\section{CAPÍTULO 3: PREPARACIÓN Y ACONDICIONAMIENTO DE SOPORTES}

3.1.- Preparación y acondicionamiento de soportes . .77

3.1.1.- $\gamma-\mathrm{Al}_{2} \mathrm{O}_{3}(\mathrm{~A})$ 77

3.1.2.- Carbón activado (C) .77

3.1.3.- Preparación de $\mathrm{ZrO}_{2}(\mathrm{Z})$ y $\mathrm{ZrO}_{2}$ soportada sobre $\mathrm{Al}_{2} \mathrm{O}_{3}(\mathrm{Z}-\mathrm{A})$............................................77

3.1.4.- Preparación de Zirconia fosfatada (ZP) y Zirconia fosfatada sobre $\gamma-\mathrm{Al}_{2} \mathrm{O}_{3}(\mathrm{ZP}-\mathrm{A})$..................79

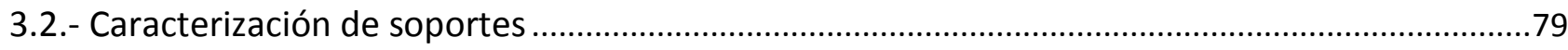

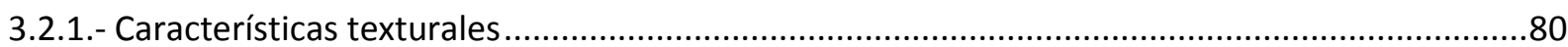

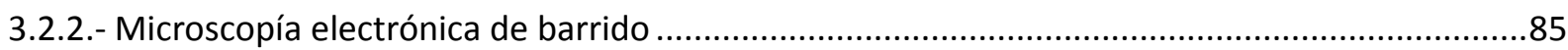

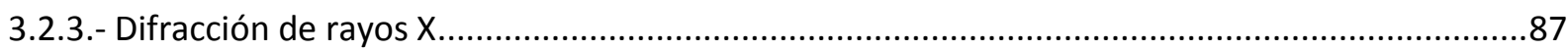

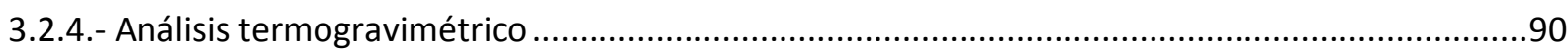

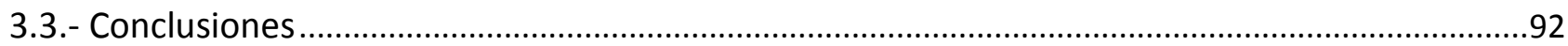

\section{CAPÍTULO 4: PREPARACIÓN Y CARACTERIZACIÓN DE CATALIZADORES}

4.1.- Preparación de catalizadores monometálicos ..............................................................................95

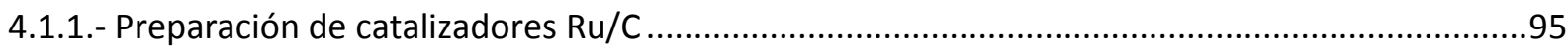

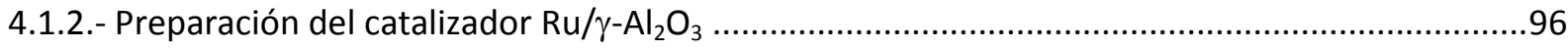

4.1.3.- Preparación de catalizadores $\mathrm{Ru} / \mathrm{Z}, \mathrm{Ru} / \mathrm{ZA}$, Ru/ZP y Ru/ ZP-A .........................................96

4.2.- Preparación de catalizadores bimetálicos RuSn/C .....................................................................97

4.2.1.- Reacción entre el catalizador monometálico soportado $(\mathrm{Ru} / \mathrm{C})$ y $\mathrm{Sn}\left(\mathrm{n}-\mathrm{C}_{4} \mathrm{H}_{9}\right)_{4}\left(\mathrm{SnBu}_{4}\right) \ldots \ldots \ldots \ldots . . . .97$

4.3.- Caracterización de catalizadores monometálicos ............................................................. 100

4.3.1.- Microscopía electrónica de transmisión ................................................................100

4.3.2.- Reducción a temperatura programada.............................................................. 103

4.4.- Caracterización de catalizadores bimetálicos .....................................................................106

4.4.1.- Determinación del contenido de estaño ....................................................................106

4.4.2.- Microscopía electrónica de transmisión ..................................................................107

4.4.3.- Reducción a temperatura programada.................................................................109 
4.5.- Hidrogenación de trans-2-pentenal como test catalítico.

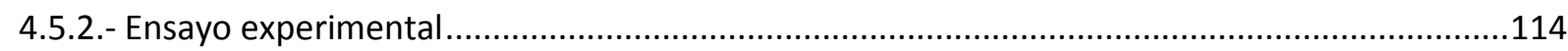

4.6.- Conclusiones

\section{CAPÍTULO 5: ESTUDIO DE CONDICIONES DE REACCIÓN}

5.1.- Etapas controlantes de las reacciones de hidrogenación ..........................................................125

5.2.- Características de las reacciones en catálisis heterogénea .......................................................125

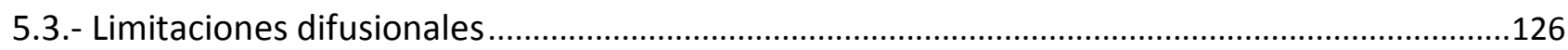

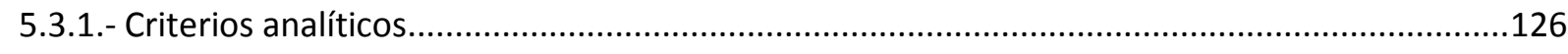

5.3.1.1.- Limitaciones difusionales en la interfase gas/líquido ..............................................126

5.3.1.2.- Limitaciones difusionales en la interfase líquido/sólido ...........................................128

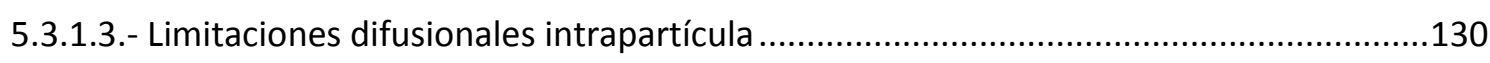

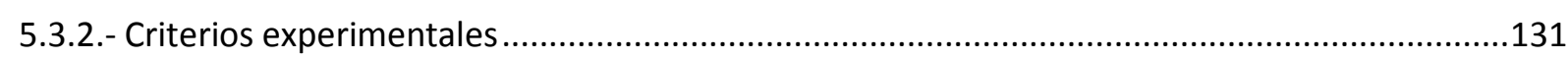

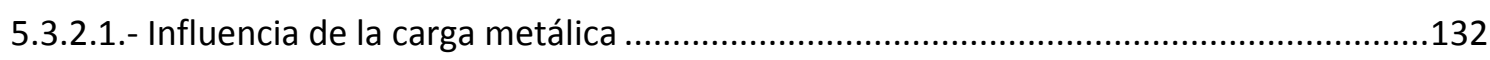

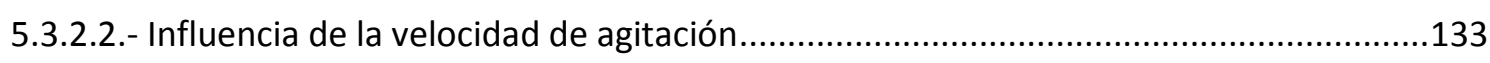

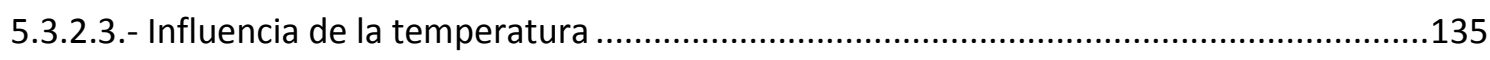

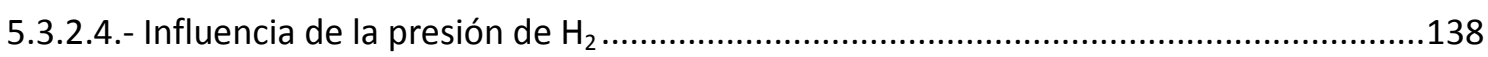

5.3.2.5.- Influencia de la concentración inicial de glucosa ......................................................140

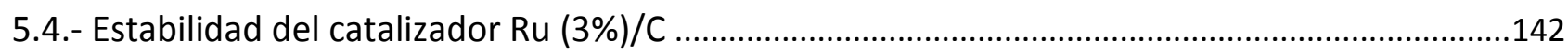

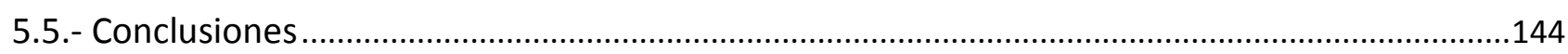

CAPÍTULO 6: ESTUDIO DE HIDROGENACIÓN DE MONO Y DISACÁRIDOS CON CATALIZADORES DE RUTENIO SOPORTADO

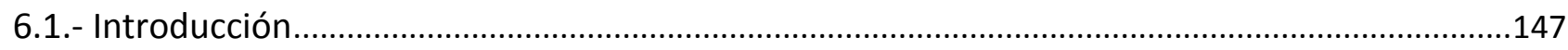

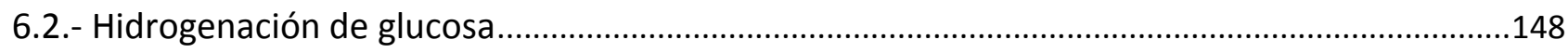

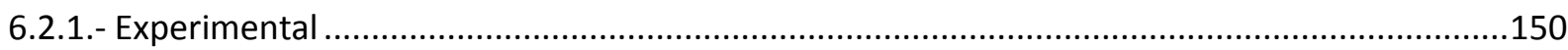

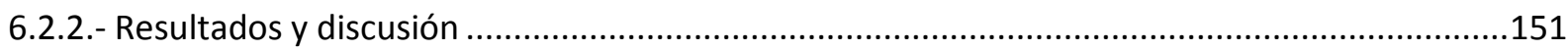

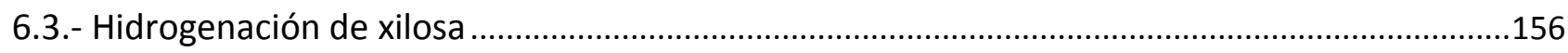

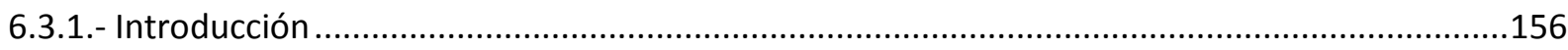

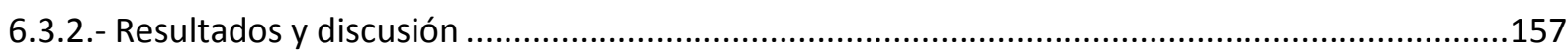

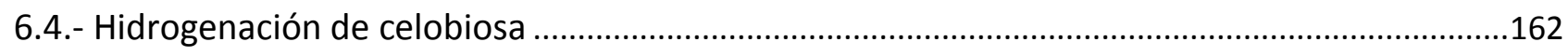

6.5.- Hidrólisis enzimática para la obtención de azúcares .................................................................163

6.5.1.- Transformación fúngica de los restos de Festuca sp. bajo condiciones de fermentación 
en estado sólido 166

6.5.2.- Procesamiento de la biomasa pretratada y colonizada con el hongo 167

6.6.- Conclusiones

CAPÍTULO 7: ESTUDIO DE HIDROGENACIÓN DE FURFURAL CON CATALIZADORES DE RUTENIO SOPORTADO

7.1.- Introducción. 172

7.2.- Condiciones experimentales 177

7.3.- Hidrogenación con catalizadores monometalicos 178

7.4.- Hidrogenación con catalizadores bimetálicos 185

7.5.- Reutilización de los catalizadores 197

7.6.- Conversión catalítica de furfural proveniente de la pirólisis de cáscaras de semillas de girasol para producir bio-alcohol furfurílico 199

7.7.- Conclusiones 203

CAPÍTULO 8: CONCLUSIONES FINALES Y PERSPECTIVAS A FUTURO

8.1.- Conclusiones finales .207

8.2.- Perspectivas a futuro

NOMENCLATURA 213

BIBLIOGRAFÍA 222 


\section{Resumen}

Aunque existe una gran variedad de fuentes renovables para la generación de energía, como son la energía solar, eólica, hidroeléctrica, mareomotriz, geotérmica, biomásica, entre otras, es esta última la única fuente de carbono sustentable capaz de sustituir al petróleo para la obtención de productos químicos, así como en la obtención de combustibles. Además, muestra un ciclo favorable de regeneración del orden de años y no de millones de años, como en el caso de las fuentes fósiles. Esto ha impulsado a los investigadores a estudiar el aprovechamiento de productos derivados de la biomasa, tendiendo a disminuir de esta manera el uso de compuestos provenientes del petróleo. A partir de estos productos químicos de origen natural se busca obtener derivados con un mayor valor agregado, siendo la catálisis heterogénea una muy buena herramienta para la obtención de los mismos en una forma más sostenible.

En este marco general planteado es que en el capítulo 1 se presenta una introducción a conceptos como el de biomasa, su origen, relevancia y sus derivados; obtenidos de su transformación en la biorrefinería. Se describen brevemente las características generales de esta última, así como su clasificación en las diferentes plataformas según el conjunto de procesos involucrados para transformar las materias primas en productos. Entre las distintas plataformas presentadas, se hace especial hincapié en los carbohidratos y el furfural y su transformación en productos químicos de mayor valor agregado.

Entre los posibles productos se centra la atención particularmente en los polialcoholes obtenidos de la hidrólisis y posterior hidrogenación catalítica de los primeros y el alcohol furfurílico a partir del furfural; ya que estas transformaciones son las que conducirán la investigación de esta tesis. Para ello se presenta en primera instancia un estudio bibliográfico con el objeto de conocer el estado del arte del tema a desarrollar.

En el capítulo 2 se proporcionan los detalles técnicos de todos los experimentos realizados a lo largo de la Tesis, realizando una descripción de los métodos empleados en la preparación de los soportes y catalizadores utilizados; y resumiendo brevemente las técnicas de caracterización utilizadas, mencionando el propósito de su empleo. 
Los capítulos 3 y 4 describen la preparación y el acondicionamiento de los soportes de los sistemas catalíticos empleados en esta tesis, así como la obtención de los catalizadores mono y bimetálicos de Ru y RuSn sintetizados para las reacciones de hidrogenación que se llevan a cabo en el desarrollo de la tesis. Además, se presentan y discuten los resultados obtenidos de la caracterización fisicoquímica.

En el capítulo 4 se presentan también ensayos de hidrogenación de trans-2pentenal realizados como test catalíticos para evaluar los catalizadores sintetizados; resultando una reacción de importancia tanto desde el punto de vista comercial como por las posibilidades de investigación que brinda, ya que tiene las mismas funcionalidades que están presentes en las fracciones acuosas de materias primas derivadas de la biomasa.

Durante el desarrollo del capítulo 5 se efectúan estudios en los cuales se determinaron las condiciones bajo las cuales se realizaron los ensayos experimentales en lo concerniente a los fenómenos de transferencia de materia para conocer la existencia o no de controles difusionales en los resultados, analizando la influencia de diferentes variables operativas en la hidrogenación en fase acuosa de glucosa.

En los capítulos 6 y 7 se estudian las reacciones en fase acuosa (APH) de los diferentes sustratos seleccionados, derivados de biomasa. Primeramente, en el capítulo 6 se presentan y discuten los resultados obtenidos de los ensayos con monosacáridos (glucosa y xilosa) y el disacárido celobiosa (sustrato modelo de la fragmentación de celulosa) con catalizadores de Ru monometálico sobre diferentes soportes. Luego en el capítulo 7 se investiga la naturaleza del soporte, su interacción con el Ru y su influencia sobre la actividad y selectividad de los catalizadores preparados en la hidrogenación de furfural. Posteriormente se presenta el estudio del efecto, en esta reacción, del agregado de Sn como promotor mediante técnicas de QOMS/M a un catalizador de Ru monometálico.

También se presentan estudios de la conversión catalítica de furfural proveniente de la pirólisis de cáscaras de semillas de girasol para producir bio-alcohol furfurílico, evaluando la performance en la hidrogenación de los catalizadores de Ru/C y $\mathrm{RuSn}_{0.4} / \mathrm{C}$. El empleo de estos sistemas catalíticos se determinó, luego de ser 
seleccionados teniendo en cuenta los mejores resultados obtenidos frente a los demás catalizadores en los estudios previamente mencionados.

Finalmente en el capítulo 8 se exponen, en base a los resultados obtenidos, las conclusiones finales de este trabajo de Tesis y se presentan algunos ensayos preliminares de las líneas de investigación a seguir y profundizar en estudios futuros. 


\section{CAPÍTULO 1}

INTRODUCCIÓN Y OBJETIVOS 
En este capítulo se hará una introducción al concepto de biomasa, su origen, relevancia y sus derivados, obtenidos de su transformación en la biorrefinería. Se describirán brevemente las características generales de esta última, así como su clasificación en las diferentes plataformas según el conjunto de procesos involucrados para transformar las materias primas en productos.

Entre las distintas plataformas se hará especial hincapié en los carbohidratos y el furfural obtenidos a partir de la biomasa y su transformación en productos químicos de mayor valor agregado; en particular, los polialcoholes obtenidos de la hidrólisis y posterior hidrogenación catalítica de los primeros y el alcohol furfurílico a partir del segundo. Estas transformaciones conducirán la investigación de esta tesis y para ello se presentará en primera instancia un estudio bibliográfico con el objeto de conocer el estado del arte del tema a desarrollar. 


\section{1.- Introducción}

El aprovechamiento de la biomasa con fines industriales no es una idea innovadora. Antes de la revolución industrial del siglo XIX, la biomasa era la principal fuente de obtención de energía y materiales. Sin embargo, debido a la alta disponibilidad y bajo costo de los recursos de origen fósil, el uso de la biomasa para fines industriales se vio desplazado en gran parte durante la segunda mitad del siglo XX, a excepción de las industrias orientadas a la producción de resinas, madera y fibras, así como aquellas dedicadas a la extracción de sabores y fragancias procedentes de plantas (Gallezot P., 2008). En la sociedad actual, la energía se ha convertido en el principal factor de desarrollo y crecimiento de un país, donde un aumento de la calidad de vida viene asociado con un incremento en el consumo de energía primaria en todos sus sectores: industrial, doméstico, transporte, servicios, etc. (Tolón Becerra A. y col., 2011). Hoy en día, las principales fuentes energéticas son de origen fósil: petróleo, gas natural y carbón. Desafortunadamente, poseen una limitada localización geográfica, además de no ser renovables y, por lo tanto, son susceptibles de agotamiento. Además, desde el punto de vista medioambiental, su combustión produce gases causantes, tanto del calentamiento global (efecto invernadero) como de la contaminación del aire y acuíferos, principalmente emisiones de $\mathrm{SO}_{2}, \mathrm{CO}, \mathrm{NOx}, \mathrm{CO}_{2}$, CFCs, $\mathrm{CH}_{4}$, además de material particulado, entre otros (Sábada Zubiri I., 2012). Todos estos inconvenientes, unido a un crecimiento exponencial en el consumo de energía primaria en los últimos años asociado a la demanda de los países emergentes, como India y China, han fomentado el interés de la sociedad por la búsqueda de fuentes energéticas alternativas.

En un futuro no muy lejano, la disminución de las reservas de petróleo traerá consigo un aumento en los costos de extracción y tratamiento, y esto no solamente se reflejará en el alza del precio de los combustibles, sino también en el precio de todos los productos químicos derivados del petróleo (lubricantes, ceras, detergentes, polímeros, barnices, pinturas, fertilizantes, insecticidas, etc.) (Sábada Zubiri I., 2012; Kamm B. y Kamm M., 2004). 
Aunque existe una gran variedad de fuentes renovables para la generación de energía, como son la energía solar, eólica, hidroeléctrica, mareomotriz, geotérmica, biomásica, entre otras, es esta última la única fuente de carbono sustentable capaz de sustituir al petróleo para la obtención de productos químicos, así como en la obtención de combustibles. Además, muestra un ciclo favorable de regeneración del orden de años y no de millones de años, como en el caso de las fuentes fósiles (Sarkar A. y Pramanik P., 2009; Baerlocher C., Mccusker L.B. y Olson D.H., 2007; Bajpai P.K., 1986).

En este sentido, se define "Biomasa" a cualquier materia orgánica disponible de origen renovable, en la que se incluyen por ejemplo cultivos energéticos y forestales, alimentos de procedencia agrícola, así como los residuos generados, plantas acuáticas, madera y residuos de la madera, desechos de animales y otros materiales de desecho (Kamm B. y Kamm M., 2004; Kamm B. Gruber P. R. y Kamm M., 2005).

\section{2.- Biorrefinería}

En el proceso del aprovechamiento de la biomasa, ya sea como fuente de energía o de productos químicos, se estableció el concepto de "Biorrefinería". Una Biorrefinería es una plataforma integrada por procesos biológicos, químicos y térmicos dirigidos a la conversión de la biomasa, que a su vez aprovecha la sinergia entre las distintas tecnologías para producir combustibles, energía y productos químicos de valor agregado, siendo este concepto análogo al de la refinería basada en el petróleo (Figura 1.1). Sin embargo, Ed de Jong proporciona una visión más amplia del concepto de biorrefinería, incluyendo la obtención de materiales, así como de productos alimentarios orientados tanto para consumo humano como animal (Annevelink E. y col., 2006). 


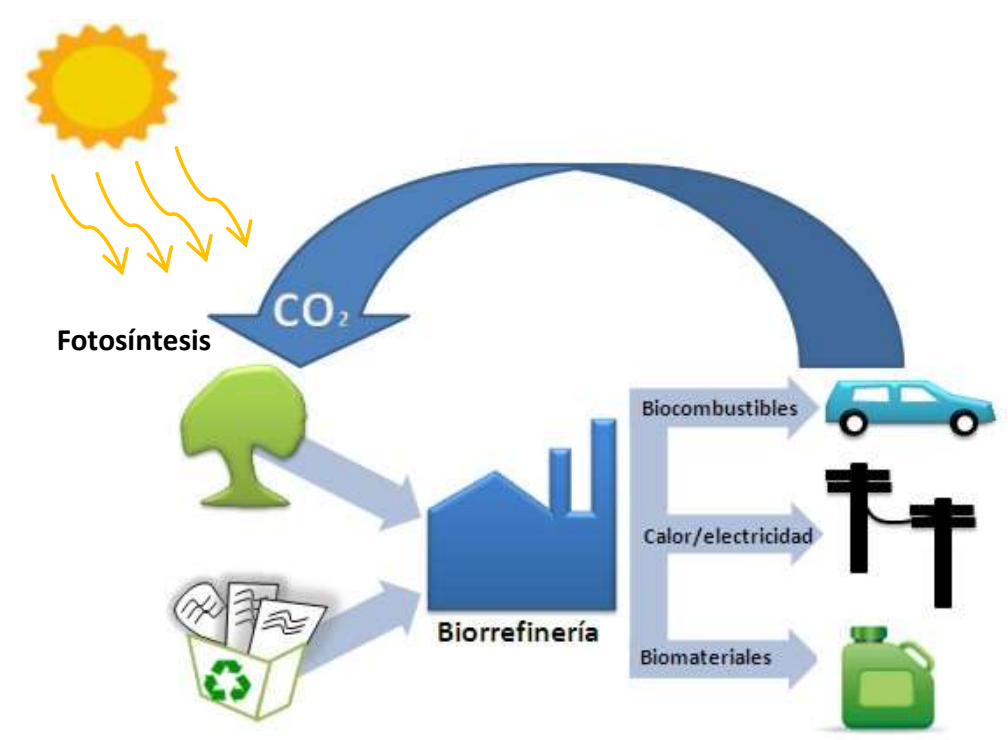

Figura 1.1. Transformaciones en una Biorefinería

Este nuevo concepto de biorrefinería no solamente se centraría en el aspecto de autosuficiencia energética, mediante la producción de combustibles y energía (electricidad, calor), sino que constituiría los cimientos de una economía basada en la biomasa como se muestra en la Figura 1.2, creando nuevos mercados (Clark J.H., Deswarte F.E. y Farmer T.J., 2009; Annevelink E. y col., 2006)

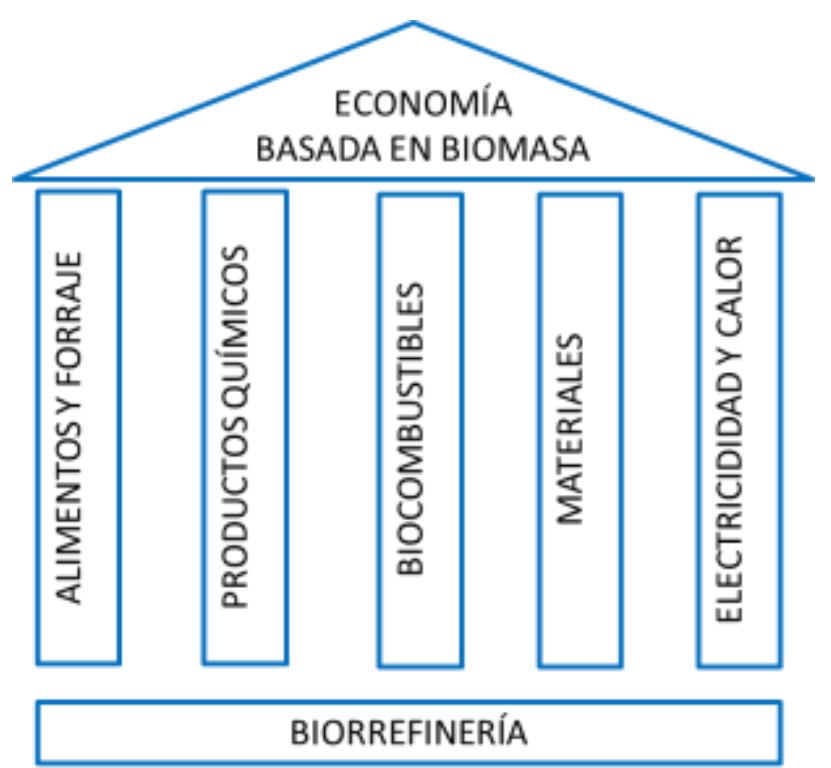

Figura 1.2. Pilares de una economía basada en la Biorrefinería (Kamm B. y Kamm M., 2004) 
El término biorrefinería no apareció hasta 1990, por lo que se encuentra prácticamente en su etapa de crecimiento y no existe un criterio de clasificación homogéneo de los diferentes tipos de biorrefinerías, pudiéndose encontrar diversas clasificaciones referidas a plataformas, productos de reacción, materias primas o procesos. Existen diversos criterios para clasificar las biorrefinerías en la bibliografía, la mayoría de ellos basados en plataformas.

En este contexto, se define el término plataforma al conjunto de procesos intermedios para transformar la materia prima en productos.

Siguiendo este criterio, entre las plataformas más relevantes que se pueden encontrar en una biorrefinería están (Cherubini F. y col., 2009; de Jong E. y col., 2011):

- Plataforma de biogás: mezcla de $\mathrm{CH}_{4}$ y $\mathrm{CO}_{2}$ procedente de una digestión anaeróbica.

- Plataforma syngas: mezcla de $\mathrm{H}_{2}$ y $\mathrm{CO}$ procedente de una gasificación.

- Plataforma de hidrógeno $\left(\mathrm{H}_{2}\right)$ : procedente de la reacción Water- Gas-Shift, reformado con vapor y fermentación.

- Plataforma de azúcares (C6 y C5): amplia variedad de productos obtenidos mediante reacciones de deshidratación, hidrogenación, fermentación y oxidación de los azúcares (C5 y C6) constituyentes de la hemicelulosa y celulosa obtenidos previamente mediante hidrólisis.

- Plataforma de lignina: mezcla de compuestos aromáticos procedentes del procesado de la lignina.

- Plataforma oleoquímica: producción de bio-productos y biocombustibles procedentes de las reacciones de esterificación de ácidos grasos libres y transesterificación de triglicéridos.

- Plataforma de solución orgánica: mezcla de fibras rica en lignocelulosa y solución orgánica, obteniéndose carbohidratos, proteínas, amino-ácidos, enzimas, ácidos orgánicos, minerales y hormonas; para la obtención de bio-productos y combustibles. 
- Plataforma pirolítica: termodespolimerización de la biomasa a temperaturas medias en ausencia de oxígeno.

- Plataforma de cogeneración eléctrica y calorífica: combustión de residuos de la biorrefinería utilizada para cubrir las necesidades internas de la biorrefinerías y venta de los excedentes a la red eléctrica.

Las primeras biorrefinerías, comúnmente conocidas como biorrefinerías de primera generación, se orientaban a la producción exclusiva de biocombustibles, utilizando una única fracción de la propia biomasa. Es más, dicha materia prima se usaba también en el sector alimentario, llegando a competir la producción de biocombustibles y alimentos. Estos inconvenientes dieron origen a la creación de unos principios en la selección de las materias primas, encaminados hacia sistemas más sostenibles que eviten cualquier impacto sobre los suministros alimentarios, y el medio ambiente. En este sentido, se dio paso a las biorrefinerías de segunda generación que tratan de emplear la biomasa en su totalidad, minimizando su repercusión en el sector alimentario.

Las biorrefinerías de segunda generación, además de satisfacer las necesidades energéticas y de producción de biocombustibles, suministran materiales a la industria, así como intermedios y productos químicos de mayor valor agregado. Sin embargo, la mayoría de estas biorrefinerías hasta el día de hoy trabajan como sistemas individuales o descentralizados. La integración de diferentes plataformas dentro de una misma biorrefinería le aportaría una mayor eficiencia y rentabilidad (Hughes S. y col., 2013). De esta manera, se consigue la optimización del flujo de materias primas, subproductos y energía entre las diferentes unidades de producción industrial, minimizando la generación de residuos y maximizando la obtención de productos. De este concepto integrador han surgido las biorrefinerías de tercera generación (Octave S. y Thomas D., 2009; King D. y col. 2010).

De la misma manera que la industria petroquímica puede ser esencialmente desarrollada a partir de unos pocos bloques de construcción, un estudio realizado por el Departamento de Energía de Estados Unidos (mediante la selección a partir de alrededor de 300 sustancias) ha identificado 12 prometedores derivados de biomasa, teniendo en cuenta entre otros aspectos, sus costos de producción y el potencial de 
estas moléculas como bloques de construcción para el desarrollo de procesos de biorrefinería (Werpy T. y Perterson P., 2004; Holladay J. E. y col., 2007).

Hoy en día existe un amplio consenso en considerar que de todas las biorrefinerías industriales, una de las que tiene grandes perspectivas de éxito es la basada en lignocelulosa. Esta materia prima presenta la ventaja de su abundancia, su bajo costo y no introduce excesivas tensiones en la industria agroalimentaria como otros tipos de biomasa (granos de cereal: como maíz, trigo, avena o cebada; oleaginosas; caña de azúcar, etc.) (Huber G.W., Iborra S. y Corma A., 2006). Las materias primas aprovechables son muy variadas, incluyendo, obviamente, la biomasa cultivada con tal propósito, pero también restos de cosechas, restos de talas forestales e incluso residuos sólidos urbanos.

Se estudian procesos que permitan transformar selectivamente la lignocelulosa, tras la obtención de soluciones acuosas de monosacáridos (pentosas y/o hexosas), a productos base como furfural, 5-hidroximetil-furfural o ácido levulínico y también la obtención de polialcoholes derivados de sus respectivos azúcares, y la transformación de todos estos a biocombustibles y productos químicos de alto valor agregado (Figura 1.3). Estos productos están llamados a sustituir, total o parcialmente, a los actualmente derivados del petróleo, sean combustibles líquidos o compuestos de base para la industria química, con potenciales aplicaciones en diversos sectores productivos (aditivos de alimentos, fármacos, polímeros, síntesis química, disolventes, aditivos de combustibles, etc.). 


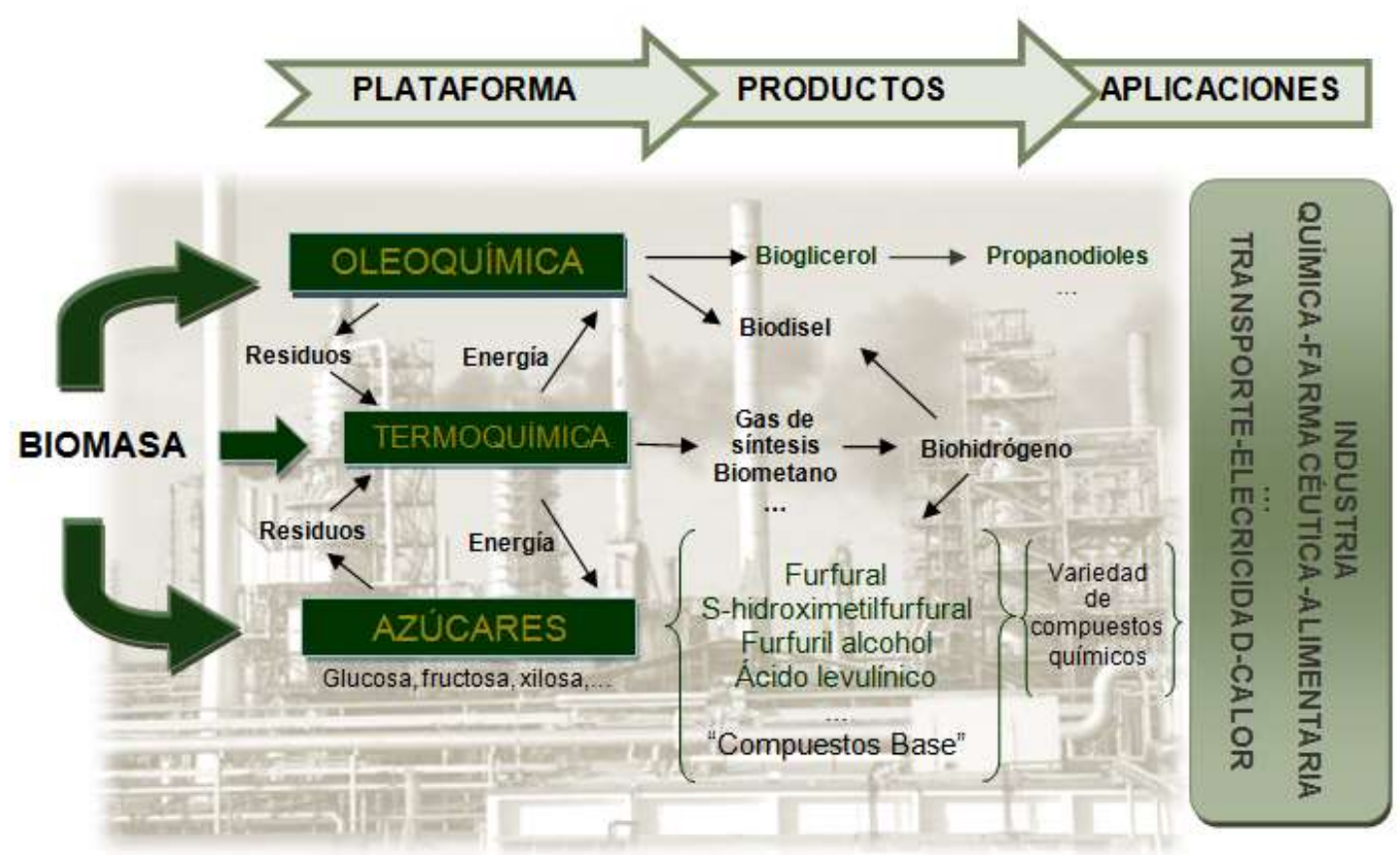

Figura 1.3. Procesos integrados en biorrefinerías.

Teniendo esto en cuenta, es en este tipo de plataformas donde se centrará este trabajo de tesis, estudiando la conversión de azúcares en productos químicos de mayor valor agregado obtenidos a partir de hemicelulosa y celulosa por un lado y reacciones de hidrogenación en fase acuosa para la transformación de furfural, compuesto aromático derivado de la deshidratación de azucares como xilosa por otro.

\subsection{1.- Biomasa Lignocelulósica}

En la reacción de la fotosíntesis se producen grandes cantidades de hidratos de carbono y oxígeno a partir de dióxido de carbono y agua en las plantas que utilizan la luz solar. Los azúcares pueden encontrarse, bien como reserva de metabolitos, tipo almidón o sacarosa, o bien formando parte de su estructura, como en la lignocelulosa. El primer tipo de azúcares es de fácil accesibilidad y si bien se emplean en la producción de bioetanol, su destino principal es la industria alimentaria. En cambio, los compuestos lignocelulósicos, resultan no comestibles, proviniendo en su mayoría de residuos agrícolas y forestales. Es por ello que se espera que sean el primer objetivo de 
la química de los recursos de la biomasa. Sin embargo, son más complejos y difíciles de extraer.

La lignocelulosa es uno de los materiales más abundantes en la naturaleza, siendo el componente mayoritario de los vegetales y su función es la de proporcionar la estructura rígida. Se encuentra presente tanto en las raíces como en los tallos o troncos y hojas. Está constituida por celulosa (40-50\%), hemicelulosa (25-35\%) y lignina (15-20\%) (Mamman A.S.; 2008). La Figura 1.4 muestra la estructura de la lignocelulosa.

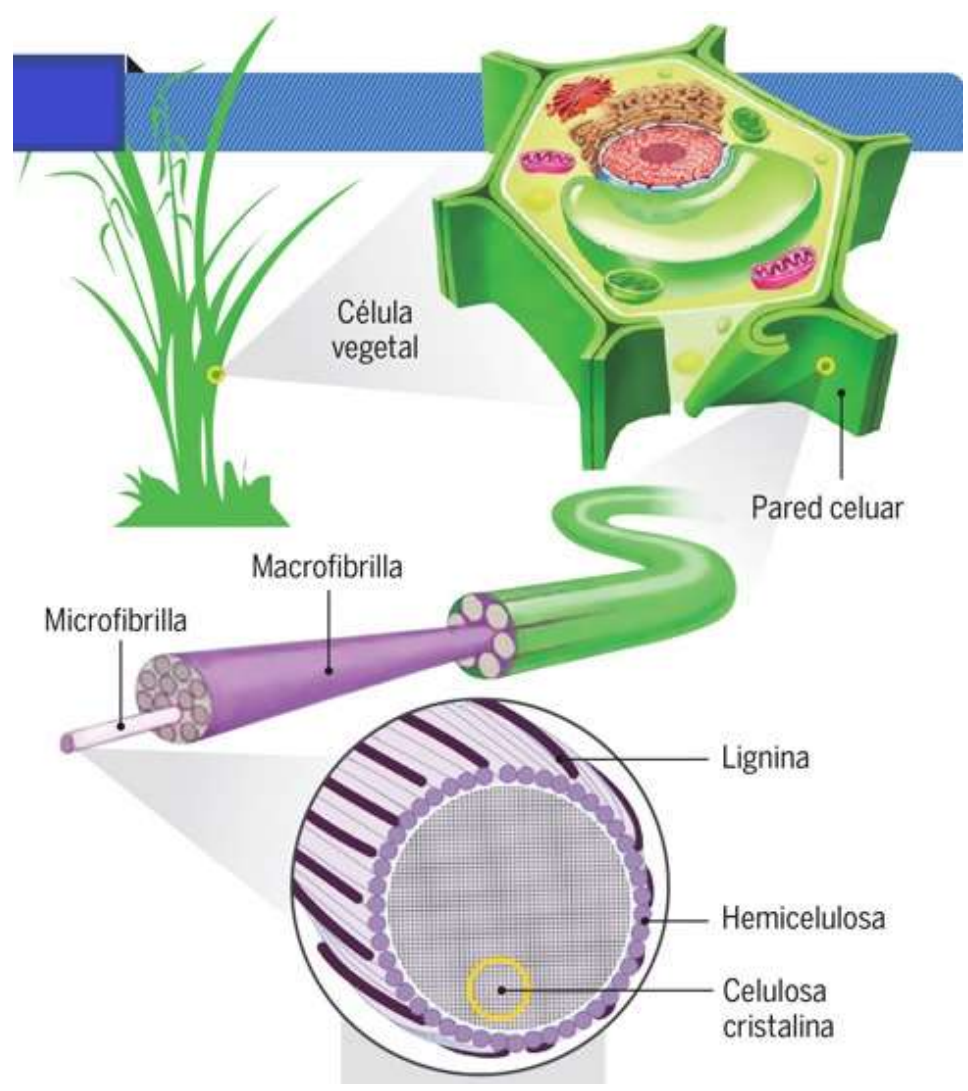

Figura 1.4. Estructura esquemática de la lignocelulosa y sus componentes.

La celulosa es un polímero insoluble en agua compuesto de unidades de glucosa unidas por enlaces $\beta-1,4-$ glicosídicos (Figura 1.5), que forma fuertes estructuras cristalinas con enlaces de hidrógeno inter- e intramoleculares, proporcionándole una alta estabilidad química y una baja solubilidad en la mayoría de los solventes, incluyendo el agua (Kondo T. S., 2005). Aporta rigidez a la estructura vegetal, impidiendo su hidrólisis. El número de unidades monoméricas enlazadas en la cadena (grado de polimerización G.P.), varía en los diferentes materiales celulósicos. 


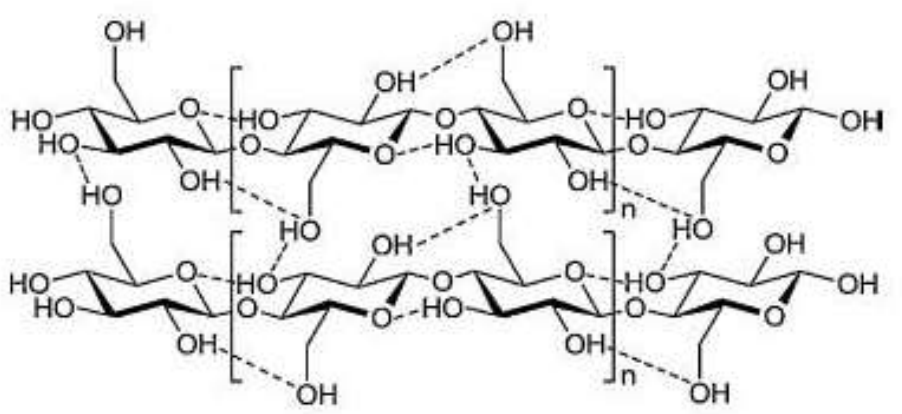

Figura 1.5. Estructura de celulosa

Recubriendo la superficie de la celulosa y entrelazada con la lignina se localiza la hemicelulosa (Figura 1.6), un polímero amorfo compuesto por más de un tipo de azúcar (D-xilosa, L-arabinosa, D-galactosa, D-glucosa y D-manosa), siendo la D-xilosa el monosacárido más abundante.

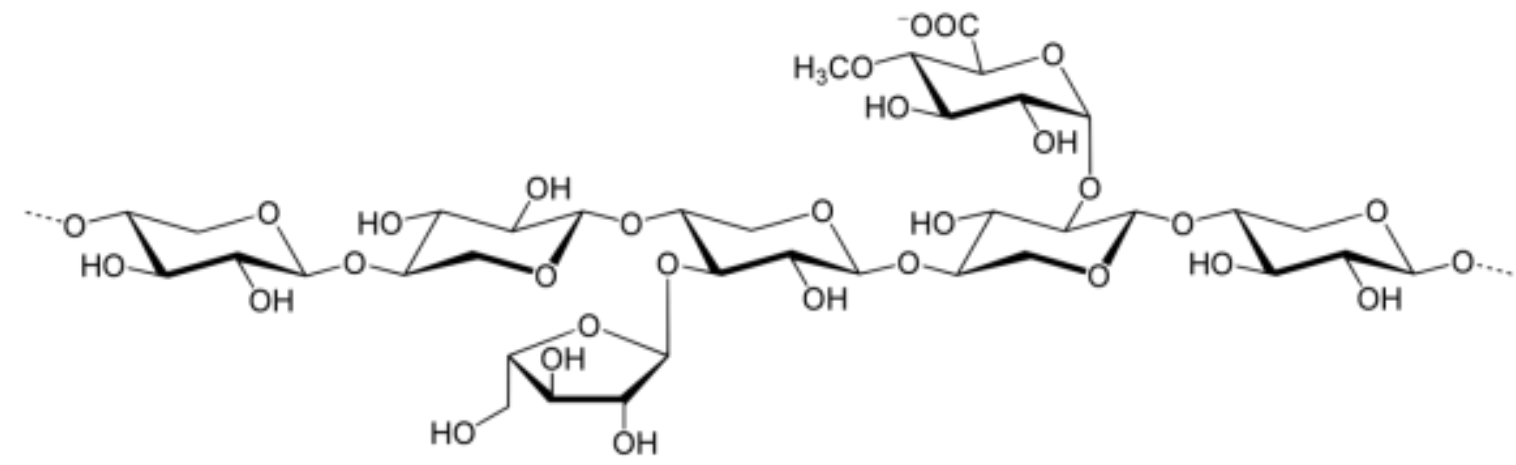

Figura 1.6. Estructura de la hemicelulosa

Por último, recubriendo a la hemicelulosa aparece la lignina (Figura 1.7), un polímero de alcoholes aromáticos que proporciona rigidez e hidrofobicidad a la estructura (Alonso D.M., Bond J.Q. y Dumesic J. A. , 2010). 


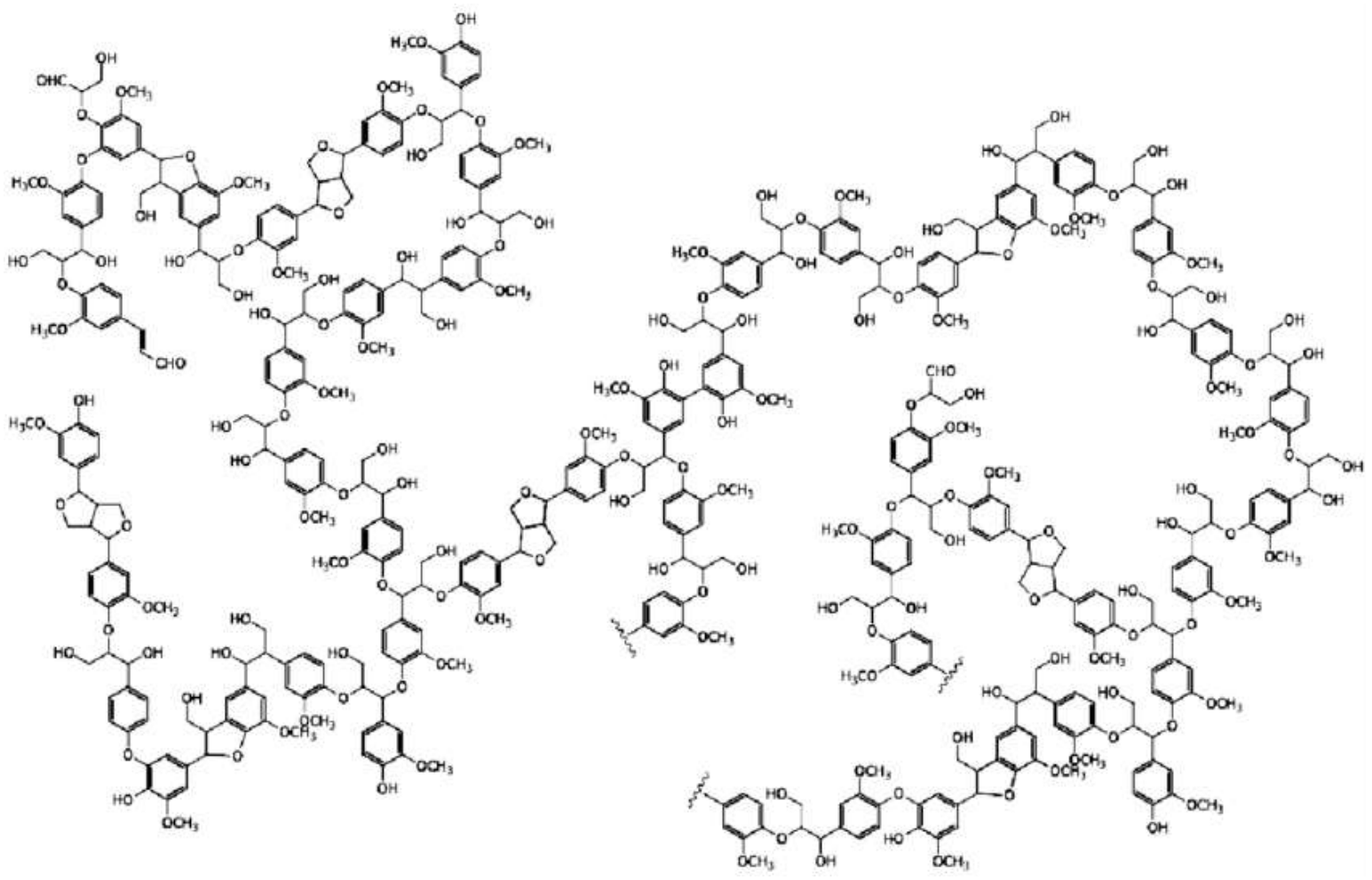

Figura 1.7. Estructura de la lignina

Existes dos estrategias para el tratamiento de la lignocelulosa: i) procesado de la lignocelulosa en su totalidad mediante rutas termoquímicas a altas temperaturas y/o presiones, como la pirólisis, gasificación o licuefacción, obteniéndose mezclas de diferentes compuestos, y ii) fraccionamiento e hidrólisis que hacen posible realizar un procesado selectivo, aprovechando íntegramente las propiedades físico-químicas de cada fracción, y obtener productos químicos de gran interés (Dutta S. y col., 2012).

Para el fraccionamiento de la lignocelulosa se emplean tratamientos físicoquímicos con el objetivo de despolimerizar la lignina y aumentar la accesibilidad a la hemicelulosa y celulosa, además de incrementar su área superficial (Alonso D.M., Bond J.Q. y Dumesic J. A., 2010). Entre los diferentes procesos se encuentran:

- Tratamiento con vapor: se suele llevar a cabo en un reactor discontinuo, introduciendo la biomasa pulverizada y calentándolo a alta temperatura y presión. A continuación la presión se baja ya sea de forma violenta, para descargar el contenido del reactor en un tanque receptor de forma que se produce una explosión de vapor que rompe la lignina (steam explosion), o 
bien de forma paulatina sin explosión. Estos pretratamientos dan lugar a un material marrón oscuro que contiene hemicelulosa parcialmente hidrolizada que se recupera fácilmente por un tratamiento de lavado. Cuando se emplea la explosión de vapor en presencia de $\mathrm{H}_{2} \mathrm{SO}_{4} \circ \mathrm{SO}_{2}$ se recupera completamente la hemicelulosa. En caso contrario, se denomina autohidrólisis y es el ácido acético liberado en la descomposición de la materia de partida el que cataliza el proceso.

- Explosión de fibra con amoníaco (AFEX): al igual que en el caso anterior ocurre una explosión, pero en atmósfera de amoníaco, que debe ser reciclado.

- Explosión con $\mathrm{CO}_{2}$ : en este caso se emplea $\mathrm{CO}_{2}$ que forma ácido carbónico mejorando de este modo la velocidad de hidrólisis.

- Proceso Organosol: en este proceso se emplean solventes orgánicos (o mezcla de éstos con agua) para romper los enlaces estructurales entre la lignina y la hemicelulosa. Normalmente se emplean metanol, etanol, acetona, etilenglicol, etc. Puede añadirse ácido para mejorar el rendimiento, y es de vital importancia la recuperación del solvente, para hacer este proceso competitivo.

En la etapa de hidrólisis, el objetivo es separar los azúcares, además de procesarlos selectivamente. Este procedimiento se puede llevar a cabo mediante ácidos o enzimas.

Un gran número de trabajos se han dedicado a estudiar la hidrólisis química de la celulosa en glucosa, siendo el ácido sulfúrico el catalizador típico para esta reacción (Rinaldi R. y Schüth F., 2009), sin embargo, este procedimiento tiene un importante aspecto negativo en la propiedad corrosiva del ácido, la complicada separación de los productos de la reacción y la necesidad de neutralización de los residuos ácidos.

Generalmente, se emplean ácidos inorgánicos concentrados $\left(\mathrm{H}_{2} \mathrm{SO}_{4}\right.$ y $\left.\mathrm{HCl}\right)$, siendo de gran importancia la optimización de las condiciones de reacción para que no se produzcan reacciones secundarias, como la degradación de la D-xilosa. Estas condiciones experimentales dependen del tipo de materia prima utilizada; por ejemplo, para la sacarificación de la madera se emplea un proceso en dos etapas: una 
primera hidrólisis ácida empleando un $72 \% \mathrm{p} / \mathrm{p}$ de $\mathrm{H}_{2} \mathrm{SO}_{4}$ a $30^{\circ} \mathrm{C}$ durante una hora, seguida de una segunda hidrólisis con el $4 \% \mathrm{p} / \mathrm{p}$ de $\mathrm{H}_{2} \mathrm{SO}_{4}$ a $121^{\circ} \mathrm{C}$, durante una hora. En el primer paso se forman los oligosacáridos, mientras que posteriormente se obtienen los azúcares simples. Alternativamente, para obtener D-xilosa y L-arabinosa se utiliza en la segunda hidrólisis el $1 \% \mathrm{p} / \mathrm{p}$ de $\mathrm{H}_{2} \mathrm{SO}_{4}$, debido a que son más sensibles a sufrir reacciones secundarias indeseadas (Mäki-Arvela P. y col., 2011; Wettstein S.G. y col., 2012).

Este mismo inconveniente surge para el caso de la glucosa, que puede descomponerse fácilmente en condiciones severas debido a la presencia del grupo hemiacetal en su estructura. Así, Fukuoka y colab. llevaron a cabo ensayos para hidrolizar celulosa mediante el uso de zeolitas y otros óxidos y observaron que el rendimiento a glucosa era menor al 4\% (Fukuoka A. y Dhepe P.L., 2006). A fin de evitar este problema, se propuso la realización de este proceso en dos etapas, en la primera se realizaba la hidrólisis de la celulosa a glucosa y a continuación la hidrogenación de la glucosa formada a alcoholes térmicamente estables, evitando de ese modo la descomposición de la glucosa.

Por otro lado, también es posible convertir selectivamente la celulosa en glucosa en condiciones ambientales por medio de enzimas celulasas (Zhang H.P. y Lynd L.R., 2004).

La hidrólisis enzimática consume menos energía y puede dar un producto puro con un rendimiento cuantitativo. Sin embargo, debe tenerse en cuenta que la enzima es una macromolécula por lo que su acceso a la celulosa está restringido por muchos factores que no afectan a la catálisis ácida. Los obstáculos principales son: la envoltura de lignina en torno a las fibras celulósicas y la resistencia estructural de la celulosa. Para romper la asociación lignina-celulosa, dejando intacta la celulosa, existen varios métodos de pretratamiento: físicos, químicos y biológicos. Los pretratamientos físicos incluyen la molienda, vaporización a presión, irradiación y pirólisis. Entre los pretratamientos químicos, los más usuales involucran la utilización de álcalis, ácidos, gases, agentes oxidantes, solventes de la celulosa, extracción de la lignina, etc. Finalmente, los pretratamientos biológicos hacen uso de microorganismos que atacan la madera y son capaces de degradar la lignina (Hall M. y col., 2011). 
En las últimas décadas, se ha despertado un gran interés en la investigación y la generación de sistemas enzimáticos para la bioconversión de lignocelulosa (Menon V. y Rao M., 2012 y referencias allí citadas). Las celulasas son sintetizadas por hongos, bacterias y plantas. Se sabe que hay por lo menos tres componentes de las celulasas implicadas en la hidrólisis de la celulosa en base a sus propiedades estructurales:

Endoglucanasa $(C x) 1,4-\beta-D$ glucanglucano hidrolasa: produce escisión al azar de la cadena de celulosa dando glucosa, celobiosa y celotriosa. Peso molecular de 18.000 a 60.000 .

Exoglucanasa (C1) 1,4- $\beta-D$ glucancelobiohidrolasa: ataca por el extremo no reductor de la cadena de celulosa dando celobiosa como producto primario. Peso molecular de 50.000 a 71,000.

Celobiasa ( $\beta$-glucosidasa): Hidroliza la celobiosa a glucosa con una elevada actividad con respecto a las celodextrinas. Su peso molecular es de 76.000.

La acción hidrolítica de las celulasas puede describirse, de forma esquemática, como un proceso en dos etapas. El primer paso es la conversión de celulosa a celobiosa, por la acción sinergística de endo- y exo-celulasas, que son fuertemente adsorbidas en la superficie de la celulosa sólida y la segunda etapa, es la conversión de celobiosa a glucosa por acción de la $\beta$-glucosidasa, en la fase acuosa.

Sin embargo este método presenta actualmente ciertos inconvenientes como son los altos costos de las enzimas, las bajas velocidades de reacción y la dificultad para la recuperación de las enzimas a partir de las mezclas de reacción.

Es por estas razones que se espera que el empleo de catalizadores sólidos sea favorable para la conversión de celulosa, teniendo en cuenta sus características de buena separabilidad, capacidad de reutilización y aplicación de variadas condiciones de reacción. En particular, los catalizadores metálicos soportados son uno de los grupos más atractivos dentro de los catalizadores sólidos, ya que sus propiedades catalíticas pueden ser ajustadas de acuerdo a la necesidad de la reacción mediante la variación de los componentes metálicos, el empleo de promotores y los métodos de preparación utilizados.

Estos catalizadores deberían cumplir los siguientes requisitos: no lixiviarse en el medio líquido de reacción, ser selectivos al producto deseado y estables/reutilizables 
durante numerosos ciclos (si se trabaja en modo discontinuo) o durante largos tiempos de operación (si se trabaja en continuo).

\subsection{2.- Carbohidratos}

Los carbohidratos presentes en la biomasa representan una fuente potencial de carbono para la obtención de combustibles, energía y productos químicos de alto valor agregado. A diferencia de los hidrocarburos, los carbohidratos son moléculas con un alto grado de funcionalización que les hace ser altamente reactivas, además de contener un alto porcentaje de oxígeno en su composición, lo que hace necesario el desarrollo de nuevas rutas catalíticas para controlar dicha funcionalidad (Corma A., Iborra S. y Velty A., 2007). Una de las estrategias propuestas es la reducción del contenido en oxígeno para producir intermedios que son el punto de partida para la síntesis de una gran variedad de productos químicos, son las denominadas moléculas plataforma (Building Blocks) (Alonso D.M. y col., 2011). Entre estas moléculas se encuentra el sorbitol (D-glucitol, D-sorbitol, D-glucohexano-1,2,3,4,5,6-hexaol). Dicho compuesto se produce a escala industrial (producción de 1,1 millones $t$ / año) mediante hidrogenación catalítica de glucosa. Es un proceso batch con un volumen de producción de 1,1 millones de toneladas por año (Patel M., 2006).

Aunque se pueden usar varios metales para esta transformación, el catalizador de níquel Raney es preferido para producción a escala industrial. En general, el sorbitol es producido por hidrogenación de soluciones acuosas de glucosa, con un contenido en este monosacárido de hasta 65\% (derivado de la hidrólisis de almidones), en reactores discontinuos de tanque agitado funcionando con presiones de hidrógeno de 6-20 MPa y temperaturas entre $120^{\circ} \mathrm{C}$ y $150^{\circ} \mathrm{C}$ (393 y $423 \mathrm{~K}$ ) (Corma A., Iborra S. y Velty A, 2007)

Sin embargo, el níquel tiene el inconveniente de lixiviarse, lo que resulta en una pérdida de actividad e importantes concentraciones de metal en la solución del producto. Para uso en alimentos, aplicaciones médicas y cosméticos, el níquel debe ser eliminado por intercambio iónico, lo que resulta en un alto costo adicional. Por tanto, catalizadores basados en otros metales activos también han sido evaluados, incluyendo platino, paladio, rodio y rutenio. (Li H. y col., 2002; Kusserow B. Schimpf S., Claus P., 2003; Wisniak J. y col., 1974; Wisniak J. y Simon R., 1979) 
En este sentido, también más recientemente Lazaridis y colaboradores estudiaron la hidrogenación / hidrogenólisis de d-glucosa sobre catalizadores de Pt y Ru soportados en carbón micro/mesoporoso ( $\mathrm{AC}$ ) activado, a 1.6 MPa de presión y relativamente alta temperatura de reacción $\left(180^{\circ} \mathrm{C}\right)$, variando el contenido metálico (1$5 \%) \mathrm{p} / \mathrm{p}$ ) y el método de reducción del metal $\left(\mathrm{H}_{2}\right.$ a $350^{\circ} \mathrm{C}$ o $\left.\mathrm{NaBH}_{4}\right)$ obteniendo valores de conversión $\geq 97 \%$ ) con Pt y selectividad a sorbitol $\geq 90 \%$. Por otro lado, Ru/AC mostró una amplia gama de selectividad de sorbitol valores (55-93\%), con varios alcoholes de azúcar C3-C6 (1,2,5,6-hexanetetrol, arabinitol, treitol, glicerol y 1,2propanodiol) como subproductos principales, dependía de la naturaleza amorfa/cristalina de partículas de $\mathrm{Ru}$ y $\mathrm{Ru}(\mathrm{O})_{\mathrm{x}}{ }^{\delta+}$ que a su vez se vieron afectadas por el contenido de Ru y el método de reducción (Lazaridis P. A. y col., 2015).

También han sido sugeridas rutas fermentativas, (Akinterinwa O., Khankal R., Cirino P.C., 2008) aunque es poco probable que puedan reemplazar el proceso de hidrogenación catalítica técnicamente maduro. Un mayor desarrollo podría ser la implementación industrial de un proceso continuo.

Además otras rutas de investigación incluyen el desarrollo de condiciones de procesamiento más suaves $\mathrm{y} / \mathrm{u}$ otros catalizadores para reemplazar los catalizadores de níquel que se utilizan hoy en día.

El sorbitol se emplea en los alimentos, como agente edulcorante, estabilizador de humedad. Además de esto, también se utiliza como materia prima para otros productos, como se muestra en la Figura 1.8. El sorbitol se puede transformar en ácido ascórbico, sorbitano (sorbitan en la figura 1.8), isosorbida (isosorbide en la figura 1.8) (deshidratación selectiva), 1,2-propanodiol por hidrogenolisis y precursor de surfactantes y poliuretanos (Woodbridge Foams). (Bos, H., Harmsen P. y Annevelink E., 2010). 


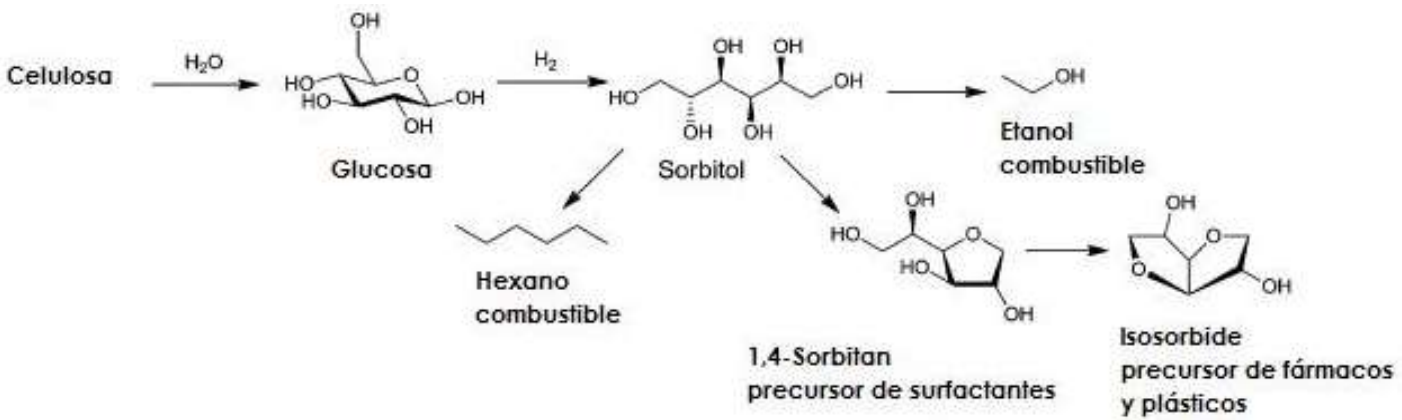

Figura 1.8. Obtención y transformación de sorbitol

En la Tabla 1.1 se resumen los derivados del sorbitol, así como su producción mundial.

Tabla 1.1. Derivados de sorbitol

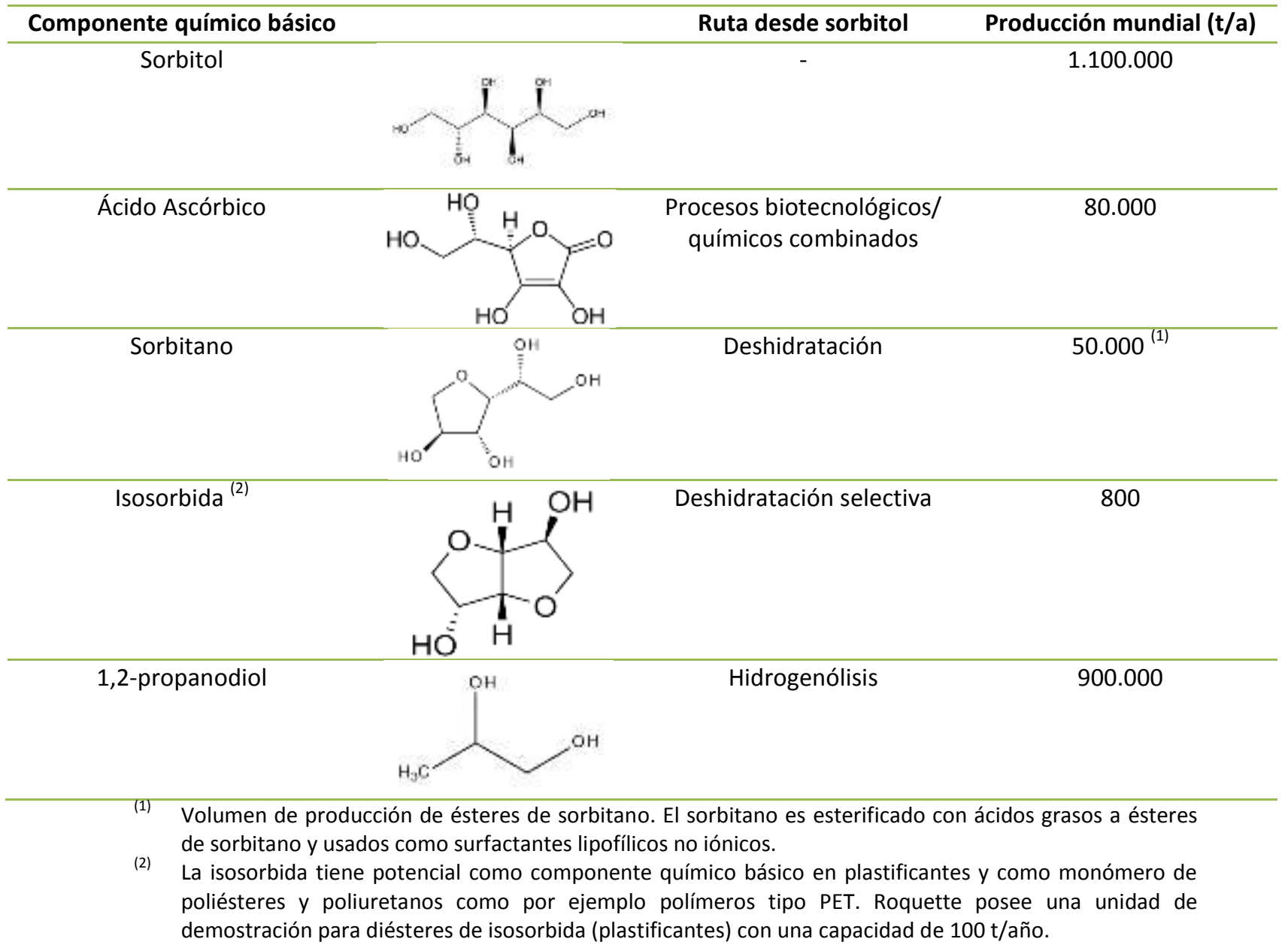

Otro de los productos considerados dentro del top 10 establecido por el Departamento de Energía estadounidense para moléculas plataforma lo constituye el xilitol, polialcohol de 5 átomos de carbono (Figura 1.9). Sus propiedades interesantes 
como sustituto del azúcar, con aproximadamente la misma dulzura que la sacarosa y menor contenido calórico, hacen que se la pueda emplear como edulcorante a la vez que previene la caries dental (Makinen K.K., 1992). Estas características lo convierten en un valioso competidor para una amplia gama de aplicaciones en alimentos, productos farmacéuticos, así como también en cosmética e industrias de resinas sintéticas. Este compuesto puede ser obtenido por hidrogenación de xilosa.

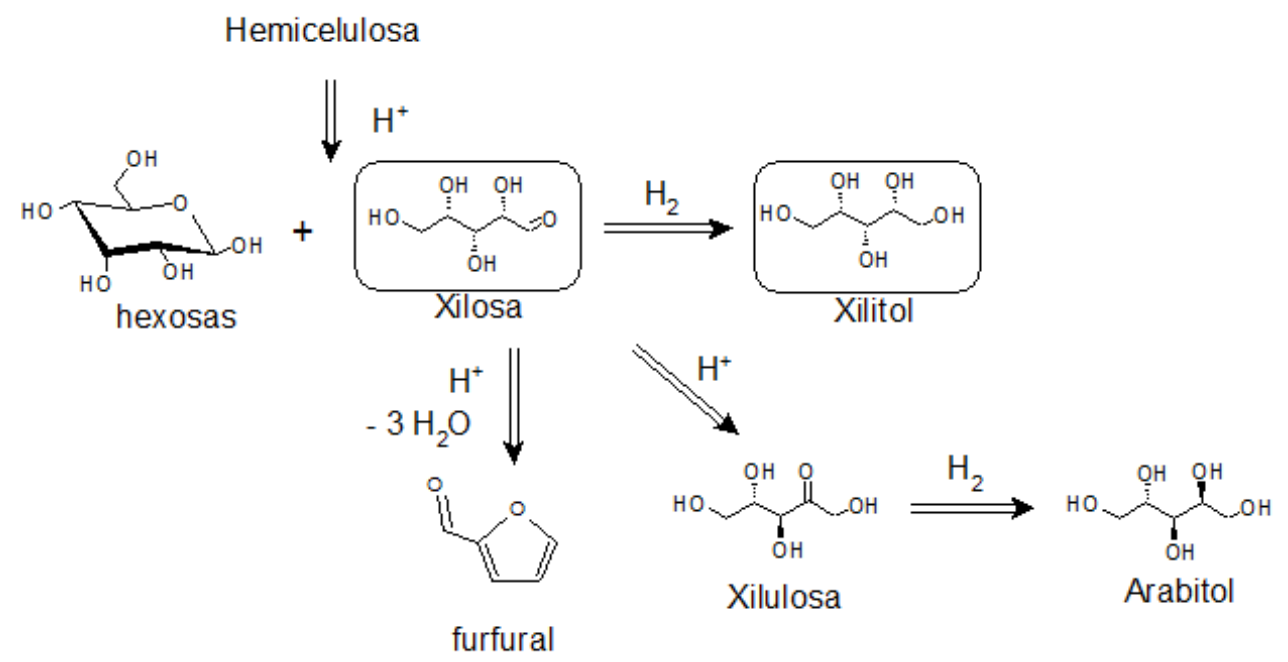

Figura 1.9. Obtención y transformación de xilitol

El consumo global de xilitol fue de aproximadamente 160 mil toneladas métricas en 2013, que es equivalente al valor de mercado de U\$S 670 millones y se espera que alcance las 242 mil toneladas métricas para 2020 equivalentes a USS \$ 1.000 millones. A nivel mundial, Asia produce el $50 \%$ del xilitol total y el resto de la producción es de Europa, Estados Unidos y Australia (Rao y col., 2012). Asia es el mayor consumidor de xilitol. China tiene el mayor mercado de xilitol y también se prevé que India tenga el mercado de más rápido crecimiento (Industry Experts, 2004) (Figura 1.10). La industria de la goma de mascar tiene el mayor mercado de consumo de xilitol, en comparación con otras industrias. Se estima que consumirá alrededor de 163 mil métricas toneladas para 2020, representando el $67 \%$ del consumo mundial de xilitol (Industry Experts, 2004) (Figura 1.11). 


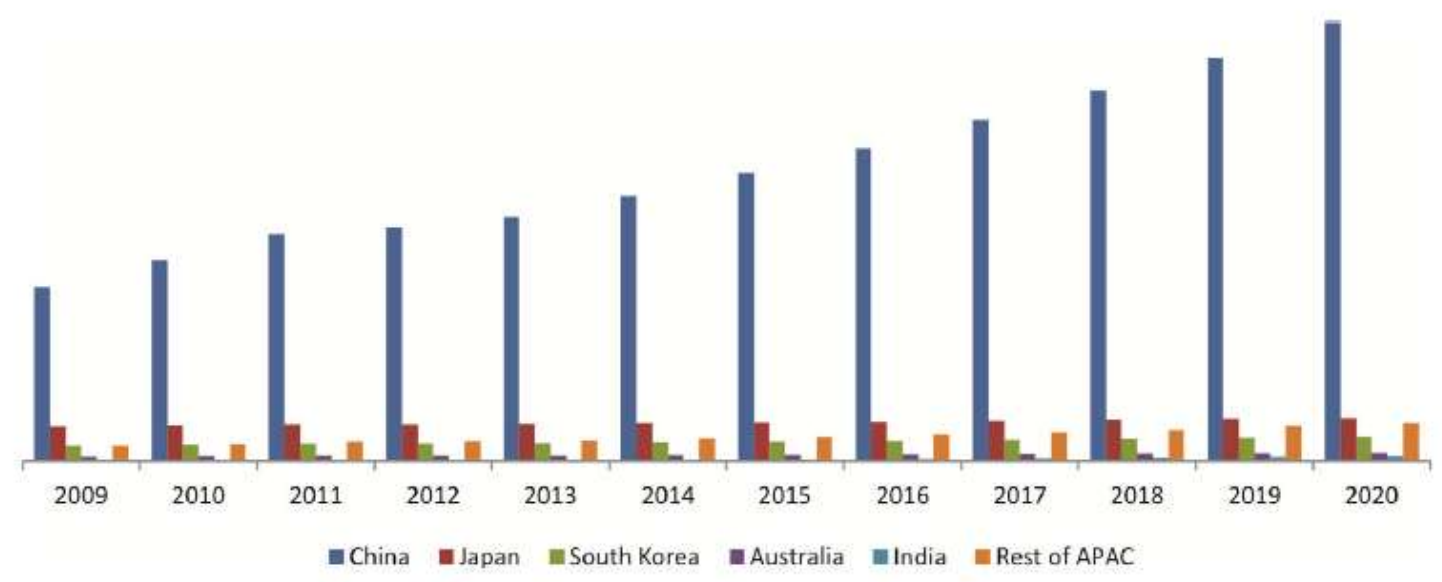

Figura 1.10. Panorama del mercado de xilitol en Asia y el Pacífico (2009-2020) en toneladas métricas

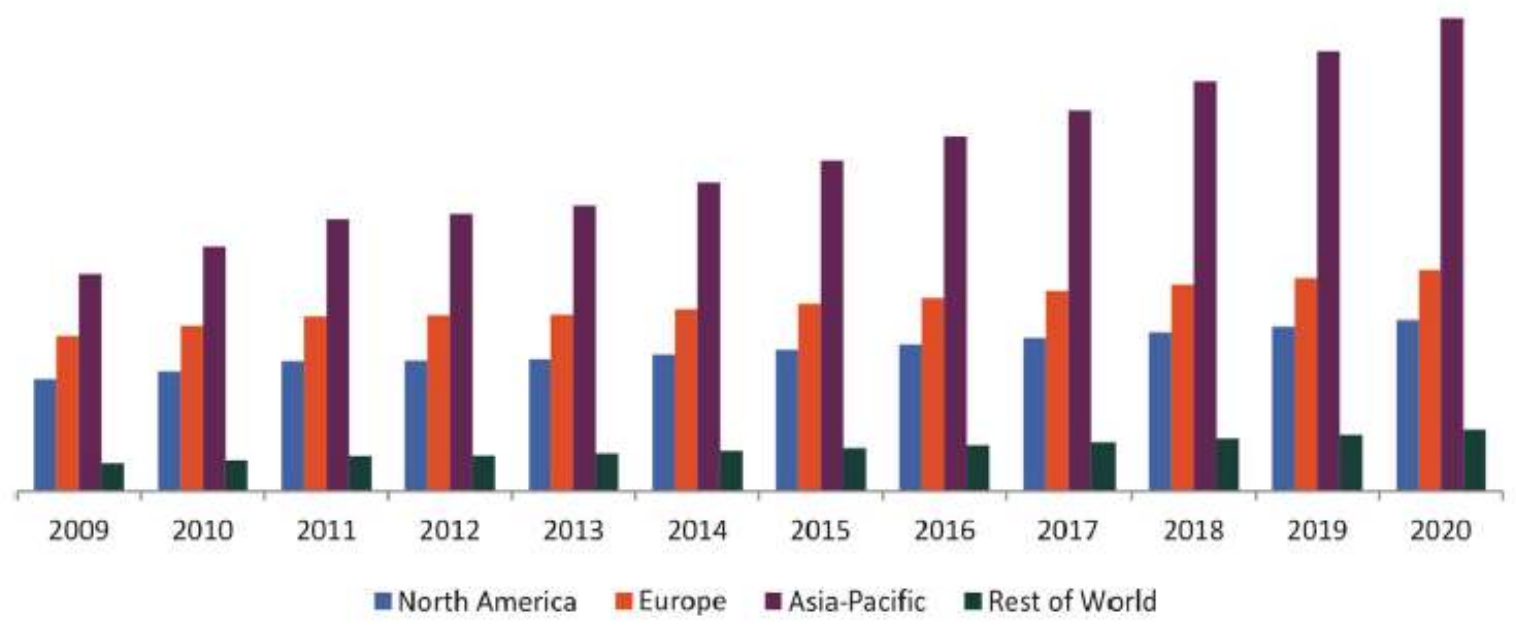

Figura 1.11. Mercado global de goma de mascar de xilitol (2009-2020) por región geográfica en toneladas métricas.

La obtención de xilitol por hidrogenación de xilosa generalmente se realiza en soluciones acuosas en reactores discontinuos a temperaturas entre $100^{\circ} \mathrm{C}$ y $140^{\circ} \mathrm{C}(373$ y $413 \mathrm{~K}$ ) en presencia de catalizadores de níquel Raney y bajo presiones de hasta 5 MPa. Otros estudios se han efectuado para esta reacción empleando catalizadores de Ru. Así Tung Ngoc Pham y colaboradores estudiaron la actividad de rutenio sobre espumas de carbón (Ru/CF) en la hidrogenación de D-Xilosa en distintas condiciones de reacción (4-6 $\mathrm{MPa}_{2}$ y $100-120^{\circ} \mathrm{C}$ ), Reportaron que la actividad catalítica así como la estabilidad del catalizador preparado fue comparable con el catalizador comercial 
sobre carbón activado (Ru/AC), con conversión mayor a 99\% y selectividad a xilitol superior a 98\% (Pham T.N., 2016).

Por otro lado, catalizadores de Ru soportados $\mathrm{TiO}_{2}$ modificado con NiO también han sido ensayados en la hidrogenación de xilosa, obteniendo conversión casi total con una selectividad a xilitol superior al 99\% (Yadav M. y col., 2012). Los autores afirman que el porcentaje $\mathrm{NiO}$ incorporado en soporte modificado $\left(\mathrm{NiO}(5 \%)-\mathrm{TiO}_{2}\right)$ jugó un papel importante para minimizar la generación de arabinitol y otros subproductos, que generalmente se forman durante la hidrogenación de la xilosa (Wisniak J. y col., 1974; Heikkila, H. y col., 1999; Heikkilae, H. y col. 2002; Kohno, S y col. 1971).

\subsection{3.- Furfural}

El furfural (2-furfuraldehido) es un compuesto orgánico obtenido a partir de subproductos agrícolas. El nombre proviene de la palabra latina furfur, que significa salvado. Tras su destilación es un líquido incoloro, con un fuerte olor a almendras, que se oscurece en contacto con la atmósfera por autooxidación (Zeitsch K.J., 2000).

Fue aislado por primera vez en 1832 por el químico alemán Johann Wolfgang Döbereiner, que produjo una pequeña cantidad de furfural como subproducto de la síntesis del ácido fórmico (Döbereiner J.W., 1832). Algunos años más tarde, en 1840, el químico escocés John Stenhouse lo obtuvo por destilación de biomasa agraria en presencia de ácido sulfúrico y determinó la fórmula empírica (Stenhouse J., 1840).

La producción anual de furfural es superior a las 300.000 toneladas, y actualmente el furfural es el único producto químico con elevada producción obtenido a partir de la lignocelulosa. China es el principal productor mundial de furfural, seguido por la República Dominicana. Además, se anticipa que la producción de furfural aumentará en los próximos años (de Jong E. y col., 2015)

Es un compuesto muy versátil y con un gran potencial como plataforma química renovable del que se pueden obtener una gran variedad de productos químicos como muestra la Figura 1.12.

Algunos de ellos son comerciales (enmarcados en la Figura), entre los que cabe destacar el furano y el ácido furoico, utilizados para aumentar el octanaje en las 
gasolinas y como materia prima y producto intermedio para la síntesis de medicamentos y perfumes, respectivamente. También son de gran interés los alcoholes furfurílico y tetrahidrofurfurílico, empleados en la obtención de resinas termo-endurecidas (Corma A., Iborra S. y Velty A., 2007). Hacia la obtención del primero de estos alcoholes es que se dará mayor importancia en este trabajo de tesis.

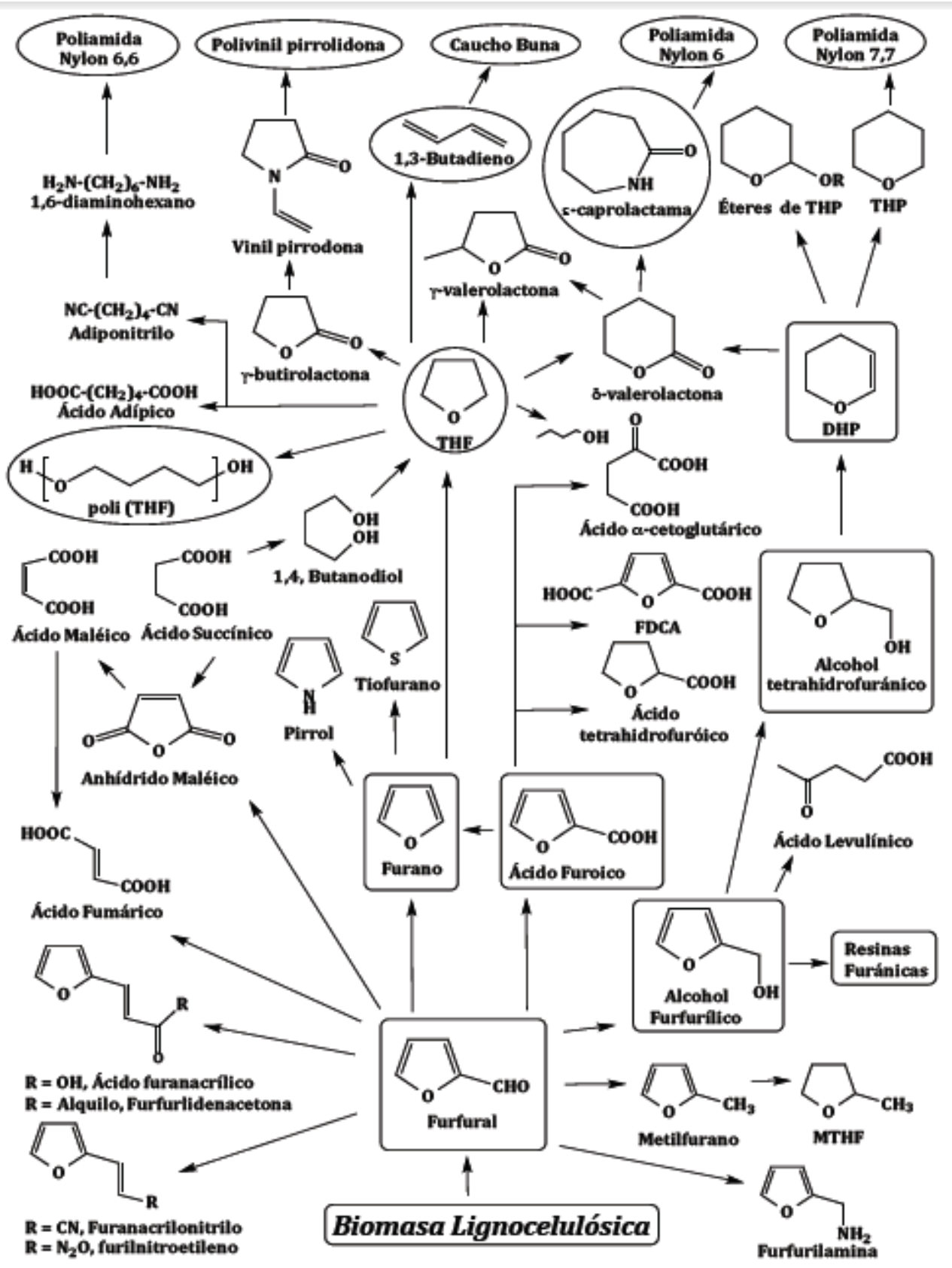

Figura 1.12. Productos químicos derivados del furfural.

El alcohol furfurílico se obtiene por hidrogenación catalítica de furfural, la cual se puede realizar tanto: en fase líquida como en fase gaseosa (Corma A., Iborra S. y Velty A., 2007). A su vez en cuanto al agente hidrogenante, la reacción se puede se 
realizar en forma directa mediante $\mathrm{H}_{2}$ molecular o indirecta mediante trasferencia de hidrógeno a través de compuestos dadores, como algunos alcoholes.

Por lo general, en fase gas, se trabaja con bajas presiones y temperaturas elevadas, pudiendo ocurrir la hidrogenación total de furfural a alcohol tetrahidrofurfurílico, y la hidrogenólisis del grupo $\mathrm{C}-\mathrm{OH}$ para dar 2-metilfurano. (Rao R.S., Baker R.T.K. y Vannice M.A., 1999)

En cambio, en fase líquida se requieren altas presiones y temperaturas moderadas, lo que puede originar la formación de compuestos secundarios por apertura del anillo furánico. Teniendo en cuenta que las reacciones estudiadas en el presente trabajo de tesis son en fase acuosa, se hará un estudio bibliográfico más detallado orientado a los trabajos que hayan abordado esta vía de reacción y empleando $\mathrm{H}_{2}$ gaseoso molecular como agente hidrogenante.

A nivel industrial, la hidrogenación de furfural se realiza con catalizadores de cromito de cobre, empleando reactores discontinuos a altas presiones y temperaturas (Wu J. y col., 2005; Rao R., y col., 1997; Frainier L. J. y Fineberg H., 1981). Estos catalizadores presentan una alta actividad y selectividad a alcohol furfurílico, pero el principal problema de los mismos es su alta toxicidad debido a la presencia de cromo, que causa un elevado grado de contaminación ambiental. Por lo tanto, el diseño de catalizadores activos y selectivos para la obtención del alcohol insaturado es un tema de interés, que aún presenta grandes desafíos.

\section{3.- Hidrogenación en Fase Líquida}

En comparación con los componentes del petróleo, que son generalmente no funcionalizados, los compuestos plataforma provenientes de la biomasa, presentan un alto grado de funcionalización, dado por la presencia de grupos oxigenados.

Esta naturaleza química particular obliga a diseñar diferentes estrategias de procesamiento para ambos recursos. Por ejemplo, puesto que los suministros provenientes del petróleo son hidrofóbicos, tienen baja reactividad y alta volatilidad, los procesos de alta temperatura (para activar los compuestos inertes) y las reacciones en fase gaseosa son las típicas en refinerías. Por el contrario, el alto contenido de 
oxígeno de los derivados de la biomasa los hace solubles en agua (son normalmente obtenidos en forma de soluciones acuosas diluidas después del procesamiento biológico y químico de los azúcares de biomasa), altamente reactivos (con una tendencia natural a descomponerse con la temperatura) y de baja volatilidad. Tales moléculas son, por lo tanto, más adecuadamente transformadas mediante su procesamiento en fase acuosa a temperaturas suaves. Este enfoque nos permite llevar a cabo las transformaciones requeridas en las moléculas plataforma de biomasa en el medio clásico en que se obtienen y de una manera controlada, evitando una reactividad no deseada que conduce a la formación de coque y a la pérdida de carbón que ocurre típicamente temperaturas elevadas. (Serrano-Ruiz J. C., Luque R. y Sepúlveda-Escribano A., 2011).

Estas características especiales de las moléculas plataforma, que sugieren que serían procesadas más eficientemente a temperaturas moderadas, plantean nuevos requisitos sobre las propiedades de los catalizadores sólidos empleados. Así, en lugar de ser térmicamente estables (requisito en catálisis heterogénea para las biorrefinerías comunes), estos nuevos catalizadores para la conversión de biomasa deben ser estables en condiciones hidrotermales (temperaturas moderadas y altas concentraciones de agua).

Una de las posibles transformaciones de los compuestos oxigenados, como ya ha sido mencionado, es su hidrogenación; adición de dos átomos de hidrógeno a sustratos insaturados tales como grupos carbonilo. De esta manera, los polisacáridos (celulosa, hemicelulosa, inulina, etc.) pueden hidrolizarse en azúcares monoméricos y estos, a su vez, pueden someterse además a reacciones de hidrogenación producir alcoholes de azúcar.

En este tipo de reacciones una variable importante a considerar también es la presión a la cual ocurren. Así, sumado a las condiciones mencionadas previamente para las reacciones en fase acuosa, es de destacar las ventajas obtenidas en cuanto a lo que refiere el desarrollo de técnicas ambientalmente amigables y así como también mejores condiciones de seguridad, reduciendo el riesgo, de ser posible, y las limitaciones asociadas con el hidrógeno molecular y su manipulación en condiciones de presión elevadas. 
De esta manera, la síntesis de alcoholes a partir de lignocelulosa es una de las reacciones más significativas en el desarrollo de la biorrefinería.

En los últimos años, la hidrogenación hidrolítica de celulosa utilizando catalizadores heterogéneos ha progresado rápidamente. Por ejemplo, Luoy colab. emplearon un catalizador Ru/AC(AC: carbón activado) para la degradación de celulosa microcristalina, obteniendo un 39\% de rendimiento a alcoholes (Luo C., Wang S. y Liu H., 2007), valor prácticamente igual al que se obtenía sin catalizador. Se logró mejorar el rendimiento mediante el uso de Ru /CNT (CNT: nanotubos de carbono) y pretratando la celulosa con $\mathrm{H}_{3} \mathrm{PO}_{4}$ (Deng W. y col., 2009). Los autores proponen que los sitios ácidos del Ru/CNT contribuyen en la etapa de hidrólisis, mientras que el tamaño de partícula de Ru es un factor importante para lograr un alto rendimiento hacia los alcoholes.

También se ha investigado la utilización de catalizadores homogéneos combinados con catalizadores metálicos soportados con el fin de facilitar la despolimerización de la celulosa, que es el paso determinante de la velocidad. Así, una combinación de $\mathrm{HRuCl}(\mathrm{CO})\left(\mathrm{PPh}_{3}\right)_{3}-\mathrm{KOH}$ como catalizador metálico soportado se empleó en la producción de sorbitol (Ignatyev I.A. y col., 2010). Como resultado de esta reacción se produjo la hidrólisis de la celulosa en glucosa y la hidrogenación subsiguiente de glucosa a sorbitol.

Para el uso práctico de esta reacción, es necesario que el rendimiento hacia alcoholes sea elevado, por lo que el sistema catalítico a base de $\mathrm{Pt}$, con su reconocida capacidad hidrogenante, ha sido ampliamente estudiado en la bibliografía (Kobayashi H. y col., 2011). Estas investigaciones abarcan aspectos tales como: influencia del pretratamiento de la celulosa, precursor de Pt, y soporte catalítico (Kobayashi H. y col., 2011; Zhao H. y col., 2006).

Desafortunadamente, los soportes clásicos de óxido metálico son inestables en estas condiciones y esta cuestión se agrava cuando las reacciones se llevan a cabo a pH básico o ácido.

Entre los catalizadores a base de Pt analizados, se encontró que el sistema $\mathrm{Pt} / \mathrm{Al}_{2} \mathrm{O}_{3}$ fue capaz de convertir selectivamente celulosa a sorbitol y manitol; sin embargo, la actividad catalítica decayó fuertemente en los experimentos de 
reutilización. De acuerdo a los ensayos de caracterización por difracción de rayos $\mathrm{X}$, el soporte $\gamma-\mathrm{Al}_{2} \mathrm{O}_{3}$ se transformó parcialmente en boehmita $(\mathrm{AlO}(\mathrm{OH}))$ durante la reacción de hidrogenación hidrolítica, resultando en la destrucción de la estructura porosa del catalizador, haciendo que las partículas de Pt quedaran sumergidas en su estructura. Por lo tanto, resulta altamente atractivo trabajar sobre la naturaleza del soporte de la fase metálica que permita desarrollar sistemas catalíticos de mayor estabilidad (Kobayashi H. y col., 2011).

Recientemente, se han comenzado a estudiar otros catalizadores a base de metales de transición como alternativa a los metales nobles para la conversión de celulosa. Ding y col. investigaron un sistema catalítico $\mathrm{Ni}_{2} \mathrm{P} / \mathrm{AC}(\mathrm{AC}=$ carbón activado), el cual mostró una elevada actividad en la hidrogenación hidrolítica de celulosa microcristalina, aunque no resultó estable en experimentos de reutilización, debido a la lixiviación del fósforo (Ding L. N. y col., 2010). Por otra parte, catalizadores convencionales $\mathrm{Ni} / \mathrm{Al}_{2} \mathrm{O}_{3} \circ \mathrm{Ni} / \mathrm{C}$ no fueron eficientes para esta reacción, lo que sugiere que la estructura y características del soporte son cruciales en esta reacción.

Materiales alternativos como el carbono, zirconia monoclínica y rutilo (oxido de titanio) son soportes preferibles para el procesamiento en fase acuosa de derivados de biomasa.

Muchas de las reacciones catalíticas implicadas en la transformación de biomasa a combustibles y productos químicos se catalizan con ácido, como ya se mencionó previamente con las hidrólisis de los carbohidratos a sus unidades estructurales para luego ser hidrogenadas. Dado que el agua normalmente envenena los sitios ácidos, el diseño de nuevo sólidos ácidos acuo-tolerantes que mantengan su actividad bajo condiciones hidrotérmicas es clave para lograr conversiones en fase acuosa eficientes y rentables. Una variedad de ácidos sólidos incluyendo zeolitas con alta relación $\mathrm{Si} / \mathrm{Al}$, heteropoliácidos tales como $\mathrm{H}_{3} \mathrm{PW}_{12} \mathrm{O}_{40}$ y $\mathrm{HNbMoO}_{6}$, y óxidos y fosfatos de niobio y zirconio son buenos ejemplos de materiales ácidos con alta compatibilidad con agua (Serrano-Ruiz J. C., Luque R. y Sepúlveda-Escribano A., 2011; Mishra D.K., Dabbawala A.A. y Hwang J., 2013).

En lo que respecta a la hidrogenación de furfural, hay que tener en cuenta que comparado con otros aldehídos, además del grupo carbonilo, el furfural contiene un 
anillo aromático de furanilo que también puede ser hidrogenado. Así, catalizadores metálicos que tienen fuertes interacciones con los enlaces $C=C$ insaturados pueden saturar el anillo.

Entre los metales del grupo 11, el Cu ha sido el más intensivamente investigado como catalizador para la hidrogenación de furfural (Seo G. y Chon H., 1981; Rao R. y col., 1997; Sitthisa S. y col., 2011). La plata ha sido utilizada en algunos estudios, mientras que no hay reportes sobre los catalizadores de Au (Claus, P., 1998). Los metales del grupo 11 son significativamente menos activos que otros metales. Sin embargo, ellos exhiben una notable selectividad hacia la hidrogenación del grupo carbonilo dejando los dobles enlaces $\mathrm{C}=\mathrm{C}$ en el anillo furánico sin reaccionar. En este sentido, se ha encontrado que el Cu es el más selectivo entre todos los catalizadores metálicos probados. Se han logrado selectividades superiores al $98 \%$ al alcohol furfurílico con catalizadores monometálicos de $\mathrm{Cu} / \mathrm{SiO}_{2}$ (Sitthisa S. y col. 2011). Además, se ha encontrado que los catalizadores monometálicos de $\mathrm{Ag}$ son capaces de hidrogenar el grupo $\mathrm{C}=\mathrm{O}$ de furfural con relativa buena selectividad, pero no tan alta como la de $\mathrm{Cu}$. Por ejemplo, un $80 \%$ de selectividad se obtuvo sobre un catalizador $\mathrm{Ag}$ / $\mathrm{SiO}_{2}$ preparado por el método sol-gel (Claus P., 1998).

Los metales del grupo $10(\mathrm{Ni}, \mathrm{Pd}$ y Pt) también se han usado para esta reacción de hidrogenación tanto en las fases vapor como líquida en diferentes soportes. Sin embargo también se observa que conducen a la hidrogenación del anillo furánico que produce el alcohol saturado debido a una interacción más fuerte del anillo con el metal superficial que la ocurrida con los metales del grupo 11 (Bradley M.K., Robinson J. y Woodruff D.P., 2010).

Como resultado, $\mathrm{Cu}$ y $\mathrm{Ag}$ podrían ser los catalizadores preferidos si la alta selectividad al alcohol furfurílico es deseable, particularmente a altas temperaturas. Sin embargo, la actividad intrínseca para la hidrogenación de furfural es menor en los metales del grupo 11 que con los metales del grupo 10. Esto normalmente se explica por la diferencia en llenado y extensión de los orbitales $d$. Es decir, los orbitales d se completan en el grupo 11, lo que reduce la fuerza de enlace. (Resasco D. E. y col, 2011)

Es por ello que con el objeto de mejorar la actividad y/o selectividad es que se han realizado estudios con el agregado de otro metal ( $\mathrm{Ce}$, Fe, etc) como promotor. Por 
ejemplo, se han usado catalizadores de $\mathrm{Ni}$ a bajas temperaturas $\left(100^{\circ} \mathrm{C}\right)$ en fase líquida (empleando etanol como solvente), exhibiendo> 95\% de selectividad a alcohol furfurílico ( Li, H. y col., 2003; Liaw B. y col., 2008).

Sin embargo, a pesar de los resultados exitosos obtenidos, en algunos casos la principal desventaja observada es que el catalizador no puede ser reutilizado (Merat N., Godawa C. y Gaset A., 1990).

Rodiansono y col. prepararon catalizadores $\mathrm{Ni}$ Raney y aleaciones $\mathrm{Ni}-\mathrm{Sn}$ soportados sobre hidróxido de aluminio, obteniendo valores de conversión superior al 95\% y de selectividad de $94 \%$ a alcohol furfurílico para el sistema bimetálico ensayado en alcohol isopropílico como solvente (Rodiansono y col., 2015).

Del mismo modo, se han reportado trabajos con catalizadores de Pt soportados y dopados con óxidos de metales de transición. Por ejemplo, $\mathrm{Pt} / \mathrm{TiO}_{2} / \mathrm{SiO}_{2}$ (selectividad $=94 \%$ ) y $\mathrm{Pt} / \mathrm{ZrO}_{2} / \mathrm{TiO}_{2}$ (selectividad = 95\%) (Kijeński, J. y col., 2002).

Merlo y col. trabajaron con catalizadores monometálicos $\mathrm{Pt}(1 \%) / \mathrm{SiO}_{2}$ y bimetálicos $\mathrm{Pt}(1 \%)-\mathrm{Sn}(0,3-1 \%) / \mathrm{SiO}_{2}$. En este caso, el catalizador monometálico fue preparado por intercambio iónico, mientras que el agregado de Sn se realizó por reacciones superficiales controladas entre el catalizador monometálico previamente reducido y tetrabutil estaño ( $\mathrm{SnBu} 4)$ en un solvente parafínico como $\mathrm{n}$-heptano o $\mathrm{n}$ decano. Obtuvieron conversiones cercanas al $100 \%$ y selectividades a alcohol furfurílico del $96 \%$ en distintos solventes. (Merlo A. y col, 2009).

Mironenko y colaboradores (Mironenko R. M. y col., 2015) estudiaron catalizadores de $\mathrm{Pd}(1,5 \%)$ y $\mathrm{Ru}(1,5 \%)$ soportados sobre nanotubos de carbono (CNT) y sobre negro de carbón (CB). Realizaron las pruebas de actividad catalítica a en condiciones de presión y temperatura moderada $\left(50-90^{\circ} \mathrm{C}, 0,5-2 \mathrm{MPa}\right.$ de $\left.\mathrm{H}_{2}\right)$ y agua como solvente. Reportaron que a $50^{\circ} \mathrm{C}$ el catalizador de $\mathrm{Pd} / \mathrm{CB}$ fue altamente selectivo a alcohol furfurílico (99\%), mientras que la muestra Pd/CNT no fue activa. $\mathrm{A} 90^{\circ} \mathrm{C}$, observaron que Pd/CNT fue activo y que se produjo la hidrogenación del anillo furánico, alcanzando una selectividad a alcohol tetrahidrofurfurílico de $52 \%$. Informaron además que los catalizadores de $\mathrm{Ru}$ fueron poco activos en la 
hidrogenación. Atribuyeron esto a la adsorción irreversible del agua sobre los sitios activos.

Yuan y colaboradores (Yuan Q. y col., 2015) emplearon catalizadores de Ru soportados sobre estructuras basadas en Zr como UiO-66, UiO-67, Zr6-NDC, MIL-140A, MIL-140B, y MIL-140C. Realizaron los ensayos a $20^{\circ} \mathrm{C}, 0,5 \mathrm{MPa}$ de $\mathrm{H}_{2}$, empleando agua como solvente y con una relación volumen de furfural/masa de catalizador de $1 \mathrm{~cm}^{3} / \mathrm{g}$. Observaron que todos los catalizaron fueron altamente selectivos a alcohol furfurílico (FOL) (S $\approx 100 \%$ ), aunque los rendimientos fueron variables. Informaron que la muestra más activa fue Ru/UiO-66, alcanzando un rendimiento a FOL de 94,9\%. Por otra parte, utilizaron el mismo catalizador durante cinco ciclos consecutivos sin observar una pérdida apreciable de la actividad catalítica. Relacionaron la alta actividad de Ru/UiO66 con las especies de Ru formadas luego de la activación con $\mathrm{H}_{2}$.

A partir del estudio bibliográfico, observamos que hay una gran variedad de compuestos que pueden obtenerse a partir de la hidrogenación del furfural y, aunque han sido muchos los catalizadores estudiados, sigue siendo un desafío el diseño de sistemas que sean altamente selectivos al producto buscado, alcohol furfurílico. 


\section{4.- Objetivos}

\subsection{1.- Objetivos generales}

El objetivo general de esta tesis doctoral es el de generar y transferir conocimientos relacionados al desarrollo racional y a la comprensión del modo de acción de catalizadores sólidos heterogéneos que puedan resultar activos, selectivos y estables en procesos vinculados con las biorrefinerías, como ser la hidrogenación hidrolítica de celulosa con el objeto de generar productos para química fina y energía, en condiciones suaves que sean ambientalmente amigables (empleando agua como solvente y presiones y temperaturadas moderadas).

\subsection{2.- Objetivos específicos}

Los objetivos específicos se pueden resumir de la siguiente manera:

i) Preparar catalizadores monometálicos soportados Ru/Soporte (Soporte $=$ $\mathrm{Al}_{2} \mathrm{O}_{3}, \mathrm{C}, \mathrm{ZrO}_{2}, \mathrm{ZrO}_{2}$-fosfatada, $\mathrm{ZrO}_{2} / \mathrm{Al}_{2} \mathrm{O}_{3}$ y $\mathrm{ZrO}_{2}$-fosfatada/ $\mathrm{Al}_{2} \mathrm{O}_{3}$ ) con diferentes características de tamaño de partícula, acidez, etc.

ii) Preparar catalizadores bimetálicos Ru-Sn., mediante el uso de técnicas derivadas de la Química Organometálica de Superficies sobre Metales (QOMS/M), que proporciona los procedimientos técnicos para preparar sistemas catalíticos de una manera controlada.

iii) Estudiar la reacción de hidrogenación en fase acuosa de sustratos provenientes de la degradación de celulosa y hemicelulosa: furfural, glucosa, xilosa y celobiosa, desarrollando metodologías adecuadas para llevar a cabo la reacción propuesta. Esto implica establecer las condiciones de temperatura, presión, concentración de sustrato, agitación, etc., que optimicen los experimentos.

iv) Caracterizar los catalizadores preparados mediante distintas técnicas de estudio fisicoquímicos con el objeto de obtener la información que permita establecer el mecanismo de activación de los enlaces de los reactivos involucrados, la naturaleza de las especies intermedias formadas, la interacción con la superficie y el papel que éstas desempeñan en la reacción de activación. 


\section{CAPÍTULO 2}

\section{METODOLOGÍA EXPERIMENTAL}


En este capítulo se proporcionan los detalles técnicos de todos los experimentos realizados a lo largo de la Tesis. El capítulo se estructura en tres secciones. Primeramente, se realiza una descripción de los métodos empleados en la preparación de los soportes y catalizadores utilizados. A continuación, se resumen brevemente las técnicas de caracterización utilizadas, mencionando el propósito de su empleo así como un breve comentario sobre el fundamento teórico de la técnica. Finalmente se presenta una descripción detallada del procedimiento y de las condiciones experimentales seguidas para obtener los resultados así como de los métodos de reacción empleados durante el desarrollo de esta Tesis Doctoral. 


\section{1.- Preparación de soportes y catalizadores}

\subsection{1.- Soportes de catalizadores}

El soporte es la matriz sobre la cual se deposita la fase activa y el que permite optimizar sus propiedades catalíticas. Este soporte puede ser poroso y por lo tanto presentar un área superficial por gramo elevada, aumentando significativamente el área de contacto de los metales activos, mejorando su dispersión y permitiendo el acceso de los reactivos hacia los sitios activos y la difusión de los productos fuera del mismo sitio activo. Debido a que la catálisis heterogénea es un fenómeno superficial, cuanto más disperso esté el metal, más eficiente es su uso. Ya que los componentes catalíticamente activos de un catalizador suelen ser metales caros, solo una pequeña cantidad de este se halla disperso sobre el soporte. De esta manera, la función de los soportes no es solo la de proveer al metal de un medio físico en el cual permanecer, sino que también brindan una ventaja económica.

Además, los soportes pueden cumplir otras funciones como la de mejorar la resistencia mecánica del catalizador cuando se lo emplea en un sistema con agitación mecánica o en un lecho relleno, mejorar la estabilidad térmica y la vida útil del catalizador.

\subsection{2.- Características generales de los soportes}

Los soportes son sólidos, normalmente porosos, que deben presentar determinadas características: 1) ser capaces de estabilizar la fase metálica en un estado de dispersión elevada, dado que las propiedades catalíticas en sistemas heterogéneos son función de la superficie expuesta; 2) poseer propiedades texturales adecuadas, son generalmente deseables altas superficies, puesto que se busca extender el área disponible para el metal activo; 3) presentar buenas propiedades mecánicas; 4) poseer estabilidad y ser generalmente inertes (aunque algunas veces juega un papel importante sobre la actividad y selectividad de la reacción); 5) presentar buenas propiedades en transferencia de calor y geometrías adecuadas; 6 ) tener un bajo costo (Perego C. y Villa P., 1997). 
En la bibliografía podemos encontrar varios sólidos que poseen las características mencionadas. Dado que las condiciones de reacción, en este caso, no son severas (temperaturas y presiones moderadas) resultan apropiados soportes como $\mathrm{SiO}_{2}, \mathrm{Al}_{2} \mathrm{O}_{3}, \mathrm{TiO}_{2}, \mathrm{C}$, etc. de los cuales, teniendo en cuenta estudios previos, hemos seleccionado $\mathrm{C}$ y $\mathrm{Al}_{2} \mathrm{O}_{3}$.

Además teniendo en cuenta que para la reacción de hidrólisis de biomasa se requiere de condiciones ácidas, se han preparado soportes a base de zirconio $\left(\mathrm{ZrO}_{2} \mathrm{Y}\right.$ $\mathrm{ZrO}_{2}-\mathrm{PO}_{4}^{-3}$ ), tanto en forma másica como de fases soportadas sobre alúmina.

Los soportes a base de zirconio fueron preparados por el método sol-gel, uno de los más utilizados cuando se requiere preparar films delgados, polvos o membranas. Esta técnica tiene muchas ventajas sobre otras técnicas de preparación, incluyendo la facilidad de procesamiento, control sobre la composición, pureza y la homogeneidad de los materiales obtenidos (Gomez Silva C. y Faria J.L., 2009).

Los soportes empelados en esta Tesis son o bien amorfos como el carbón activado o bien cristalinos como la zirconia.

A continuación se describirán brevemente la estructura y propiedades de los soportes empleados en este trabajo.

\subsubsection{1.- $\gamma-\mathrm{Al}_{2} \mathrm{O}_{3}$}

Existen una serie de materiales que son referidos como alúminas. Estas especies difieren entre sí en su composición química y su estructura cristalina. Entre ellos, podemos encontrar los trihidróxidos, $\mathrm{Al}(\mathrm{OH})_{3}$, de los cuales las dos formas cristalinas Gibbsita y Bayerita, son las más comunes. La pérdida de una molécula de agua conduce a los oxihidróxidos, AlO $(\mathrm{OH})$, bohemita, pseudo bohemita y diásporo, diferenciándose en su arreglo cristalino. La deshidratación adicional conduce a las alúminas de transición que tienen la fórmula genérica $\mathrm{Al}_{2} \mathrm{O}_{3} \cdot \mathrm{xH}_{2} \mathrm{O}$, con $0<\mathrm{x}<1$. La deshidratación completa da corindón o $\alpha$-alúmina. La relación y temperaturas aproximadas de transición entre éstas especies se muestran en la Figura 2.1. 


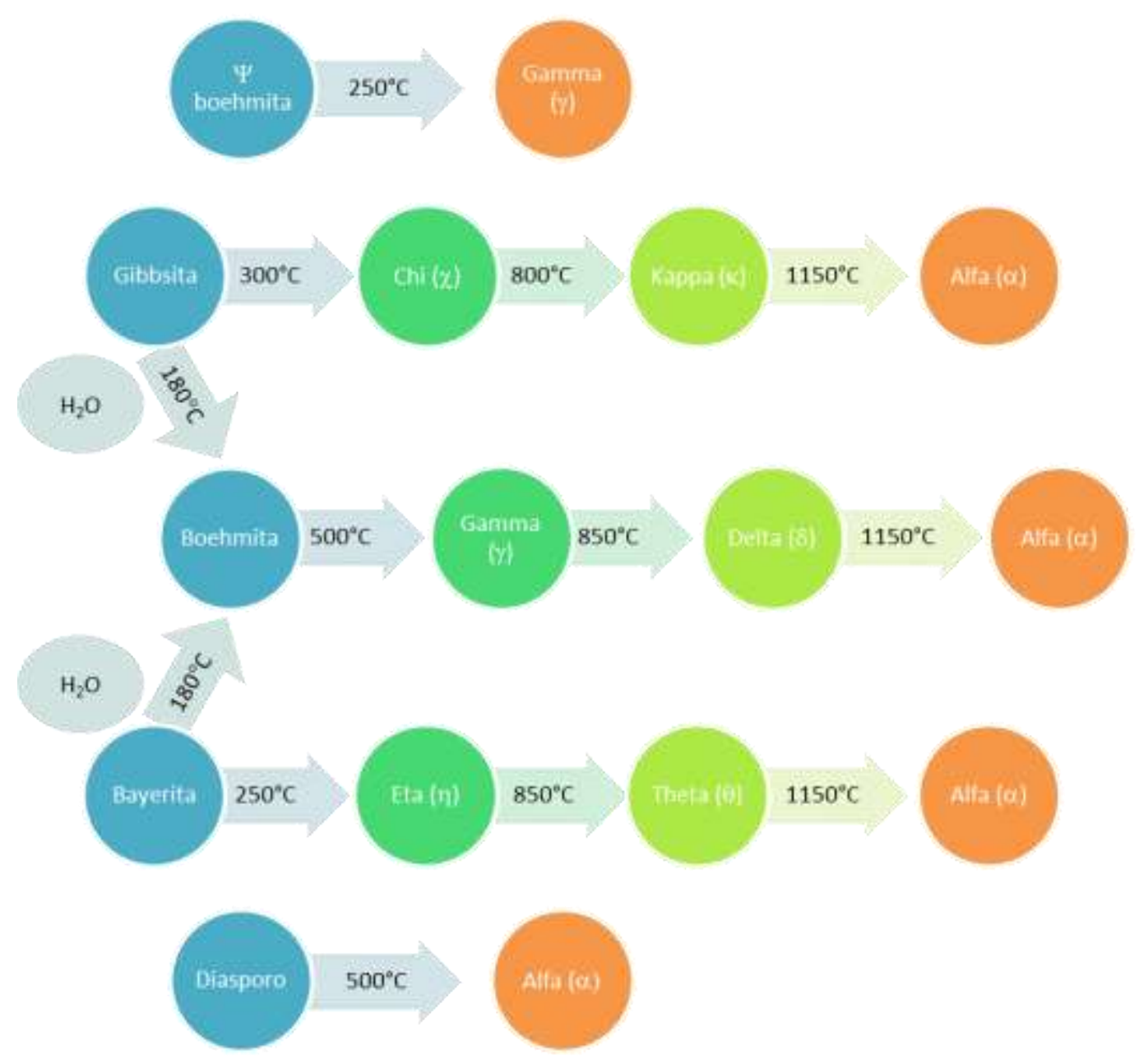

Figura 2.1. Transiciones entre especies de alúminas.

Estos materiales pueden tener áreas que oscilan entre 0,1 y $400 \mathrm{~m}^{2} / \mathrm{g}$, volúmenes de poros entre 0,1 y $1,5 \mathrm{~cm}^{3} / \mathrm{g}$ y un promedio un tamaño de poro promedio entre $2 \mathrm{~nm}$ y $170 \mu \mathrm{m}$. Puesto que se puede preparar una alúmina que tenga las características superficiales necesarias para casi cualquier proceso, no es de extrañar por qué la "alúmina" ha sido utilizada tan ampliamente como soporte de catalizador. Los soportes catalíticos más comunes son las alúminas transicionales, particularmente $\gamma$-alúmina, la cual es elaborada por calentamiento de $\Psi$ boehmita. Este proceso proporciona una alúmina que tiene un área superficial entre $150-300 \mathrm{~m}^{2} / \mathrm{g}$, un volumen de poro entre $0,5-1 \mathrm{~cm}^{3} / \mathrm{g}$ y un gran número de poros en el intervalo de 3-12 $\mathrm{nm}$. Las $\gamma$-alúminas preparadas a partir de otros orígenes tienen significativamente menores áreas superficiales y volúmenes de poros. Por el contrario, la $\alpha$-alúmina, la 
forma más deshidratada de la alúmina, es esencialmente no porosa con superficies comprendidas entre 0,1 y $5 \mathrm{~m}^{2} / \mathrm{g}$ (Augustine R. L., 1996).

La $\gamma-\mathrm{Al}_{2} \mathrm{O}_{3}$ es un sólido de baja cristalinidad con iones $\mathrm{Al}^{+3}$ ocupando posiciones tetraédricas y octaédricas en la red cubica compacta de iones $\mathrm{O}^{-2}$. La estructura cristalina de este material se debe probablemente a la presencia de aproximadamente en la red (un mol de $\mathrm{H}_{2} \mathrm{O}$ por tres moles de $\mathrm{Al}_{2} \mathrm{O}_{3}$ ) que llenan todos los espacios en una red de espinela.

Su alta superficie específica permite una buena distribución de los precursores que forman parte del catalizador y por ende, de los sitios activos del catalizador. Su volumen poral alto facilita la difusión de moléculas relativamente grandes.

\subsubsection{2.- Carbones}

El carbón activo (CA) es un material sólido preparado artificialmente, que se caracteriza por una estructura porosa bien desarrollada, lo que le confiere una elevada superficie específica y capacidad de adsorción. Presenta una gran versatilidad debido a la posibilidad de modificar y controlar el tamaño y distribución de sus poros en la estructura carbonosa, así como la naturaleza química de su superficie durante su proceso de preparación.

En cuanto a su composición química está formado mayoritariamente por átomos de carbono, en torno a un 87-97 \%. El resto de su composición incluye heteroátomos como hidrógeno, oxígeno, azufre y nitrógeno procedentes de la materia prima, o incorporados durante el proceso de preparación.

Su estructura está constituida por microcristales de grafito, formados por una serie de anillos aromáticos entrelazados según la estructura del grafito, y formando entre 5 y 15 láminas de planos grafíticos con una separación de 3 - 4 Á entre las mismas (Marijuan de Santiago L., 1988). Las láminas aromáticas de carbono aparecen unidas entre sí de forma irregular y aleatoria, de tal forma que no aparecen perfectamente paralelas, o incluso se solapan unas con otras (Bansal R. C., Donnet J.B., Stoeckli F. , 1988). Los espacios intersticiales entre las láminas aromáticas dan lugar a la formación de poros (Stoeckli F., 1990), defectos estructurales, electrones 
desapareados y vacantes en el sistema en el borde de los planos basales. En presencia de heteroátomos en el medio de reacción (azufre, nitrógeno, hidrógeno y oxígeno molecular), se pueden formar grupos superficiales en dichos centros activos.

Tanto la ordenación aleatoria de las capas como su entrecruzamiento impiden el reordenamiento de la estructura para obtener grafito, aun cuando se caliente este material hasta $3000^{\circ} \mathrm{C}$. Ésta es la característica del carbón activo que más contribuye a su propiedad más importante, la estructura porosa interna altamente desarrollada y accesible para los procesos de adsorción (Rodríguez Reinoso F., 2009).

Según la nomenclatura IUPAC (International Union of Pure and Applied Chemists) los poros se clasifican según su tamaño, tomando como referencia la boca de poro, en microporos ( $\Phi<2 \mathrm{~nm}$ ), mesoporos $(2<\Phi<50 \mathrm{~nm}$ ) y macroporos $(\Phi>50$ nm) (Sing K.S.W. y col., 1985). En la Figura 2.2 se representa esquemáticamente la estructura porosa que presentan comúnmente los carbones activos.

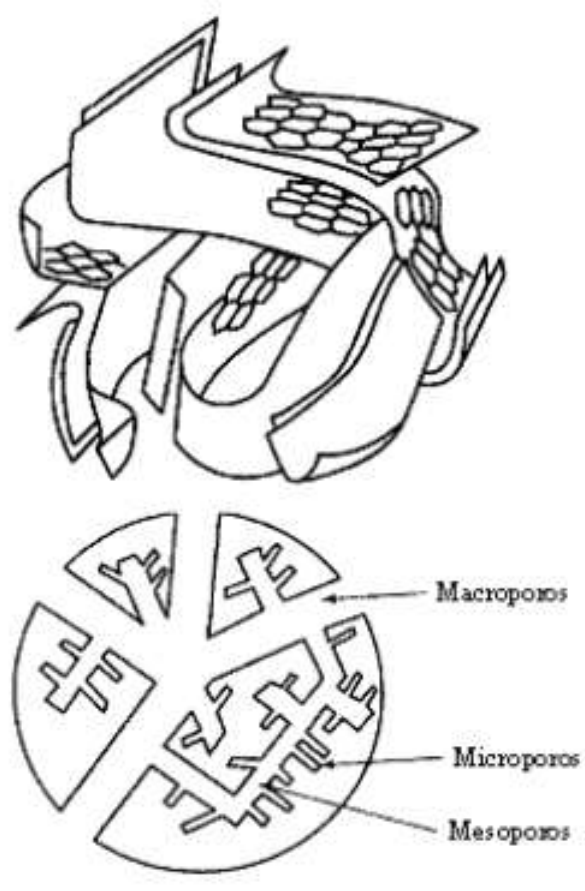

Figura 2.2. Estructura porosa del carbón activo (Stoeckli F. y col., 1990).

La mayoría de los carbones utilizados como soportes se preparan a partir de fuentes naturales tales como árboles, plantas, caparazones, carbón, madera, frutos secos, etc. por pirólisis a alta temperatura en gases inertes, $\mathrm{CO}_{2} \mathrm{y} / \mathrm{o}$ vapor, aunque 
también puede producirse a partir de carbón mineral o coque de petróleo. Se tiene especial interés sobre los residuos de biomasa (Ioannidou O. y Zabaniotou A., 2007), puesto que son materia prima de bajo costo, además su tratamiento es amigable con el medio ambiente.

En consecuencia, sus propiedades físicas y químicas varían no sólo con las condiciones de pirólisis, sino también con el origen y época de crecimiento de las fuentes naturales. El tratamiento a temperaturas de pirólisis moderadamente altas $\left(800-1500^{\circ} \mathrm{C}\right)$ en una atmósfera ligeramente activa produce "carbones activados" de superficie ultra alta, mientras que el tratamiento en gases inertes a temperaturas muy altas (hasta $3000^{\circ} \mathrm{C}$ ) produce carbones grafíticos de baja superficie. Los carbones activados pueden tener áreas superficiales tan altas como $1000-1500 \mathrm{~m}^{2} / \mathrm{g}$ con microporos en el intervalo de 0,5-1 $\mathrm{nm}$. Debido a su alta estabilidad térmica en ambientes reductores y su capacidad para facilitar la preparación de metales bien dispersos, son los más comúnmente usados para soportar metales preciosos para la hidrogenación de grupos funcionales orgánicos en la industria de química fina. Está claro que la naturaleza de las propiedades superficiales del carbón juega un papel importante en la catálisis. Por ejemplo, la capacidad de los portadores de carbono para adsorber moléculas orgánicas desempeña un papel crítico en las hidrogenaciones orgánicas. (Bartholomew C. H. y Farrauto R. J., 2005).

\subsubsection{3.- $\mathrm{ZrO}_{2}$}

Es un soporte ampliamente empleado en catálisis en reacciones redox (Tanabe. K., 1985) y es el único metal óxido que posee cuatro propiedades químicas en su superficie: acidas, básicas y propiedades de reducción y oxidación (Tidahy H.L., y col., 2007).

La zirconia $\left(\mathrm{ZrO}_{2}\right)$ pura se presenta en diversas formas cristalinas como son la monoclínica, la tetragonal y cúbica. Aunque la fase monoclínica es estable por debajo de aproximadamente $1150^{\circ} \mathrm{C}$, la fase tetragonal puede bajo ciertas condiciones, estar presente como una fase metaestable a temperaturas más bajas (Tidahy H.L., y col., 2007; Srinivasan R. y col., 1995). 
- forma monoclínica $(\mathrm{m})$ existe por debajo de $1170^{\circ} \mathrm{C}$. En su estructura los cationes $\mathrm{Zr}^{+4}$ están situados en planos paralelos al 001 y separados por los planos de aniones $\left(\mathrm{O}^{2-}\right)$

forma tetragonal $(t)$ se encuentra entre $1170^{\circ}$ y $2370^{\circ} \mathrm{C}$. Posee una estructura donde cada ión $\mathrm{Zr}^{+4}$ está rodeado por ocho iones de oxígeno, cuatro de ellos a una distancia de $2.455 \AA$ y los otros cuatro a una distancia de $2.064 \AA$.

forma cubica (c) se halla por encima de $2370^{\circ} \mathrm{C}$. Tiene una estructura en donde cada ión de $\mathrm{Zr}^{+4}$ está coordinado con ocho iones de oxigeno equidistantes y a su vez, cada ion de oxígeno está coordinado tetraédricamente con cuatro iones de $\mathrm{Zr}^{+4}$ similar a una estructura fluorita con los iones de $\mathrm{Zr}^{+4}$ formando una subred cúbica centrada en las caras y los iones de oxígeno formando una sub red cúbica simple.

Las diferentes fases de la zirconia en función la temperatura se representa en la Figura 2.3.

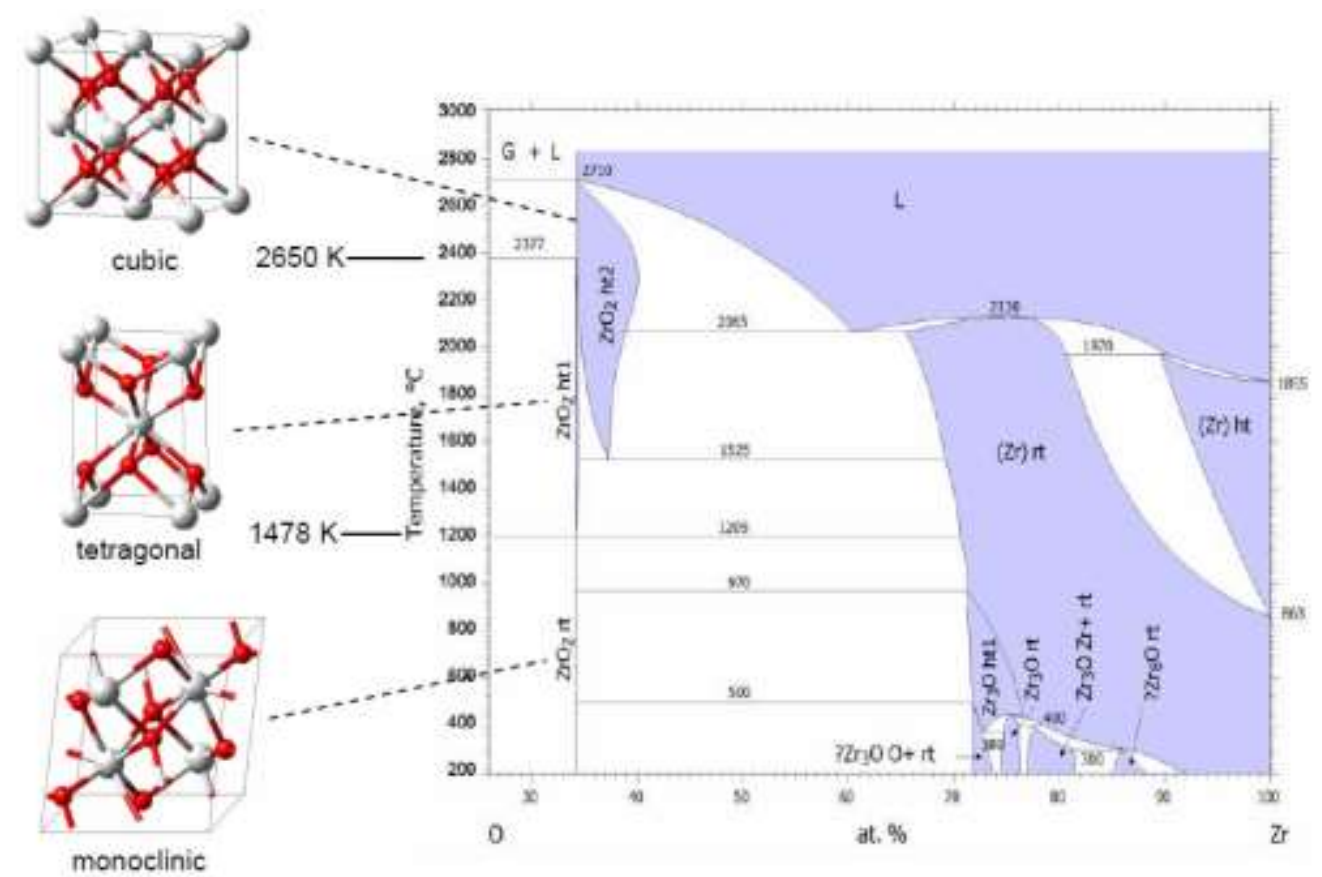

Figura 2.3. Diagrama de fase de la zirconia. Las transiciones de fase se observan a $1205^{\circ} \mathrm{C}$ (1478 K) y $2377^{\circ} \mathrm{C}$ (2650 K). (Extraída de Materials Design, Application Note Phase Transitions in $\mathrm{ZrO}_{2}, 2009$ ). 
La transformación de la estructura tetragonal metaestable a la forma monoclínica es sensible a las impurezas o aditivos. Dicha transformación es completa alrededor de los $650-700^{\circ} \mathrm{C}$ (Yamaguchi T., 1994).

Mediante la adición de ciertos óxidos metálicos como dopantes, los cuales deben presentar estructuras cristalinas cúbicas del tipo fluorita y alta solubilidad en la zirconia, es posible estabilizar el material en las formas tetragonal y cúbica a temperatura ambiente (evitando así la transformación tetragonal-monoclínica).

La $\mathrm{ZrO}_{2}$ que se usa como soporte de catalizadores corresponde a las formas tetragonal y monoclínica.

El área superficial y la forma cristalina de la $\mathrm{ZrO}_{2}$ son sensibles a la temperatura de calcinación, como se puede apreciar en la Figura 2.4 .

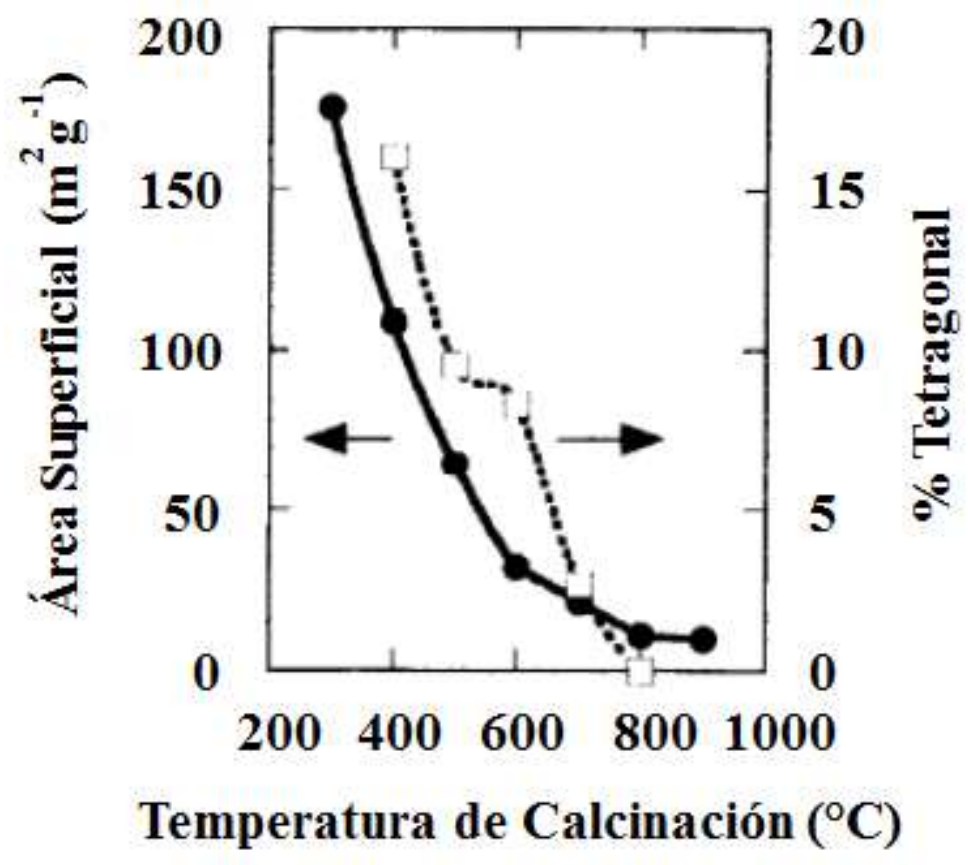

Figura 2.4. Cambios en el área superficial y la forma cristalina de $\mathrm{ZrO}_{2}$ con la temperatura de calcinación (Figura adaptada de Yamaguchi T., 1994).

El área superficial de la $\mathrm{ZrO}_{2}$ no es tan grande comparada con la de la $\mathrm{SiO}_{2} \mathrm{o} \gamma$ $\mathrm{Al}_{2} \mathrm{O}_{3}$ que son usados comúnmente como soportes. Con el objeto de aumentar el área superficial de la $\mathrm{ZrO}_{2}$ se la ha dispersado en soportes de alta área superficial como $\mathrm{SiO}_{2}, \mathrm{Al}_{2} \mathrm{O}_{3} \circ \mathrm{TiO}_{2}$. El objeto de esta dispersión es obtener grandes aéreas superficiales y controlar la exposición de las superficies $\left(\begin{array}{lll}1 & 1 & 1\end{array}\right),\left(\begin{array}{lll}1 & 1 & 0\end{array}\right)$ entre otras (Klimova T. y col., 
1998). El uso de óxidos mixtos $\mathrm{ZrO}_{2}-\mathrm{Al}_{2} \mathrm{O}_{3}$ permite ajustar las propiedades texturales del soporte cambiando las relaciones de los dos óxidos para de esta manera diseñar catalizadores más selectivos. (Klimova T. y col., 1998).

La preparación de los óxidos mixtos $\mathrm{ZrO}_{2}-\mathrm{Al}_{2} \mathrm{O}_{3}$ se lleva a cabo mediante el método sol-gel. De esta manera el óxido $\mathrm{ZrO}_{2}$ se halla disperso en la matriz de $\mathrm{Al}_{2} \mathrm{O}_{3}$. La relación entre los óxidos $\mathrm{ZrO}_{2}$ y $\mathrm{Al}_{2} \mathrm{O}_{3}$ permite ajustar las propiedades químicas y texturales de la superficie del soporte (Klimova T. y col., 1998).

\subsection{3.- Preparación de catalizadores}

Los catalizadores metálicos soportados son uno de los grupos más atractivos dentro de los catalizadores sólidos, ya que sus propiedades catalíticas pueden ser ajustadas de acuerdo a la necesidad de la reacción mediante la variación de los

componentes metálicos y/o soportes, el empleo de promotores y los métodos de preparación utilizados.

La preparación de los catalizadores metálicos comprende varias etapas: acondicionamiento y preparación del soporte, impregnación del soporte con los precursores, lavado, secado y activación. Todas ellas son muy importantes pero probablemente la impregnación es la que más contribuye a la estructura final del sitio activo en un sistema catalítico.

A continuación se describen las etapas de mayor relevancia.

\section{1) Acondicionamiento y preparación del soporte}

Como ya se mencionó la función del soporte es facilitar la dispersión y estabilidad de la fase catalítica activa (definida a continuación). El acondicionamiento del soporte implica su tratamiento, fraccionamiento, calcinación y/o preparación.

Entre los procesos para preparar soportes está el llamado método sol-gel. Dicho nombre es dado a un gran número de procesos que involucran una solución o SOL, el cual se transforma en un GEL. El sol es una solución coloidal que puede ser descripta como una dispersión de partículas en medio líquido. El gel es un sistema polimérico, que ha sido condensado químicamente. 
La mayoría de los procesos de sol-gel se pueden categorizar en tres métodos:

a. Un sol coloidal es preparado y las partículas coloidales (polvo) son precipitadas del sol (usualmente por un cambio de $\mathrm{pH}$ ). Los polvos resultantes se secan y se procesan.

b. Se prepara un sol, al igual que en el primer método, en donde las partículas se enlazan para formar un gel (en lugar de precipitarse), posteriormente el gel se seca para formar una cerámica porosa y se calcina para cristalizar o densificar el material.

c. El gel se forma por la polimerización de unidades oligoméricas (en lugar de partículas coloidales).

El producto de la gelificación es secado y calcinado. Este proceso incluye evaporación de agua, evaporación del solvente, desaparición de los residuos orgánicos si los hubiera y cambios estructurales y microestructurales. Durante el secado la red se contrae hasta formar un gel de mayor resistencia que se transformará en un sólido poroso.

2) Adición y acondicionamiento del precursor del metal base.

La preparación de un catalizador consiste en colocar en primer lugar el precursor del metal base sobre el soporte dando lugar a un catalizador monometálico. Posteriormente en algunos catalizadores se agrega además otro precursor del promotor del metal base (cuya definición se da más adelante) dando lugar a un catalizador bimetálico.

El metal base en los catalizadores monometálicos forma la fase activa. La función de la fase activa es catalizar una determinada reacción química. En los catalizadores bimetálicos, en cambio, puede haber dos o más fases activas.

La forma en que esta etapa se lleva a cabo juega un papel fundamental en la distribución macroscópica y microscópica de los componentes, así como en la concentración final de metal depositado.

En una gran mayoría de casos, la adición de los precursores de los catalizadores soportados se realiza mediante un procedimiento que puede describirse en términos generales como impregnación, poner en contacto el soporte con una 
solución del elemento activo. La palabra, impregnación, sin embargo, se ha utilizado para describir una serie de diferentes procedimientos de preparación que, aunque todos ellos pueden englobarse bajo el mismo encabezado general, tienen diferencias significativas entre sí. Se pueden distinguir así, la impregnación a humedad incipiente cuando los elementos activos están contenidos en un volumen de solución correspondiente al Volumen de poro del soporte. Este procedimiento también se ha denominado como impregnación a volumen de poro o impregnación seca. Cuando el volumen de la solución excede el volumen de poros del soporte, el proceso se denomina impregnación en húmedo o en exceso de solución. Si la superficie de los soportes se modificada para dar una especie que reacciona químicamente con los precursores, el proceso se llama intercambio iónico (Augustine R. L., 1996).

Luego de la impregnación, el sólido húmedo se puede separar por decantación, centrifugación o filtración y se seca en estufa.

\section{3) Adición y acondicionamiento del promotor}

El promotor es aquella sustancia que incorporada a la fase activa o al soporte en pequeñas proporciones, permite mejorar las características de un catalizador en cualquiera de sus funciones de actividad, selectividad o estabilidad. En algunos casos no son imprescindibles en la formulación del catalizador. Se conocen dos tipos de promotores: texturales los cuales contribuyen a dar mayor estabilidad a la fase activa, y electrónicos, los que aumentan la actividad.

Una de las técnicas de adición de promotores, empleada en este Tesis, corresponde a la Química Organometálica de Superficies.

\section{4) Activación}

Es el tratamiento previo a la utilización del catalizador. Por ejemplo, los catalizadores metálicos suelen reducirse con $\mathrm{H}_{2}$.

\subsection{4.- Catalizadores bimetálicos soportados}

Desde su primer uso en la década del ' 50 los catalizadores bimetálicos soportados han sido ampliamente utilizados en la industria petroquímica, refinería y química fina. El comportamiento catalítico de estos sistemas depende de: el tamaño 
de las partículas metálicas, la interacción entre ellas y con el soporte, otros componentes del catalizador, etc. El segundo metal puede influenciar al primero a través de interacciones electrónicas o modificando la arquitectura del sitio activo. Muy a menudo, las interacciones entre los dos metales son complejas y en gran parte desconocidas, en consecuencia el procedimiento de preparación de los mismos influye de manera crítica en la naturaleza del sistema catalítico obtenido (Basset J.M. y col., 2009 y referencias allí citadas).

Las diferentes estrategias utilizadas para obtener catalizadores bimetálicos han sido clasificadas por Alexeev y Gates, que analizaron las propiedades estructurales de los distintos sistemas en función del método de preparación utilizado (Alexeev O.S y Gates B.C., 2003). Las diferentes metodologías que se conocen para la obtención de catalizadores bimetálicos son:

> Técnicas convencionales de impregnación o co-impregnación. A pesar de su simplicidad, estas técnicas generalmente no logran controlar la formación de la fase bimetálica y, por tanto, rara vez son reproducibles.

$>\quad$ Síntesis de catalizadores bimetálicos soportados utilizando clusters moleculares. Esta técnica presenta dos desventajas importantes: complejidad operatoria y que la estequiometría del catalizador resultante depende del precursor utilizado.

"Ship-in-a Bottle". Síntesis de clusters bimetálicos en zeolitas. Para este método el precursor debe ser lo suficientemente pequeño para atravesar el canal de una zeolita.

Anclaje de especies bimetálicas sobre la superficie de un óxido. Esta técnica involucra una secuencia de reacciones superficiales dando como resultado un sistema en el cual ambos metales tienen una fuerte interacción. Una de las estrategias propuestas para obtener estos catalizadores fue desarrollada en la escuela rusa dirigida por profesor Yermakov, e implica el anclaje de un complejo de un metal sobre un metal soportado (Yermakov Y.I., Kuznetsov B.N. y Zakharov V.A., 1981). El procedimiento de la preparación implica varios pasos, el primero involucra la interacción de un complejo organometálico del primer compuesto (ej. Ge $\left(\mathrm{OC}_{2} \mathrm{H}_{5}\right)_{4}$, $\left.\mathrm{Sn}\left(\mathrm{CH}_{3} \mathrm{COO}\right)_{2}, \mathrm{~Pb}\left(\mathrm{CH}_{3} \mathrm{COO}\right)_{4}\right)$ con los grupos hidroxilos superficiales del soporte. El 
segundo componente es generalmente un metal del grupo VIII (ej. Ni, Pd, Pt, etc.). La interacción entre los dos metales debe ser lo suficientemente fuerte como para que el complejo bimetálico se mantenga intacto después de la etapa de activación del catalizador. Aunque mediante esta técnica se obtienen sistemas estables y altamente dispersos, también se forman partículas monometálicas, producto de la interacción de la especie organometálica con el soporte. Sin embargo, alternativas que derivan de la Química Organometálica de Superficie han llevado a la obtención de catalizadores bimetálicos soportados altamente dispersos, donde el complejo organometálico reacciona selectivamente con una partícula o un cluster metálico soportado y no con la superficie del soporte. Estas técnicas se basan en la elección cuidadosa de dicho complejo y en el control de los parámetros de reacción (Basset J.M. y col., 2009 referencias allí citadas).

\subsection{5.- Química Organometálica de Superficies sobre Metales}

La Química Organometálica de Superficies sobre metales (QOMS/M) puede ser definida como el área de la química que relaciona química organometálica y la ciencia de superficies (Basset J.M. y col., 1983). En 1984, Tavers (Travers C., Bournonville J.P. y Martino G. C., 1984) y Margitfalvi (Margitfalvi J. y col., 1984) describieron simultáneamente la aplicación de la QOMS para la preparación de catalizadores bimetálicos.

La aplicación de esta técnica no sólo permite preparar catalizadores que posean aleaciones bimetálicas de una composición determinada, sino que también es posible localizar adátomos o fragmentos orgánicos en la superficie de las partículas del metal de transición, mejorando de esta manera la actividad y/o selectividad de los sistemas catalíticos monometálicos, en muchas reacciones de interés (Candy J.P. y col., 1994; Santori G.F. y col., 2004).

La utilización de estas técnicas permite controlar las distintas etapas de preparación de los catalizadores, dando lugar a sólidos reproducibles desde el punto de vista de la estructura y de su performance catalítica. Estas técnicas consisten en la reacción entre un metal de transición $\mathrm{M}(\mathrm{M}=\mathrm{Pt}, \mathrm{Rh}, \mathrm{Ni}, \mathrm{Pd}, \mathrm{Ru})$, soportado (carbón 
activado, $\left.\mathrm{SiO}_{2} \circ \mathrm{Al}_{2} \mathrm{O}_{3}\right)$ y un compuesto organometálico $\mathrm{M}^{\prime} \mathrm{R}_{\mathrm{n}}\left(\mathrm{M}^{\prime}=\mathrm{Sn}, \mathrm{Ge}, \mathrm{Pb}, \mathrm{Sb} ; \mathrm{R}=-\right.$ $\mathrm{CH}_{3},-\mathrm{C}_{2} \mathrm{H}_{5},-\mathrm{C}_{4} \mathrm{H}_{9}$ y $\left.\mathrm{n}=3,4\right)$ en atmósfera de $\mathrm{H}_{2}$.

Dado que esta última fue la técnica seleccionada en esta Tesis para la preparación de catalizadores bimetálicos, más detalles acerca de ella se darán en el capítulo correspondiente.

\section{2.- Técnicas de caracterización de los sólidos}

La caracterización, tanto de los soportes como de los catalizadores metálicos, se llevó a cabo mediante el empleo de distintas técnicas físico-químicas, las cuales brindan información acerca de la estructura, composición y propiedades físicoquímicas de los mismos. Esto se realiza con el objeto de obtener información que permita establecer una relación estructura-actividad de los sistemas catalíticos; analizando mecanismos de activación de los enlaces de los reactivos involucrados, la naturaleza de las especies intermedias formadas, la interacción con la superficie y el papel que éstas desempeñan en la reacción de activación. A continuación se describen las técnicas empleadas para caracterizar los soportes empleados en esta tesis.

\subsection{1.- Caracterización textural: isotermas de adsorción de $\mathbf{N}_{2}$}

La fisisorción de $\mathrm{N}_{2}$ es utilizada para determinar propiedades texturales de los sólidos porosos: superficie específica, distribución de poros, volumen de poros y diámetro medio de poros. El método BET permite determinar el área superficial específica de los sólidos a partir de datos obtenidos por fisisorción de $\mathrm{N}_{2}$.

\subsubsection{1.- Método BET}

El área superficial de un material es una propiedad de importancia fundamental para el control de velocidad de interacción química entre sólidos y gases o líquidos. La magnitud de esta área determina, por ejemplo, que tan rápido se quema un sólido, que tan pronto se disuelve un polvo dentro de un solvente, que tan satisfactoriamente un catalizador promueve una reacción química, o que tan efectivamente elimina un contaminante. 
El método BET desarrollado por Brunauer, Emmet y Teller (Brunauer S., Emmett P.H. y Teller E., S., 1938; Gregg, S.J. y Sing, K.S.W., 1982) es reconocido mundialmente como estándar. Se basa en la técnica desarrollada por Langmuir, extendida a la formación de multicapas y presupone que el calor de adsorción de la monocapa es distinto al de las otras capas, pero todas las siguientes capas presentan el mismo calor de adsorción.

La fisisorción se produce cuando un gas no polar, generalmente nitrógeno, se pone en contacto con un sólido desgasificado, originándose fuerzas de Van der Waals. Al ponerse en contacto el gas con la superficie del sólido se produce un equilibrio entre las moléculas adsorbidas y las moléculas en fase gaseosa, que depende de la presión del gas y de la temperatura. La relación entre las moléculas adsorbidas y la presión a temperatura constante se puede recoger en una isoterma de adsorción. Estas isotermas, que nos informan directamente del volumen adsorbido a una determinada presión nos permiten también calcular el área superficial del sólido, el tamaño de poro y su distribución.

En la literatura se pueden encontrar muchas isotermas de adsorción medidas sobre una amplia variedad de sólidos porosos. A pesar de tal diversidad, la mayoría de estas isotermas pueden ser agrupadas convenientemente según la clasificación de la IUPAC.

En las recomendaciones de la IUPAC de 1985, las isotermas de fisisorción se agruparon en seis tipos. Sin embargo, durante los 30 años siguientes se han identificado varios nuevos tipos característicos de isotermas y se ha demostrado una estrecha relación con estructuras particulares de poros. Así es que en 2015 se estableció una nueva clasificación actualizada de las isotermas de fisisorción (Thommes M. y col., 2015), la cual se muestra en la Figura 2.5. 


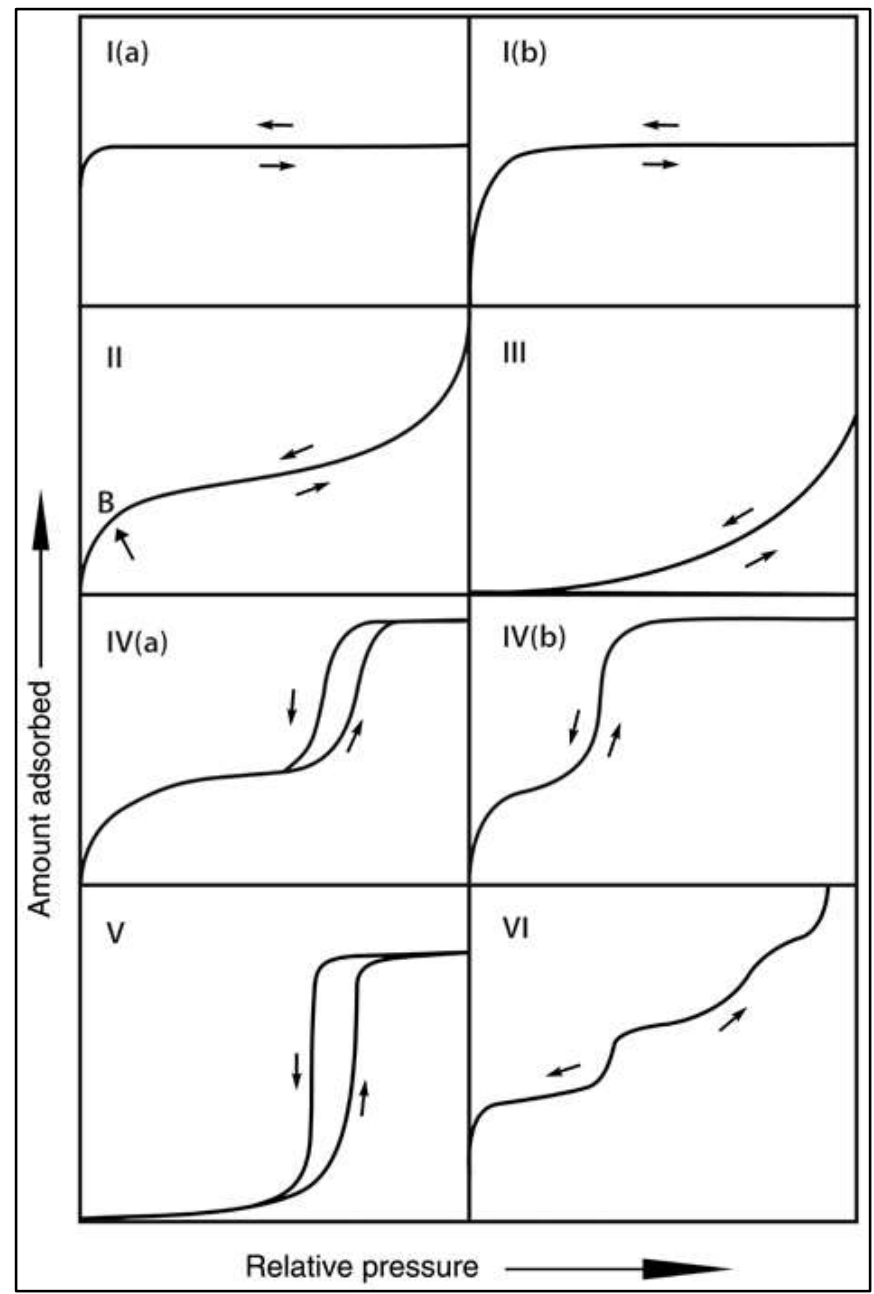

Figura 2.5: Clasificación de las isotermas de fisisorción según IUPAC.

Cada tipo de isoterma obtenida se asocia a un determinado tipo de proceso de adsorción y tipo de sólido.

Las isotermas reversibles del tipo I se dan en los sólidos microporosos que tienen relativamente pequeñas superficies externas (Por ejemplo, algunos carbones activados, zeolitas de tamiz molecular y ciertos óxidos porosos).

Una isoterma de tipo I es cóncava al eje $\mathrm{p} / \mathrm{p}_{0}$ y la cantidad adsorbida se aproxima a un valor límite. Esta limitación de la capacidad de adsorción se rige por el volumen de microporos accesible más que por el área de superficie interna.

Una curva empinada a muy baja $\mathrm{p} / \mathrm{p}_{0}$ es debido a que se favorecen las interacciones adsorbentes-adsorbato en microporos estrechos (microporos de dimensiones moleculares), lo que resulta en el llenado de microporos a muy baja $\mathrm{p} / \mathrm{p}_{0}$. Para la adsorción de nitrógeno y de argón a $-196^{\circ} \mathrm{C}$ y $-186^{\circ} \mathrm{C}$, las isotermas de tipo I (a) 
son producidas por materiales microporosos que tienen microporos principalmente estrechos (de ancho < $1 \mathrm{~nm}$ ); Las isotermas del tipo I (b) se encuentran con materiales que tienen distribuciones de tamaño de poro en un rango más amplio incluyendo amplios microporos y posiblemente mesoporos más estrechos (< 2,5 nm).

Las isotermas reversibles de tipo II se dan por la fisisorción de la mayoría de los gases en adsorbentes no porosos o macroporosos. La forma es el resultado de la adsorción monocapa-multicapa sin restricciones hasta altas relaciones $\mathrm{p} / \mathrm{p}_{0}$. Si la rodilla (punto B) es aguda, por lo general corresponde a la finalización de la cobertura de monocapa. Una curvatura más gradual (es decir, un punto B menos distintivo) es una indicación de una cantidad significativa de solapamiento de cobertura de monocapa y la aparición de adsorción de múltiples capas. El espesor de la multicapa adsorbido en general, parece aumentar sin límite cuando $p / p_{0}=1$.

En el caso de una isoterma de tipo III, no hay punto B y por lo tanto no hay formación de monocapa identificable; las interacciones adsorbente-adsorbato son ahora relativamente débiles y las moléculas adsorbidas se agrupan alrededor de los sitios más favorables en la superficie de un sólido no poroso o macroporoso. En contraste con las isotérmas tipo II, la cantidad adsorbida permanece finita a la presión de saturación (es decir, a $\mathrm{p} / \mathrm{p}_{0}=1$ ).

Las isotermas del tipo IV están dadas por adsorbentes mesoporosos (por ejemplo, muchos geles de óxido, adsorbentes industriales y tamices moleculares mesoporosos). El comportamiento de adsorción en sistemas mesoporos está determinado por las interacciones adsorbato-adsorbente y también por las interacciones entre las moléculas en el estado condensado. En este caso, la adsorción monocapa-multicapa inicial en las paredes del mesoporo, que toma la misma forma de la parte correspondiente de una isoterma de Tipo II, se sigue por condensación en los poros; fenómeno por el cual un gas se condensa a una fase similar a un líquido en un poro a una presión $\mathrm{p}$ menor que la presión de saturación $\mathrm{p}_{0}$ del líquido bulk. Una característica típica de las isotermas de Tipo IV es una meseta de saturación final, de longitud variable (a veces reducida a un mero punto de inflexión).

En el caso de una isoterma tipo IVa, la condensación capilar se acompaña de histéresis. Esto ocurre cuando el ancho de poro excede una cierta valor crítico, que 
depende del sistema de adsorción y de la temperatura (por ejemplo, para la adsorción de nitrógeno y argón en poros cilíndricos a $-196^{\circ} \mathrm{C}$ y $-186^{\circ} \mathrm{C}$, respectivamente, la histéresis comienza a ocurrir para los poros más anchos de $\sim 4 \mathrm{~nm}$ ). Con adsorbentes que tienen mesoporos de menor ancho, se observan isotermas de tipo IVb totalmente reversibles.

En el rango bajo de la relación $\mathrm{p} / \mathrm{p}_{0}$, la forma isotérmica del Tipo $\mathrm{V}$ es muy similar a la del Tipo III y esto se puede atribuir a interacciones adsorbente-adsorbato relativamente débiles. A mayor $\mathrm{p} / \mathrm{p}_{0}$, el argupamiento molecular es seguido por el llenado de poros. Por ejemplo, se observan isotermas de tipo $\mathrm{V}$ para la adsorción de agua sobre adsorbentes hidrófobos micro y mesoporosos.

La isoterma reversible de tipo VI es representativa de la adsorción capa por capa en una superficie no porosa altamente uniforme. La altura de cada capa representa la capacidad de cada capa adsorbida, mientras que lo agudo de la capa depende del sistema y de la temperatura. Entre los mejores ejemplos de las isotermas de Tipo VI se encuentran las obtenidas con argón o criptón a baja temperatura sobre carbón negro grafitado. (Thommes M. y col., 2015)

El método BET de cálculo se basa en la representación de la isoterma BET en su forma linealizada habitual, según la ecuación:

$$
\frac{P}{V\left(P_{0}-P\right)}=\frac{1}{V_{M} \cdot C}+\left(\frac{C-1}{V_{M} \cdot C}\right) \cdot \frac{P}{P_{0}}
$$

Donde:

P: es la presión de equilibrio

$\mathrm{P}_{0}$ es la presión de saturación del $\mathrm{N}_{2}$ a $-196^{\circ} \mathrm{C}$

V: es el volumen de gas adsorbido en condiciones normales ( $1 \mathrm{~atm}$ de presión y $0{ }^{\circ} \mathrm{C}$ ) a la presión parcial P del adsorbato.

$\mathrm{V}_{\mathrm{M}}$ : es el volumen de gas requerido para formar una monocapa.

C: es una constante relacionada con la energía de adsorción. 
Para la determinación del volumen de gas adsorbido de la monocapa $\left(V_{M}\right)$ se utilizan los datos de los volúmenes adsorbidos correspondientes a las presiones relativas $\left(P / P_{0}\right)$ de adsorbato $\left(N_{2}\right)$. Con estos datos, reemplazando en $P /\left[V .\left(P_{0}-P\right)\right]$ y en $\mathrm{P} / \mathrm{P}_{0}$, por regresión lineal con la ecuación 2.1 se obtiene una recta cuya pendiente es $(\mathrm{C}-1) /\left(\mathrm{V}_{\mathrm{M}} \cdot \mathrm{C}\right)$ y la ordenada al origen es $1 /\left(\mathrm{V}_{\mathrm{M}} \cdot \mathrm{C}\right)$. Si a la pendiente se la llama $\mathrm{A}$ y a la ordenada al origen $\mathrm{B}$, se tiene:

$$
\begin{aligned}
& A=\left(\frac{C-1}{V_{M} \cdot C}\right) \\
& B=\frac{1}{V_{M} \cdot C}
\end{aligned}
$$

Una vez conocido el volumen de gas adsorbido en la monocapa $\left(V_{M}\right)$, se obtiene el área de la superficie $\left(\mathrm{S}_{\mathrm{BET}}\right)$ de la muestra a partir de la ecuación:

$$
S_{B E T}=\frac{10^{-20} \cdot V_{M} \cdot N_{0 .} a}{v \cdot W}
$$

Donde:

$\mathrm{S}_{\mathrm{BET}}$ : es la superficie específica $\left(\mathrm{m}^{2} / \mathrm{g}\right)$

$\mathrm{V}_{\mathrm{M}}$ : es el volumen de gas requerido para formar una monocapa.

$\mathrm{N}_{0}$ : es el número de Avogadro $\left(6,02 \times 10^{23}\right.$ moléculas. $\left.\mathrm{g} / \mathrm{mol}\right)$.

a: área ocupada por una molécula de $\mathrm{N}_{2}$ adsorbida $\left(0,162 \mathrm{~nm}^{2}\right)$.

v: es el volumen molar $\left.22400 \mathrm{~cm}^{3} / \mathrm{gmol}\right)$.

$\mathrm{W}$ : masa de muestra (g). 


\subsection{2.- Caracterización estructural}

\subsubsection{1.- Difracción de rayos $X$}

Desde su descubrimiento en 1912 por von Laue, la difracción de rayos X (DRX) ha proporcionado un medio adecuado y práctico para la identificación cualitativa de compuestos cristalinos y sobre el ordenamiento y espaciado de los átomos en materiales cristalinos. El método de difracción de rayos $X$ en general y en particular de polvo cristalino es el único método analítico capaz de suministrar información cualitativa y cuantitativa sobre los compuestos cristalinos presentes en un sólido, basándose en el hecho de que cada sustancia cristalina presenta un diagrama de difracción único. Así, pueden compararse un diagrama de una muestra desconocida y el de una muestra patrón, y determinar su identidad y composición química (Skoog, D.A. y West D.M., 2001).

La técnica consiste en hacer incidir un haz de rayos $X$ sobre el sólido sujeto a estudio. La interacción entre el vector eléctrico de la radiación X y los electrones de la materia que atraviesa dan lugar a una dispersión. Al producirse la dispersión tienen lugar interferencias (tanto constructivas como destructivas) entre los rayos dispersados, ya que las distancias entre los centros de dispersión son del mismo orden de magnitud que la longitud de onda de la radiación. El resultado es la difracción, que da lugar a un patrón de intensidades que puede interpretarse según la ubicación de los átomos en el cristal, por medio de la ley de Bragg. La misma postula que cuando un haz de rayos $X$ incide sobre la superficie de un cristal formando un ángulo $\theta$ una porción del haz es dispersada por la capa de átomos de la superficie; la porción no dispersada del haz penetra en la segunda capa de átomos donde, nuevamente una fracción es dispersada y así sucesivamente con cada capa hasta la profundidad de aproximadamente $1000 \mathrm{~nm}$, lo que lo hace una técnica másica. El efecto acumulativo de esta dispersión producida por los centros regularmente espaciados del cristal es la difracción del haz.

En 1912, W. L. Bragg trató la difracción de rayos X por cristales, como se muestra en la Figura 2.6: 


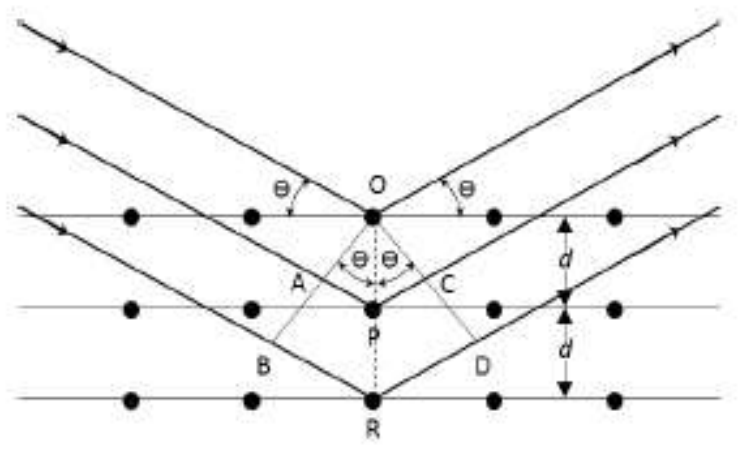

Figura 2.6. Interacción entre los rayos $X$ y la estructura cristalina de un material.

Un haz estrecho de radiación choca contra la superficie del cristal formando un ángulo $\theta$, la dispersión tiene lugar como consecuencia de la interacción de la radiación con los átomos localizados en O, P y R.

Se puede escribir que las condiciones para que tenga lugar una interferencia constructiva del haz que forma un ángulo $\theta$ con la superficie del cristal, son:

$$
\mathrm{n} \lambda=2 \mathrm{~d} \operatorname{sen} \theta
$$

donde $\mathrm{n}$ es un número entero que representa el orden de la difracción y d es la distancia interplanar del cristal. En ésta ecuación llamada Ecuación de Bragg, hay que señalar que los rayos $X$ son reflejados por el cristal sólo si el ángulo de incidencia satisface la condición

$$
\operatorname{sen} \theta=\frac{n \lambda}{2 d}
$$

Para todos los demás ángulos, tienen lugar interferencias destructivas.

Los requisitos para la difracción de rayos $\mathrm{X}$ son:

(1) que el espaciado entre las capas de átomos sea aproximadamente el mismo que la longitud de onda de la radiación

(2) que los centros de dispersión estén distribuidos en el espacio de una manera muy regular.

La muestra cristalina se muele hasta obtener un polvo fino y homogéneo. De esta forma, los numerosos pequeños cristales están orientados en todas las direcciones posibles $\mathrm{y}$, por tanto, cuando un haz de rayos $\mathrm{X}$ atraviesa el material, se 
puede esperar que un número significativo de partículas estén orientadas de tal manera que cumplan la condición de Bragg de la reflexión para todos los espacios interplanares posibles.

La identificación de las especies a partir de su diagrama de difracción de polvo cristalino se basa en la posición de líneas y en sus intensidades relativas. El ángulo de difracción $2 \theta$ se determina por el espaciado entre un grupo particular de planos, con la ayuda de la ecuación de Bragg, la distancia d se calcula a partir de una longitud de onda de la fuente conocida y del ángulo medido. Las intensidades de las líneas dependen del número y del tipo de centros atómicos de reflexión que existen en cada grupo de planos y las concentraciones relativas de los distintos planos. Para identificar las diferentes fases cristalinas obtenidas se utilizan los patrones de difracción contenidos en bases de datos.

Los materiales producen picos de difracción cuyas anchuras se relacionan con el tamaño de los cristales. Los materiales con cristales muy desarrollados producen picos bien definidos, y los menores a $1 \mu \mathrm{m}$ generan picos de difracción anchos.

En el análisis de estructura cristalina, aparte de la identificación de la fase cristalina, es posible determinar el tamaño promedio del cristal o los cristales bajo estudio. El cálculo del tamaño aparente o promedio de los cristalitos puede estimarse mediante la fórmula de Scherrer, la cual relaciona el ancho de la línea de difracción con las dimensiones del cristal según la siguiente ecuación:

$$
\tau=\frac{0.9 \lambda}{\beta \cos \theta}
$$

dónde $\tau$ es el tamaño del cristal, $\lambda$ es la longitud de onda de radiación $\mathrm{K} \alpha$ del $\mathrm{Cu}, \beta$ es el ancho del pico (en radianes) a mitad de altura considerado para el cálculo (esta cantidad también se denota a veces como $\Delta(2 \theta)$ ) y $\theta$ es el ángulo de difracción de Bragg.

\subsubsection{2.- Microscopía electrónica de barrido}

El microscopio electrónico de barrido (SEM, del acrónimo inglés de Scanning Electron Microscopy) es uno de los instrumentos más versátiles para el examen y 
análisis de características microestructurales de sólidos; proporciona información morfológica y topográfica de la superficie de los mismos. Una de las razones de ello es su alta resolución (de 20 a $50 \AA$ A).

A diferencia de la microscopía electrónica de transmisión que requiere que los electrones atraviesen la muestra, en SEM la imagen se forma por los electrones dispersados al incidir sobre la superficie de la muestra. De este modo, un detector puede dar cuenta de la cantidad de electrones secundarios emitidos por una región específica de la muestra, y a partir de la señal obtenida puede realizarse un "mapa" de la superficie en cuestión.

Una característica importante es la apariencia tridimensional de la imagen de la muestra, resultado de su gran profundidad de foco (aproximadamente entre $100 \mathrm{y}$ 1000 veces mayor que la de un microscopio óptico a la misma magnificación).

La gran profundidad de campo disponible en el SEM permite la obtención de imágenes estereoscópicas. Actualmente se han desarrollado equipos que permiten la evaluación cuantitativa de la topografía superficial haciendo uso de la estereoscopía.

\subsection{3.- Análisis termogravimétrico}

La termogravimetría (TGA, del acrónimo inglés de Thermal Gravimetric Analysis) es una técnica analítica que permite medir la variación de peso de una muestra, frente a la temperatura o el tiempo, cuando se le aplica un programa de temperatura controlada y una atmósfera específica.

Esta técnica ofrece la determinación de composiciones de material y estructura detallada de las diferentes fases de una muestra dada. Es posible también, obtener resultados cuantitativos a partir de los cambios de peso que tiene lugar a medida que la muestra se calienta.

Se trata de un método de análisis común en la industria química y farmacéutica. El análisis termogravimétrico se realiza en polímeros, alimentos, productos farmacéuticos, así como muchos otros materiales. 
Las muestras se colocan en crisol de alúmina poco profundo que se introduce en un horno sobre un soporte de cuarzo unido a una balanza de registro automático. El peso de la muestra se registra continuamente a medida que se incrementa la temperatura.

Los datos obtenidos por TGA son útiles en la caracterización de precursores y catalizadores, como así también en la caracterización de depósitos carbonosos formados postreacción en los catalizadores en estudio.

Para esta trabajo se realizaron estudios de pérdida de peso en función del tiempo sobre los cuatro soportes a base de zirconio preparados en una termobalanza Shimadzu modelo TGA-50H, en corriente de He.

\subsection{4.- Microscopía electrónica de transmisión}

La microscopía electrónica de transmisión (TEM, de la sigla en inglés de Transmission electron microscopy) es otra de las herramientas utilizadas a la hora de caracterizar sistemas catalíticos heterogéneos, la cual nos permite obtener información directa sobre la morfología y estructura del catalizador.

En general, un microscopio electrónico de transmisión cuenta con una fuente de electrones, generados a partir de un filamento caliente de tungteno (en algunos casos por un cátodo de $\left.\mathrm{LaB}_{6}\right)$, que son acelerados a través de un voltaje de 100-200 kV. Un sistema de lentes condensador da una imagen reducida de la fuente sobre la muestra, luego un lente objetivo agranda la imagen de la muestra (aproximadamente $\mathrm{x} 100$ ) y finalmente un sistema de lentes de proyección magnifica la imagen intermedia $\left(10^{3}-10^{6}\right)$ sobre una pantalla fluorescente. La magnificación total varía entre $10^{4}-10^{6}$. El espesor de la muestra debe ser muy fino de manera que sea posible transmitir el haz de electrones. La experiencia se lleva a cabo en vacío $\left(10^{-6}\right.$ torr) para no perturbar el haz de electrones. La formación de la imagen puede realizarse con el sistema de campo claro o de campo oscuro. En el primer caso, los electrones transmitidos sin difracción forman la imagen, en el segundo la imagen se forma con un rayo difractado. El uso de una u otra técnica depende fundamentalmente de las características de la muestra y de la información que se desee obtener. 
La técnica de TEM ha sido usada ampliamente en la determinación de tamaño promedio y distribución de tamaño de partícula. A partir de la imagen obtenida, como la que se muestra en la Figura 2.7 a modo de ejemplo, se puede representar en forma de histograma la distribución de tamaño de partícula.

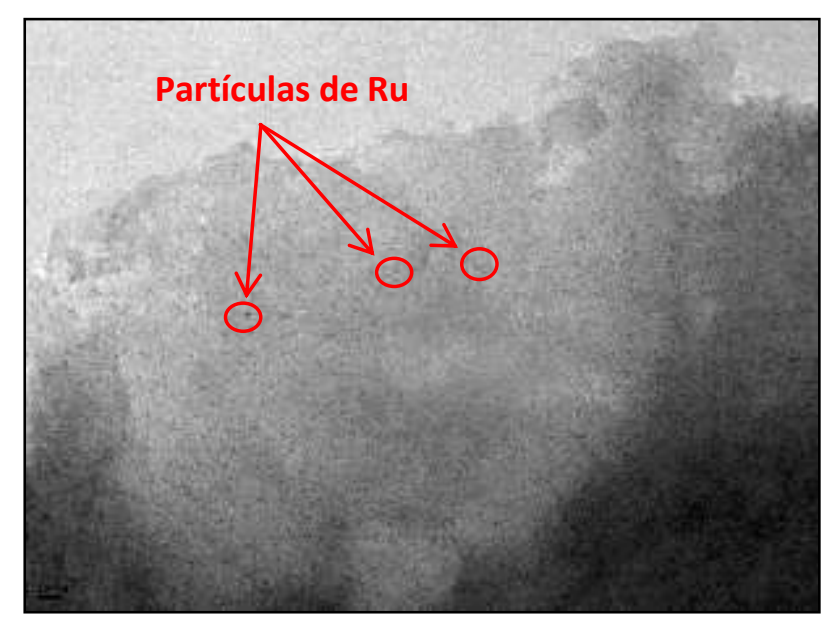

Figura 2.7. Imagen TEM de un catalizador de Ru soportado sobre carbón

Siendo $\mathrm{n}_{\mathrm{i}}$ el número de partículas en un intervalo dado de tamaño $\mathrm{d}_{\mathrm{i}}$, pueden calcularse y graficarse distintos tipos de distribuciones:

La distribución de número es obtenida graficando $n_{i}$ en función de $d_{i}$, el diámetro promedio es:

$$
d=\frac{\sum n_{i} d_{i}}{n_{i}}
$$

- $\quad$ La distribución de área se obtiene graficando $n_{i} d_{i}^{2}$ en función de di con un diámetro medio superficial igual a:

$$
d=\frac{\sum n_{i} d_{i}^{3}}{n_{i} d_{i}^{2}}
$$

La determinación de la distribución de área suele ser mucho más útil que la distribución de número, debido a la estrecha relación que se sabe que existe entre las propiedades catalíticas y el área superficial. Además estos datos se relacionan directamente con medidas obtenidas directamente por quimisorción.

Por último puede obtenerse también un diámetro medio de volumen, que si bien no tiene un significado físico directo, es comparable con tamaños calculados por difracción de rayos $\mathrm{x}$ : 


$$
d=\frac{\sum n_{i} d_{i}^{4}}{n_{i} d_{i}^{3}}
$$

La distribución del tamaño de partícula de los catalizadores monometálicos estudiados se determinó en Microscopio Electrónico de Transmisión JEOL 100 CX II, de 100 kV. Previo al análisis los catalizadores se redujeron, luego se tomaron $10 \mathrm{mg}$., previamente molidos, se suspendieron en unos mililitros de agua bidestilada y se colocaron 5 minutos en un baño ultrasónico. Finalmente se colocaron gotas de esta solución sobre una grilla de cobre, provista de un film, y se la dejó secar a temperatura ambiente durante una hora. El estudio se realizó en campo claro, obteniéndose una imagen directa del catalizador.

\subsection{5.- Reducción a temperatura programada}

La técnica de reducción a temperatura programada (o TPR, por su sigla en inglés de temperature programmed reduction) consiste en la reducción de un solido por un gas a medida que la temperatura del sistema varía en forma predeterminada, permitiendo la identificación de las diferentes especies presentes en la muestra a través de la facilidad con la cual dichas especies pueden ser reducidas. No se trata de una técnica superficial, sino que la reducción que tiene lugar involucra a la totalidad de las especies reducibles del catalizador. De esta manera, se obtiene un diagrama (reducción vs. T) que presenta una serie de picos, cada uno de los cuales representa el proceso de reducción de una especie química particular en el sólido. La posición del pico en el diagrama queda determinada por la naturaleza de dicha especie y su entorno, y el área de los picos refleja la concentración de la especie en el sólido (Jones A. y Mc Nicol B., 1986)

\subsection{6.- Caracterización superficial}

\subsubsection{1.- Espectroscopia fotoelectrónica de rayos $X$}

La espectroscopía de electrones (XPS, por su sigla en inglés de X-ray photoelectron spectroscopy) para el análisis químico proporciona información acerca 
de la composición atómica de la muestra y también sobre la estructura y el grado de oxidación de los elementos que forman los compuestos que están siendo examinados.

La espectroscopia fotoelectrónica de rayos $X$ se basa en el efecto fotoelectrónico, que consiste en la emisión de electrones procedentes de los niveles internos de los átomos que se produce cuando una muestra se irradia con un haz de rayos $X$ monoenergético de alta energía $(h \cdot v)$. Cuando la energía del fotón excede la energía de ligadura del electrón excitado, este se emitirá con una cierta energía cinética, que debe cumplir la ecuación del efecto fotoelectrónico.

La Figura 2.8 muestra una representación esquemática del proceso físico implicado en XPS, donde las tres líneas más bajas designadas por $E_{b}, E_{b}{ }^{\prime}$ y $E_{b}{ }^{\prime \prime}$, representan las energías de los electrones de las capas internas $\mathrm{K}$ y $\mathrm{L}$ de un átomo. Las tres líneas superiores representan algunos de los niveles de energía de los electrones de la capa más externa o de valencia.

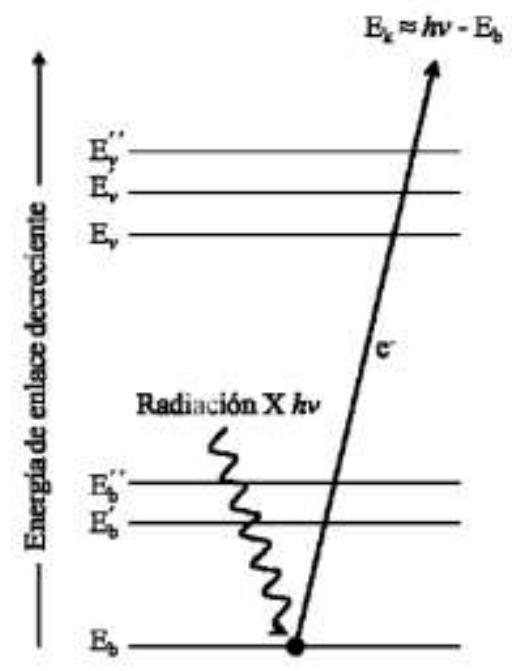

Figura 2.8. Esquema del proceso de XPS.

Como se muestra en la Figura 2.8, uno de los fotones de un haz monocromático de rayos $x$ de energía conocida como $h v$ desplaza a un electrón $\left(\mathrm{e}^{-}\right)$de un orbital $\mathrm{K}$ de energía $E_{b}$. La reacción se puede representar por:

$$
\mathrm{A}+\mathrm{hv} \rightarrow \mathrm{A}^{+*}+\mathrm{e}^{-}
$$




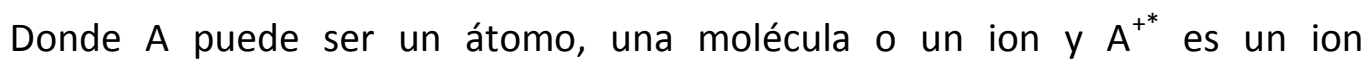
electrónicamente excitado con una carga positiva más que $A$.

La energía cinética del electrón emitido $E_{k}$ se mide en un espectrómetro de electrones. La energía de enlace del electrón $E_{b}$ se puede calcular mediante la ecuación:

$$
E_{b}=h v-E_{k}-\Phi
$$

Donde $E_{b}$ es la energía cinética del electrón emitido, hv la energía de excitación, $E_{b}$ la energía de enlace del electrón excitado y $\Phi$ la función de trabajo del espectrómetro.

En un espectro XPS se representa la intensidad de flujo de electrones emitidos por la muestra en función de su energía cinética o, más frecuentemente, frente a la energía de enlace de los mismos. Cada elemento se identifica por una energía de enlace, aunque la información más importante se basa en que se puede obtener información sobre el entorno químico del átomo (estado de oxidación y coordinación) a partir de pequeñas variaciones de la misma. Las energías de enlaces aumentan a medida que el estado de oxidación se hace más positivo. Este desplazamiento químico se puede explicar suponiendo que la atracción del núcleo para un electrón interno disminuye por la presencia de electrones externos. Cuando uno de estos electrones es expulsado, la carga efectiva que afecta a los electrones internos aumenta, de modo que la energía de enlace aumenta.

También pueden llevarse a cabo medidas cuantitativas ya que la intensidad de una línea fotoelectrónica es proporcional al número de átomos de ese elemento presentes en la muestra. Esta técnica es superficial, ya que solamente los fotoelectrones procedentes de las capas más externas tienen oportunidad de escapar del material y llegar al detector (Faraldos M. y Goberna C., 2002).

Un problema específico del análisis de catalizadores no metálicos es el efecto de carga positiva de la muestra como resultado de la emisión continua de electrones y el desplazamiento a energías de ligadura mayores. Este efecto puede resolverse con el uso de un patrón interno si se supone que este desplazamiento es homogéneo en toda la muestra. Así, es habitual tomar como energía de enlace de referencia la de los 
electrones $1 \mathrm{~s}$ del carbono $(284,6 \mathrm{eV})$ que se encuentran presentes en todas las muestras como consecuencia de la contaminación de hidrocarburos ambientales adsorbidos.

\section{3.- Medidas de actividad catalítica}

\subsection{1.- Descripción general del sistema de reacción utilizado}

Los experimentos de actividad catalítica fueron llevados a cabo en un reactor tipo autoclave, modelo comercial Berghof BR 100, construido en acero inoxidable con un volumen $100 \mathrm{~cm}^{3}$ (Figura 2.9).

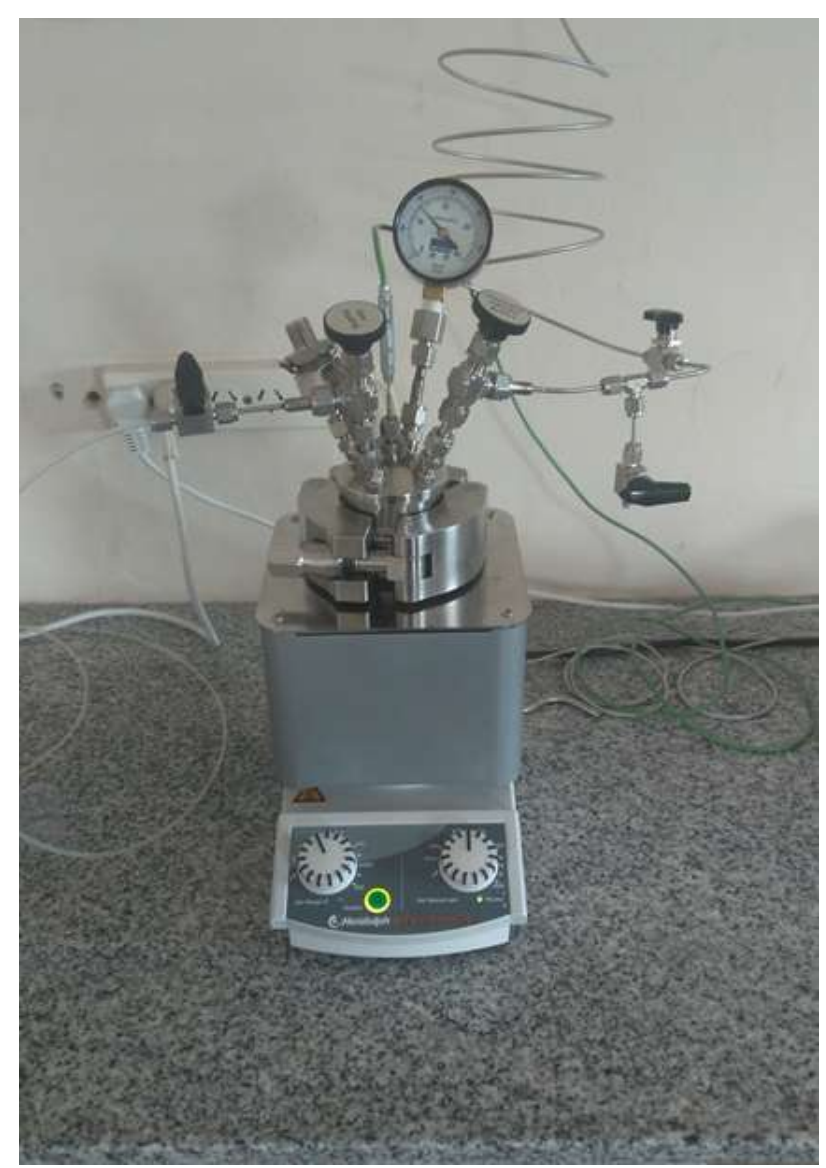

Figura 2.9. Reactor instalado en el laboratorio.

El funcionamiento del mismo fue de tipo semicontinuo, ya que los reactivos, junto con el catalizador, se cargaron al inicio de las experiencias, pero el $\mathrm{H}_{2}$ se iba alimentando a medida que se consumía de manera de mantener la presión constante en el sistema. En la Figura 2.10 se muestra un esquema del reactor con todos sus 
detalles constructivos, donde pueden observarse las válvulas de ingreso y egreso del mismo. En el interior se encuentran el tubo para toma de muestras, al cual a su vez se le colocó en su interior una malla metálica (tamiz) a modo de filtro que impide la pérdida de catalizador que podría ocurrir por arrastre cuando se abre la válvula y se extrae la muestra por diferencia de presión. En paralelo a este tubo se ubica la vaina de la termocupla, la cual ingresa al reactor hasta una profundidad cercana al fondo. De esta manera, se puede medir la temperatura en un punto cercano a donde se toma la muestra. La agitación del sistema se realiza por medio de un buzo magnético ubicado en el fondo de tanque.

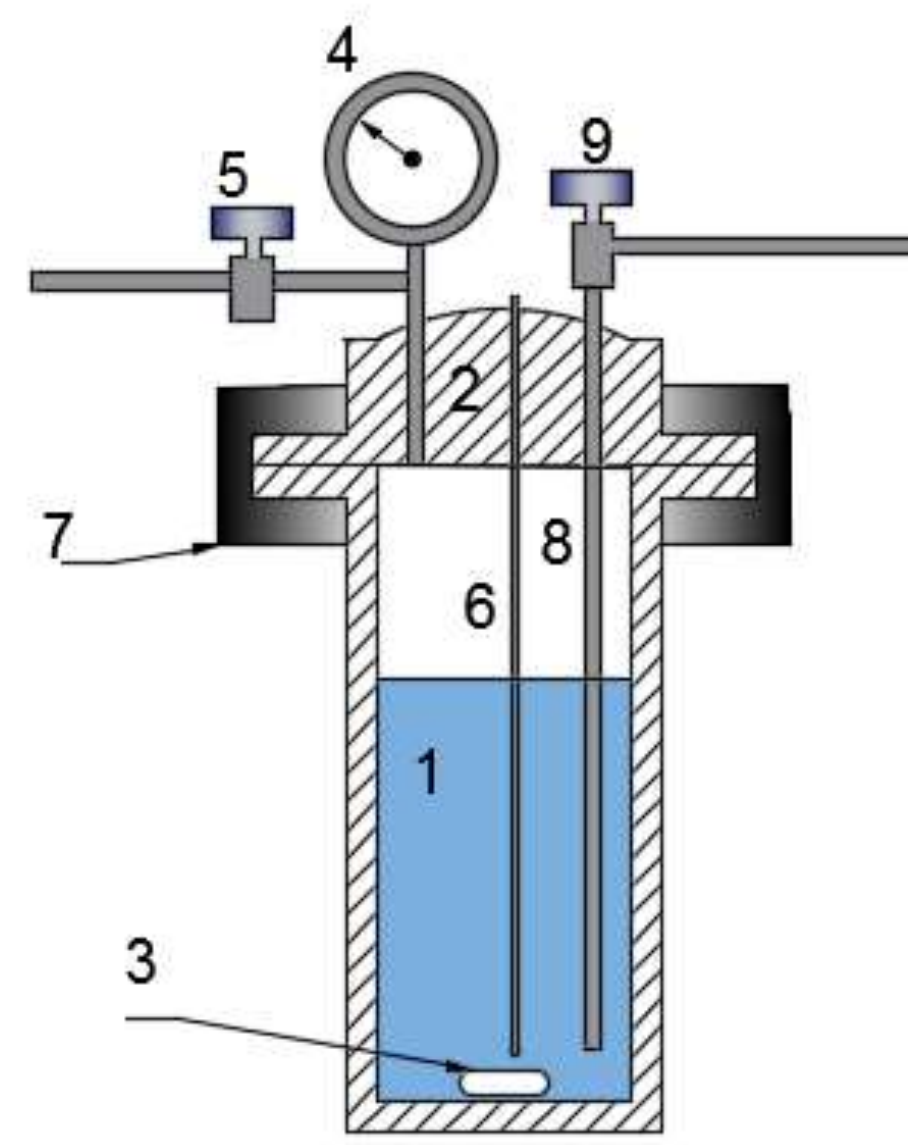
1. Reactor
2. Tapa del reactor
3. buzo magnético
4. manómetro
5. válvula de venteo

6. Vaina de termocupla

7. Brida de seguridad

8. Tubo de extracción de muestras

9. válvulas de admisión de gases y toma de muestras

Figura 2.10. Esquema del reactor utilizado para las reacciones de hidrogenación. 
El reactor, como se muestra en la Figura 2.11 se encuentra dentro de un horno calefactor, conectado a su vez a un programador/controlador de temperatura, con el cual se regula la temperatura en el interior del reactor, medida con la termocupla. También se cuenta con un controlador de agitación del medio de reacción, el cual regula la velocidad de giro del buzo magnético mencionado anteriormente.

El reactor se acopló a un sistema de suministro y control de caudal de gases, que permitió la provisión alternativa de nitrógeno o hidrógeno al reactor y sistema de muestreo. Este último permitió la toma de muestras correspondientes y su posterior análisis con el objetivo de evaluar la evolución de las concentraciones de reactivos y productos durante el curso de la reacción. Para esto, las muestras fueron analizadas, ex situ, por cromatografía de gases y cromatografía líquida de alta resolución (HPLC) dependiendo de la reacción estudiada.

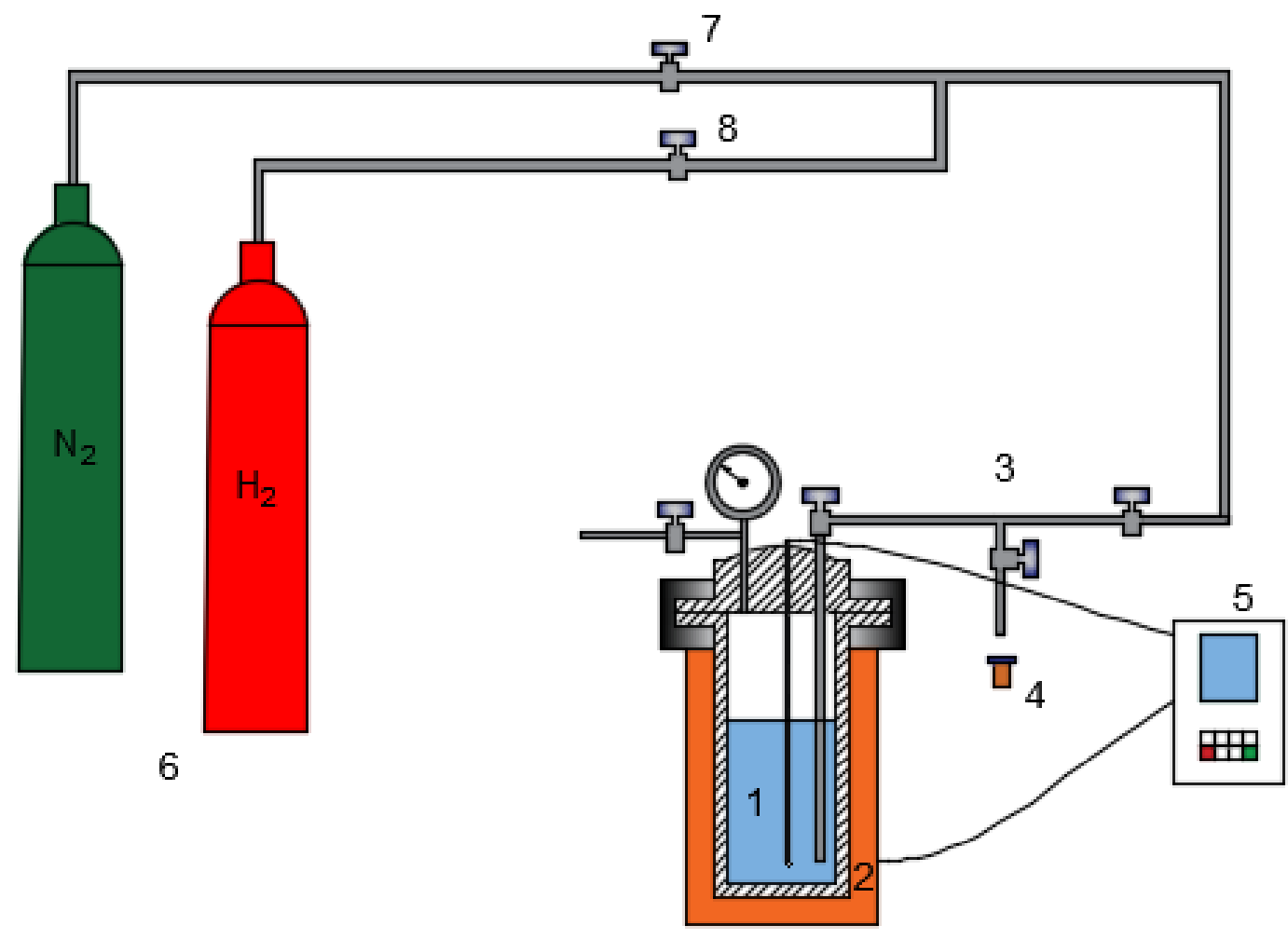

1. Reactor

2. Horno calefactor

3. Sistema para alimentación de gases y toma de muestra

4. Vial para muestra de reacción
5. Controlador de temperatura y agitación

6. Tubos de gases

7. Válvula de cierre para $\mathrm{N}_{2}$

8. Válvula de cierre para $\mathrm{H}_{2}$

Figura 2.11. Esquema del equipo empleado para llevar a cabo las experiencias catalíticas. 


\subsection{2.- Procedimiento de carga y operación del reactor}

Para las reacciones de hidrogenación, se procede a cargar el catalizador reducido dentro del reactor, previamente cargado con las cantidades determinadas en cada caso de sustrato y solvente. A continuación se coloca el reactor en el horno calefactor y se cierra, acoplándolo al sistema de muestreo y suministro de gases. Se encienden los sistemas de agitación y calentamiento y se purga el interior con una corriente de $\mathrm{N}_{2}$ de $60 \mathrm{~cm}^{3} /$ min y una presión cercana a la de trabajo durante 5 minutos para barrer el aire remanente (abriendo la válvula E en la Figura 2.12).

Una vez alcanzada la temperatura de trabajo deseada se procede a cambiar el suministro de $\mathrm{N}_{2}$ por el de $\mathrm{H}_{2}$. Para ello, se cierra la alimentación de $\mathrm{N}_{2}$ (válvula $\mathrm{E}$ ) y se abre la válvula de salida del reactor (válvula C) hasta que la presión interior se iguala a la atmosférica. Luego se abre la alimentación de $\mathrm{H}_{2}$ (válvula $\mathrm{F}$ ) y se barre con un flujo de $50 \mathrm{~cm}^{3} / \mathrm{min}$ el interior del reactor durante 5 minutos de eliminar el $\mathrm{N}_{2}$ remanente. Pasado este tiempo se cierra la válvula de salida (válvula C).

El tiempo de reacción se comienza a medir a partir del ingreso de $\mathrm{H}_{2}$ al reactor. A partir de ese momento se comenzaron a tomar muestras de la mezcla de reacción a intervalos regulares de tiempo con el objeto de monitorear el avance de la reacción.

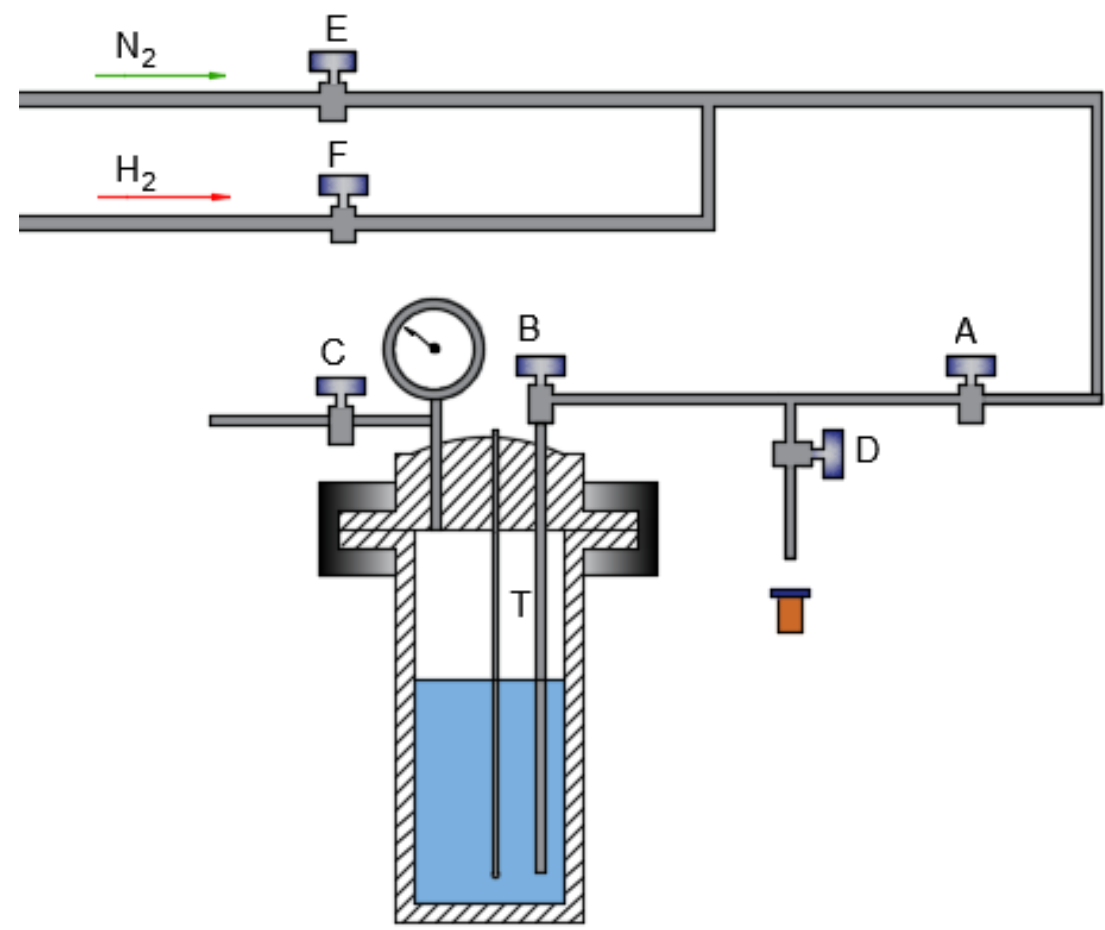

Figura 2.12. Conexiones de gases y sistemas de válvulas para extracción de muestras. 


\subsection{3.- Procedimiento para la toma de muestras}

El sistema de muestreo, llevando a cabo una reacción de hidrogenación, fue operado según el procedimiento descripto a continuación:

1. Se cierra la válvula $A$ para evitar la fuga de $\mathrm{H}_{2}$ proveniente del tubo de suministro.

2. Se abre lentamente la válvula $D$, de manera que la mayor presión interior del reactor respecto a la atmosférica impulsa la salida del medio de reacción, permitiendo la toma de muestra.

3. Se toma una muestra de $0,5 \mathrm{~cm}^{3}$. en un vial limpio o tubo Eppendorf.

4. Se cierra la válvula D.

5. Se abre la válvula A suavemente para restablecer la presión de $\mathrm{H}_{2}$ hasta la presión de trabajo. En caso de ser necesaria alguna corrección/ajuste de la presión, se realiza mediante la regulación de las válvulas B y C de entrada y salida directa del reactor.

\subsection{4.- Análisis de la mezcla de reacción}

Para realizar el seguimiento del curso de reacción, en los casos de trans-2pentenal y furfural como sustratos, se llevó a cabo el análisis de las muestras extraídas del reactor por medio de un cromatógrafo de gases Varian CP-3800, provisto de una columna capilar CP Wax 52 CB (30 m; 0,3 mm diámetro interno) y equipado con un detector de ionización de llama (FID),

Las condiciones utilizadas en dicho análisis cromatográfico fueron las siguientes:

$\checkmark \quad$ Tipo de inyector: on-column.

$\checkmark \quad$ Temperatura del inyector: $170^{\circ} \mathrm{C}$.

$\checkmark \quad$ Temperatura del detector: $170^{\circ} \mathrm{C}$.

$\checkmark \quad$ Caudal del gas carrier $\left(\mathrm{N}_{2}\right): 10 \mathrm{~cm}^{3} / \mathrm{min}$.

$\checkmark \quad$ Volumen de muestra inyectado: $1 \mu \mathrm{l}$.

$\checkmark \quad$ Temperatura de Columna: 
Furfural:

\begin{tabular}{c|c|c}
\hline Temperatura (oC) & Velocidad de calentamiento (oC/ min) & Tiempo (min) \\
\hline 50 & - & 5 \\
\hline 120 & 20 & 10 \\
\hline 150 & 20 & 5 \\
\hline
\end{tabular}

Trans-2-pentenal:

\begin{tabular}{c|c|c}
\hline Temperatura (ㅇ) & Velocidad de calentamiento (oc/ min) & Tiempo (min) \\
\hline 50 & - & 5 \\
\hline 120 & 20 & 10 \\
\hline 150 & 20 & 5 \\
\hline
\end{tabular}

En la Figura 2.13 se muestra un cromatograma típico de una reacción de hidrogenación de furfural en agua.

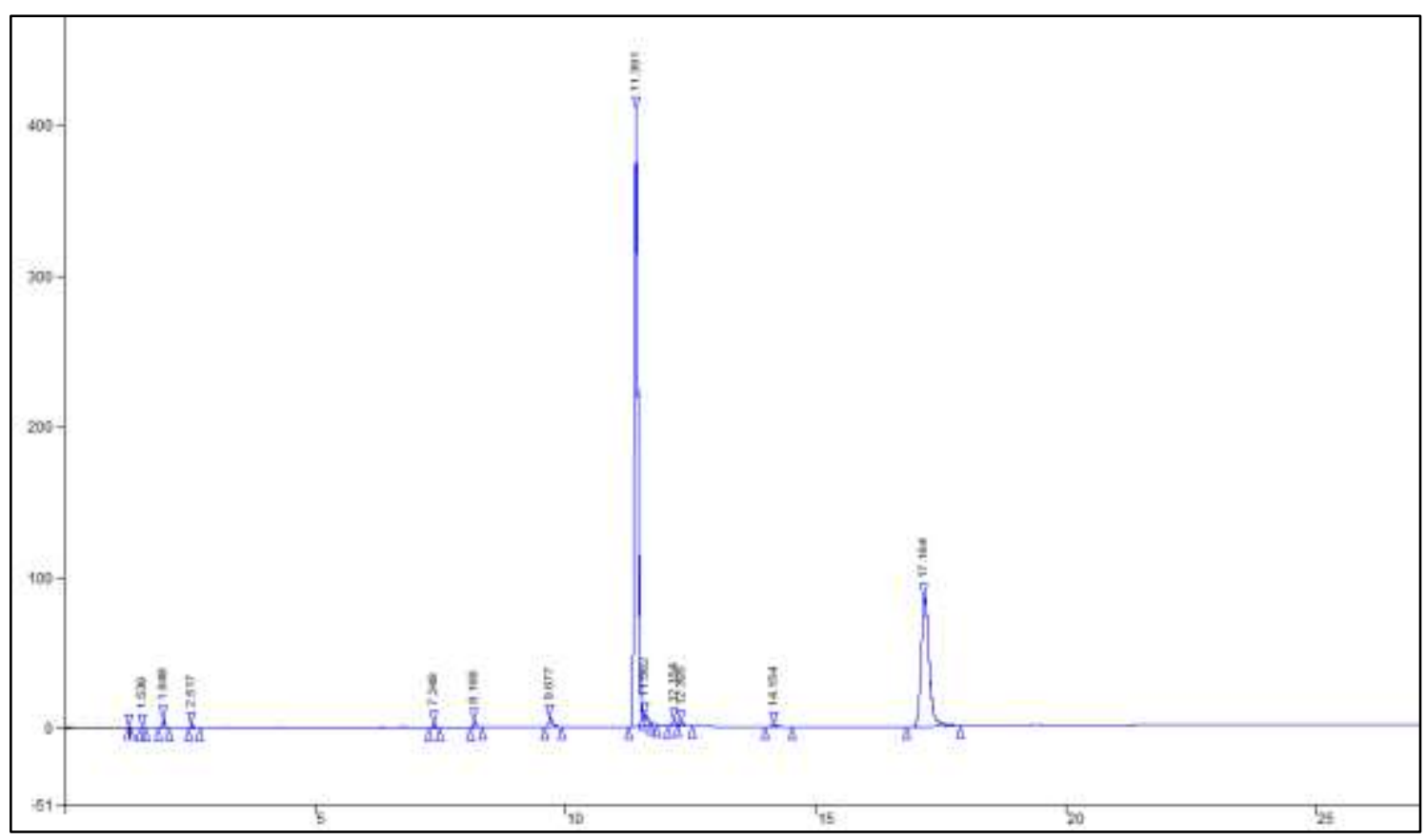

Figura 2.13. Cromatograma representativo de un análisis por cromatografía gaseosa.

Por otra parte, las reacciones utilizando mono y disacáridos como sustratos (glucosa, xilosa y celobiosa) fueron analizadas por cromatografía líquida de alta 
resolución (HPLC) utilizando un equipo UHPLC DIONEX UltiMate 3000 con detector de índice de refracción (RI) a $40^{\circ} \mathrm{C}$ después de la separación de compuestos en una columna de exclusión iónica Phenomenex Rezex $\mathrm{RCM} \mathrm{Ca}^{+2}$ Monosaccharide (300 x 7,8 $\mathrm{mm})$ a $80^{\circ} \mathrm{C}$.

Se utilizó agua milli $Q$ como fase móvil con un flujo de $0,6 \mathrm{~cm}^{3} / \mathrm{min}$. Los productos fueron identificados por comparación con patrones puros. En la Figura 2.14 se muestra un cromatograma típico para este tipo de análisis, donde se identifica cada pico de compuesto con su número de orden y tiempo de retención en minutos.

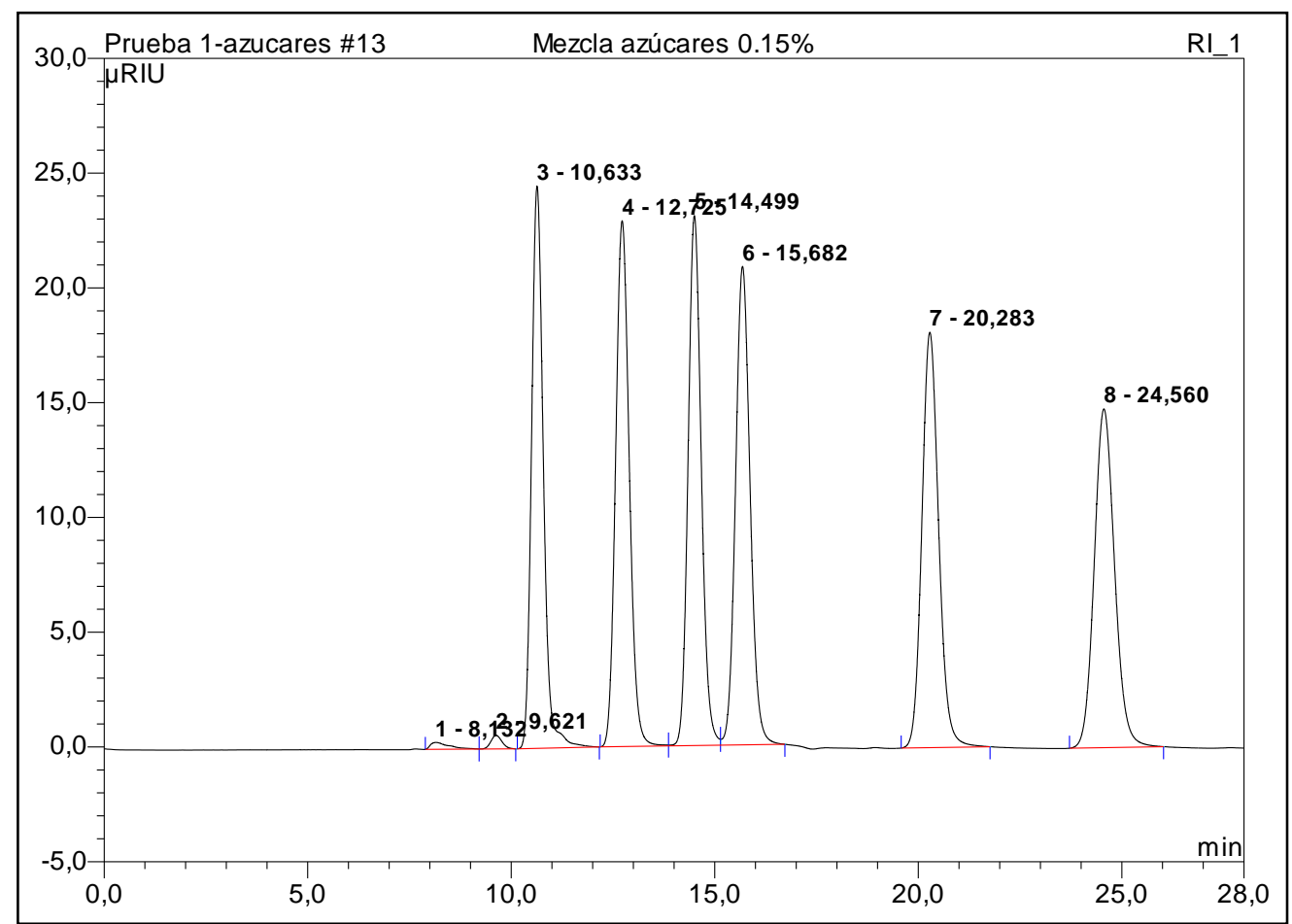

Figura 2.14. Cromatograma típico de HPLC de patrones de monosacáridos y polialcoholes. 


\section{CAPÍTULO 3}

\section{PREPARACIÓN Y ACONDICIONAMIENTO DE SOPORTES}


En el presente capítulo se describen la preparación y el acondicionamiento de los soportes de los sistemas catalíticos empleados en esta tesis. Además, se presentan los resultados obtenidos de la caracterización realizada mediante las distintas técnicas fisicoquímicas descriptas en el capítulo anterior. 


\section{1.- Preparación y acondicionamiento de soportes}

\subsection{1.- $\gamma-\mathrm{Al}_{2} \mathrm{O}_{3}(\mathrm{~A})$}

Se utilizó como soporte una alúmina comercial (Air Products). La misma se molió a un tamaño entre 60 mesh $(0.246 \mathrm{~mm})$ y 100 mesh $(0.147 \mathrm{~mm})$. Posteriormente el soporte se calcinó durante $2 \mathrm{~h}$ a $500^{\circ} \mathrm{C}$ en mufla con el objeto de eliminar impurezas volátiles.

\subsection{2.- Carbón activado (C)}

Se utilizó también como soporte un carbón activado (C) comercial (NORIT) GAC 1240W. Este producto, según declara el fabricante, es fabricado a partir de materias primas de ocurrencia natural y contiene en total $<10 \%$ de sílice cristalina (cuarzo, CAS 14808-60-7). Presenta un aspecto granular negro y posee una densidad aparente de $500 \mathrm{~kg} / \mathrm{m}^{3}$.

Para su utilización en nuestro trabajo, el material se molió a un tamaño entre 60 mesh $(0,246 \mathrm{~mm})$ y 100 mesh $(0,147 \mathrm{~mm})$.

\subsection{3.- Preparación de $\mathrm{ZrO}_{2}(\mathrm{Z})$ y $\mathrm{ZrO}_{2}$ soportada sobre $\mathrm{Al}_{2} \mathrm{O}_{3}(\mathrm{Z}-\mathrm{A})$}

Estos soportes fueron preparados en nuestro laboratorio por el método sol-gel de acuerdo al siguiente procedimiento: la sal precursora, $\mathrm{ZrOCl}_{2} \cdot 8 \mathrm{H}_{2} \mathrm{O}$ (SIGMAALDRICH, reagent grade $98 \%)$, se disolvió en agua Milli Q $\left(600\right.$ a $\left.800 \mathrm{~cm}^{3}\right)$. Se añadió $\mathrm{NH}_{4} \mathrm{OH}$ (Cicarelli, p.a.)(1 M aprox.) para obtener $\mathrm{Zr}(\mathrm{OH})_{4}$ hasta que el pH de la solución alcanzó un valor de 10 y se observó la formación del gel. La mezcla se envejeció durante 7 días a temperatura ambiente. El precipitado blanco obtenido (como puede verse en la Figura 3.1) se lavó con agua destilada hasta que se verificó que el agua de lavado estaba libre de iones cloruro (determinado por $\mathrm{AgNO}_{3}$ ), se filtró y se secó a $105^{\circ} \mathrm{C}$ durante $24 \mathrm{~h}$. Finalmente el material obtenido, designado $\mathrm{Z}$, se calcinó a $600^{\circ} \mathrm{C}$ durante 2 h. La siguiente ecuación representa la preparación de zirconia:

$$
\mathrm{ZrOCl}_{2} \cdot 8 \mathrm{H}_{2} \mathrm{O}+\mathrm{OH}^{-} \rightarrow \mathrm{ZrO}_{2}+2 \mathrm{Cl}^{-}+\mathrm{H}^{+}+8 \mathrm{H}_{2} \mathrm{O}
$$




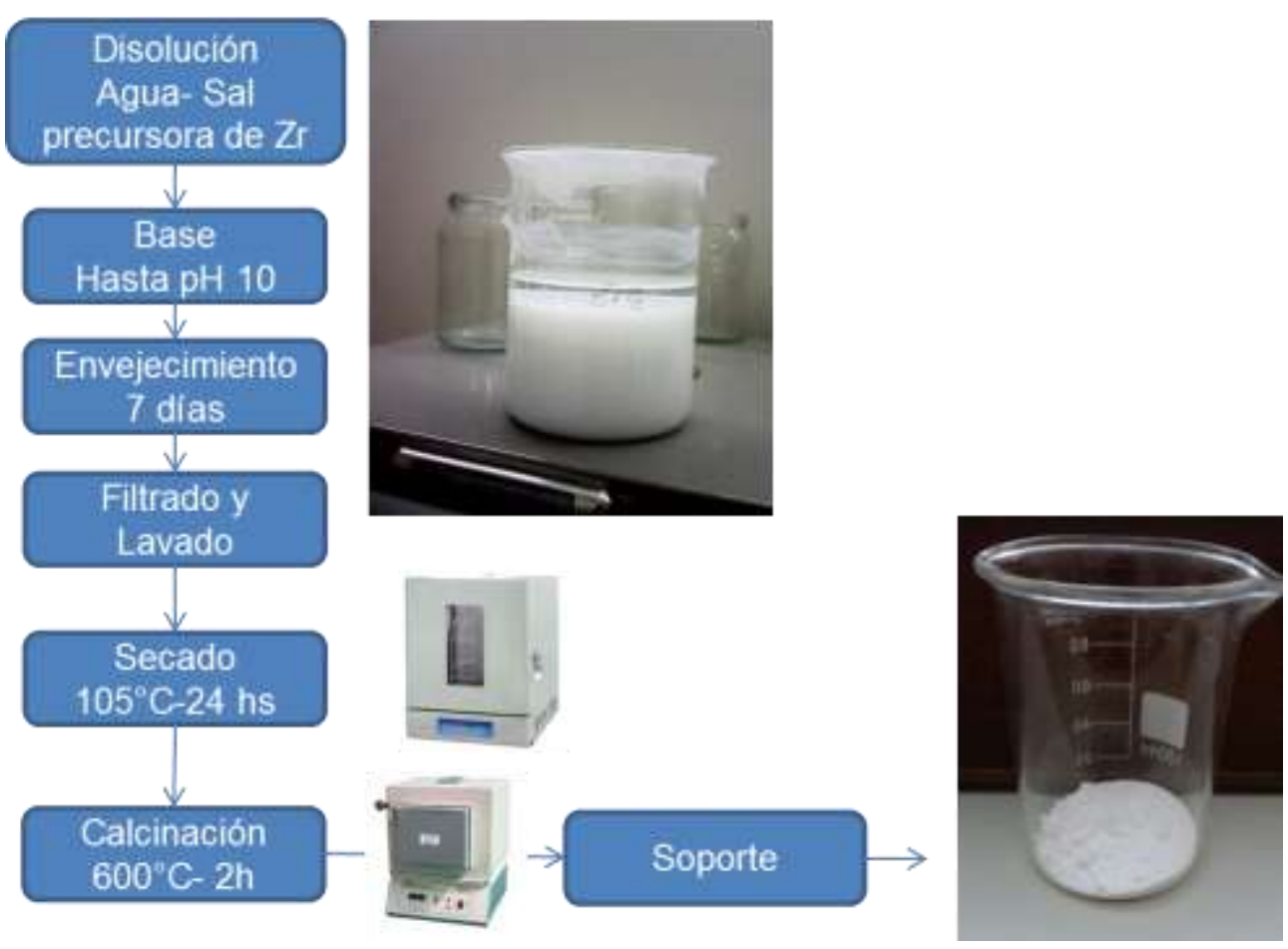

Figura 3.1. Proceso de obtención de $\mathrm{ZrO}_{2}$

El depósito de $\mathrm{ZrO}_{2}$ sobre el soporte $\gamma-\mathrm{Al}_{2} \mathrm{O}_{3}$ (60-100 mesh) se llevó a cabo también por medio del método sol-gel. Con este objetivo, se determinó la masa de $\mathrm{ZrOCl}_{2} .8 \mathrm{H}_{2} \mathrm{O}$ necesaria para obtener $15 \% \mathrm{p} / \mathrm{p}$ de $\mathrm{ZrO}_{2}$ sobre la $\mathrm{Al}_{2} \mathrm{O}_{3}$, según el procedimiento seguido por Jaworski y col.(Jaworski M. A. y col, 2014) Resultados previos encontrados en nuestro grupo de investigación (Jaworski M. A. y col, 2014) demuestran que un $15 \%$ de $\mathrm{ZrO}_{2}$ depositada sobre alúmina permite obtener un soporte que, a la vez que desarrolla un área superficial adecuada para la catálisis (166 $\mathrm{m}^{2} / \mathrm{g}$, ver sección 3.2.1- Características texturales) presenta las características de una fase cristalina de la $\mathrm{ZrO}_{2}$ (ver sección 3.2.3.- Difracción de rayos X (DRX)).

Para la preparación se dispuso una suspensión de $\mathrm{Al}_{2} \mathrm{O}_{3}$ y la cantidad pesada de $\mathrm{ZrOCl}_{2} \cdot 8 \mathrm{H}_{2} \mathrm{O}$ en agua Milli Q. La mezcla se mantuvo bien agitada a temperatura ambiente y se agregó $\mathrm{NH}_{4} \mathrm{OH}$ (1 M aprox.) hasta que el pH de la solución alcanzó un valor de 10. Se observó la formación del gel. Se dejó envejecer 7 días. El precipitado obtenido se lavó con agua destilada hasta que se verificó que el agua de lavado estaba libre de iones cloruro (determinado por $\mathrm{AgNO}_{3}$ ), se filtró y se secó a $105^{\circ} \mathrm{C}$ durante 24 h. El sólido resultante se calcinó a $600^{\circ} \mathrm{C}$ durante 2 h y fue designado Z-A. 
3.1.4.- Preparación de Zirconia fosfatada (ZP) y Zirconia fosfatada sobre $\gamma-\mathrm{Al}_{2} \mathrm{O}_{3}$ (ZPA)

Estos soportes fueron preparados en nuestro laboratorio también por el método sol-gel. Se preparó un soporte de $\mathrm{ZrO}_{2}$ según el procedimiento descripto previamente en el punto 3.1.3. Luego se impregnó con solución de $\mathrm{H}_{3} \mathrm{PO}_{4}$, (Biopack, p.a.) en base al procedimiento propuesto por Hernández y col. (Hernández Enríquez J.M., 2009) (Hernández Enríquez J. M. y col., 2009). Se calculó la cantidad estequiométrica de ácido concentrado para obtener $20 \% \mathrm{p} / \mathrm{p}$ de $\mathrm{PO}_{4}^{-3}$ y se diluyó en agua Milli $Q$ hasta tener una relación líquido/sólido del catalizador de 5:1. Se dejó en reposo 24 h. Y luego se secó en estufa otras 24 h. Posteriormente el soporte se calcinó $600^{\circ} \mathrm{C}$ durante $2 \mathrm{~h}$. Este soporte fue denominado ZP.

Para el material depositado sobre alúmina, se preparó un soporte $\mathrm{ZrO}_{2} / \gamma-\mathrm{Al}_{2} \mathrm{O}_{3}$ siguiendo los pasos descriptos en el punto 3.1.3. Luego se impregnó con solución de $\mathrm{H}_{3} \mathrm{PO}_{4}$ (Biopack, p.a.), siguiendo el mismo procedimiento descripto para obtener el soporte ZP. El sólido resultante luego de la calcinación fue designado ZP-A.

En la Tabla 3.1 se presentan los soportes estudiados y su designación.

Tabla 3.1. Composición y nomenclatura de los soportes preparados

\begin{tabular}{lc}
\multicolumn{1}{c}{ Soporte } & Nomenclatura \\
\hline Carbón activado & $\mathrm{C}$ \\
\hline$\gamma-\mathrm{Al}_{2} \mathrm{O}_{3}$ & $\mathrm{~A}$ \\
\hline $\mathrm{ZrO}_{2}$ & $\mathrm{Z}$ \\
\hline $\mathrm{ZrO}_{2}(15 \%) / \gamma-\mathrm{Al}_{2} \mathrm{O}_{3}$ & $\mathrm{Z}-\mathrm{A}$ \\
\hline $\mathrm{ZrO}_{2}-\mathrm{PO}_{4}^{-3}$ & $\mathrm{ZP}$ \\
\hline $\mathrm{ZrO}_{2}(15 \%)-\mathrm{PO}_{4}^{-3} / \gamma-\mathrm{Al}_{2} \mathrm{O}_{3}$ & $\mathrm{ZP}-\mathrm{A}$ \\
\hline
\end{tabular}

\section{2.- Caracterización de soportes}

En este apartado se presentan los resultados de las técnicas de caracterización de los soportes catalíticos descriptas en el capítulo anterior, con el objeto de obtener información sobre la composición de los sistemas empleados, propiedades texturales, 
estructurales y morfología; para luego relacionar esta información con los resultados de actividad catalítica.

\subsection{1.- Características texturales}

Los soportes de los sistemas catalíticos fueron analizados por adsorción física de $\mathrm{N}_{2}$ a $-196^{\circ} \mathrm{C}$ usando un equipo Micromeritics ASAP 2020. A partir de este estudio se determinaron sus propiedades texturales como superficie específica mediante el método BET, distribución de poros, volumen de poro y diámetro medio de poro.

En la Figura 3.2 se muestra la isoterma de adsorción obtenida para la muestra de carbón activado, la cual es de tipo I(a) de acuerdo a la clasificación establecida por las recomendaciones de IUPAC 2015 (Thommes M. y col., 2015), es decir es cóncava al eje $\mathrm{p} / \mathrm{p}_{0}$ y la cantidad adsorbida se aproxima a un valor límite. Las isotermas de tipo I son características de sólidos microporosos que tienen relativamente pequeñas superficies externas. La limitación de la capacidad de adsorción se rige por el volumen de microporos accesible más que por el área de superficie interna.

La alta energía de adsorción de los microporos hace que el gas se adsorba a bajas presiones. Una vez que se ha completado todo el volumen de los microporos la isoterma permanece en un valor casi constante sobre un amplio rango de presiones, lo que genera la aparición de un plateau.

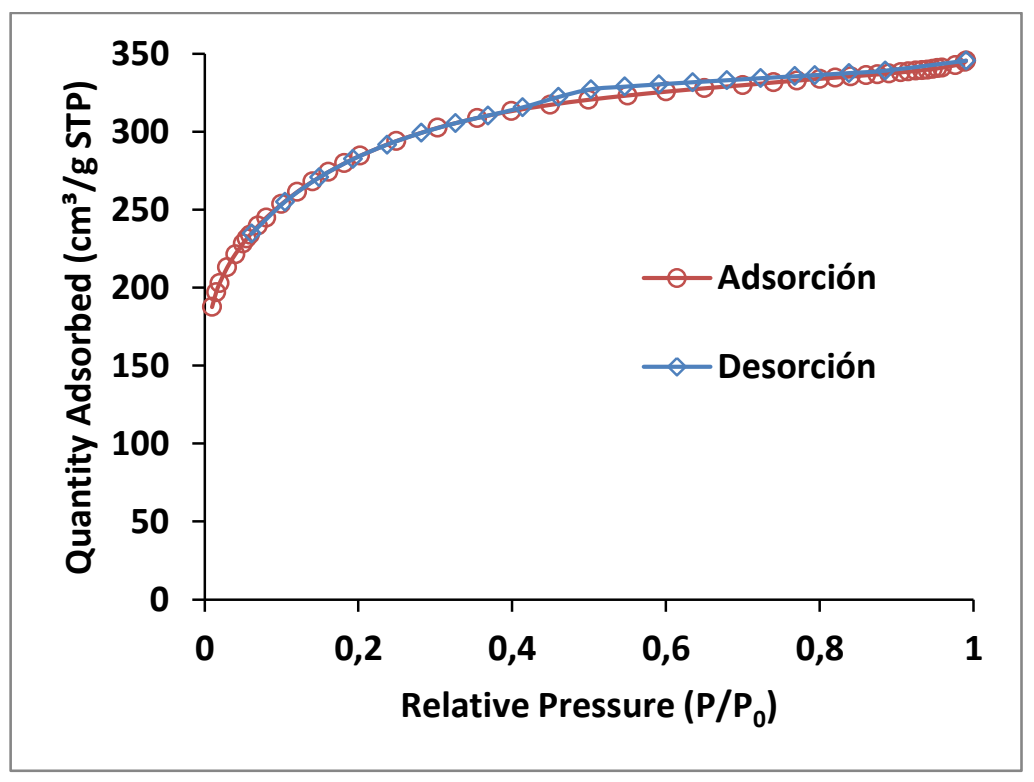

Figura 3.2. Isoterma de adsorción de $\mathrm{N}_{2}$ a $-196^{\circ} \mathrm{C}$ del soporte $\mathrm{C}$ 
La isoterma de $\mathrm{Al}_{2} \mathrm{O}_{3}$ (Figura 3.3) es de tipo IV (a) de acuerdo a la clasificación IUPAC. Esta clase de isoterma es característica de adsorbentes mesoporosos, cuyo comportamiento de adsorción está determinado por las interacciones adsorbatoadsorbente y también por las interacciones entre las moléculas en el estado condensado. En estos sólidos la adsorción ocurre en multicapas y presentan además un ciclo de histéresis que es propio del fenómeno de condensación capilar. En estos casos, la adsorción monocapa-multicapa inicial en las paredes del mesoporo, que toma la misma forma de la parte correspondiente de una isoterma de Tipo II, es seguida por condensación en los poros.

La condensación capilar es el fenómeno por el cual un gas se condensa a una fase similar a un líquido en un poro a una presión $\mathrm{P}$ menor que la presión de saturación Po del líquido bulk (Thommes M., Cychosz. K. A., 2014; Monson P. A., 2012).

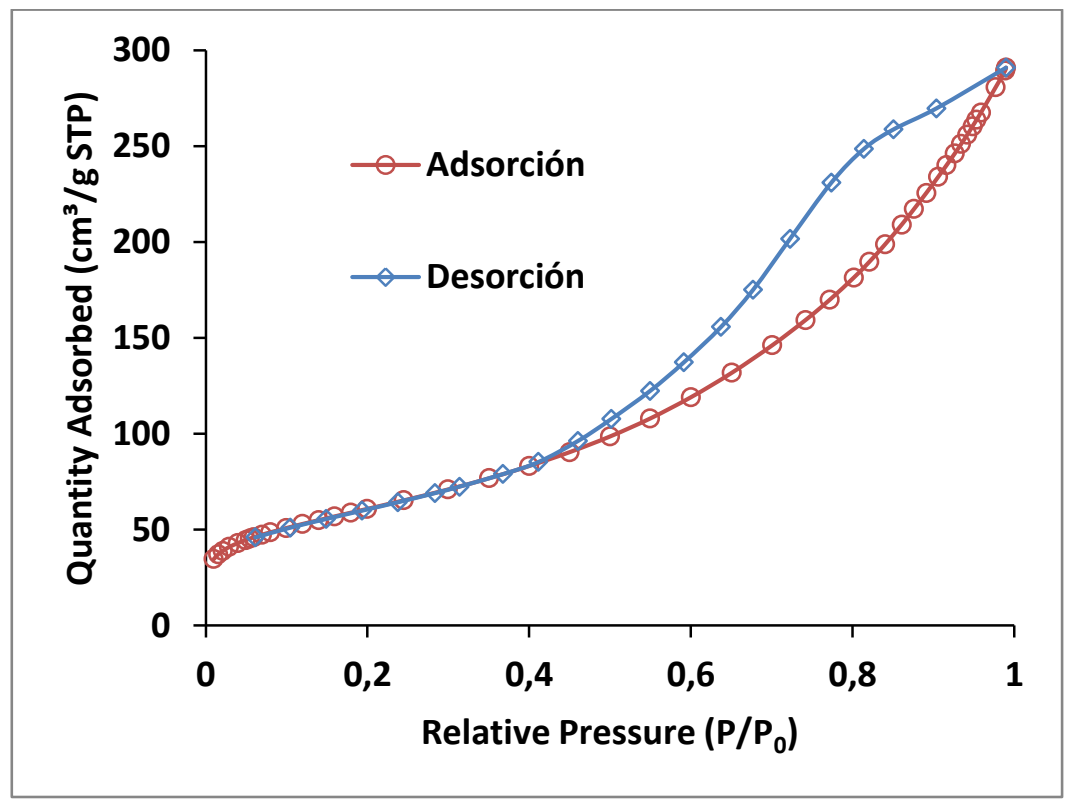

Figura 3.3. Isoterma de adsorción de $\mathbf{N}_{2}$ del soporte $A$.

En la Figura 3.4 se muestran las isotermas del soporte $Z$ preparado en nuestro laboratorio. Antes de su calcinación presenta una isoterma de tipo II (Figura 3.4 (a)), resultado de la adsorción monocapa-multicapa sin restricciones hasta altas relaciones $\mathrm{p} / \mathrm{p}_{0}$. El punto de inflexión observado a relaciones de presión bajas, corresponde a la 
finalización de la cobertura de monocapa y la aparición de adsorción de múltiples capas. El espesor de la multicapa adsorbido en general, parece aumentar sin límite cuando $\mathrm{p} / \mathrm{p}_{0}=1$.

Luego de su calcinación a $600^{\circ} \mathrm{C}$, el soporte $\mathrm{Z}$ exhibe una isoterma tipo IV (a), de acuerdo a la clasificación IUPAC, al igual que la de $\mathrm{Al}_{2} \mathrm{O}_{3}$. La misma puede verse en la Figura 3.4 (b).
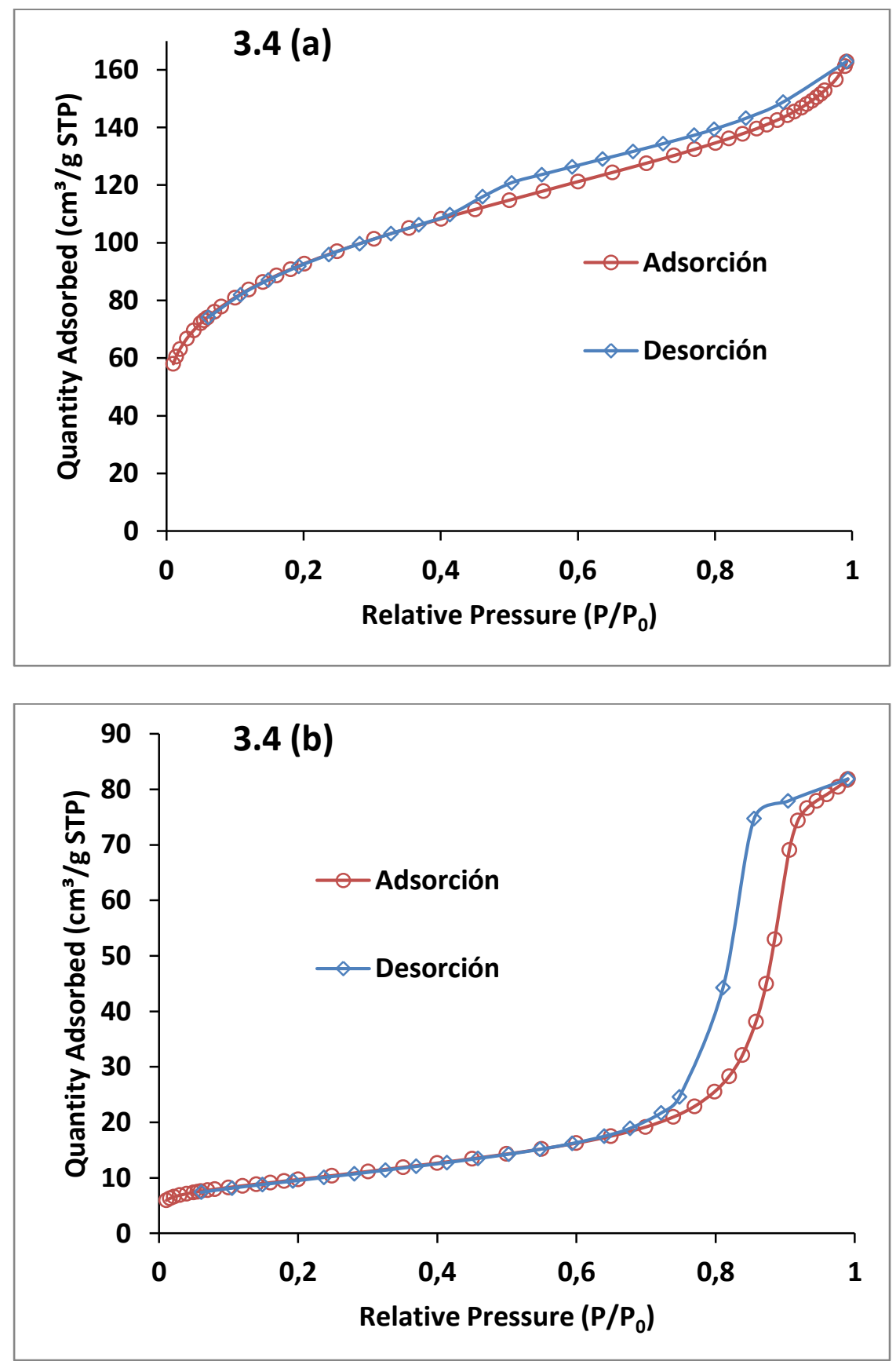

Figura 3.4. Isotermas de adsorción de $\mathrm{N}_{2}$ de: (a) $\mathrm{Z}$ sin calcinar y (b) Z calcinada a $600^{\circ} \mathrm{C}$ 
El soporte ZP también presentó isotermas de tipo IV (a); tanto en el análisis de fisisorción de $\mathrm{N}_{2}$ realizado antes de su calcinación como el que se efectuó luego de calcinar el material a $600^{\circ} \mathrm{C}$.

Las isotermas de los soportes de zirconia depositada sobre alúmina, Z-A (Figura 3.5 (a) y (b)) y ZP-A (Figura 3.5 (c)), son de tipo IV (a) también y además resultan ser muy similares a la correspondiente al soporte A (Figura 3.3), lo que indica que las características superficiales de estos soportes son semejantes.

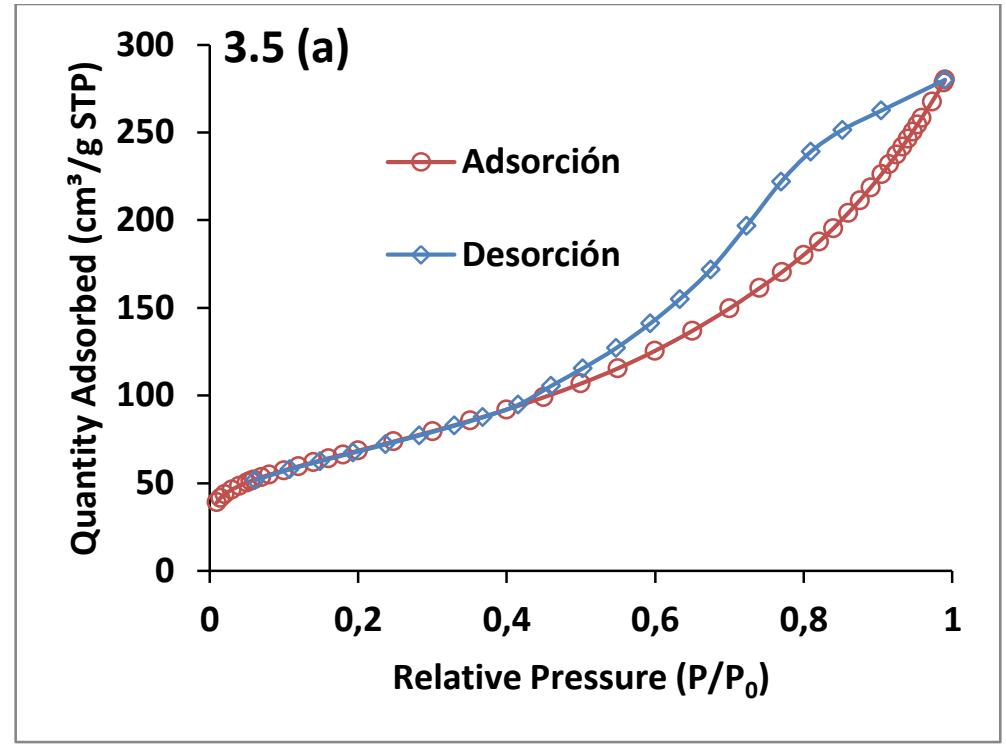

(a) Z-A sin calcinar

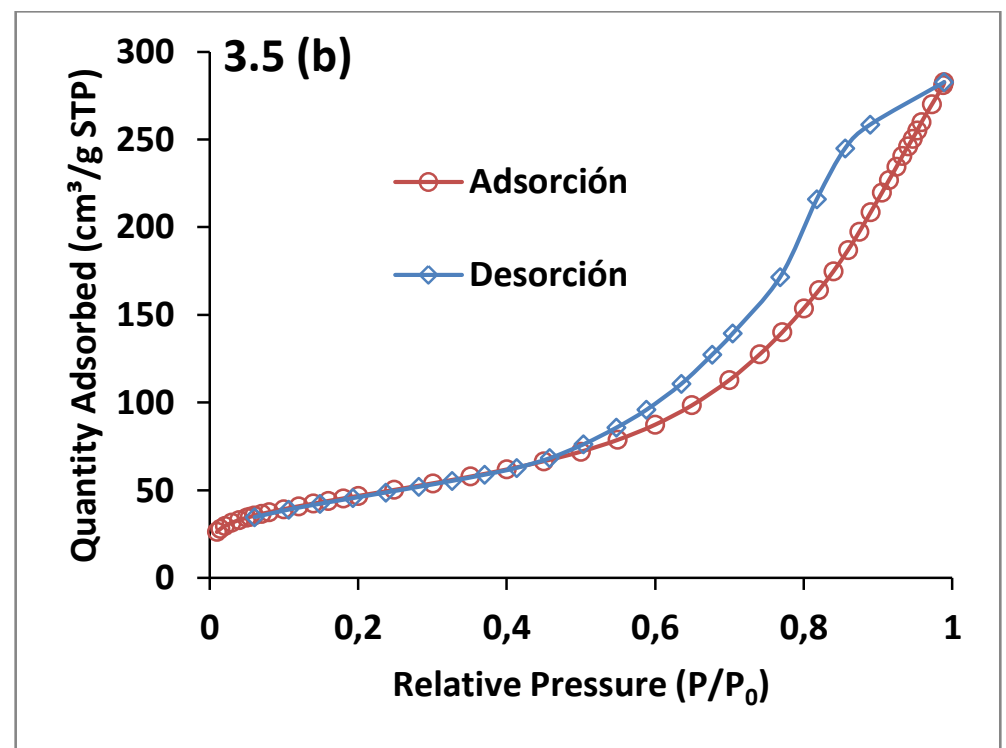

(b) Z-A calcinada a $600^{\circ} \mathrm{C}$

Figura 3.5. Isotermas de adsorción de $\mathrm{N}_{2}$ de (a) Z-A sin calcinar, (b) Z-A calcinada a $600^{\circ} \mathrm{C}$. 


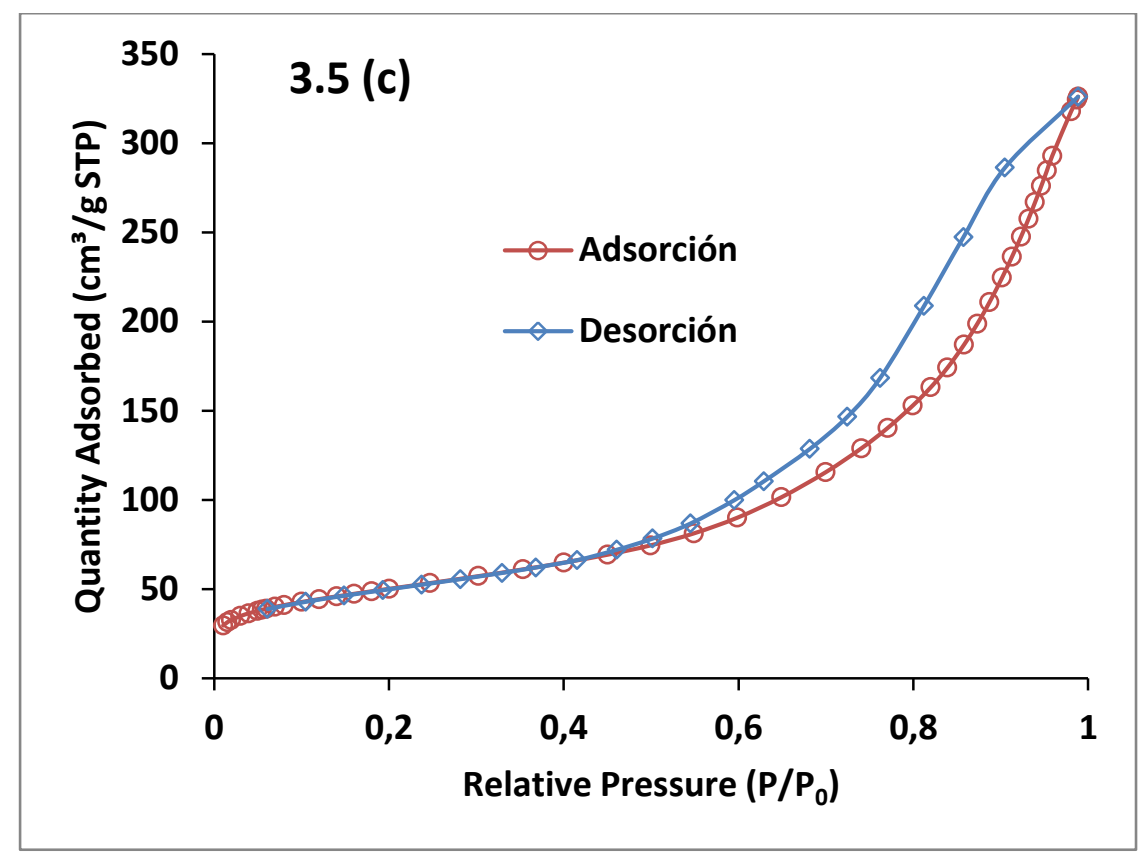

(c) ZP-A calcinada a $600^{\circ} \mathrm{C}$.

Figura 3.5 (cont.). Isoterma de adsorción de $\mathrm{N}_{2}$ de (c) ZP-A calcinada a $600^{\circ} \mathrm{C}$.

La Tabla 3.2 resume los datos de las propiedades texturales, tanto para los soportes comerciales como los sintetizados. El soporte $C$ es el que presenta mayor área superfcial, siendo el único en superar los $1000 \mathrm{~m}^{2} / \mathrm{g}$. Los óxidos de zirconio presentan valores de área mucho menores y se puede observar a su vez que hay una gran diferencia entre el área superficial del hidrogel de zirconia y la zirconia calcinada. Así, el área superficial del soporte de zirconia preparada es $330 \mathrm{~m}^{2} / \mathrm{g}$, mientras que luego de la calcinación el soporte $Z$ tiene un $\mathrm{S}_{\mathrm{BET}}$ de $24 \mathrm{~m}^{2} / \mathrm{g}$. La calcinación a $600^{\circ} \mathrm{C}$ conduce al colapso de parte de la estructura porosa, dando esta área inferior. Por otra parte, también se puede ver que este proceso condujo a un aumento en el diámetro promedio de poro. Este fenómeno podría derivarse de un cambio en la morfología del soporte, pudiendo haberse formado interporos entre las partículas (Jaworski M. A. y col., 2014).

La $\mathrm{Al}_{2} \mathrm{O}_{3}$ por su parte presenta una $\mathrm{S}_{\mathrm{BET}}$ de $216 \mathrm{~m}^{2} / \mathrm{g}$. El depósito de $\mathrm{Z}$ en la alúmina produce una disminución del área superficial específica de este último, muy probablemente por bloqueo de poro (Jaworski M. A. y col., 2014). Sin embargo, la alta superficie de $\mathrm{A}$ permite que $\mathrm{ZrO}_{2}$ se disperse, creando soportes con un área BET significativa, mayor con respecto a los soportes másicos (166 y $178 \mathrm{~m}^{2} / \mathrm{g}$ para Z-A y ZPA respectivamente). Además, comparando Z-A con ZP-A se aprecia, en acuerdo a lo 
reportado en bibliografía, que la introducción del ión fosfato a la estructura del óxido de circonio promovió un aumento en el área específica. (Aboulayt A. y col., 2017).

Tabla 3.2. Soportes de los sistemas catalíticos empleados

\begin{tabular}{cccc} 
Soporte & $\begin{array}{c}\text { Área superficial } \\
\text { BET }\left(\mathbf{m}^{2} / \mathbf{g}\right)\end{array}$ & $\begin{array}{c}\text { Volumen de } \\
\text { poro }\left(\mathbf{c m}^{3} \mathbf{~ g}\right)\end{array}$ & $\begin{array}{c}\text { Diámetro de } \\
\text { poro BJH (Å) }\end{array}$ \\
\hline C & 1011 & 0.53 & 26 \\
\hline $\mathrm{Al}_{2} \mathrm{O}_{3}$ & 216 & 0.45 & 75 \\
\hline Z sin calcinar & 330 & 0.25 & 40 \\
\hline Z & 24 & 0.10 & 174 \\
\hline Z-A sin calcinar & 243 & 0.43 & 68 \\
\hline Z-A & 166 & 0.43 & 96 \\
\hline ZP sin calcinar & 2.78 & 0.003 & 88 \\
\hline ZP & 4 & 0.016 & 208 \\
\hline ZP-A sin calcinar & n.d. & n.d. & n.d. \\
\hline ZP-A & 178 & 0.50 & 111 \\
\hline *n.d.: no determinado & & &
\end{tabular}

\subsection{2.- Microscopía electrónica de barrido}

Las mediciones SEM se llevaron a cabo empleando un microscopio Phillips SEM 505, equipado con un espectrómetro de energía dispersiva de rayos $X$ (EDX). Este análisis permitió investigar las características morfológicas de los soportes Z, Z-A, ZP y ZP-A (Figura 3.6). La composición global de Z-A fue examinada también por esta técnica junto con EDX.

Las microfotográfias de los catalizadores se obtuvieron previa metalización de las muestras con una capa muy delgada de oro, para evitar distorsión de la imagen por acumulación de electrones en la superficie de la muestra lo cual genera una región de carga que puede deflectar el haz incidente en los reiterados barridos. 
Las Figuras 3.6 (a) y (b) muestran una superficie de forma laminar que corresponden a $\mathrm{ZrO}_{2}$. Se puede observar una estructura cristalina bien definida y de poca porosidad para las muestras Z y ZP, lo cual concuerda con los resultados por medidas de área superficial, que condujeron a sólidos de baja área (como se muestra en la Tabla 3.2). Al dispersar la zirconia y la zirconia fosfatada sobre la alúmina se aprecian estructuras de mayor porosidad (Figuras 3.6 (c) y (d)).
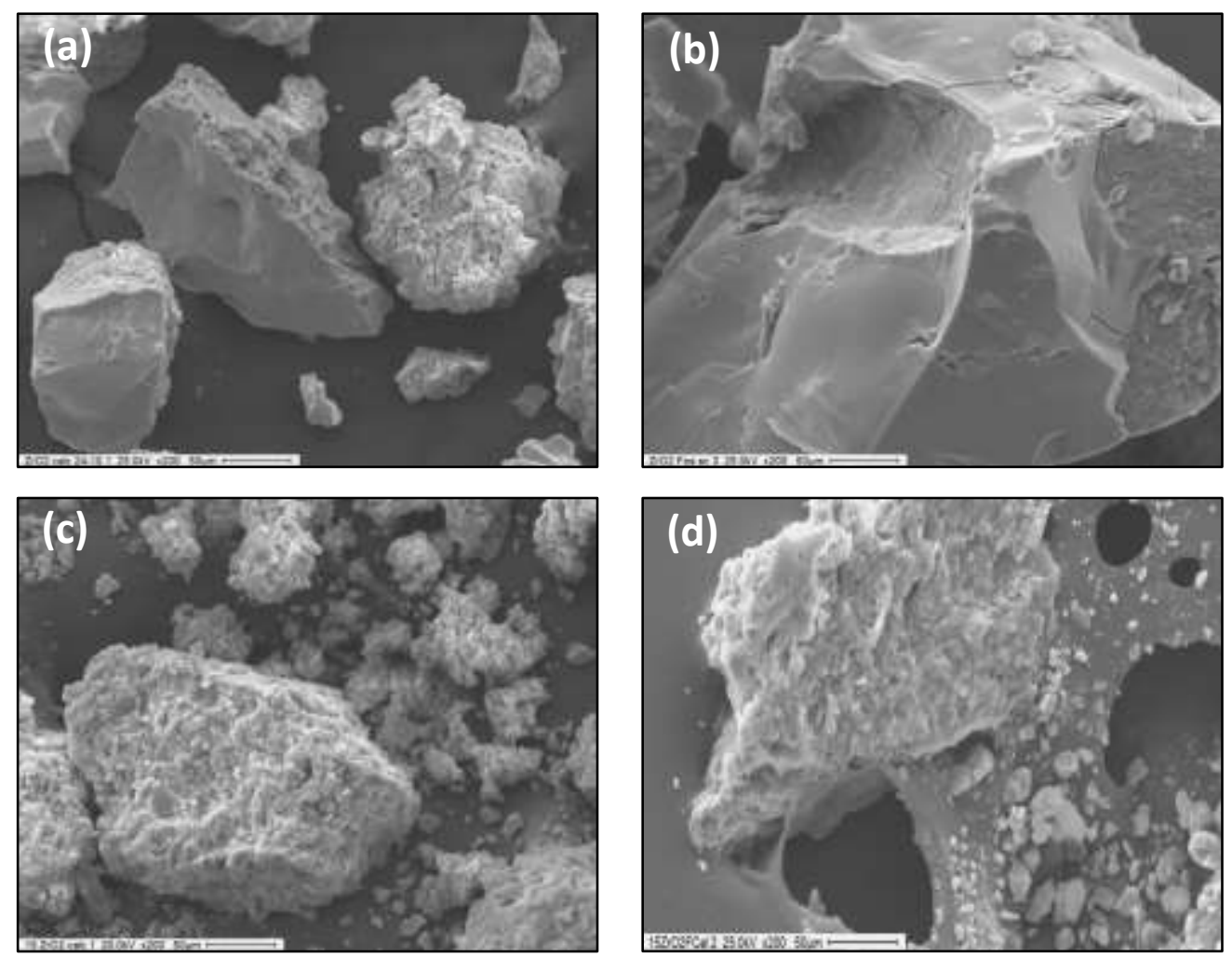

Figura 3.6. Micrografías SEM 200 aumentos de: (a) Z, (b) ZP, (c) ZA (d) ZP-A

Muestras de soportes Z-A calcinada y sin calcinar fueron analizadas por EDX con la finalidad de llevar a cabo un análisis semi-cuantitativo de las mismas (Figura 3.7). Al analizar la composición global de Z-A, se encuentra que el porcentaje de Zr obtenido fue de aproximadamente un $20 \%$ antes de calcinar y $17 \%$ para la muestra calcinada (Figuras 3.8 (a) y (b) respectivamente). Teniendo en cuenta que el Au empleado en la técnica para preparar la muestra y el Zr tienen el mismo nivel de energía, la línea $L$ de Zr está muy cerca de la línea $M$ de Au y puede ser que se esté sobreestimando Zr, por lo que se podría concluir que el \% de Zr concuerda con el esperado. 

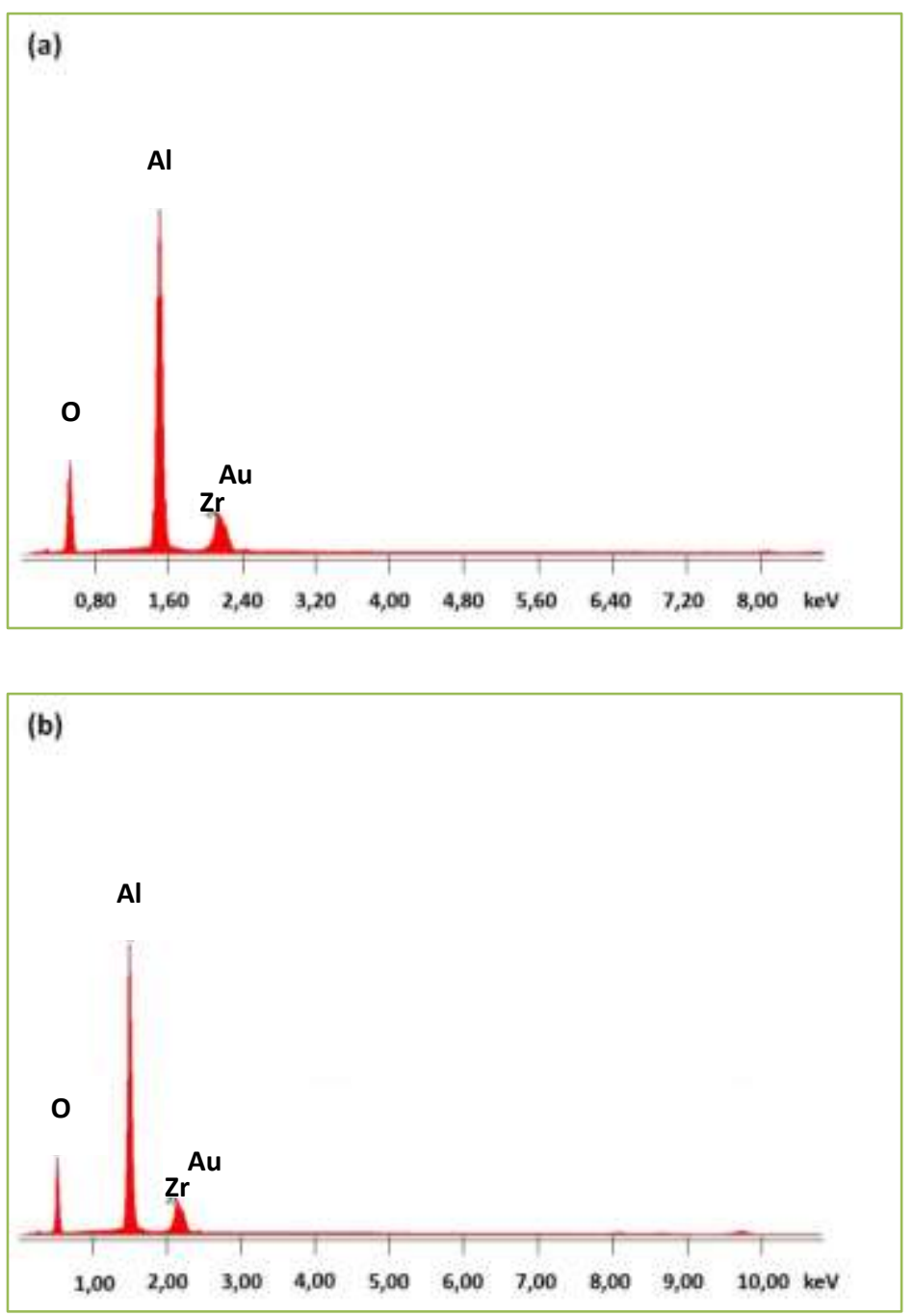

Figura 3.7. Espectros EDX. (a) Z-A sin calcinar, (b) Z-A calcinada

Cuando se quiso analizar del mismo modo el soporte ZP-A nos encontramos con que: la línea de Zr y el fosfato están muy cerca por ende es muy difícil de resolver y la integración no es valedera, ya que puede estar tomando ambos picos simultáneamente.

\subsection{3.- Difracción de rayos $X$}

Con el objetivo de analizar la estructura de los soportes preparados en el laboratorio (Z, Z-A, ZP y ZP-A), se realizaron estudios de difracción de rayos de rayos $X$, usando radiación $\mathrm{K} \alpha$ de $\mathrm{Cu}(\lambda=0,154 \mathrm{~nm})$ en un difractómetro Phillips PW 1390. 
Según estudios bibliográficos, los patrones de difracción de rayos $\mathrm{X}$ indican que la zirconia es amorfa cuando la temperatura de calcinación se mantiene por debajo de $300^{\circ} \mathrm{C}$ (Chang Q. y col., 2009). La cristalización ocurre cuando este material se calcina entre $300^{\circ} \mathrm{C}$ y $550^{\circ} \mathrm{C}$. La muestra resultante presenta una mezcla de fases correspondiente a las estructuras tetragonal y monoclínica. Un aumento de la temperatura de calcinación da lugar al engrosamiento de los cristales. Luego de que el material es calcinado por encima de $550^{\circ} \mathrm{C}$, la zirconia se encuentra con predominio de fase monoclínica (Chang Q. y col., 2009; Tangchupong N. y col., 2010).

En la Figura 3.8 se presenta el difractograma de los soportes $Z$ y Z-A. Los perfiles de picos de difracción de $Z$ (curva (a)) son agudos, indicando la formación de una fase cristalina compuesta por una mezcla de fases monoclínica $(m)$ y tetragonal $(t)$, que se verificaron por la presencia de picos a $(2 \theta)=28,2^{\circ}, 31,5^{\circ}$ y $34,5^{\circ}$ correspondientes a los planos (-111), (111) y $(002)$ de la fase monoclínica y $(2 \theta)=30,5^{\circ}, 35^{\circ}, 50,1^{\circ}$ y $60^{\circ}$ (planos (101), (110), (112) y (211) respectivamente), para la fase tetragonal.

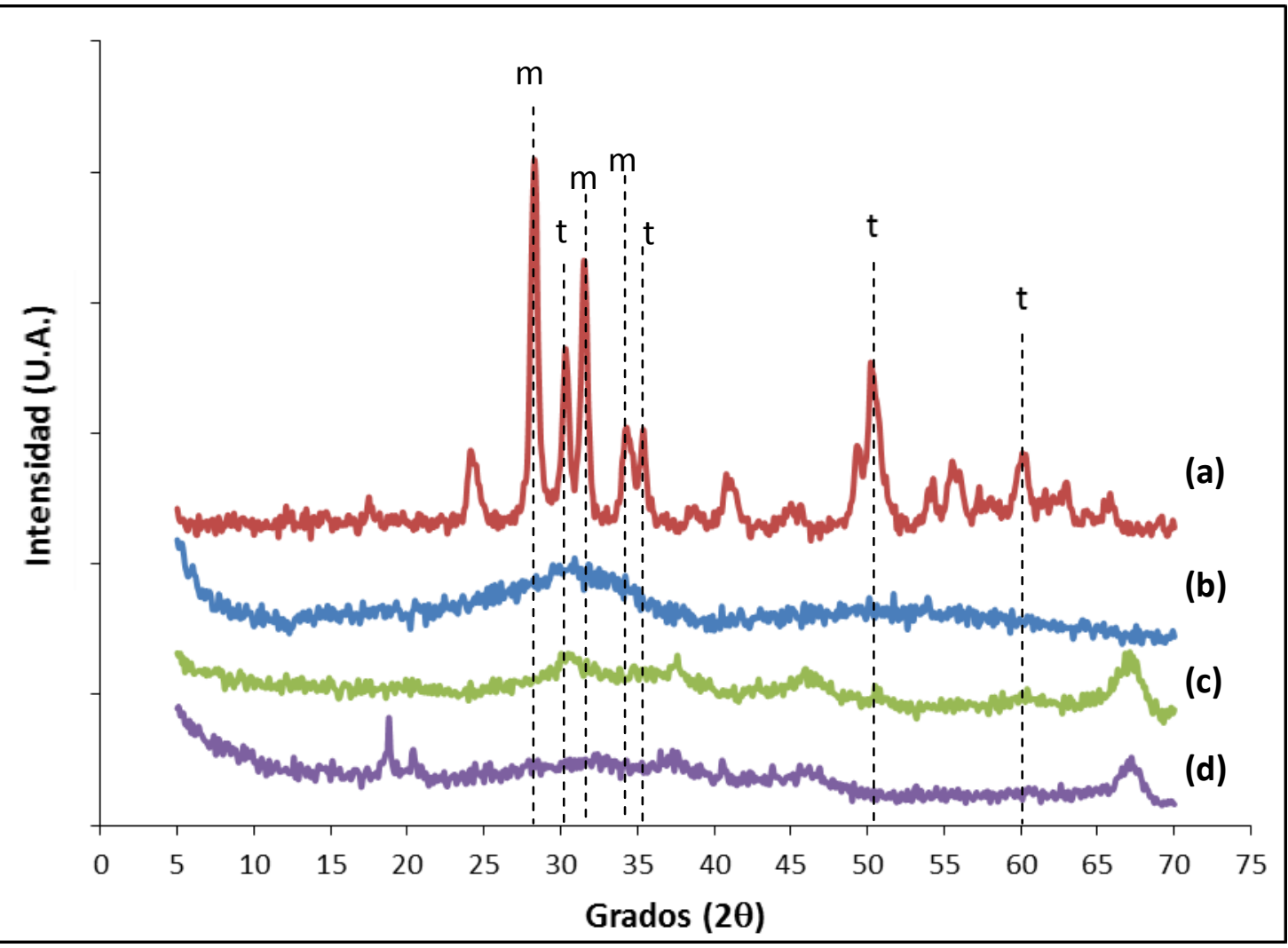

Figura 3.8. Patrones DRX de (a) Z calcinada, (b) Z sin calcinar, (c) ZA calcinada, (d) ZA sin calcinar 
Las fracciones de las fases monoclínica y tetragonal de zirconia fueron calculadas con la siguiente ecuación (Toraya H., Yoshimura M. y Somiya S., 1984):

$$
X_{m}=\frac{I_{m}(-111)+I_{m}(111)}{I_{m}(-111)+I_{m}(111)+I_{t}(101)}
$$

donde $I_{m}(-111)$ e $I_{m}(111)$ son las intensidades de línea de los picos $(-111)$ (a $2 \theta=$ $28,2^{\circ}$ ) y (111) (a $2 \theta=31,5^{\circ}$ ) para la fase monoclínica $(\mathrm{m})$ y $I_{t}(101)$ es la intensidad del pico (101) (a $2 \theta=30,2^{\circ}$ ) para la fase tetragonal $(\mathrm{t})$ de $\mathrm{ZrO}_{2}$. Se pudo establecer que la $\mathrm{Z}$ preparada en este trabajo es una mezcla de $76 \%$ zirconia monoclínica y $24 \%$ zirconia tetragonal metaestable.

El soporte ZA presentó una estructura cristalina correspondiente a la fase tetragonal metaestable, aunque sólo la línea más intensa a $(2 \theta)=30,5^{\circ}$ pudo ser observada (curva (c), Fig. 3.8).

El tamaño promedio de cristal se determinó mediante el uso de la ecuación de Scherrer (Patterson A.L., 1939).

$$
\tau=\frac{0.9 \lambda}{\beta \cos \theta}
$$

dónde $\tau$ es el tamaño del cristal, $\lambda$ es la longitud de onda de radiación $\mathrm{K} \alpha$ del $\mathrm{Cu}, \beta$ es el ancho del pico a mitad de altura considerado para el cálculo (en radianes) y $\theta$ es el ángulo de difracción de Bragg. El tamaño de cristal de la fase monoclínica en Z calculado arroja un valor de $12 \mathrm{~nm}$.

En cuanto a los soportes modificados con fosfato, la muestra de ZP (curva (a), Fig. 3.9) fue en gran medida amorfa, excepto por tres reflexiones de muy baja intensidad (identificados como "•" en la Figura 3.9) a $2 \theta=20,0^{\circ}, 21,4^{\circ}$ y $26,2^{\circ}$ respectivamente, que indican la presencia de una fase de fosfato de zirconio. (Ikeda Y. y col., 2000). En el soporte ZP-A, se obtuvo como resultado una fase amorfa al analizarla por DRX (curva (c) Fig. 3.9). 


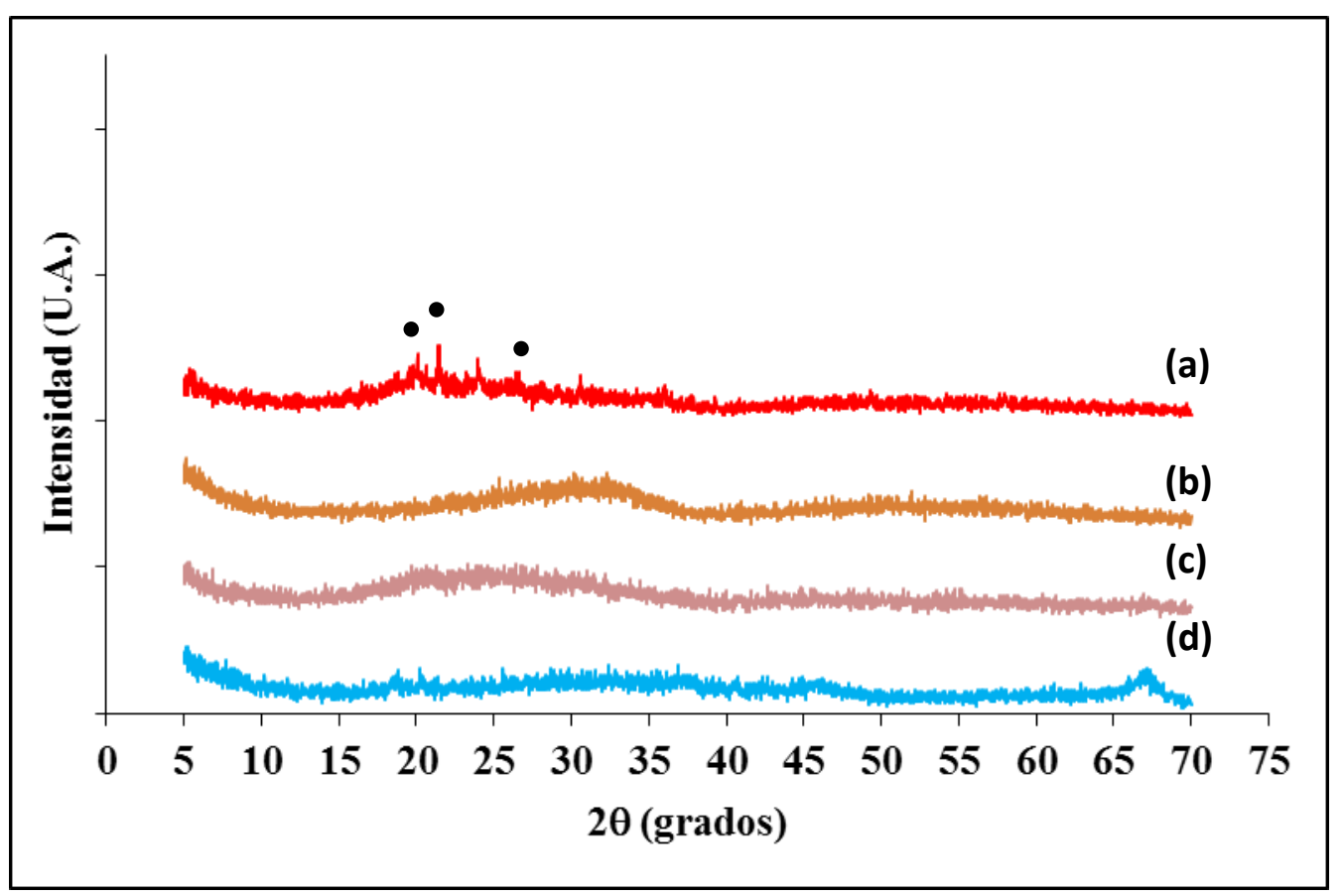

Figura 3.9. Patrones DRX de (a) ZP calcinada, (b) ZP sin calcinar, (c) ZP-A calcinada, (d) ZP-A sin calcinar.

\subsection{4.- Análisis termogravimétrico}

Los estudios de pérdida de peso en función del tiempo se realizaron sobre los cuatro soportes preparados en una termobalanza Shimadzu modelo TGA-50H, en corriente de He.

En los diagramas de pérdida de masa (TGA-DrTGA) de los precursores de los soportes Z y Z-A (sin calcinar) mostrados en la Figura 3.10, fueron identificadas cuatro etapas entre $25^{\circ} \mathrm{C}$ y $500^{\circ} \mathrm{C}$. Las primeras tres etapas, entre los $25^{\circ} \mathrm{C}$ y los $250^{\circ} \mathrm{C}$, pueden ser atribuidas a la pérdida de masa de agua físicamente adsorbida y a la pérdida de los grupos hidroxilos terminales, que permanecen de la síntesis, ocluidos hasta ese momento en la estructura porosa del material (Cao Y. y col., 2002). La última etapa sería originada por la oxolación de los grupos $\mathrm{OH}$ puenteados para formar grupos oxídicos embrionarios, que luego crecerán hasta formar cristales. 


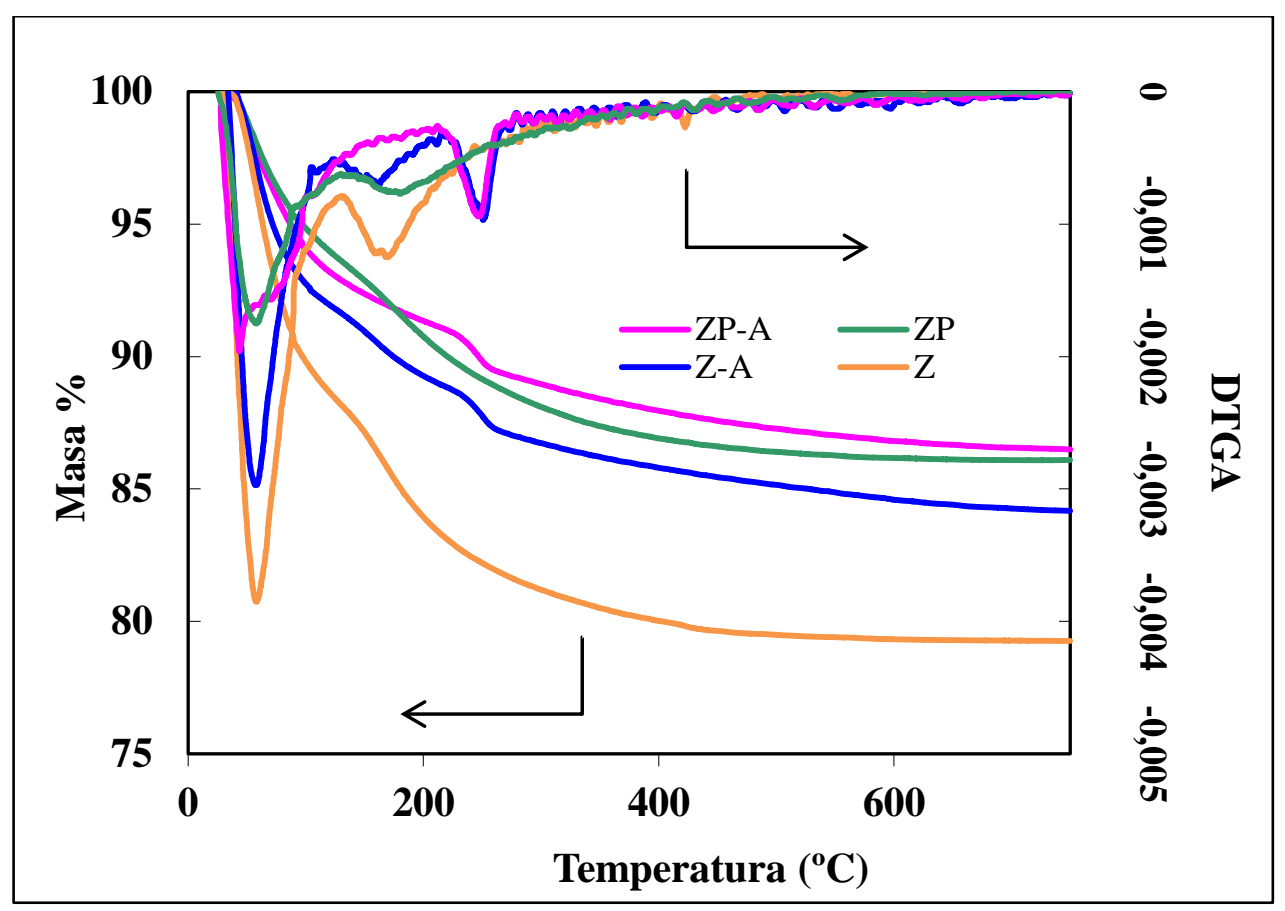

Figura 3.10. Análisis térmico (TGA y DrTGA) de los soportes estudiados

Estas etapas también se observan en los diagramas de los soportes promovidos con ión fosfato (ZP y ZP-A). El origen de esas pérdidas es el mismo que en el caso de los soportes Z y Z-A. Es notoria, sin embargo, la menor pérdida de masa obtenida respecto a la observada en el hidrogel original (Tabla 3.3). Este comportamiento se asocia, en las zirconias dopadas con aniones, a la alta estabilidad de los iones dopantes, en este caso fosfatos, que establecen enlaces más fuertes con el zirconio que aquellos establecidos por los grupos $-\mathrm{OH}$. Esto genera un retardo o aún impide la formación temprana de las fases cristalinas de la zirconia y, además, conduce a sólidos con mayor superficie específica, tal como se ha observado en los resultados de DRX y BET (Hernández Enríquez J.M. y col., 2009).

Tabla 3.3. Pérdidas de masa obtenidas por TGA e identificación de fases de soportes sintetizados

\begin{tabular}{ccc} 
Soporte & Pérdida de masa (\%) & Fase cristalina \\
\hline Z & 20,74 & m-ZrO2 and t-ZrO2 \\
\hline Z-A & 15,87 & t-ZrO2 \\
\hline ZP & 13,91 & Fosfato de Zirconio \\
\hline ZP-A & 13,50 & amorfa \\
\hline
\end{tabular}




\section{3.- Conclusiones}

Se acondicionaron soportes de carbón activado y $\gamma-\mathrm{Al}_{2} \mathrm{O}_{3}$ comerciales, para ser utilizados en la preparación de catalizadores para hidrogenación de compuestos derivados de la biomasa. Ambos soportes presentan valores elevados de superficie específica ( $\mathrm{S}_{\mathrm{BET}}=1011 \mathrm{~m}^{2} / \mathrm{g}$ y $216 \mathrm{~m}^{2} / \mathrm{g}$ respectivamente).

Se prepararon soportes a base de zirconio: $\mathrm{ZrO}_{2}$ másico puro $(\mathrm{Z})$ y modificado con $\mathrm{H}_{3} \mathrm{PO}_{4}$ (ZP) por el método de sol-gel, con objeto de mejorar las características ácidas del soporte. Los soportes fueron calcinados a $600^{\circ} \mathrm{C}$, generando cambios texturales, estructurales y morfológicos en Z: desarrollo de fases cristalinas con predominio de fase monoclínica, observado por estudios de difracción de rayos $x$ (DRX) y disminución del área superficial.

Se prepararon soportes de $\mathrm{ZrO}_{2}$ depositados sobre $\mathrm{Al}_{2} \mathrm{O}_{3}$ (Z-A y ZP-A). La dispersión de $Z$ y ZP sobre $A$ generó un aumento en el área superficial específica respecto a los soportes másicos.

Todos los soportes a base de zirconio preparados, resultaron ser materiales mesoporosos (diámetros de poro $96-208 \AA ̊$ calculado por BJH).

Los óxidos de circonio modificados con fosfato (ZP y ZP-A) permanecieron estables térmicamente después de la calcinación. Se observó, por análisis termogravimétricos (TGA), que el fosfato aumenta la estabilidad térmica de $Z$. 


\section{CAPÍTULO 4}

\section{PREPARACIÓN Y CARACTERIZACIÓN DE CATALIZADORES}


En el presente capítulo se describe la preparación de los catalizadores monometálicos y bimetálicos empleados en esta tesis, utilizando como soportes los materiales analizados en el capítulo anterior. Además, se presentan y discuten los resultados obtenidos de la caracterización realizada mediante las distintas técnicas fisicoquímicas descriptas en el capítulo 2.

Finalmente se presentan ensayos de hidrogenación de trans-2-pentenal realizados como test catalíticos para evaluar los catalizadores sintetizados. La hidrogenación de trans-2-pentenal es una reacción de importancia tanto desde el punto de vista comercial como por las posibilidades de investigación que brinda, ya que tiene las mismas funcionalidades que están presentes en las fracciones acuosas de materias primas derivadas de la biomasa. 


\section{1.- Preparación de catalizadores monometálicos}

En este apartado se expone la preparación de los catalizadores monometálicos y bimetálicos sobre los soportes descriptos en el capitulo 3.

\subsection{1.- Preparación de catalizadores $\mathrm{Ru} / \mathrm{C}$}

Se preparó una familia de catalizadores soportados en carbón activado variando la proporción de Ru desde $0,5 \%$ hasta $3 \%$ en peso. En cada caso, se pesó la cantidad calculada de sal de $\mathrm{RuCl}_{3} \mathrm{xH}_{2} \mathrm{O}$ (Sgma-Aldrich), y se disolvió en $10 \mathrm{~cm}^{3}$ de acetona (Cicarelli, p.a.), mezclando con una varilla de vidrio (la solución presenta color marrón oscuro). La acetona (en lugar de agua) se empleó para facilitar el contacto de la sal de rutenio con el soporte carbonoso, el cual presenta cierto carácter hidrófobo. Se utilizaron $8 \mathrm{~cm}^{3}$ para disolver la sal de rutenio y luego de agregarlos a $2 \mathrm{~g}$ de carbón, se utilizaron $2 \mathrm{~cm}^{3}$ más para enjuagar el vaso, obteniendo una relación v líquido/p sólido de 5:1; es decir se realizó la impregnación del soporte con exceso de solución. El sistema se dejó en reposo durante $24 \mathrm{~h}$ en recipientes tapados para evitar la evaporación del solvente en esta etapa. Transcurridas las 24 h, se dejó evaporar la acetona durante 90 minutos aproximadamente a temperatura ambiente, bajo campana extractora. Luego se dejó en estufa a $60^{\circ} \mathrm{C}$ durante $1 \mathrm{~h}$ para terminar de secar. Posteriormente se redujeron en corriente de $\mathrm{H}_{2}$ durante $2 \mathrm{~h}$ a $300^{\circ} \mathrm{C}$, que es la temperatura requerida para obtener la reducción total de rutenio y luego se lavaron con agua hasta reacción negativa de $\mathrm{Cl}$ - con $\mathrm{AgNO}_{3}$.

La Tabla 4.1 resume las composiciones de los catalizadores preparados, tomando como base $2 \mathrm{~g}$ soporte:

Tabla 4.1. Composición de catalizadores de Ru soportados sobre C

\begin{tabular}{ccc} 
Catalizador & Masa de Ru (g) & $\begin{array}{c}\text { Masa de } \\
\mathrm{RuCl}_{3} \cdot \mathrm{XH}_{\mathbf{2}} \mathrm{O}(\mathrm{g})\end{array}$ \\
\hline $\mathrm{Ru}(\mathbf{0 . 5 \% ) / C}$ & 0,01 & 0,0205 \\
\hline $\mathrm{Ru}(\mathbf{1 \%}) / \mathrm{C}$ & 0,02 & 0,0410 \\
\hline $\mathrm{Ru}(\mathbf{1 . 5 \% ) / C}$ & 0,03 & 0,0615
\end{tabular}




\begin{tabular}{ccc}
$\mathrm{Ru}(2 \%) / \mathrm{C}$ & 0,04 & 0,0821 \\
\hline $\mathrm{Ru}(3 \%) / \mathrm{C}$ & 0,06 & 0,1231
\end{tabular}

\subsection{2.- Preparación de catalizador $\mathrm{Ru} / \gamma-\mathrm{Al}_{2} \mathrm{O}_{3}$}

Para la preparación de este catalizador se siguió el mismo procedimiento que el descripto previamente para los catalizadores soportados sobre carbón activado, con la excepción de que se utilizó agua como solvente en lugar de acetona para la etapa impregnación del soporte con la sal precursora de Ru. Esto es: se pesó la cantidad calculada de sal de $\mathrm{RuCl}_{3} \mathrm{xH}_{2} \mathrm{O}$ (Sgma-Aldrich) para obtener un catalizador $3 \% \mathrm{p} / \mathrm{p}$ de $\mathrm{Ru}$ y se disolvió en $10 \mathrm{~cm}^{3}$ de agua, mezclando con una varilla de vidrio (la solución presenta color marrón oscuro). Se utilizaron $8 \mathrm{~cm}^{3}$ para disolver la sal de rutenio $y$ luego de agregarlos a $2 \mathrm{~g} \gamma-\mathrm{Al}_{2} \mathrm{O}_{3}$, se utilizaron $2 \mathrm{~cm}^{3}$ más para enjuagar el vaso, obteniendo una relación líquido/sólido de 5:1; es decir se realizando la impregnación del soporte con exceso de solución. El sistema se dejó en reposo durante $24 \mathrm{~h}$ en un recipiente tapado para evitar la evaporación del solvente en esta etapa. Transcurridas las $24 \mathrm{~h}$ se dejó en estufa a $105^{\circ} \mathrm{C}$ durante $24 \mathrm{~h}$ para secar. Posteriormente se redujo en corriente de $\mathrm{H}_{2}$ y luego se lavó con agua destilada hasta reacción negativa de $\mathrm{Cl}$ - con $\mathrm{AgNO}_{3}$.

\subsection{3.- Preparación de catalizadores $R u / Z, R u / Z-A, R u / Z P$ y Ru/ ZP-A}

Se prepararon soluciones de $\mathrm{Ru}$ a partir de la sal precursora $\mathrm{RuCl}_{3} \mathrm{xH}_{2} \mathrm{O}$ (Merck) a fin de ponerla en contacto con los soportes Z, ZP, Z-A, y ZP-A sintetizados previamente. El método empleado para la preparación de los catalizadores fue el de "impregnación húmeda". Se pesó la cantidad calculada de sal de $\mathrm{RuCl}_{3} \mathrm{xH}_{2} \mathrm{O}$ de manera de obtener catalizadores $3 \% \mathrm{p} / \mathrm{p}$ de Ru, y se disolvió en $10 \mathrm{~cm}^{3}$ de agua, mezclando con una varilla de vidrio. Se utilizaron $8 \mathrm{~cm}^{3}$ para disolver la sal de rutenio y luego de agregarlos a $2 \mathrm{~g}$ de soporte, se utilizaron $2 \mathrm{~cm}^{3}$ más para enjuagar el vaso, obteniendo una relación líquido/sólido de 5:1. Se dejó en reposo durante 24 h, para la impregnación, en recipientes tapados para evitar evaporación. Luego se dejó en estufa a $105^{\circ} \mathrm{C}$ durante $24 \mathrm{~h}$ para secar. Una vez que los catalizadores fueron reducidos, se 
eliminó todo el cloruro presente en el catalizador lavando con agua destilada hasta reacción negativa de cloruros con nitrato de plata.

\section{2.- Preparación de catalizadores bimetálicos RuSn/C}

En este apartado se expone la preparación de sistemas catalíticos bimetálicos presentando diferentes relaciones atómicas $\mathrm{Sn} / \mathrm{Ru}$ preparados vía Química Organometálica de Superficies sobre Metales (QOMS/M) sobre carbón activado, utilizando como precursor tetrabutilestaño $\left(\mathrm{SnBu}_{4}\right)$.

\subsection{1.- Reacción entre el catalizador monometálico soportado $(\mathrm{Ru} / \mathrm{C})$ y $\mathrm{Sn}\left(\mathrm{n}-\mathrm{C}_{4} \mathrm{H}_{9}\right)_{4}$} $\left(\mathrm{SnBu}_{4}\right)$

La técnica utilizada para la preparación de estos catalizadores consiste en el agregado de una solución del compuesto organometálico (en este caso $\mathrm{SnBu}_{4} \mathrm{Sigma}$ Aldrich 93\%) en un solvente parafínico, sobre el catalizador monometálico, previamente reducido, de Ru sobre carbón con $3 \% \mathrm{p} / \mathrm{p}$ de $\mathrm{Ru}$ (en adelante Ru/C). Esta reacción transcurre en dos etapas: en la primera (a temperatura entre 90 y $150^{\circ} \mathrm{C}$ ) tiene lugar la formación de un compuesto organobimetálico, en donde los grupos orgánicos están anclados a la superficie metálica (MSn-OM), y en la segunda (temperatura entre 150 y $500^{\circ} \mathrm{C}$ ) la formación del compuesto bimetálico buscado después de que todos los fragmentos orgánicos han sido liberados (MSn-BM).

Las reacciones que tienen lugar en estas dos etapas se puede representar por las siguientes ecuaciones:

$$
\begin{gathered}
R u / C+y S n B u_{4}+\frac{x y}{2} H_{2} \rightarrow R u\left(\operatorname{SnB} u_{4-x}\right)_{y} / C+x y B u H \\
R u\left(\operatorname{SnB} u_{4-x}\right)_{y} / C+\frac{(4-x) y}{2} H_{2} \rightarrow R u S n_{y} / C+(4-x) y B u H
\end{gathered}
$$

La especificidad de las reacciones que tienen lugar durante la preparación de catalizadores bimetálicos utilizando técnicas de QOMS/M ha sido probada por varios autores, concluyendo que todo el estaño añadido es selectivamente depositado sobre el metal soportado (Ferretti O.A. y col., 2009; Humblot F. y col., 1998). Así, si la superficie del catalizador monometálico (en nuestro caso $\mathrm{Ru} / \mathrm{C}$ ) se cubre con $\mathrm{H}_{2}$, la 
reacción del tetra-n-butilestaño conduce a su depósito selectivo en las partículas de metal y el soporte queda intacto, sin ocurrir ninguna reacción sobre él. Este hecho fue confirmado realizando una reacción blanco: una cantidad dada del soporte de carbono fue puesta en contacto con soluciones de $\mathrm{SnBu}_{4}$ a las diferentes temperaturas de reacción testeadas $\left(90,120\right.$ y $\left.150^{\circ} \mathrm{C}\right)$. Para todos los casos, se encontró que la cantidad de $\mathrm{SnBu}_{4}$ fijada fue menor que $1 \%$ en peso, después de 5 horas de reacción. La reacción entre $\mathrm{SnBu}_{4}$ y el catalizador $\mathrm{Ru} / \mathrm{C}$ reducido fue seguida por cromatografía gaseosa, midiendo la variación de la concentración de $\mathrm{SnBu}_{4}$ en la solución de impregnación en función del tiempo y determinando a partir de esta diferencia, el contenido de Sn fijado.

La temperatura de reacción y el tiempo de contacto entre el catalizador monometálico y el compuesto de organoestaño son dos variables fundamentales en la obtención de un sistema catalítico con una determinada relación $\mathrm{Sn} / \mathrm{Ru}$, como se ha sido demostrado anteriormente por nuestro grupo de investigación al aplicar esta técnica a diferentes metales de transición (Santori G.F. y col., 2000). Basándonos en estos estudios, fue posible establecer la temperatura de trabajo y el tiempo de reacción necesarios para lograr cada una de las relaciones $\mathrm{Sn} / \mathrm{Ru}$ deseadas.

También se ha determinado que la concentración inicial de la solución de $\mathrm{SnBu}_{4}$ no afecta la máxima cantidad de Sn fijada. Por tanto, el valor de saturación depende únicamente de la temperatura, incrementándose cuando esta aumenta (Ferretti O.A. y col., 2009; Merlo A.B. y col., 2010).

La reacción fue llevada a cabo en una atmósfera de $\mathrm{H}_{2}$ a $90^{\circ} \mathrm{C}, 120^{\circ} \mathrm{C}$ o $150^{\circ} \mathrm{C}$ usando o $\mathrm{n}$-heptano o $\mathrm{n}$-decano como disolvente, dependiendo de la temperatura de reacción. Una vez que la reacción terminó, la fase lıquida se separó y el sólido se lavó repetidamente con $n$-heptano bajo un flujo de $N_{2}$. Luego, los catalizadores fueron reducidos en un flujo de $\mathrm{H}_{2}$ a $500^{\circ} \mathrm{C}$ durante $2 \mathrm{~h}$. Este paso se realiza en el mismo equipo donde fueron preparados los sistemas catalíticos. La temperatura empleada asegura la obtención de fases bimetálicas por eliminación de todos los grupos butilo del $\mathrm{SnBu}_{4}$ empleado como precursor de estaño. Los sistemas bimetálicos así obtenidos se designaron $\mathrm{RuSn}_{\mathrm{y}} / \mathrm{C}$, donde los valores de y $(0,1 ; 0,4$ y 0,8$)$ representa la relación molar Sn/Ru nominal. La Tabla 4.2 enumera los catalizadores bimetálicos preparados y 
las condiciones de reacción empleadas en cada caso, incluyendo la concentración inicial y final de $\mathrm{SnBu}_{4}$ medida. También se indica la relación atómica entre los dos metales, que varía entre 0,14 y 0,80 .

Tabla 4.2. Condiciones de reacción empleadas en la preparación de los catalizadores bimetálicos mediante técnicas QOMS/M. La concentración inicial y final de $\mathrm{SnBu}_{4}$ fue medida por cromatografía de gases.

\begin{tabular}{|c|c|c|c|c|c|c|c|}
\hline Cat. & $\mathrm{T}\left({ }^{\circ} \mathrm{C}\right)^{(1)}$ & $M(g)^{(2)}$ & $\begin{array}{l}\text { Tiempo } \\
\text { de reac. } \\
\text { (h) }\end{array}$ & $\begin{array}{l}\text { Tiempo } \\
\text { de reac. } \\
\text { total }(h)\end{array}$ & $\begin{array}{c}\mathrm{C}_{\mathrm{i}} \\
\left(\mathrm{mmol} \mathrm{L}^{-1}\right)^{(3)}\end{array}$ & $\begin{array}{c}\mathrm{C}_{\mathrm{f}} \\
\left.(\mathrm{mmol} \mathrm{L})^{-1}\right)^{(3)}\end{array}$ & $\mathrm{Sn} / \mathbf{R} \mathbf{u}^{(4)}$ \\
\hline $\operatorname{RuSn}_{0.1} / \mathrm{C}$ & 90 & 1.5 & 4.5 & 5.5 & 4.2 & 1.1 & 0.14 \\
\hline $\mathrm{RuSn}_{0.4} / \mathrm{C}$ & 120 & 3.0 & 4 & 5.5 & 60.8 & 54,1 & 0.45 \\
\hline $\mathrm{RuSn}_{0.8} / \mathrm{C}$ & 150 & 2.0 & 4.5 & 5.5 & 19 & 7,1 & 0.80 \\
\hline \multicolumn{8}{|c|}{${ }^{(1)}$ Temperatura de Reacción } \\
\hline \multicolumn{8}{|c|}{$\begin{array}{l}{ }^{(3)} \text { Concentración de } \mathrm{SnBu}_{4} \text { normalizada a } 1 \mathrm{~g} \text { de } \mathrm{Ru} / \mathrm{C}\left(\mathrm{C}_{\mathrm{i}}=\text { concentración inicial y } \mathrm{C}_{\mathrm{f}}=\text { concentración }\right. \\
\text { final) }\end{array}$} \\
\hline \multicolumn{8}{|c|}{ (4) Relación atómica. } \\
\hline
\end{tabular}

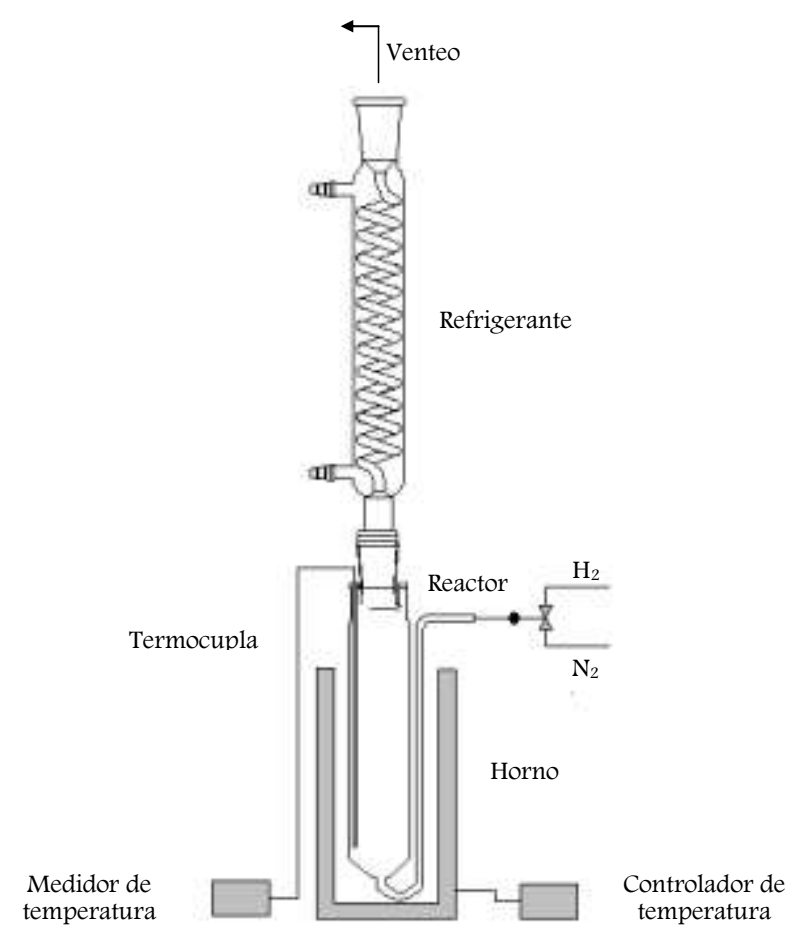

Figura 4.1: Esquema del equipo de preparación de los sistemas catalítico 


\section{3.- Caracterización de catalizadores monometálicos}

\subsection{1.- Microscopía electrónica de transmisión}

La microscopía electrónica de transmisión es una de las herramientas utilizadas a la hora de caracterizar sistemas catalíticos heterogéneos, la cual nos permite obtener información directa sobre la estructura del catalizador (Su D., 2017).

La distribución del tamaño de partícula de los catalizadores monometálicos estudiados se determinó para todos los catalizadores con contenido de Ru del $3 \%$ en peso, en un Microscopio Electrónico de Transmisión JEOL 100 CX II de 100 kV. En la Figura 4.2 se muestran micrografías TEM de los distintos catalizadores preparados (izquierda). A partir de ellas, se midieron los tamaños de partículas y se realizaron los histogramas con las respectivas distribuciones de tamaño de partícula (derecha). El histograma para Ru/Z no se muestra debido a que por cuestiones instrumentales no fue posible tomar mediciones.
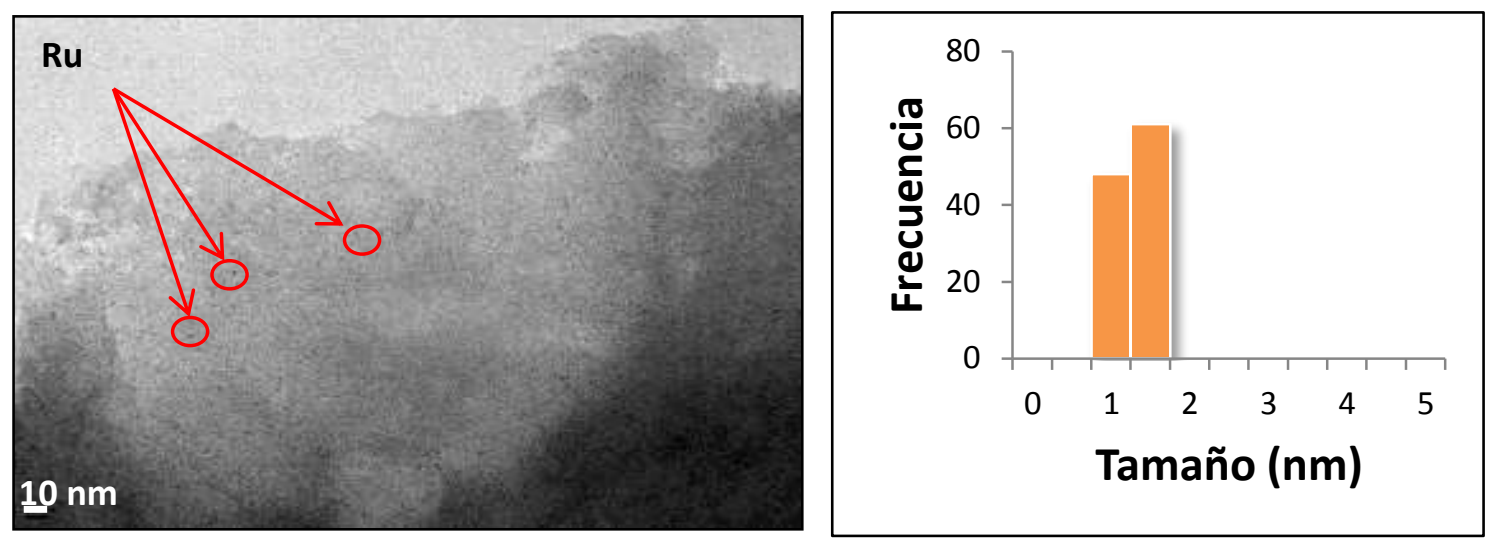

(a) Ru/C
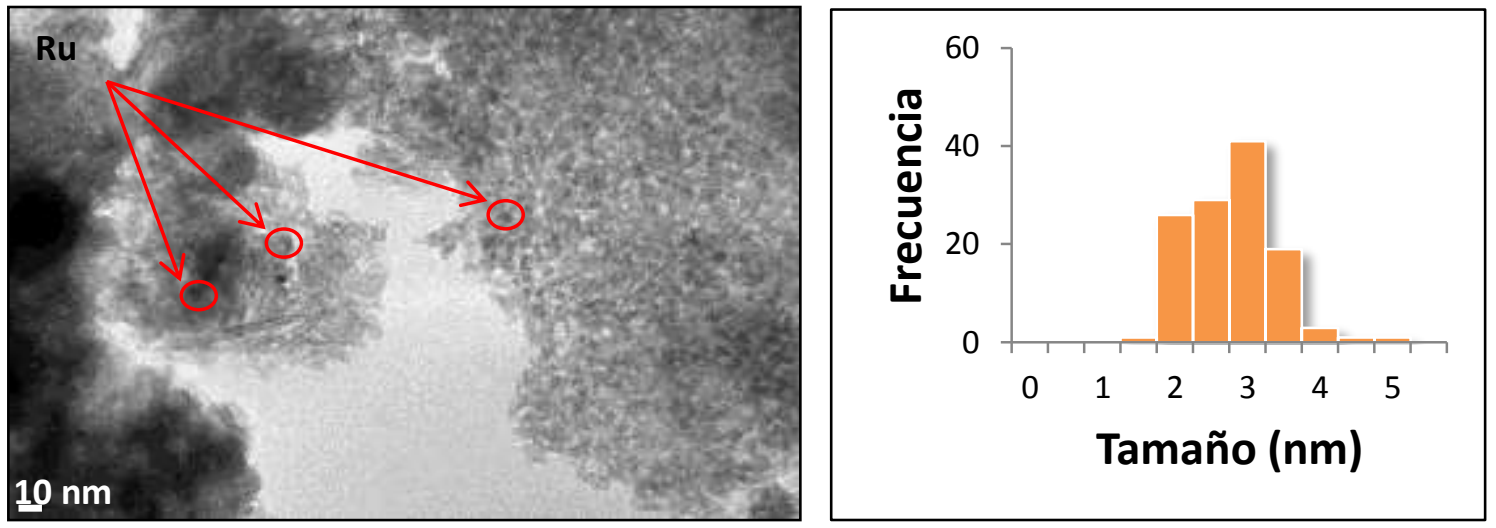

(b) $\mathrm{Ru} / \mathrm{Al}_{2} \mathrm{O}_{3}$

Figura 4.2. Micrografías TEM (amplificación: 450000X) y distribución del tamaño de partícula de las especies $3 \%$ en peso de $\mathrm{Ru}$. (a) $\mathrm{Ru} / \mathrm{C}$, (b) $\mathrm{Ru} / \mathrm{Al}_{2} \mathrm{O}_{3}$ 


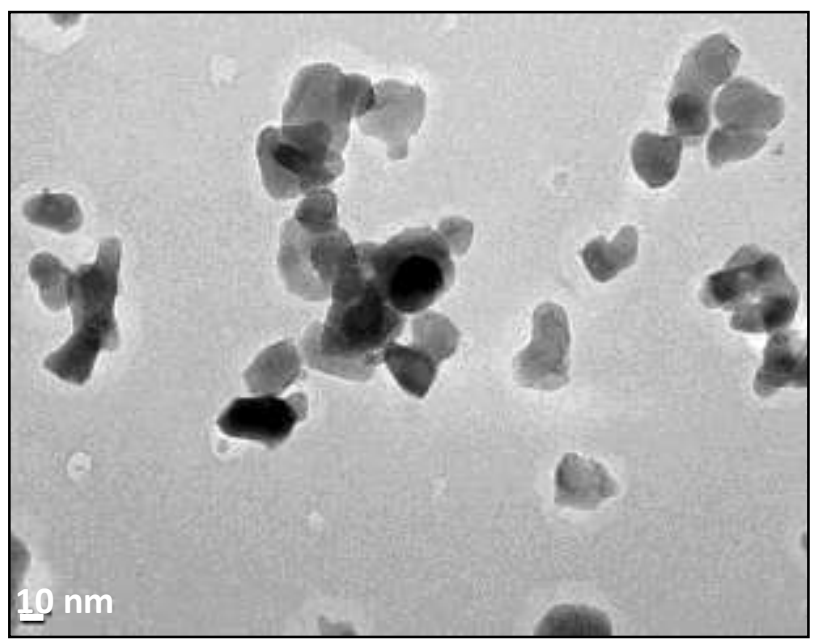

(c) Ru/Z
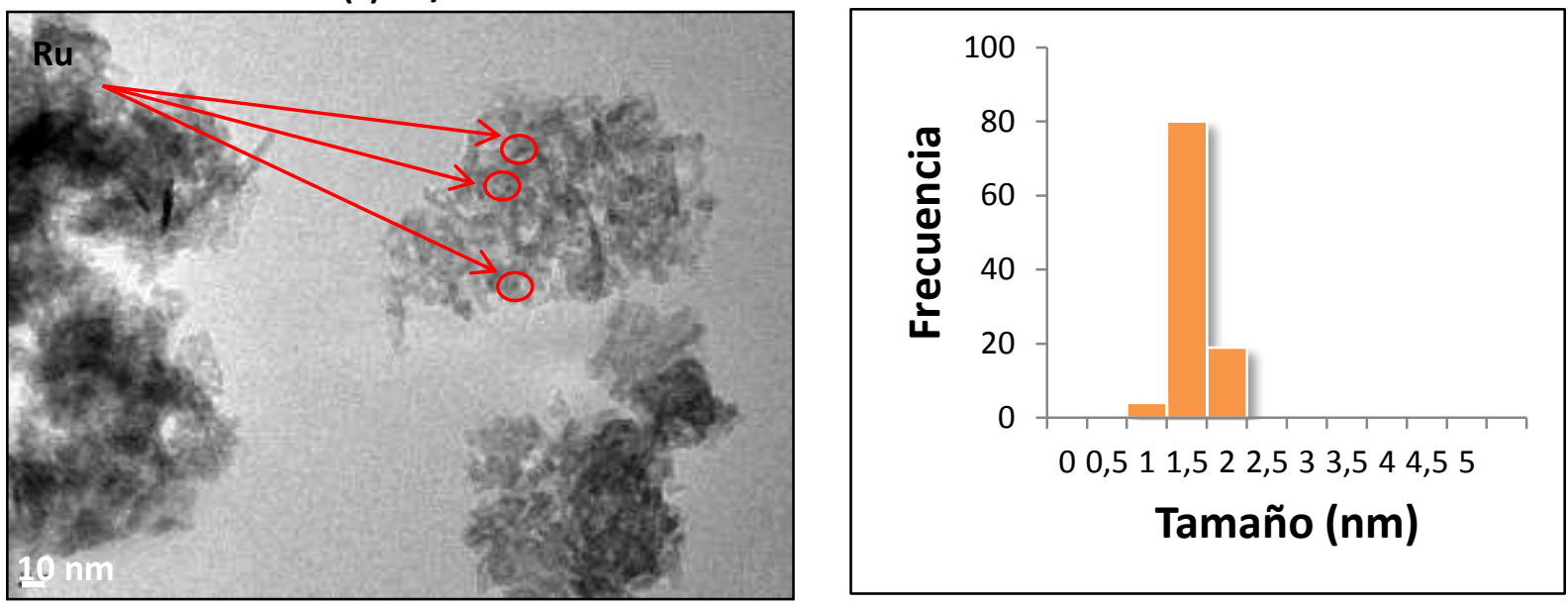

(d) Ru/Z-A
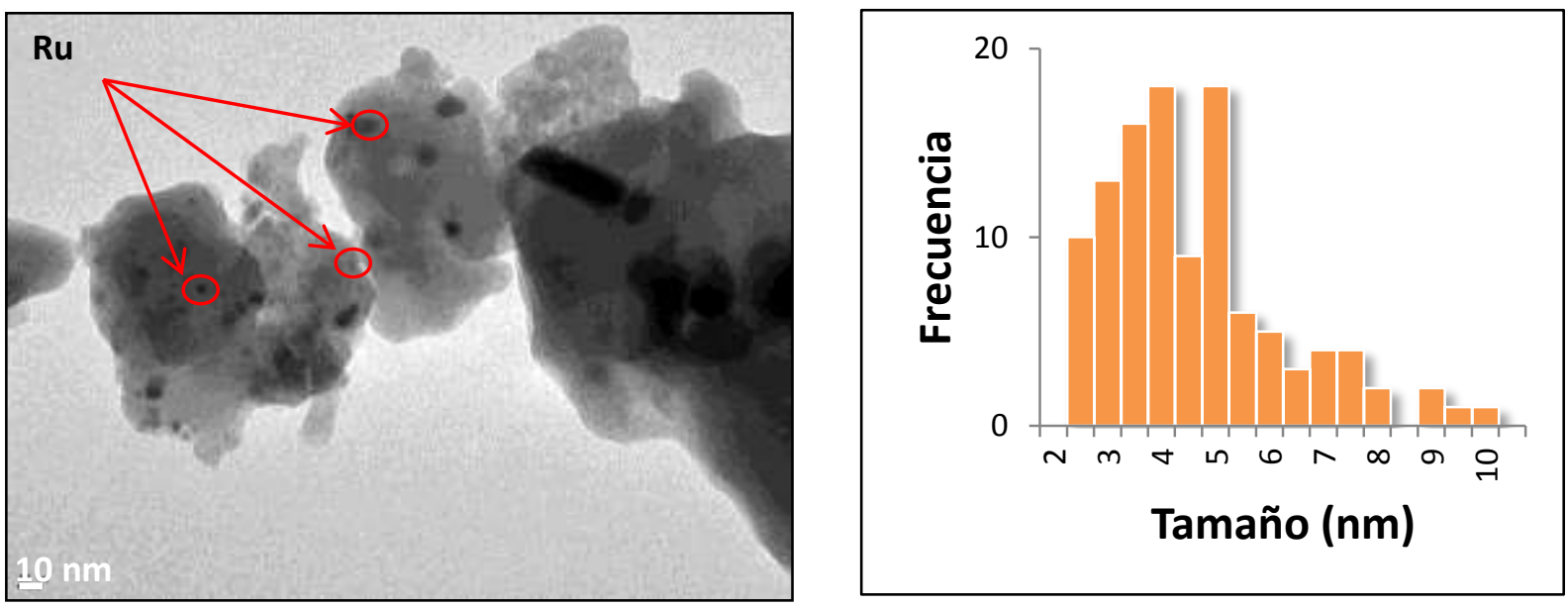

(e) Ru/ZP

Figura 4.2 (cont.). Micrografías TEM (amplificación: 450000X) y distribución del tamaño de partícula de las especies 3\% en peso de Ru. (c) Ru/Z, (d) Ru/Z-A, (e) Ru/ZP, (f) Ru/ZP-A 

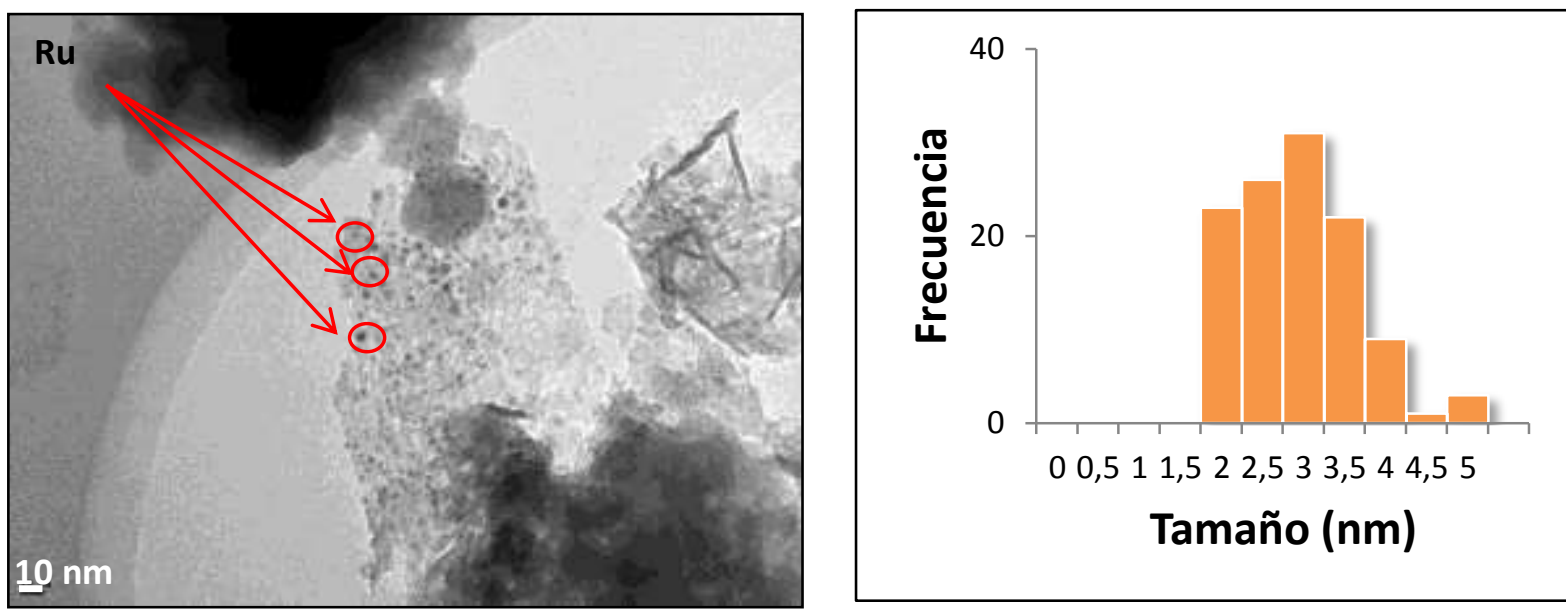

(f) Ru/ZP-A

Figura 4.2 (cont.). Micrografías TEM (amplificación: 450000X) y distribución del tamaño de partícula de las especies $3 \%$ en peso de Ru. (f) Ru/ZP-A

Para realizar los histogramas se cuentan el número de partículas $n_{i}$ (en este caso 200 partículas) de diámetro di en un área dada.

A partir de los histogramas se calcularon los tamaños medios de partículas $d_{\text {TEM }}$ (Tabla 4.3, segunda columna), expresados como diámetro medio volumen-área, los cuales fueron calculados de acuerdo a la siguiente ecuación, presentada en el capítulo II:

$$
d_{T E M}=\frac{\sum n_{i} d_{i}^{3}}{n_{i} d_{i}^{2}}
$$

Posteriormente se calculó la dispersión de Ru en los catalizadores mediante la siguiente ecuación (Bailón-García E. y col., 2016):

$$
D_{R u}=\frac{0.91}{d_{T E M}}
$$

Donde $D_{R U}$ es la dispersión de las partículas de rutenio y $d_{T E M}$ es el Diámetro medio volumétrico (o $D_{\text {va }}$ ) obtenido de las mediciones TEM. 
Tabla 4.3. Diámetros de partícula promedio determinados por TEM y dispersión \% calculada a partir de TEM.

\begin{tabular}{|cccc|}
\hline Catalizador & Dva $(\mathrm{nm})$ & Dispersión $(\%)^{(\mathbf{1})}$ & $\mathrm{S}_{\mathrm{BET}}$ del soporte $\left(\mathrm{m}^{\mathbf{2}} / \mathrm{g}\right)$ \\
\hline $\mathrm{Ru} / \mathrm{C}$ & 1.12 & 82 & 1011 \\
$\mathrm{Ru} / \mathrm{A}$ & 2.85 & 32 & 216 \\
\hline $\mathrm{Ru} / \mathrm{Z}-\mathrm{A}$ & 1.42 & 64 & 166 \\
\hline $\mathrm{Ru} / \mathrm{ZP}$ & 5.70 & 16 & 4 \\
\hline $\mathrm{Ru} / \mathrm{ZP}-\mathrm{A}$ & 3.08 & 30 & 178 \\
\hline
\end{tabular}

(1) Calculada según ecuación 4.2

Como puede observarse, soportes con mayor área superficial presentan mayores valores de dispersión del metal depositado y menores tamaños de partícula. En este sentido es notable la diferencia presentada entre el catalizador de zirconia fosfatada (ZP) en forma másica y el soportado sobre alúmina, donde la mayor área de esta última permitió obtener un soporte con mayor área superficial final y casi duplicar el grado de dispersión (16\% para Ru/ZP y $30 \%$ para Ru/ZP-A respectivamente). Es importante obtener sistemas altamente dispersos cuando se los va a emplear como catalizadores en reacciones de hidrogenación.

\subsection{2.- Reducción a temperatura programada}

Los experimentos de reducción a temperatura programada (TPR) para los catalizadores preparados se llevaron a cabo en un sistema de flujo convencional construido en nuestro laboratorio. La corriente de gas reactivo ( $5 \%$ de $\mathrm{H}_{2}$ con balance de $\mathrm{Ar}$ ) se hizo fluir a $25 \mathrm{~cm}^{3} / \mathrm{min}$ sobre $50 \mathrm{mg}$ de muestra, elevando la temperatura desde temperatura ambiente $\left(25^{\circ} \mathrm{C}\right.$ aproximadamente) hasta $700^{\circ} \mathrm{C}$ a una velocidad de $10^{\circ} \mathrm{C} / \mathrm{min}$.

La Figura 4.3 muestra los perfiles de TPR de los catalizadores de Ru soportados sobre C. 


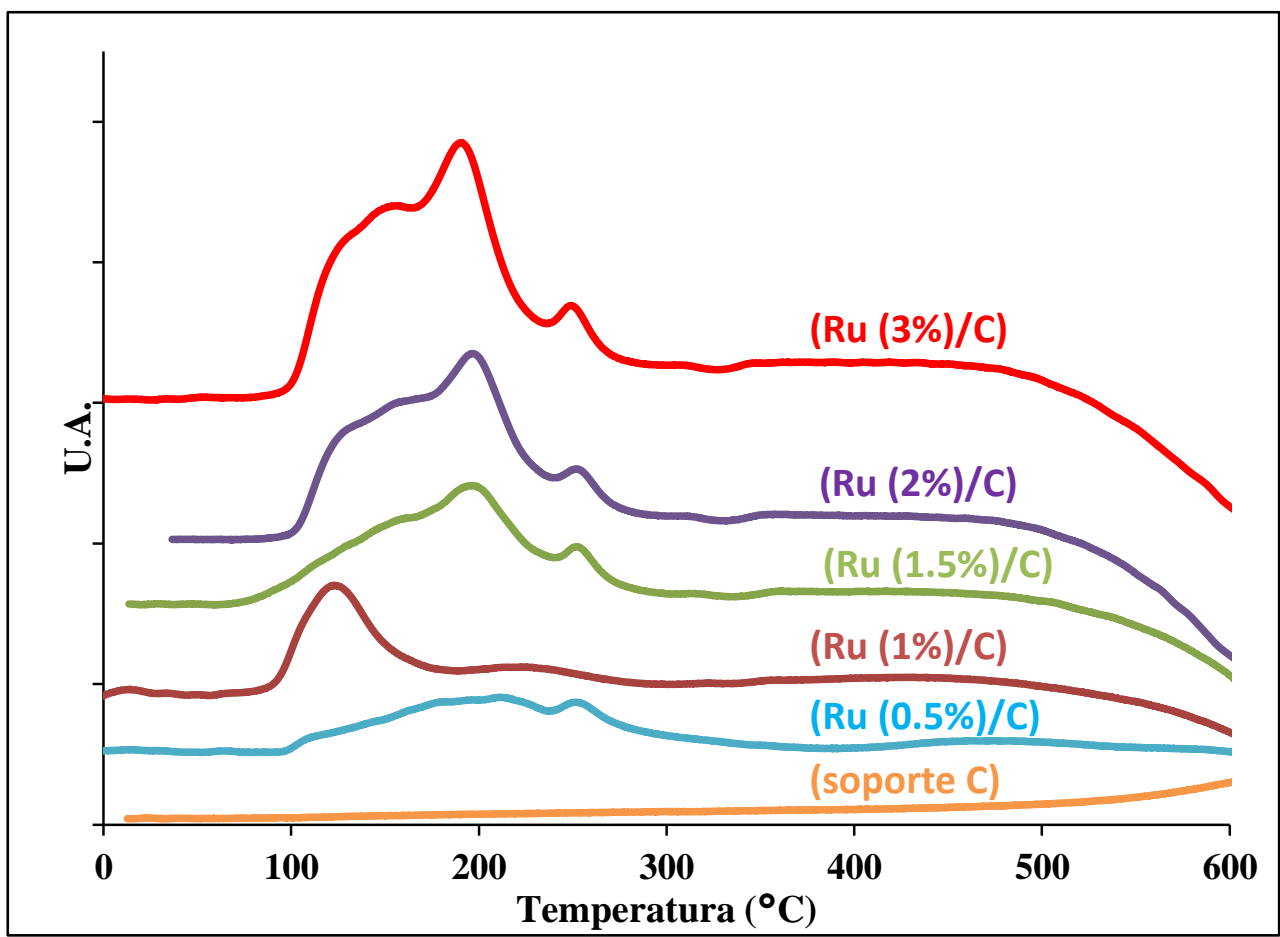

Figura 4.3. Perfiles de Reducción a Temperatura Programada para los catalizadores de Ru $(X \%) / C$, donde $X$ es el \% en peso de $R u$.

Los catalizadores de Ru soportados sobre carbón activado presentan un pico de consumo de $\mathrm{H}_{2}$ entre 80 y $260^{\circ} \mathrm{C}$, donde se encuentran 3 máximos alrededor de $140^{\circ} \mathrm{C}$, $190^{\circ} \mathrm{C}$ y $250^{\circ} \mathrm{C}$. Los dos primeros pueden ser asignados a la reducción de $\mathrm{Ru}^{3+}$ a $\mathrm{Ru}^{0}$ en dos estados diferentes, uno de ellos posiblemente en interacción con los grupos de oxígeno superficiales del soporte. El pico a $250^{\circ} \mathrm{C}$ y la banda ancha posterior, se puede asignar a la gasificación de átomos de carbono superficiales del soporte (formación de metano) alrededor de las partículas de metal (Guerrero-Ruíz A., Badenes P. y Rodríguez-Ramos I., 1998; Bachiller-Baeza B. y col., 2001; Bachiller-Baeza B., Rodríguez-Ramos I. y Guerrero-Ruíz A., 2001; Wettstein S. G. y col., 2012). Estas tres señales se observan para los sistemas con $3 \% ; 2 \% ; 1,5 \%$ y $0,5 \%$ de $R u$, aumentando su intensidad a medida que aumenta la carga metálica sobre el soporte. El catalizador de $\mathrm{Ru}(1 \%) / C$ presenta un comportamiento diferente, observándose un solo pico de reducción de $\mathrm{Ru}^{3+} \mathrm{a} \mathrm{Ru}^{0}$ en una sola etapa.

En la Figura 4.4 se presentan los perfiles TPR para los demás catalizadores de $\mathrm{Ru} 3 \%$ en peso, en diferentes soportes preparados. 


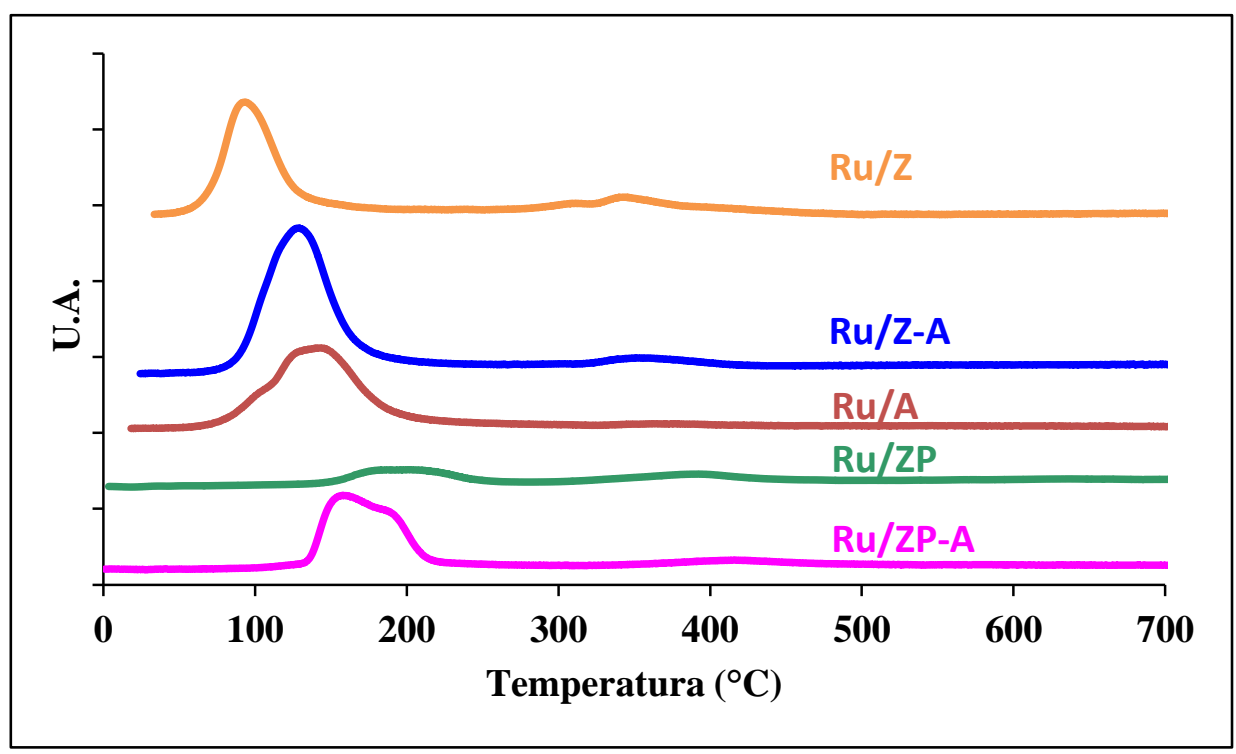

Figura 4.4. Perfiles de Reducción a Temperatura Programada para los catalizadores de Ru en diferentes soportes.

Para el catalizador Ru/A se observa un pico de consumo de $\mathrm{H}_{2}$ alrededor de $145^{\circ} \mathrm{C}$. El mismo puede ser asignado a la reducción de $\mathrm{Ru}^{+3}$ a $\mathrm{Ru}^{0}$ en una sola etapa (Betancourt P. y col., 1998).

El catalizador soportado sobre $Z$ exhibe un pico de reducción bien definido cuyo máximo se encuentra en $95^{\circ} \mathrm{C}$, mientras que el soportado sobre Z-A presenta un pico de reducción cuyo máximo se encuentra en $130^{\circ} \mathrm{C}$, es decir a una temperatura intermedia de la observada cuando el metal se deposita sobre los soportes por separado. La variación en la temperatura de reducción del $\mathrm{Ru}^{+3}$ está de acuerdo con el diferente grado de interacción del metal con los diferentes soportes utilizados. Centi y colaboradores (Centi, G. y col., 1996) sugieren que durante la calcinación de zirconia hidratada para dar $\mathrm{ZrO}_{2}$ anhidro, los grupos $\mathrm{OH}$ fueron responsables de la reducción de $\mathrm{Zr}^{4+}$ en iones $\mathrm{Zr}^{3+}$, mientras que la presencia de un estado de oxidación más bajo de $\mathrm{Zr}$ genera un aumento de la concentración de vacantes aniónicas. Este efecto afecta las propiedades redox de las especies de óxido soportadas, aumentando la reducibilidad, porque estas partículas soportadas están en un ambiente reductor.

En los soportes fosfatados también se observa el pico de consumo, pero desplazado hacia temperaturas superiores que indicaría que existen interacciones más fuertes con el soporte. Se puede observar, también, un segundo pico alrededor de 
$400^{\circ} \mathrm{C}$, el cual podría atribuirse a una interacción más fuerte del Ru con el soporte (Seok Whang H. y col., 2017)

\section{4.- Caracterización de catalizadores bimetálicos}

En esta sección se describirán los distintos ensayos de caracterización realizados con el fin de conocer algunas de las características estructurales de los catalizadores bimetálicos, determinar las relaciones atómicas entre ambos metales y analizar como se ve afectado el entorno del metal Ru con la presencia de Sn.

\subsection{1.- Determinación del contenido de estaño}

El contenido de estaño en los catalizadores bimetálicos se determinó por cromatografía gaseosa durante el transcurso de la reacción entre el catalizador monometálico y el reactivo organometálico. Según estudios previos realizados por nuestro grupo de investigación, los valores obtenidos a partir del análisis cromatográfico de la mezcla de reacción son comparables con la cantidad de estaño fijada en el sólido, determinada por Absorción Atómica (Santori G. F., 2000) o a partir de un ensayo colorimétrico. Se utilizó un cromatógrafo gaseoso Varian CP-800, provisto de un detector FID y una columna capilar Factor Four CP8907 (VF-1ms, 15m x $0,25 \mathrm{~mm} I \mathrm{D}, \mathrm{DF}=0,25)$ y se agregó a la solución de partida un volumen perfectamente medido $(50 \mu \mathrm{l})$ de dodecano como estándar interno.

La Figura 4.5 muestra la variación de la relación molar Sn/Ru en función del tiempo para los cuatro catalizadores bimetálicos $\mathrm{RuSn}_{\mathrm{y}} / \mathrm{C}$ preparados.

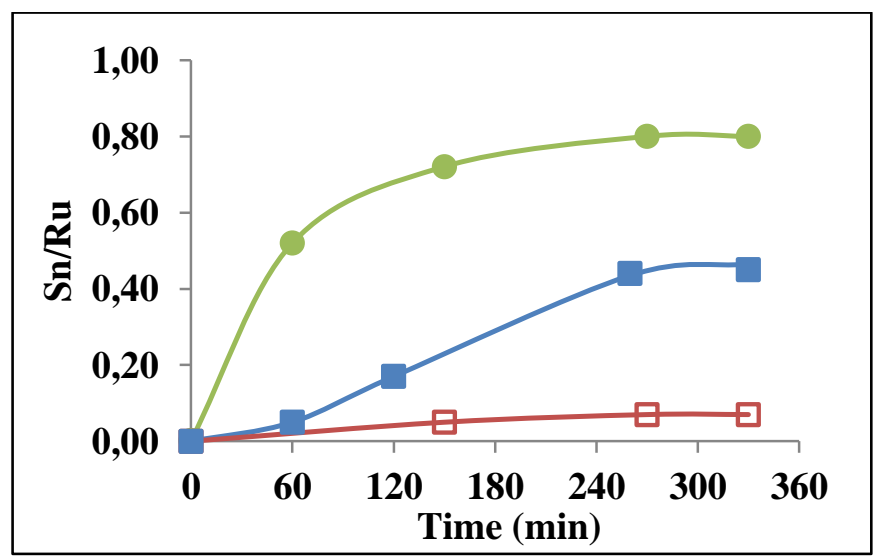

Figura 4.5. Cantidad de estaño fijado (medido como relación $\mathrm{Sn} / \mathrm{Ru}$ ) en función del tiempo (min): (•) $\mathrm{Sn} / \mathrm{Ru}=0,8\left(\mathrm{n}\right.$-decano, $\left.150^{\circ} \mathrm{C}\right),(\square) \mathrm{Sn} / \mathrm{Ru}=0,4$ (n-heptano, $\left.120^{\circ} \mathrm{C}\right)$, y $(\square) \mathrm{Sn} / \mathrm{Ru}=0,1$ (n-heptano, $90^{\circ} \mathrm{C}$ ). 
Se puede ver que para las concentraciones de $S n$ más baja $(S n / R u=0,1)$ el $\mathrm{SnBu}_{4}$ de partida se fijó todo en 270 min de reacción. Para lograr relaciones Sn/Ru más altas se requirió de temperaturas más elevadas, como se indicó en la Tabla 4.2., en el apartado de preparación de catalizadores bimetálicos.

Se observa además un "plateau" para todas las cantidades de Sn fijada. Esto estaría indicando que se ha alcanzado la máxima relación Sn/Ru posible a dichas T.

\subsection{2.- Microscopía electrónica de transmisión}

El tamaño promedio de partícula de los catalizadores bimetálicos se determinó, utilizando microscopia electrónica de transmisión (TEM), técnica que ya fue descripta en la sección de caracterización de catalizadores monometálicos.

Se observa que el valor de la distribución promedio del tamaño es superior para los catalizadores bimetálicos en comparación con el catalizador monometálico (partículas de tamaño uniforme con un diámetro medio de 1,1 nm (Figura 4.4 (a)).

Después de la adición de Sn, el tamaño medio de partícula aumentó a 2,7 nm y $2.2 \mathrm{~nm}$ para los catalizadores $\mathrm{RuSn}_{0.4} / \mathrm{C}$ y $\mathrm{RuSn}_{0.8} / \mathrm{C}$, respectivamente (Figura 4.6 (b) y C)). Este aumento en el tamaño de partícula se puede asignar en parte al depósito selectivo de estaño sobre rutenio y no sobre el soporte, según como está bien establecido en la literatura para otros sistemas catalíticos análogos a los estudiados aquí (Baudouin D. y col., 2014; Santori G.F y col, 2000).

Sin embargo, la contribución de la sinterización de las partículas de Ru no se puede dejar de tener en cuenta. El tratamiento térmico al que se somete el sistema Ru $\left(\mathrm{SnBu}_{4^{-}}\right)_{y} / \mathrm{C}$ para eliminar los restos orgánicos y obtener el catalizador bimetálico sería responsable de esa sinterización. 

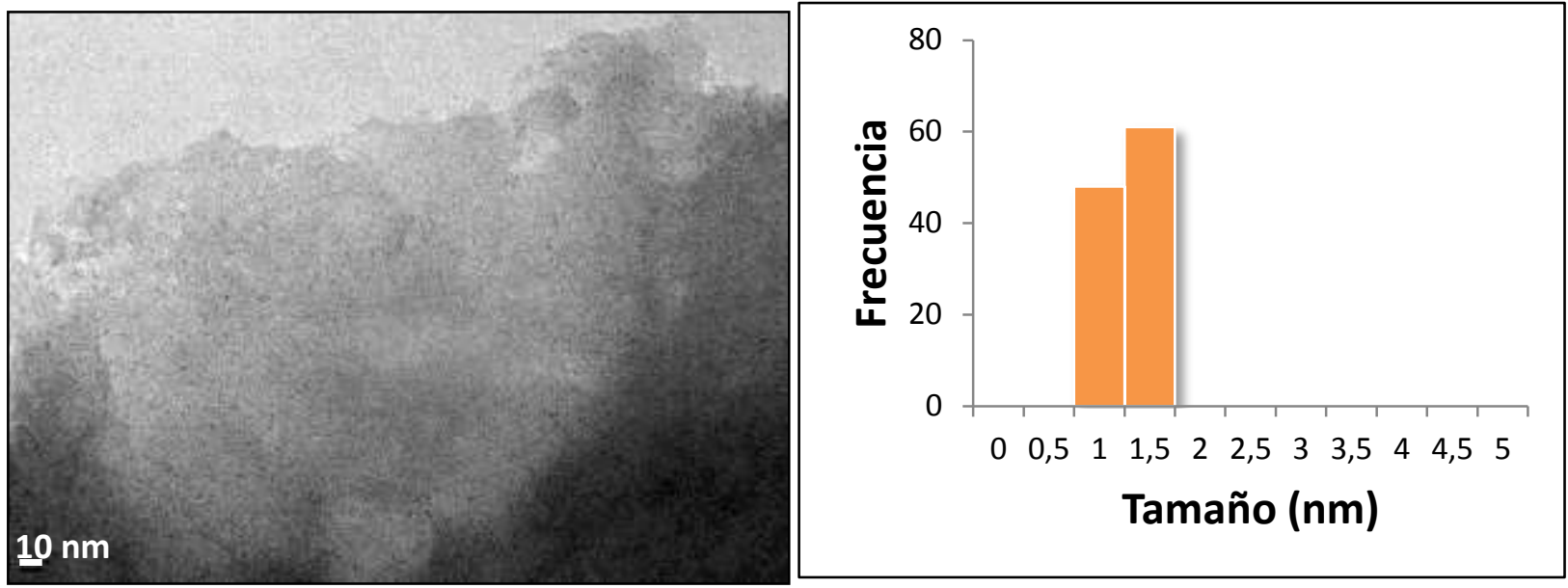

a) Ru/C
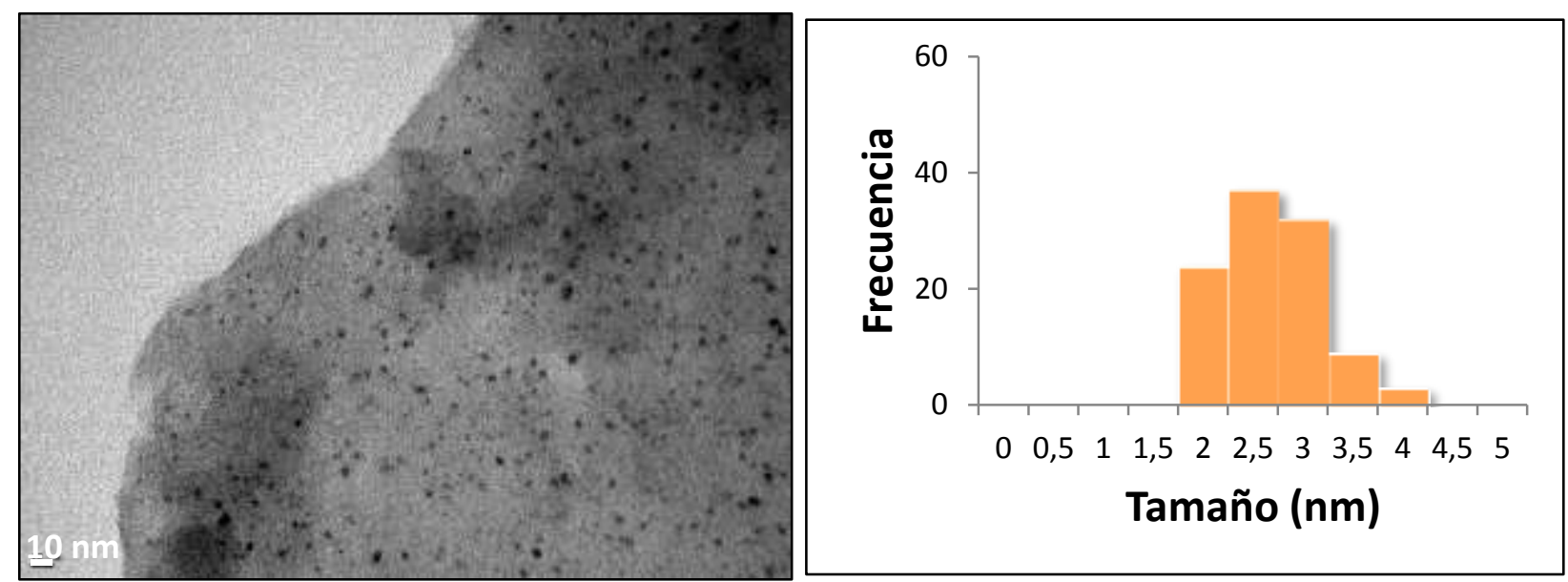

b) $\mathrm{RuSn}_{0.4} / \mathrm{C}$
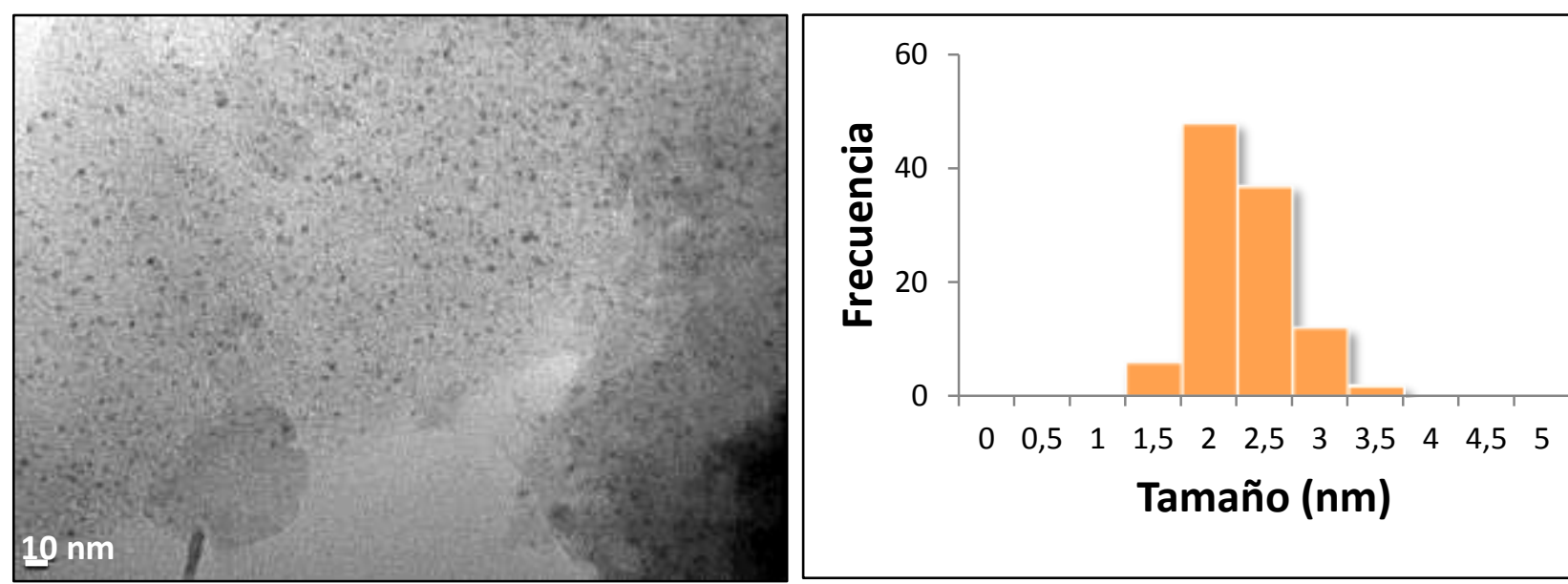

c) $\mathrm{RuSn}_{0.8} / \mathrm{C}$

Figura 4.6. Micrografías TEM (amplificación: 450000X) y distribución del tamaño de partícula de las especies $3 \%$ en peso de Ru. (a) Ru/C; (b) $R u S n_{0,4} / C$ y (c) $R u S n_{0,8} / C$. 


\subsection{3.- Reducción a temperatura programada}

Se realizaron experimentos de reducción programada por temperatura (TPR) en un equipo construido en nuestro laboratorio. Una muestra de $50 \mathrm{mg}$ fue colocada en un reactor de cuarzo de $6 \mathrm{~mm}$ de diámetro y purgada con $\operatorname{Ar}$ por 20 minutos a $20^{\circ} \mathrm{C}$ para eliminar las impurezas y el agua que pudiera estar contenida en el catalizador. A continuación, la muestra se calentó desde la temperatura ambiente hasta $700^{\circ} \mathrm{C}$ a una velocidad de calentamiento de $10^{\circ} \mathrm{C} /$ min con una mezcla reductora compuesta de $5 \%$ en volumen de Ar. Se utilizó un cromatógrafo de gases Shimadzu GC-8A equipado con un detector de conductividad térmica (TCD) para medir el consumo de hidrógeno. Las muestras se secaron a $105^{\circ} \mathrm{C}$ y luego se calcinaron a $500^{\circ} \mathrm{C}$ durante $2 \mathrm{~h}$ antes de someterse a análisis TPR.

Los perfiles de TPR de los catalizadores bimetálicos preparados y del soporte de carbón se muestran en la Figura 4.7. También se presenta el perfil del catalizador monometálico de $\mathrm{Ru} / \mathrm{C}$ a fines comparativos, aunque su análisis ya fue expuesto en el apartado correspondiente a la caracterización de los catalizadores monometálicos.

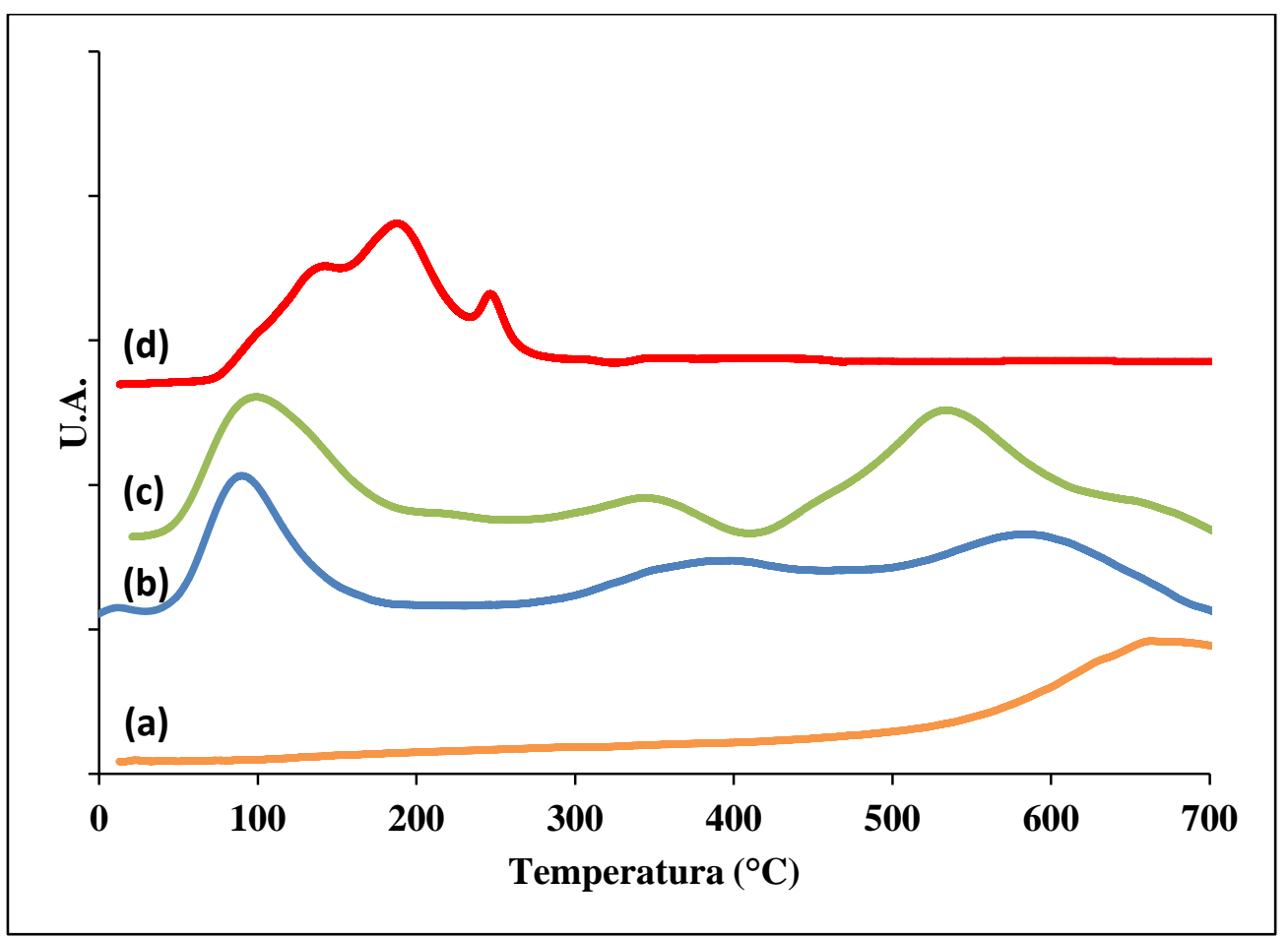

Figura 4.7. Perfiles de reducción programada a temperatura (TPR) para (a) soporte de carbono; (b) RuSn $0.4 / C$; (c) RuSn $0.8 / C$ y (d) Ru/C. 
Como se puede observar, en los catalizadores bimetálicos existe un cambio importante del pico de consumo de $\mathrm{H}_{2}$ asignado a la reducción de $\mathrm{Ru}^{+3}$ a $\mathrm{Ru}^{0}$ a temperaturas más bajas. Esta señal aparece en 90 y $100^{\circ} \mathrm{C}$ para RuSn 0.4 (curva (b)) y RuSn $_{0.8}$ (curva (c)), respectivamente. En el rango de temperatura entre 300 y $400^{\circ} \mathrm{C}$ aparece un amplio pico de $\mathrm{H}_{2}$, que podría asignarse a la reducción de Sn (II, IV).

Teniendo en cuenta que la reducción de los óxidos de estaño másicos ocurre a temperaturas superiores a $630^{\circ} \mathrm{C}$, este desplazamiento de la señal estaría indicando una fuerte interacción entre el rutenio y el estaño (Lieske H. y Völter J., 1984). Finalmente, el consumo de $\mathrm{H}_{2}$ a partir de $500^{\circ} \mathrm{C}$ puede estar asociado a la formación de metano a través de la reducción de carbono del soporte (Wettstein S.G. y col., 2012).

\subsection{4.- Espectroscopia fotoelectrónica de rayos $X$}

Los análisis XPS se realizaron en un sistema multitécnica (SPECS) equipado con una fuente de rayos $\mathrm{x}$ dual de $\mathrm{Mg} / \mathrm{Al}-\mathrm{K} \alpha$ y un analizador hemisférico de electrones PHOIBOS 150 que opera en modo de transmisión fija (FAT). Los espectros se obtuvieron con un flujo de energía de $30 \mathrm{eV}$ y un ánodo de $\mathrm{Mg}$ operado a $85 \mathrm{~W}$. La

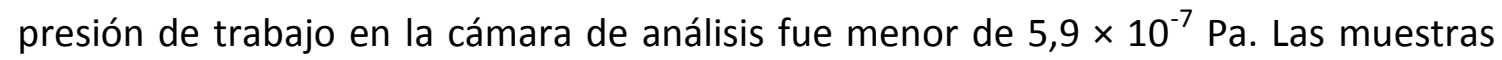
fueron soportadas sobre cinta de $\mathrm{Cu}$ de doble faz y evacuadas a ultra alto vacío durante al menos dos horas antes de la lectura. El tratamiento de datos se realizó con el programa Casa XPS (Casa Software Ltd., UK). Las áreas de los picos fueron determinadas por integración empleando un fondo de tipo Shirley, ajustando los picos experimentales con una distribución mezcla Gaussiana/Lorentziana de proporción variable.

Las energías de enlace (BE) de Ru3d, C1s, Sn3d y O1s para los catalizadores $\mathrm{Ru} / \mathrm{C}, \mathrm{RuSn}_{0.4}$ y $\mathrm{RuSn}_{0.8}$ se presentan en la Tabla 4.4. 
Tabla 4.4. Energías de enlace (BE) determinadas por XPS sobre los catalizadores Ru/C, $\mathrm{RuSn}_{0.4} /$ C y $\mathrm{RuSn}_{0.8} /$ C medidos por XPS.

\begin{tabular}{lllll}
\hline Catalizador & BE $(\mathrm{eV})$ & & & \\
\hline & Ru3d5/2 & C1s & Sn3d5/2 & 01s \\
\hline $\mathrm{Ru} / \mathrm{C}$ & 280.5 & 284.8 & - & 532.2 \\
\hline $\mathrm{RuSn} \mathbf{0 . 4} / \mathrm{C}$ & 279.4 & 284.8 & $485.5(20.8 \%)$ & \\
& & & $486.9(79.2 \%)$ & 532.3 \\
& & & $485.4(29.9 \%)$ & \\
RuSn $_{0.8} / \mathrm{C}$ & 279.6 & 284.7 & $486.8(70.1 \%)$ & 532.4 \\
\hline
\end{tabular}

Los valores de $B E$ de $R u 3 d_{5 / 2}$ registrados para los catalizadores reducidos fueron atribuido a la presencia de Ru principalmente en forma metálica, aunque el desplazamiento hacia menores valores de su BE en los catalizadores bimetálicos en comparación con $\mathrm{Ru} / \mathrm{C}(280,5 \mathrm{eV})$ es indicativo de la existencia de un efecto electrónico de estaño sobre el rutenio. Estos resultados van en la misma dirección que los informados para catalizadores de platino promovidos con estaño preparado por técnicas de QOMS/M (Siri G.J. y col., 2005). En cuanto al estado de oxidación del estaño, el pico de Sn $3 d_{5 / 2}$ obtenido por XPS contiene dos contribuciones (Figura 4.8). La primera con una energía de enlace de alrededor de 485 eV se asigna a Sn (0) Rodriguez J.A. y col., 1998); la segunda contribución corresponde a Sn (II, IV), con una energía de enlace centrada alrededor de $487 \mathrm{eV}$ (Wagner C.D., 1989). La fracción de estaño metálico es de $20,8 \%$ y $29,9 \%$ para $\mathrm{RuSn}_{0.4}$ y $\mathrm{RuSn}_{0.8}$, respectivamente. La existencia de fases RuSn bimetálico (Incluso aleaciones) se podría deducir de la presencia de estaño metálico en los catalizadores bimetálicos. 

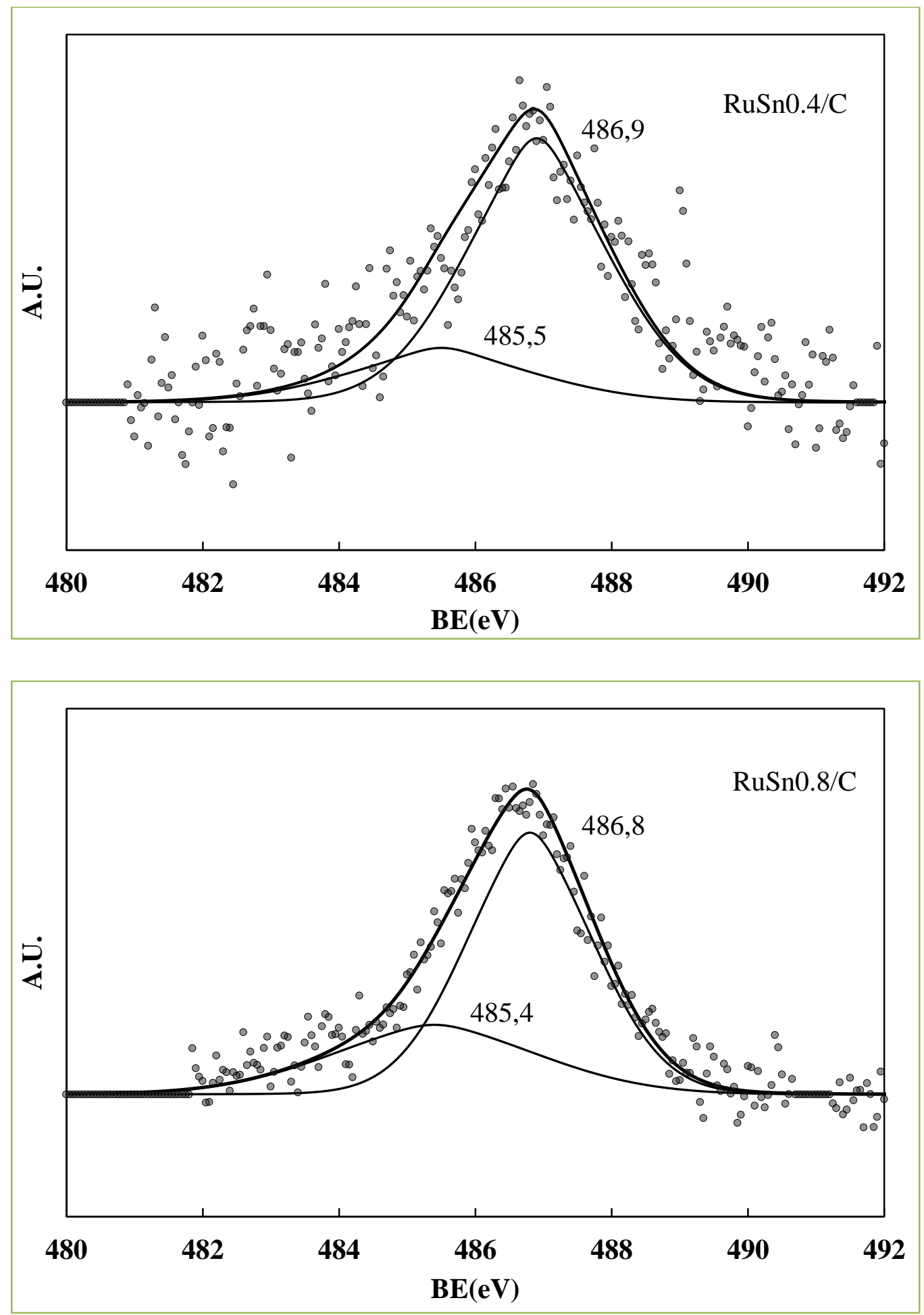

Figura 4.8. Espectros XPS del Sn $3 d_{5 / 2}$ para catalizadores bimetálicos $R u S n_{0.4} / C$ y $R u S n_{0.8} / C$. 


\section{5.- Hidrogenación de trans-2-pentenal como test catalítico}

\subsection{1.- Introducción}

Existen varios tipos de grupos funcionales que son reducidos durante la hidrogenación en fase acuosa de biomasa, entre ellos $\mathrm{C}=\mathrm{O}, \mathrm{C}=\mathrm{C}, \mathrm{C}-\mathrm{O}-\mathrm{C}$ y grupos ácidos carboxílicos. Las moléculas también pueden tener otros grupos funcionales, tales como anillos furánicos, grupos hidroxilos, etc. que afectarán la velocidad de hidrogenación. Por tal motivo, resulta interesante estudiar el efecto de la estructura del sustrato sobre la velocidad de reacción, con diferentes sistemas catalíticos. A su vez, esto sirve para dar una idea de la arquitectura del sitio catalítico (Lee J., Xu Y. y Huber G.W., 2013).

La hidrogenación de trans-2-pentenal es una reacción de importancia tanto desde el punto de vista comercial como por las posibilidades de investigación que brinda, ya que tiene las mismas funcionalidades que están presentes en las fracciones acuosas de materias primas derivadas de la biomasa, como los bioaceites producidos por pirólisis y soluciones provenientes de la hidrólisis de celulosa (Aramendía M. A. y col., 2003).

El trans-2-pentenal es un aldehído con dos grupos funcionales reactivos, un enlace $\mathrm{C}=\mathrm{C}$ y un carbonilo, por lo cual es materia prima potencial para combustibles $\mathrm{y}$ productos químicos finos. En la Figura 4.9 se muestran las posibles rutas de hidrogenación de este compuesto.

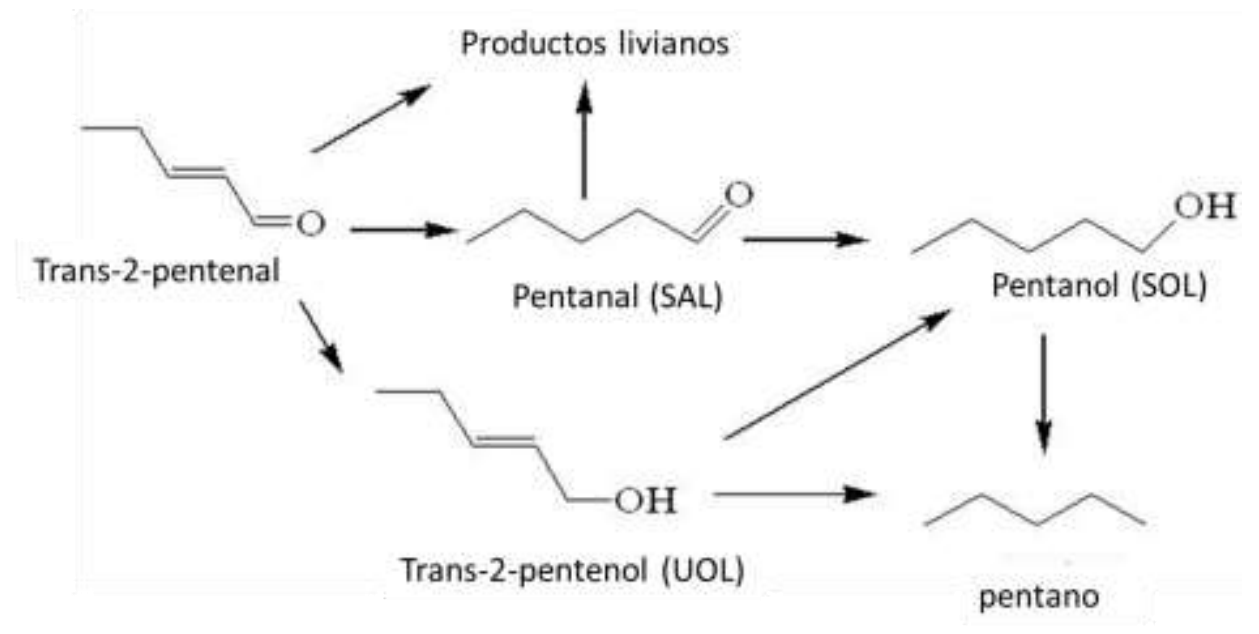

Figura 4.9. Productos de hidrogenación del trans-2-pentenal 


\subsection{2.- Ensayo experimental}

La reacción de hidrogenación de trans-2-pentenal (UAL) en fase líquida fue realizada en un reactor tipo autoclave (Autoclave Engineers) a 1,25 MPa de presión de $\mathrm{H}_{2}, 90^{\circ} \mathrm{C}$ y empleando $0,25 \mathrm{~g}$ de catalizador. En cada ensayo se utilizaron $0,5 \mathrm{~cm}^{3} \mathrm{de}$ reactivo y $50 \mathrm{~cm}^{3}$ de agua como solvente $(0,1 \mathrm{~mol} / \mathrm{L})$.

La evolución de la reacción fue seguida tomando una serie de muestras, que fueron analizadas por cromatografía gaseosa en un cromatógrafo Varian CP-3800 provisto de una columna capilar CP Wax 52 CB (30 m; 0,3 mm d.i.) y un detector FID. Los productos de reacción fueron identificados utilizando un equipo GC/MS. Los resultados se analizaron en términos de conversión de trans-2-pentenal, selectividad a los diferentes productos y velocidad inicial de reacción.

Como puede verse en la Figura 4.9, la hidrogenación puede llevarse a cabo en el doble enlace $\mathrm{C}=\mathrm{C}(\mathrm{SAL})$, en el grupo carbonilo $\mathrm{C}=\mathrm{O}(\mathrm{UOL})$ o en ambos $(\mathrm{SOL})$ e incluso hidrogenarse completamente a pentano. También pueden ocurrir reacciones de hidrogenólisis dando otros productos livianos.

En la Figura 4.10 se presentan los datos de conversión de trans-2 pentenal en función del tiempo para los catalizadores ensayados, $R u / C, R u / Z, R u / A, R u / Z-A$ y $\mathrm{Ru} / \mathrm{ZP}-\mathrm{A}$; todos ellos con un contenido de Ru de $3 \% \mathrm{p} / \mathrm{p}$.

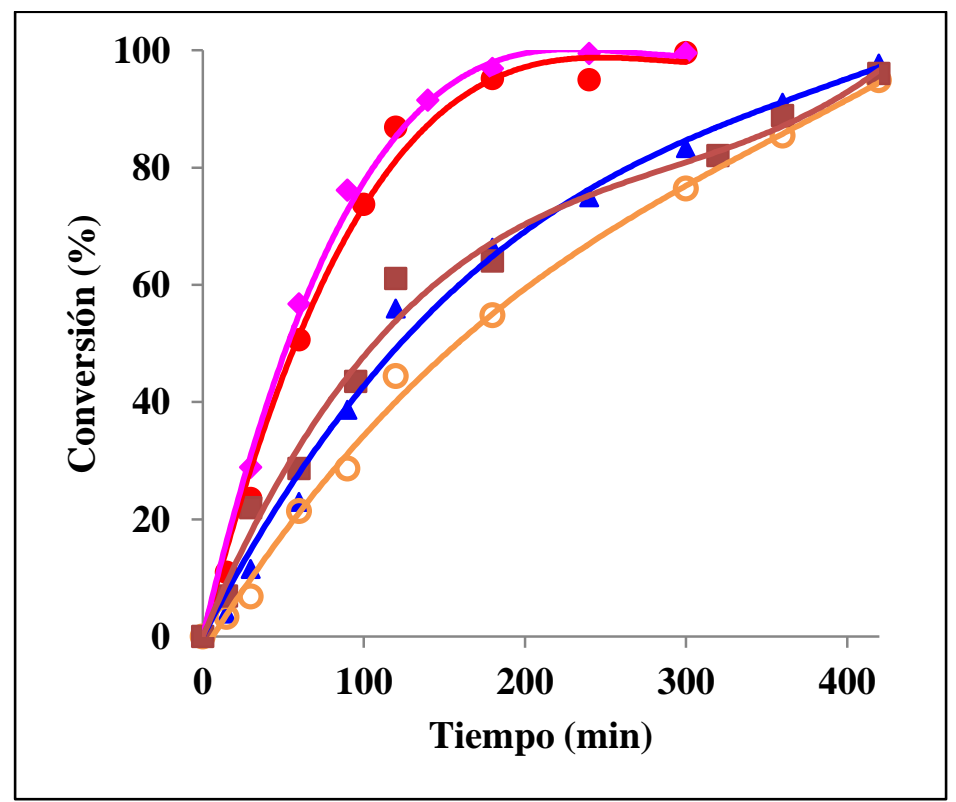

Figura 4.10. Hidrogenación de trans-2-pentenal $(\bullet)$ Ru/C, (४)Ru/ZP-A, ( $\Delta$ ) Ru/Z-A, ( $($ ) Ru/A y (○) Ru/Z. 
Tabla 4.5. Velocidades de reacción y selectividades obtenidas en la hidrogenación de trans-2pentenal.

\begin{tabular}{|c|c|c|c|c|c|c|c|c|}
\hline \multirow{2}{*}{ Catalizador } & \multirow{2}{*}{ Conversión } & \multirow{2}{*}{$r_{i}^{*}$} & \multirow{2}{*}{$\begin{array}{l}d_{\text {TEM }} \\
(n m)\end{array}$} & \multirow{2}{*}{$\operatorname{TOF}\left(h^{-1}\right)$} & \multicolumn{4}{|c|}{ Selectividad (\%) ** } \\
\hline & & & & & UOL & SAL & SOL & Otros \\
\hline $\mathrm{Ru} / \mathrm{C}$ & 100 & 6,6 & 1,12 & 49 & 2 & 49 & 49 & 0 \\
\hline Ru/ZP-A & 100 & 6,7 & 3,08 & 135 & 1 & 51 & 47,7 & 0,16 \\
\hline $\mathrm{Ru} / \mathrm{A}$ & 96 & 3,9 & 2,85 & 73 & 4 & 65 & 30 & 0,6 \\
\hline $\mathrm{Ru} / \mathrm{Z}-\mathrm{A}$ & 98 & 3,1 & 1,42 & 29 & 4 & 69 & 26,5 & 0,4 \\
\hline $\mathrm{Ru} / \mathrm{Z}$ & 95 & 2,4 & ----- & ---- & 4 & 55 & 40,3 & 0,6 \\
\hline
\end{tabular}

${ }^{*} \mathrm{r}_{\mathrm{i}}: \mathrm{mmoles}_{\mathrm{conv}} \cdot \mathrm{g}_{\mathrm{Ru}}{ }^{-1} \mathrm{~min}^{-1}$ (velocidades iniciales calculadas para un $10 \%$ de conversión)

** Selectividades obtenidas para 420 min de reacción.

UOL: alcohol insaturado (pentenol), SAL: aldehído saturado (pentanal), SOL: alcohol saturado (pentanol).

Si la actividad catalítica de los sistemas estudiados fuese dada únicamente por el área geométrica superficial del rutenio, independientemente del número de coordinación de los átomos superficiales o de la estructura electrónica de la superficie catalítica, las velocidades iniciales de hidrogenación $\left(r_{i}\right)$ disminuirían marcadamente al aumentar el tamaño de las partículas metálicas. Es decir, se esperaría que el orden creciente de actividad observado hubiera sido: Ru/ZP-A $<\mathrm{Ru} / \mathrm{A}<\mathrm{Ru} / \mathrm{Z}-\mathrm{A}<\mathrm{Ru} / \mathrm{C}$, exhibiendo una proporcionalidad inversa de $r_{i}$ con el diámetro de partícula (ver Tabla 4.5.). Esta insensibilidad a la estructura hubiera resultado en un TOF invariante frente al cambio en el tamaño de partícula y de soporte. En lugar de esto, el TOF aumentó de 29 a $135 \mathrm{~h}^{-1}$ con un aumento del tamaño de las partículas de Ru en el estrecho rango de 1.12 a $3.08 \mathrm{~nm}$ y el orden creciente de actividad para los catalizadores ensayados fue el siguiente: $\mathrm{Ru} / \mathrm{Z}-\mathrm{A}<\mathrm{Ru} / \mathrm{A}<\mathrm{Ru} / \mathrm{C}<\mathrm{Ru} / \mathrm{ZP}-\mathrm{A}$. En consecuencia, es posible concluir que la actividad de los diversos catalizadores de Ru ensayados depende no solamente de la dispersión de la fase metálica, si no también de las características del soporte, siendo que la combinación óptima entre tamaño de partículas y naturaleza del soporte se da para el sistema Ru/ZP-A. Como se mencionó al analizar el soporte ZP-A, éste posee un área superficial considerable y resultó amorfo desde el punto de vista de la difracción de Rayos $X$, características que favorecen la dispersión de la fase metálica. Además, las características polares de la zirconia fosfatada ayudan al incremento de la 
velocidad de hidrogenación del trans-2-pentenal, a través de la reorientación de la molécula.

En cuanto a la selectividad obtenida en la hidrogenación de trans-2 pentenal, se observa que el producto mayoritario es en todos los casos el aldehído saturado (pentanal, SAL), junto con una gran cantidad de SOL. Este resultado es consistente con lo que tradicionalmente propone la bibliografía (Delbecq F. y Sautet P., 1995), en cuanto a que sobre partículas metálicas pequeñas (menores a $4 \mathrm{~nm}$ ) se favorecen los modos de adsorción conducentes a la hidrogenación del doble enlace $\mathrm{C}=\mathrm{C}$, tal como se muestra en la figura 4.11, presentada a continuación:<smiles>[M]C([B])C([R])([R])C([R])C=O</smiles>
di $-\sigma_{\mathrm{CC}} \eta_{2} 11$<smiles>[R]C([R])[C@@H]([CH])C([2H])[2H]</smiles>

$\pi_{\mathrm{CC}} \eta_{2} 12$<smiles>[R]C(P)[CH]C1OCC1[M]</smiles>

$\eta_{4}$ or di $-\pi \eta_{2} 13$

Figura 4.11. Modos de adsorción de enlace $C=C$ sobre el catalizador

La figura 4.12 muestra los gráficos de composición obtenidos de las reacciones de hidrogenación de trans-2-pentenal con los catalizadores monometálicos evaluados. En los casos del Ru/C y Ru/ZP-A, que son los catalizadores con los que se obtuvo la mayor velocidad inicial de reacción se observa claramente como el pentenal (SAL) inicialmente formado es consumido luego para formar pentanol (SOL) (curvas (a) y (b), respectivamente). 

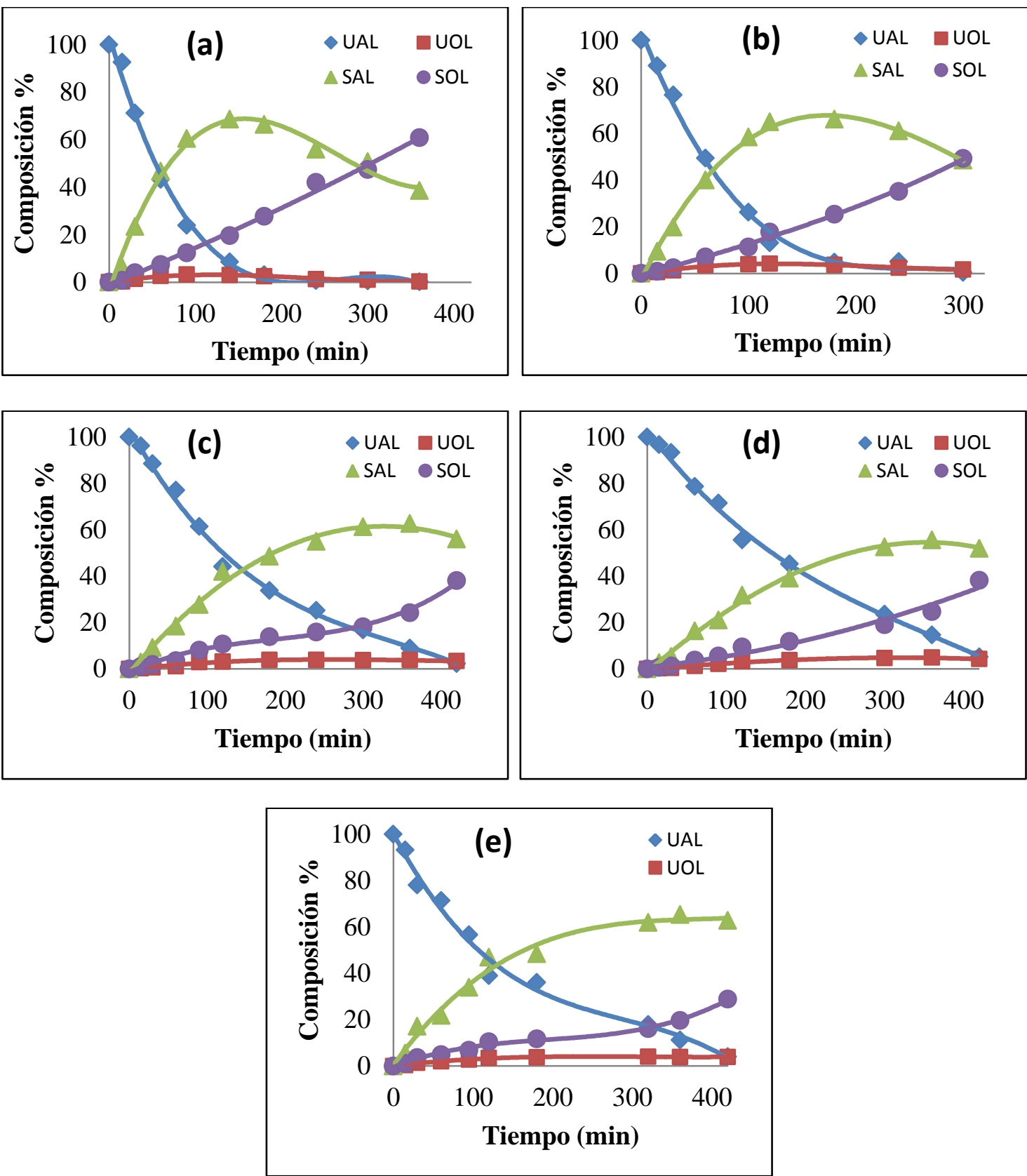

Figura 4.12. Composición de productos de reacción de hidrogenación de trans-2-pentenal. (a) Ru/ZP-A, (b) Ru/C, (c) Ru/Z-A, (d) Ru/Z y (e) Ru/A.

Como mencionamos al comienzo, los sistemas bimetálicos se utilizaron - serán utilizados en la hidrogenación de trans-2-pentenal con el objetivo de obtener alguna información relevante sobre el efecto del segundo metal (Sn) sobre el catalizador de $\mathrm{Ru} / \mathrm{C}$ que pueda ser luego utilizada para explicar el comportamiento de estos sistemas en la hidrogenación de furfural.

En la Figura 4.13 se reporta el porcentaje de conversión obtenido en función del tiempo de reacción y se puede ver claramente que hay una influencia del Sn sobre 
la actividad del catalizador monometálico de base. El orden de actividad, expresado a través de la velocidad inicial de reacción es: $\mathrm{RuSn}_{0.1}>\mathrm{RuSn}_{0.8}>\mathrm{RuSn_{0.4 }} \approx \mathrm{Ru} / \mathrm{C}$.

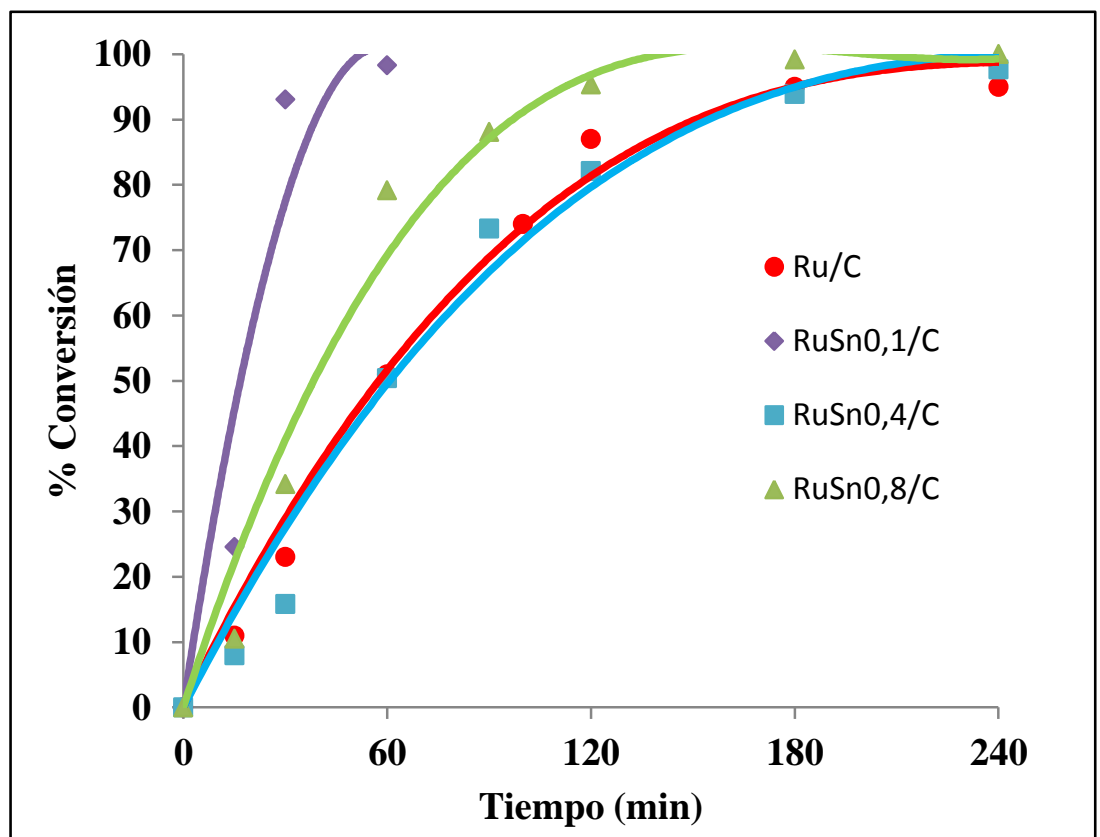

Figura 4.13. Hidrogenación de trans-2-pentenal con catalizadores bimetálicos. (•) Ru/C, (४)

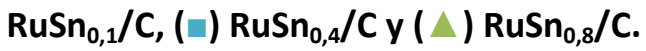

Los estudios XPS realizados sobre los sistemas $\mathrm{RuSn}_{0,8}$ y $\mathrm{RuSn}_{0,4}$, revelaron que en estos catalizadores bimetálicos existe una convergencia entre efectos geométricos (dilución de los sitios activos de Ru) y electrónicos, debido a la presencia de Sn, que modifica las características del metal de base. Los espectros de XPS del Sn 3d para dichos catalizadores, presentaron dos bandas, una que fue atribuida al Sn (0), y otra a una mayor energía de enlace que se atribuye al estaño oxidado (Sn (II) y Sn (IV)). La fracción de estaño reducido encontrada fue de aproximadamente $30 \%$, el cual podría estar aleado con el Ru, siendo uno de los orígenes de la modificación del metal de base entre otras cosas, provocando la "aislación del sitio activo". Por otro lado, el estaño en estado iónico, probablemente se encuentre en la interfase metal-soporte, actuando como sitios ácidos de Lewis promoviendo el ataque del hidrógeno al grupo carbonilo de la molécula de trans-2-pentenal.

Si analizamos la actividad de los catalizadores en función de la relación Sn/Ru, puede observarse que existe un compromiso entre la dilución de sitios de Ru, activos para la hidrogenación, y el efecto promotor del estaño iónico. 
En la Figura 4.13 se observa la variación en la composición del trans-2-pentenal y sus productos de reacción y en la Tabla 4.6 se reporta la selectividad para esos mismos productos de hidrogenación para un valor de conversión de 50\%. Como puede observarse a partir de los datos obtenidos, si bien el agregado de una muy pequeña cantidad de estaño $\left(\mathrm{RuSn}_{0,1} / \mathrm{C}\right)$ fue responsable de un importante aumento en la velocidad de hidrogenación, no se obtuvo una mejora apreciable en lo que respecta a la selectividad hacia el producto de hidrogenación del enlace $C=0$. Por otra parte, los sistemas $\mathrm{RuSn}_{0,4}$ y $\mathrm{RuSn}_{0,8}$ mostraron una selectividad hacia el alcohol insaturado de alrededor del $20 \%$.

Respecto a la selectividad obtenida en la hidrogenación de trans- 2 pentenal con los catalizadores bimetálicos, se observa en todos los casos una mejoría hacia la obtención de UOL. Esto indica que la interacción del sustrato con el catalizadores está influenciado por la presencia de Sn, favoreciendo su aproximación a la superficie metálica a través del enlace $\mathrm{C}=\mathrm{O}$, lo cual favorece el contacto del mismo con el hidrógeno adsorbido y conduce preferentemente a la formación del alcohol insaturado. Este comportamiento se acentúa a medida que aumenta la cantidad de Sn presente, como puede observarse en la Tabla 4.6.

Tabla 4.6. Velocidades de reacción y selectividades obtenidas en la hidrogenación de trans-2pentenal con catalizadores bimetálicos.

\begin{tabular}{cc|cccc|ccccc}
\hline \multirow{2}{*}{ Catalizador } & & \multicolumn{4}{c}{ Selectividad (\%) ** } & \multicolumn{4}{c}{ Selectividad (\%) *** } \\
\cline { 3 - 10 } & & UOL & SAL & SOL & Otros & UOL & SAL & SOL & Otros \\
\hline R/C & 6.6 & 7 & 79 & 14 & 0 & 2 & 49 & 49 & 0 \\
\hline RuSn $_{0,1} / C$ & 21,4 & 10 & 72 & 18 & 0 & 7 & 62 & 31 & 0 \\
\hline RuSn $_{0,4} / C$ & 6,3 & 16 & 69 & 15 & 0 & 20 & 53 & 27 & 0 \\
\hline RuSn $_{0,8} / \mathrm{C}$ & 10 & 19 & 60 & 21 & 0 & 20 & 47 & 33 & 0 \\
\hline
\end{tabular}

${ }^{*} r_{\mathrm{i}}$ : $\mathrm{mmoles}_{\mathrm{conv}} \cdot \mathrm{g}_{\mathrm{Ru}}{ }^{-1} \mathrm{~min}^{-1}$ (velocidades iniciales calculadas para un $10 \%$ de conversión)

** Selectividades obtenidas para $50 \%$ de conversión

*** Máxima selectividad a UOL (Valor de la conversión en el máximo: $\mathrm{Sn}_{0,8}-80 \% ; \mathrm{Sn}_{0,4}-73 \%$; $\left.\mathrm{Sn}_{0,1}-93 \%\right)$

UOL: alcohol insaturado (pentenol), SAL: aldehído saturado (pentanal), SOL: alcohol saturado (pentanol). 
La Figura 4.14 muestra los gráficos de composición obtenidos de las reacciones de hidrogenación de trans-2-pentenal con los catalizadores bimetálicos evaluados.
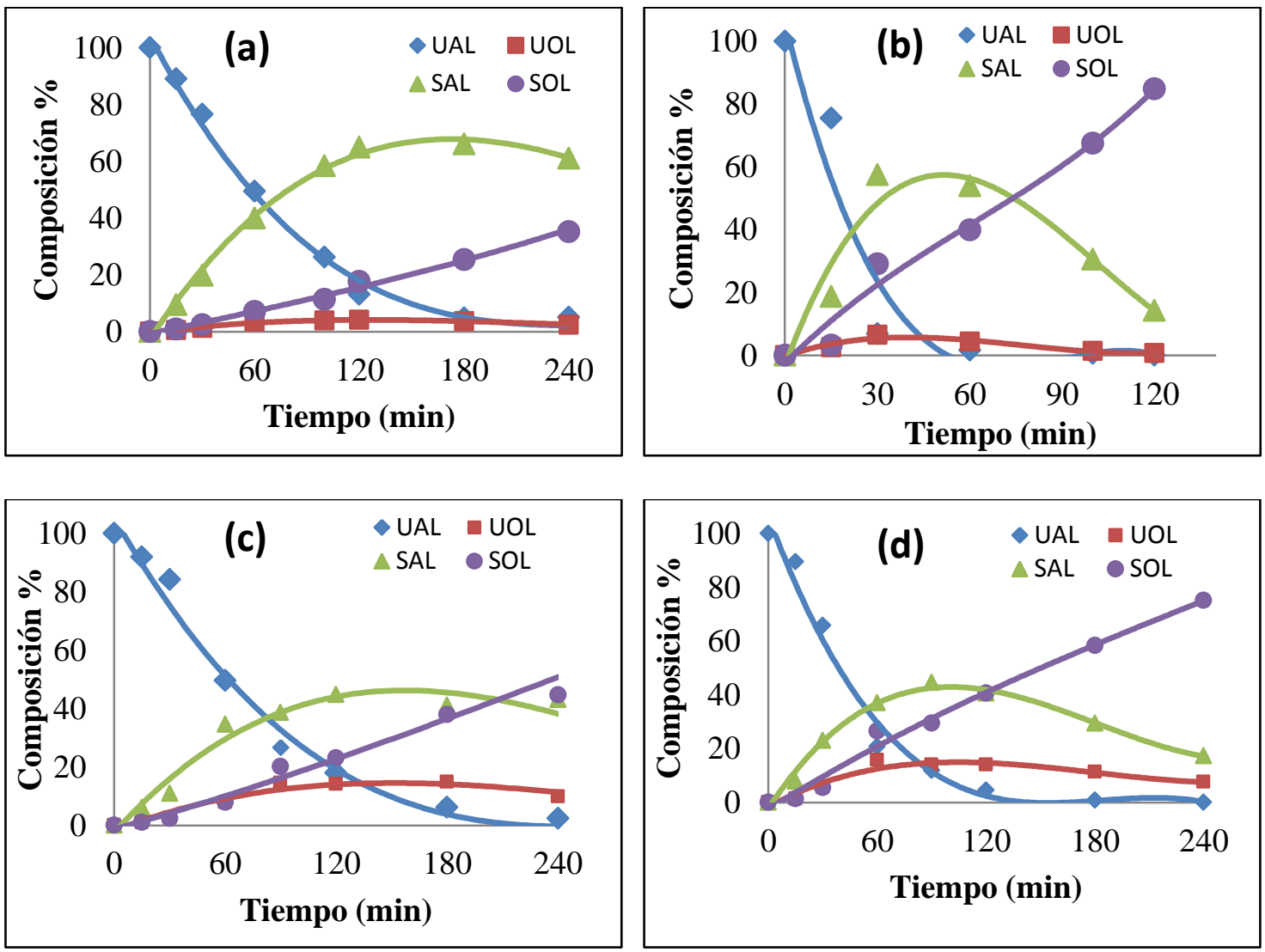

Figura 4.14. Composición de productos de reacción de hidrogenación de trans-2-pentenal. (a) $\mathrm{Ru} / \mathrm{C}$, (b) RuSn $n_{0,1} / \mathrm{C}$, (c) $\mathrm{RuSn}_{0,4} / \mathrm{C}$ y (d) $\mathrm{RuSn}_{0,8} / \mathrm{C}$. 


\section{6.- Conclusiones}

Se preparó una familia de catalizadores de Ru soportados en carbón activado comercial variando la proporción de Ru desde 0,5\% hasta 3\% en peso por el método de impregnación con exceso de solución, empleando acetona como solvente.

Se prepararon también catalizadores de $\mathrm{Ru}$ soportados sobre $\gamma-\mathrm{Al}_{2} \mathrm{O}_{3}$ (A) comercial y sobre los demás soportes sintetizados y descriptos en el capítulo 3: $\mathrm{ZrO}_{2}$ (Z), $\mathrm{ZrO}_{2}-\mathrm{PO}_{4}^{-3}(\mathrm{ZP}), \mathrm{ZrO}_{2}(15 \%) / \gamma-\mathrm{Al}_{2} \mathrm{O}_{3}(\mathrm{Z}-\mathrm{A})$, y $\mathrm{ZrO}_{2}(15 \%)-\mathrm{PO}_{4}^{-3} / \gamma-\mathrm{Al}_{2} \mathrm{O}_{3}(\mathrm{ZP}-\mathrm{A})$, también por el método de impregnación con exceso de solución, empleando agua como solvente.

Se prepararon catalizadores de Ru bimetálicos, mediante el agregado de Sn con técnicas QOMS/M sobre el catalizador de Ru/C, por ser el más activo entre los catalizadores monometálicos. Los sistemas bimetálicos así obtenidos se designaron $\mathrm{RuSn}_{\mathrm{y}} / \mathrm{C}$, donde los valores de y $(0,1 ; 0,4$ y 0,8$)$ representa la relación molar $\mathrm{Sn} / \mathrm{Ru}$ nominal.

Se determinó el tamaño de partículas de los catalizadores mediante microscopía electrónica de transmisión (TEM). Los soportes con mayor área superficial presentan mayores valores de dispersión del metal depositado y menores tamaños de partícula. En todos los casos se obtuvieron nanopartículas (1,12 - 5,70 nm). Después de la adición de $\mathrm{Sn}$, el tamaño medio de partícula aumentó a $2,7 \mathrm{~nm}$ y $2.2 \mathrm{~nm}$ para los catalizadores $\mathrm{RuSn}_{0.4} / \mathrm{C}$ y $\mathrm{RuSn}_{0.8} / \mathrm{C}$, respectivamente. Este aumento en el tamaño de partícula se puede asignar en parte al depósito selectivo de estaño sobre rutenio y no sobre el soporte.

Se efectuaron estudios de TPR a los catalizadores preparados. Por encima de los $250^{\circ}$ el Ru se reduce de $\mathrm{Ru}^{+3}$ a Ru${ }^{0}$ en todos los sistemas. Respecto a los perfiles de los catalizadores bimetálicos, se observa un desplazamiento de los picos de reducción que estaría indicando una fuerte interacción entre el rutenio y el estaño.

Mediante estudios de XPS realizados a los catalizadores bimetálicos reducidos se determinó la presencia de Ru principalmente en forma metálica, aunque el desplazamiento hacia menores valores de su BE en los catalizadores bimetálicos en comparación con $\mathrm{Ru} / \mathrm{C}(280,5 \mathrm{eV})$ es indicativo de la existencia de un efecto 
electrónico de estaño sobre el rutenio. En cuanto al estado de oxidación del estaño, el pico de $S n 3 d_{5 / 2}$ obtenido por XPS contiene dos contribuciones, una asignable a Sn (0) y otra a Sn (II, IV). La fracción de estaño metálico es de $20,8 \%$ y $29,9 \%$ para RuSn 0.4 y RuSn $_{0.8}$, respectivamente. La existencia de fases RuSn bimetálico (Incluso aleaciones) se podría deducir a partir de esto último.

Se estudió la reacción de hidrogenación de trans-2-pentenal (UAL) en fase líquida en un reactor tipo autoclave (Autoclave Engineers) a 1,25 MPa de presión de $\mathrm{H}_{2}, 90^{\circ} \mathrm{C}$. El orden creciente de actividad para los catalizadores monometálicos ensayados fue el siguiente: Ru/Z-A $<\mathrm{Ru} / \mathrm{A}<\mathrm{Ru} / \mathrm{C}<\mathrm{Ru} / \mathrm{ZP}-\mathrm{A}$. Es posible concluir que la actividad de los diversos catalizadores de Ru ensayados depende no solamente de la dispersión de la fase metálica, si no también de las características del soporte. La combinación óptima entre estas características se da para el sistema Ru/ZP-A. En cuanto a la selectividad obtenida, se observa que el producto mayoritario es en todos los casos el aldehído saturado (pentanal, SAL).

En los ensayos de hidrogenación de trans-2-pentenal con catalizadores bimetálicos el orden de actividad observado, expresado a través de la velocidad inicial de reacción es: $\mathrm{RuSn}_{0.1}>\mathrm{RuSn}_{0.8}>\mathrm{RuSn}_{0.4} \approx \mathrm{Ru} / \mathrm{C}$. Respecto a la selectividad obtenida con los catalizadores bimetálicos, se observa una mejoría hacia la obtención de UOL. Esto indica que la interacción del sustrato con el catalizadores está influenciado por la presencia de Sn, favoreciendo su aproximación a la superficie metálica a través del enlace $\mathrm{C}=\mathrm{O}$, lo cual favorece el contacto del mismo con el hidrógeno adsorbido. 


\section{CAPÍTULO 5}

\section{ESTUDIO DE CONDICIONES DE REACCIÓN}


En este apartado se determinan las condiciones bajo las cuales se realizaron los ensayos experimentales en lo concerniente a los fenómenos de transferencia de materia para conocer la existencia o no de controles difusionales en los resultados. 


\section{1.- Etapas controlantes de las reacciones de hidrogenación}

Para las reacciones de hidrogenación en fase líquida, los procesos de transferencia de masa pueden afectar la velocidad de reacción y deben estar ausentes para garantizar que la reacción esté gobernada por parámetros cinéticos y no de transferencia de masa; esto es que la velocidad de los procesos físicos sea mayor que la velocidad de las reacciones químicas.

En el caso de sistemas catalíticos trifásicos (Ramachandran P. y Chaudhari R., 1983; Gallezot P. y Richard D.; 1998; Neri G. y col 1997), los procesos de transporte de los reactivos desde la fase en que se alimentan al reactor hasta el contacto con el catalizador donde reaccionan y luego los pasos inversos seguidos por los productos son los siguientes:

- Transferencia de masa gas/líquido;

- Difusión de los reactivos y de los productos en la fase líquida hacia y desde la partícula de catalizador (difusión externa);

Difusión de reactivos y productos en el interior de los poros del catalizador (difusión interna).

\section{2.- Características de las reacciones en catálisis heterogénea}

Para que un reactivo gaseoso pueda ser convertido catalíticamente en productos en un sistema trifásico, en general debe ocurrir una secuencia dada. En primer lugar es necesario que el mismo sea transferido desde la fase gaseosa a la fase líquida y luego a la interfase catalítica. Una vez alcanzado el sitio activo puede adsorberse sobre el mismo o reaccionar con otro de los reactivos adsorbidos (reacciones del tipo Eley-Rideal). El producto debe luego ser desorbido y transferido desde la interfase a la fase líquida.

Las etapas de transporte pueden clasificarse de la siguiente manera, considerando un catalizador de estructura porosa:

1. Disolución del reactivo gaseoso en el medio líquido.

2. Difusión de los reactivos disueltos hacia la partícula de catalizador (difusión externa); 
3. Difusión de los reactivos en los poros del catalizador (difusión interna);

4. Adsorción de los reactivos en la superficie del catalizador;

5. Reacción química en la superficie activa del catalizador;

6. Desorción de los productos;

7. Difusión de los productos al exterior de la partícula de catalizador;

8. Difusión de los productos desde la partícula a la corriente líquida.

Las etapas de difusión son procesos físicos, mientras las demás son químicas.

\section{3.- Limitaciones difusionales}

Para identificar la existencia de limitaciones difusionales se pueden utilizar criterios experimentales o criterios analíticos. En el primer caso, se estudia la variación de la velocidad de reacción o algún parámetro directamente relacionado con la misma con respecto a parámetros experimentales, como la velocidad de agitación. En el segundo caso, se compara la velocidad de reacción con las velocidades máximas de transporte en las etapas físicas, mediante el cálculo de coeficientes de transferencia y difusividades.

\subsection{1.- Criterios analíticos}

Cuando se emplean criterios analíticos se compara la velocidad inicial de reacción con las velocidades máximas de transporte en las etapas físicas. En el caso de reacciones de hidrogenación en fase líquida se evalúa la difusión de reactivos y/o productos en la interfase gas/líquido, en la interfase líquido/sólido y en el interior de la partícula. A continuación se presentan las expresiones utilizadas para el cálculo de los diferentes coeficientes.

\subsubsection{1.- Limitaciones difusionales en la interfase gas/líquido}

Para asegurarse de que no exista resistencia al transporte de $\mathrm{H}_{2}$, el reactivo gaseoso, 
en la interfase gas/líquido se debe cumplir la siguiente relación:

Donde:

$$
\propto_{1}=\frac{\left(r_{i}\right)_{o b s}}{k_{L} \cdot a_{G} \cdot C_{H 2}} \leq 0,1
$$

$\left(r_{i}\right)_{\text {obs }}:$ velocidad inicial de reacción obtenida experimentalmente;

$k_{L}$ : coeficiente de transferencia de materia en la interfase gas-líquido;

$a_{G}:$ área interfacial por unidad de volumen del reactor;

$C_{\mathrm{H}_{2}}$ : concentración de $\mathrm{H}_{2}$ en la fase líquida calculada con la ecuación de Henry:

$$
C_{H_{2}}=H_{H_{2}} \cdot P_{H_{2}}
$$

$P_{H_{2}}$ : presión parcial de hidrógeno en la fase gas $(13,3 \mathrm{~atm})$

$H_{H_{2}}$ : constante de Henry para el $\mathrm{H}_{2}$ calculada mediante la siguiente expresión (Sander R., 1999):

$$
H_{H_{2}}=H_{H_{2}}^{\theta} \cdot \exp \left(\frac{-\Delta H}{R}\left(\frac{1}{T}-\frac{1}{T^{\theta}}\right)\right)
$$

$\operatorname{con} H_{H_{2}}^{\theta}=7,80 \times 10^{-4} \mathrm{~mol} / \mathrm{L}$ atm a $298,15 \mathrm{~K} ; \frac{-\Delta H}{R}=500 \mathrm{~K} \mathrm{y} T^{\theta}=298,15 \mathrm{~K}$

El criterio establece que si la velocidad de reacción observada es menor al 10\% del valor de la máxima velocidad de transferencia de materia gas/líquido, entonces el proceso de transporte es mucho más rápido que la reacción química observada, no limitando así el proceso global.

Para el cálculo del coeficiente $k_{L} \cdot a_{G}$ pueden utilizarse diversas correlaciones determinadas por varios autores. Una de ellas es la propuesta por Meille y col. (Meille V., 2004) quienes estudiaron la determinación del coeficiente $k_{L}$. $a_{G}$ en reactores tanque de laboratorio, agitados magnéticamente y sin empleo de bafles deflectores, cuyos volúmenes estaban comprendidos entre 25 y $300 \mathrm{~cm}^{3}$ (sistemas con características similares al empleado en esta tesis). En sus trabajos obtuvieron una relación lineal entre el coeficiente y la velocidad de agitación. Considerando el reactor 
de $150 \mathrm{~cm}^{3}$ de capacidad que es el de mayor similitud al empleado en este trabajo la correlación a emplear es:

$$
k_{l} \cdot a_{G}=1,14 \cdot 10^{-4} \cdot N^{2,98}
$$

Para una velocidad de agitación de $\left.\mathrm{N}=625 \mathrm{rpm}=10,4\left(\mathrm{seg}^{-1}\right)\right)$ se obtiene un coeficiente de $k_{L} \cdot a_{G}=1,23 \times 10^{-1} \mathrm{seg}^{-1}$.

Las condiciones de reacción empleadas fueron $90^{\circ} \mathrm{C}$ y $1,25 \mathrm{MPa}$ de presión de $\mathrm{H}_{2}$; empleando $250 \mathrm{mg}$ del catalizador $\mathrm{Ru}(3 \%) / \mathrm{C}$ y $0,90 \mathrm{~g}$ de glucosa como sustrato. A partir de la curva de conversión se calculó la velocidad inicial de reacción a $10 \%$ de conversión, para luego aplicar el criterio de $\propto_{1-H_{2}}$. Los resultados de la Tabla 5.1 muestran que en las condiciones de trabajo no existen limitaciones para el transporte de $\mathrm{H}_{2}$ en la interfase gas/líquido y en el seno del volumen de reacción. Debido a que se cumple que $\propto_{1-H_{2}}<0,1$ puede decirse que la velocidad de reacción de $\mathrm{H}_{2}$ no supera el $10 \%$ de la velocidad de transporte del reactivo.

Tabla 5.1. Cálculo de parámetros en la interfase gas-líquido.

\begin{tabular}{llllc|} 
Parámetro & $\boldsymbol{k}_{\boldsymbol{l}} \cdot \boldsymbol{a}_{\boldsymbol{G}}[\mathrm{1} / \mathrm{s}]$ & $\mathrm{C}_{\mathrm{H} 2}[\mathrm{~mol} / \mathrm{L}]$ & $\begin{array}{l}\left(\boldsymbol{r}_{\boldsymbol{i}}\right)_{\text {obs }} \\
{[\mathrm{mol} / \mathrm{L} . \mathrm{s}]}\end{array}$ & $\propto_{1}$ \\
\hline Valor & $1,23 \times 10^{-1}$ & 0,01 & $6,6 \times 10^{-6}$ & $5,17 \times 10^{-3}$ \\
\hline
\end{tabular}

\subsubsection{2.- Limitaciones difusionales en la interfase líquido/sólido}

Para determinar que no exista resistencia a la transferencia de los reactivos en la interfase líquido/sólido, el criterio que se toma es similar al visto para la interfase gas/líquido. Para ello se debe cumplir, para ambos reactivos $\left(\mathrm{H}_{2}\right.$ y glucosa), que la relación entre la velocidad de reacción y la velocidad de transporte de materia debe ser inferior al $10 \%$.

Esto es, si:

$$
\propto_{2}=\frac{\left(r_{i}\right)_{o b s}}{k_{C} \cdot a_{C} \cdot m_{c} \cdot C_{i}} \leq 0,1
$$

Donde: 
$\left(r_{i}\right)_{o b s}:$ Velocidad inicial de reacción obtenida experimentalmente;

$k_{C}$ : Coeficiente de transferencia de materia en la interfase líquido/sólido;

$m_{C}:$ masa del catalizador;

$C_{i}$ : Concentración del reactivo en la fase líquida (calculada con la ecuación de Henry para $\mathrm{H}_{2}$ ).

$a_{C}$ : Área externa del catalizador por unidad de masa del mismo, calculado mediante la expresión:

$$
a_{C}=\frac{6}{d_{p} \cdot \rho_{p}}
$$

Donde:

$d_{p}$ : Diámetro de partícula del catalizador; $d_{p} \approx 200$ micrones $=0,02 \mathrm{~cm}$

$\rho_{p}$ : Densidad de partículas de catalizador; $\rho_{p} \approx 540 \mathrm{~kg} / \mathrm{m} 3=0,54 \mathrm{~g} / \mathrm{cm}^{3}$

Para el cálculo del coeficiente de transferencia $k_{C}$ se empleó la expresión propuesta por Sano y col. (Sano Y., Yamaguchi N. y Adachi T., 1974) para partículas suspendidas en reactores tipo tanque agitado:

$$
S h_{P}=\frac{k_{C} \cdot d_{P}}{D_{M}}=\left[0,095 \cdot\left(\frac{\varepsilon \cdot d_{P}^{4}}{v^{3}}\right)^{0,23} \cdot\left(\frac{\mu_{M}}{\rho_{M} \cdot D_{M}}\right)^{1 / 2}\right]
$$

Donde:

$D_{M}$ : difusividad molecular de los reactivos en la mezcla de reacción;

$\varepsilon$ : energía suministrada al líquido por agitación mecánica, calculada mediante la expresión:

$$
\varepsilon=\frac{8 \cdot N^{3} \cdot d_{l}^{5} \cdot F_{f}}{d_{T}^{2} \cdot h_{2}}
$$

$\varepsilon=4521,12 \mathrm{~cm}^{2} / \mathrm{s}^{3}$

$\mathrm{d}_{\mathrm{l}}:$ diámetro del agitador $=2 \mathrm{~cm}$;

$\mathrm{d}_{\mathrm{T}}$ : diámetro del interior del tanque $=4 \mathrm{~cm}$ 
$\mathrm{h}_{2}:$ altura del nivel de líquido $=4 \mathrm{~cm}$

$F_{f}:$ factor de forma, generalmente se adopta $=1$;

$v$ : viscosidad cinemática de la mezcla de reacción; $v=3,26 \times 10^{-3} \mathrm{~cm}^{2} / \mathrm{s}$

$\rho_{M}$ : densidad de la mezcla de reacción; $\rho_{M}=1,005 \mathrm{~g} / \mathrm{cm}^{3}$

$\mu_{M}$ : viscosidad de la mezcla de reacción. $\mu_{M}=0,00315 \mathrm{~g} /(\mathrm{cm} . \mathrm{s})$

$\mathrm{D}_{\mathrm{H} 2}=6,3 \times 10^{-5} \mathrm{~cm}^{2} / \mathrm{s}$

$\mathrm{k}_{\mathrm{c}-\mathrm{H} 2}=0,048 \mathrm{~cm} / \mathrm{s}$

$D_{\text {glu }}=6,9 \times 10^{-6} \mathrm{~cm}^{2} / \mathrm{s}$

$\mathrm{k}_{\mathrm{c}-\mathrm{glu}}=0,011 \mathrm{~cm} / \mathrm{s}$

Los coeficientes de difusión se obtuvieron de tabla (Barrer R. M., 1941) para mezclas a $25^{\circ} \mathrm{C}$ y 1 atm. Teniendo en cuenta que la difusividad aumenta con la temperatura, los valores utilizados para analizar el criterio son en condiciones más desfavorables que las empleadas en nuestros ensayos.

Así con los valores de kc y el resto de los datos presentados a continuación, se calculan los valores de $\propto_{2}$ para los dos reactivos, los cuales se presentan en la tabla 5.2 .

$a_{C}=555,55 \mathrm{~cm}^{2} / \mathrm{g}$

$m_{C}=0,25 \mathrm{~g}$

Tabla 5.2. Cálculo de parámetros en la interfase líquido-sólido.

\begin{tabular}{|lcccc|} 
Parámetro & $\mathbf{k}_{\mathrm{c}-\mathrm{H} 2}[\mathrm{~cm} / \mathrm{s}]$ & $\mathbf{k}_{\mathrm{c}-\mathrm{glu}}[\mathrm{cm} / \mathrm{s}]$ & $\propto_{2-H 2}$ & $\propto_{2-g l u}$ \\
\hline Valor & 0,048 & 0,011 & 0,10 & 0,04 \\
\hline
\end{tabular}

\subsubsection{3.- Limitaciones difusionales intrapartícula}

Para verificar si existen resistencias a la transferencia de materia en el interior de la partícula de catalizador se utilizó el Criterio de Weisz-Prater para ambos reactivos.

Según este criterio, las limitaciones al transporte de materia son despreciables si se satisface que: 


$$
\Phi=\frac{\left(r_{i}\right)_{o b s} \cdot L^{2}}{D_{i}^{e} \cdot C_{i}^{S}} \ll 1
$$

Donde:

$L$ : relación entre el volumen de partícula de catalizador y la superficie externa de la misma, que para partícula esférica es:

$$
L=\frac{V_{p}}{S_{p}}=\frac{\frac{4}{3} \cdot \pi \cdot r_{p}^{3}}{4 \cdot \pi \cdot r_{p}^{2}}=\frac{r_{p}}{3}=\frac{d_{p}}{6}
$$

$D_{i}^{e}$ : difusividad efectiva de los reactivos en el interior de los poros del catalizador, calculada mediante la expresión:

$$
D_{i}^{e}=\frac{D_{M} \cdot \epsilon_{p}}{\tau}
$$

Donde:

$\epsilon_{p}:$ porosidad de la partícula de catalizador; $\epsilon_{p}=0,8$

$\tau$ : tortuosidad de la partícula de catalizador; $\tau=6$

$C_{i}^{S}$ : Concentración de los reactivos en la superficie del catalizador

Como puede observarse en la tabla 5.3, tanto para $\mathrm{H}_{2}$ como para glucosa se cumple el criterio de Weisz-Prater, ya que para ambos reactivos el valor de $\Phi<1$. Se puede determinar así que no existen limitaciones a la transferencia de materia en el interior de la partícula de catalizador.

Tabla 5.3. Cálculo de parámetros en el interior de la partícula.

\begin{tabular}{|lcc|}
\hline Parámetro & $\boldsymbol{\Phi}_{\mathrm{H} 2}$ & $\boldsymbol{\Phi}_{\mathrm{glu}}$ \\
\hline Valor & 0,097 & 0,087 \\
\hline
\end{tabular}

\subsection{2.- Criterios experimentales}

A fin de determinar las condiciones de reacción con las cuales se evaluaron los catalizadores preparados en esta tesis, se realizó un análisis de la influencia de algunas variables experimentales sobre la actividad catalítica en la hidrogenación en fase acuosa (APH) de glucosa, empleando un catalizador de $\mathrm{Ru} 3 \% \mathrm{p} / \mathrm{p}$ soportado sobre carbón activado $(\mathrm{Ru} / \mathrm{C})$, por ser un sistema que alcanza alta conversión y selectividad 
del $100 \%$ a al polialcohol correspondiente (sorbitol). La elección del catalizador se realizó a partir de una evaluación variando el contenido metálico del Ru soportado sobre carbón. Todos los catalizadores fueron preparados por igual método de impregnación con exceso de solución.

\subsubsection{1.- Influencia de la carga metálica}

Se evaluó una familia de catalizadores soportados sobre carbón activado, preparados por igual método de impregnación con exceso de solución, variando el contenido de rutenio.

Las demás condiciones de reacción fueron: $90^{\circ} \mathrm{C}, 0,90$ gramos de glucosa, 250 mg de catalizador, presión de $\mathrm{H}_{2}$ de 1,25 MPa, velocidad de agitación $625 \mathrm{rpm}$ y $50 \mathrm{~cm}^{3}$ de agua ultra pura como solvente.

En la figura 5.1 se muestran los valores de conversión para los 5 catalizadores preparados, variando la carga metálica desde $0,5 \%$ de Ru p/p hasta $3 \%$. Se puede ver que se alcanzó conversión prácticamente total con el catalizador de $\mathrm{Ru}(3 \%) / C$ luego de 7 horas de reacción, mientras que con Ru (1,5\%)/C la conversión disminuyó al 90\%.

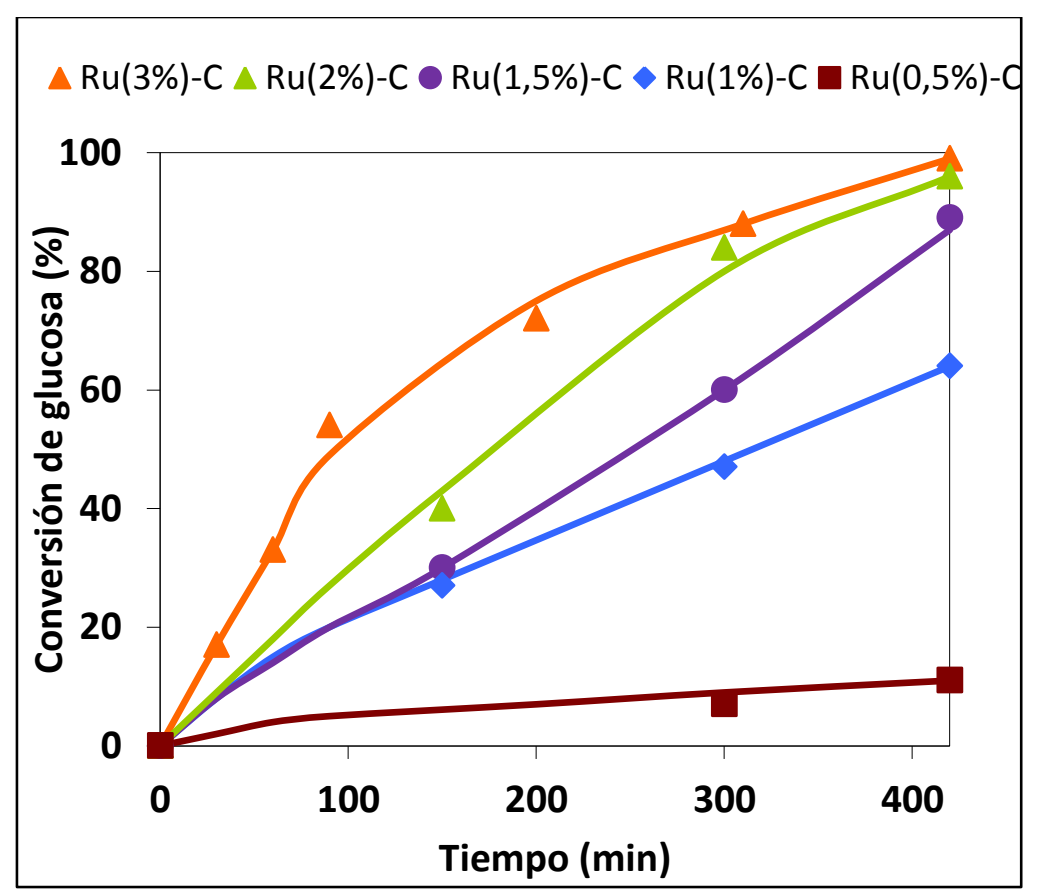

Figura 5.1. Conversión de glucosa con catalizadores de Ru/C variando el contenido metálico. 
Se observa que tanto la conversión de glucosa para un mismo tiempo de reacción como la velocidad inicial de hidrogenación por gramo de catalizador, aumentaron con la carga de Ru (Tabla 5.4). Sin embargo cuando se analizan las velocidades iniciales por gramo de $\mathrm{Ru}$, de manera de independizarlas del contenido metálico, se observan valores similares entre ellas, con excepción de los sistemas con 1,5 y $0,5 \%$ de $\mathrm{Ru}$. Las velocidades de reacción se calcularon a partir de curvas polinómicas ajustadas por cuadrados mínimos. Respecto a la selectividad, en todos los casos fue del $100 \%$ a sorbitol.

Tabla 5.4. Efecto de la carga metálica sobre la actividad del catalizador de Ru soportado en carbón activado en la APH de glucosa.

\begin{tabular}{|c|c|c|}
\hline Catalizador & $\begin{array}{c}\mathrm{r}_{\mathrm{i}}^{\mathrm{cat}} \\
\left(\mathrm{mmoles}_{\mathrm{conv}} \mathrm{g}_{\mathrm{cat}}^{-1} \mathrm{~min}^{-1}\right)^{*}\end{array}$ & ${ }_{\left(\text {mmoles }_{\text {conv }} g_{\mathrm{Ru}}{ }^{-1} \min ^{-1}\right)^{* *}}$ \\
\hline Ru (3\%)/C & $9,8 \times 10^{-2}$ & 3,27 \\
\hline Ru $(2 \%) / C$ & $6,5 \times 10^{-2}$ & 3,26 \\
\hline $\operatorname{Ru}(1,5 \%) / C$ & $3,7 \times 10^{-2}$ & 2,46 \\
\hline Ru (1\%)/C & $3,5 \times 10^{-2}$ & 3,49 \\
\hline $\operatorname{Ru}(0,5 \%) / C$ & $5 \times 10^{-3}$ & 1,00 \\
\hline
\end{tabular}

${ }^{*}{ }^{\text {cat }}$ cat (velocidades iniciales por gramo de catalizador calculadas para un 10\% de conversión)

${ }^{* *} \mathrm{r}_{\mathrm{i}}^{\mathrm{M}}$ : (velocidades iniciales por gramo de Ru calculadas para un $10 \%$ de conversión)

Por la diferencia observada en la actividad catalítica es que se seleccionó el catalizador con mayor contenido metálico $(\mathrm{Ru}(3 \%) / \mathrm{C})$ para realizar el estudio de las demás condiciones operativas, así como también la preparación de los otros catalizadores soportados estudiados en este trabajo de tesis. Si bien, la carga metálica resulta ser la más elevada, aumentando el costo económico de su preparación, resulta ser significativamente menor a la empleada comúnmente en bibliografía (contenido metálico igual o mayor a 5\%).

\subsubsection{2.- Influencia de la velocidad de agitación}

La agitación de la mezcla reaccionante en un reactor "slurry" es importante no solo para mantener las partículas de catalizador suspendidas uniformemente, sino también para facilitar el transporte del reactivo gaseoso a través de la interfase gas/líquido y del reactivo disuelto en el medio líquido hacia la superficie del 
catalizador, habiendo una relación entre el aumento de la agitación y el aumento del coeficiente de transferencia de materia.

Con el objetivo de asegurar la ausencia de limitaciones a la transferencia de masa en la interfase gas/líquido, se llevaron a cabo experiencias a distintas velocidades de agitación utilizando el catalizador de $\mathrm{Ru}(3 \%) / \mathrm{C}$, en el mismo reactor mencionado en el capítulo 2 (Berghof BR 100, $100 \mathrm{~cm}^{3}$ ) y manteniendo las demás variables operativas constantes; $90^{\circ} \mathrm{C}$ y $1,25 \mathrm{MPa} \mathrm{H}_{2}$ durante $7 \mathrm{~h}$, empleando $0,25 \mathrm{~g}$ de catalizador, $0,90 \mathrm{~g}$ de glucosa y $50 \mathrm{~cm}^{3}$ de agua como solvente.

El gráfico de conversión de glucosa para las distintas velocidades de agitación se muestra en la figura 5.2, mientras que en la figura 5.3 se representa las velocidades de reacción inicial, calculadas a partir de curvas polinómicas ajustadas por cuadrados mínimos.

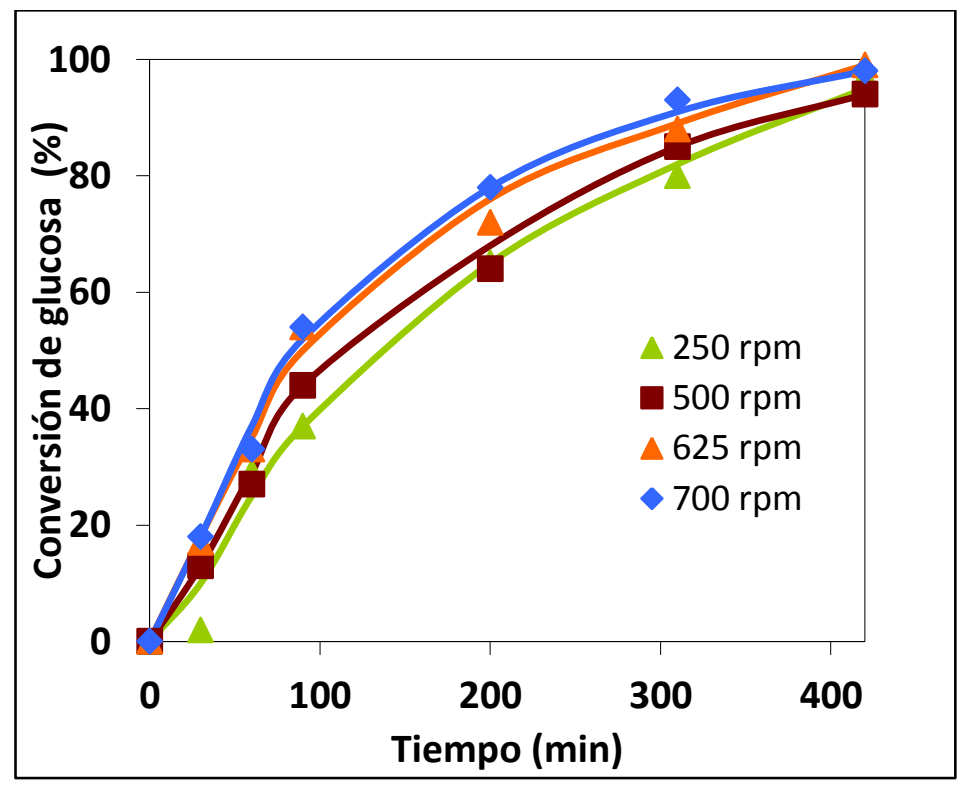

Figura 5.2. Perfiles temporales de conversión de glucosa para diferentes velocidades de agitación. 


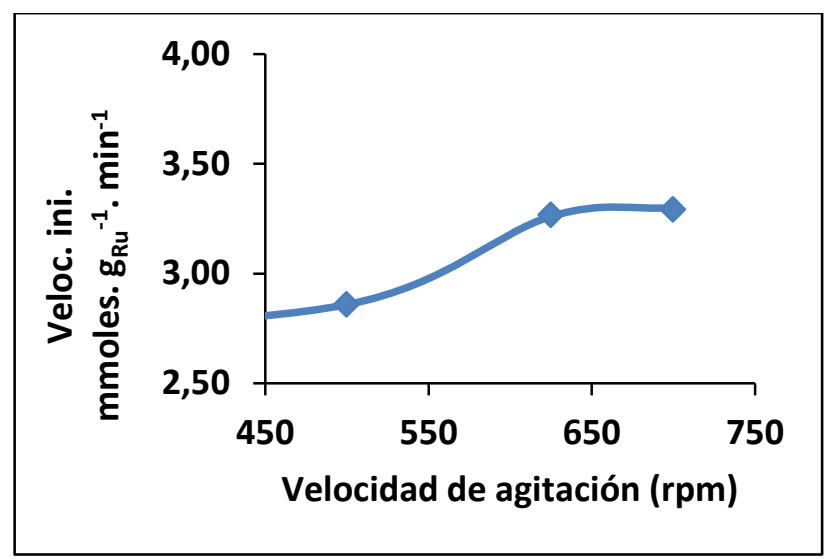

Figura 5.3. Velocidades iniciales de APH de glucosa con Ru (3\%)/C en función la velocidad de agitación.

Como puede observarse, a velocidades de agitación menores a 600 rpm aprox., la velocidad inicial de reacción desciende, pudiendo indicar la aparición de limitaciones a la transferencia de hidrógeno en la interfase gas/líquido. Por tal motivo y buscando asegurar una alimentación suficiente de $\mathrm{H}_{2}$ a la fase líquida es que se adoptó una velocidad de $625 \mathrm{rpm}$ para los ensayos catalíticos posteriores.

\subsubsection{3.- Influencia de la temperatura}

Con el objeto de observar si cambios en la temperatura de reacción producen diferencias notorias en la conversión, se realizó una experiencia manteniendo las demás variables operativas constantes (en este caso con velocidad de agitación fijada en 625 rpm, 1,25 MPa de presión de $\mathrm{H}_{2}$, 0,1M de glucosa, 250 mg de catalizador de Ru (3\%)/C) y variando la temperatura en 5 niveles diferentes desde $70^{\circ} \mathrm{C}$ a $110^{\circ} \mathrm{C}$.

En la figura 5.4 se muestran los resultados obtenidos, a partir de los cuales se puede extraer la información presentada en la tabla 5.5. Se aprecia que por debajo de $80^{\circ} \mathrm{C}$ la velocidad de reacción decrece significativamente, alcanzando en el caso de $70^{\circ} \mathrm{C}$ una conversión del $80 \%$ al cabo de las 7 horas de reacción.

Por encima de los $100^{\circ} \mathrm{C}$ se observa que el tiempo necesario para lograr conversión completa se reduce a 5 horas de reacción. Sin embargo en el tiempo de reacción total estudiado ( 7 horas) puede verse que a $90^{\circ} \mathrm{C}$ se alcanza un $99 \%$ de conversión. En todos los casos se observó que la selectividad es de 100\% a sorbitol. 


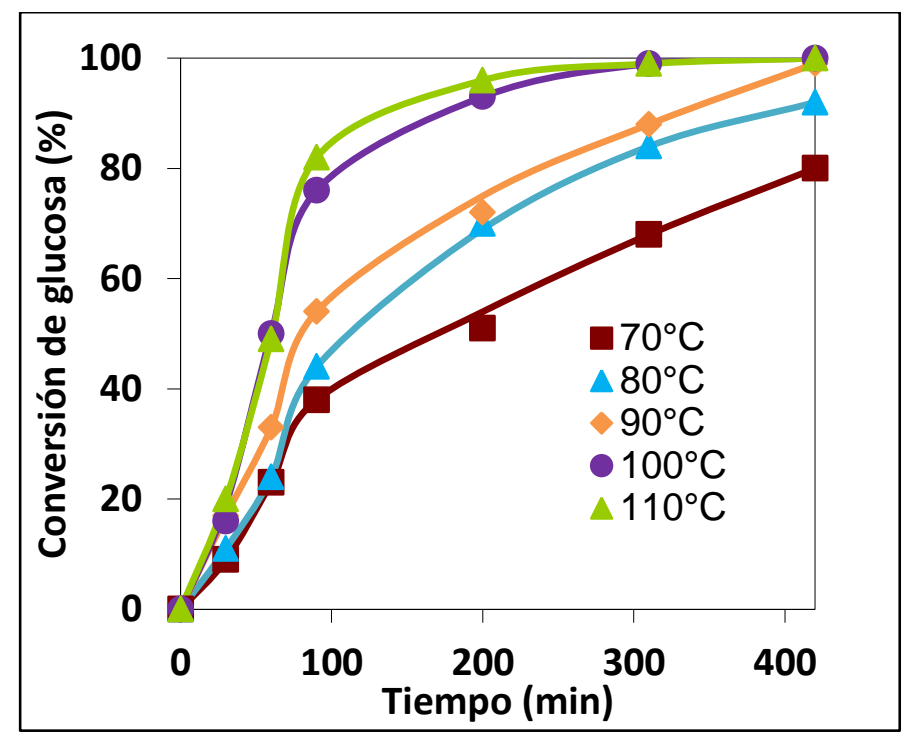

Figura 5.4. Evaluación de temperatura sobre APH de glucosa con Ru (3\%)/C.

Tabla 5.5 efecto de la temperatura sobre la actividad del catalizador $\mathrm{Ru}(3 \%) / C$ en la APH de glucosa.

\begin{tabular}{|c|c|c|}
\hline Temperatura $\left({ }^{\circ} \mathrm{C}\right)$ & Conversión (\%)* & $r_{i}\left(m_{m o l e s}{ }_{c o n v} g_{R u}^{-1} \min ^{-1}\right)^{* *}$ \\
\hline $70^{\circ} \mathrm{C}$ & 80 & 2,29 \\
\hline $80^{\circ} \mathrm{C}$ & 92 & 2,96 \\
\hline $90^{\circ} \mathrm{C}$ & 99 & 3,27 \\
\hline $100^{\circ} \mathrm{C}$ & 100 & 6,35 \\
\hline $110^{\circ} \mathrm{C}$ & 100 & 6,45 \\
\hline
\end{tabular}

De este experimento se puede concluir que la temperatura es un factor importante en la velocidad de reacción, pudiéndose seleccionar una temperatura de $90^{\circ} \mathrm{C}$, nivel térmico suave que asegura una buena actividad ( $99 \%$ de conversión) y en un tiempo de reacción razonable.

Si se considera que la velocidad de reacción sigue una ley tipo potencia de la forma:

$$
r_{i}=k \cdot\left(C_{g l u}\right)^{n} \cdot\left(P_{H 2}\right)^{m}
$$

Y para la constante de velocidad de reacción una expresión de tipo Arrhenius:

$$
k=A \cdot e^{-\left[\frac{E_{a}}{R . T}\right]}
$$


Entonces:

$$
r_{i}=A \cdot e^{-\left[\frac{E_{a}}{R \cdot T}\right]} \cdot\left(C_{g l u}\right)^{n} \cdot\left(P_{H 2}\right)^{m}
$$

Luego, aplicando logaritmo natural a toda la expresión se llega a:

$$
\ln \left(r_{i}\right)=\ln \left[A \cdot\left(C_{g l u}\right)^{n} \cdot\left(P_{H 2}\right)^{m}\right]-\left(\frac{E_{a}}{R}\right) \cdot\left(\frac{1}{T}\right)
$$

Si se grafica $\ln \left(r_{i}\right)$ en función de $1 / T$ y ajustando los puntos con una ecuación lineal se puede obtener la energía de activación aparente (Ea) a partir de la pendiente de la recta obtenida. En la figura 5.5 se presenta el gráfico del $\ln \left(r_{i}\right)$ en función de la inversa de la temperatura.

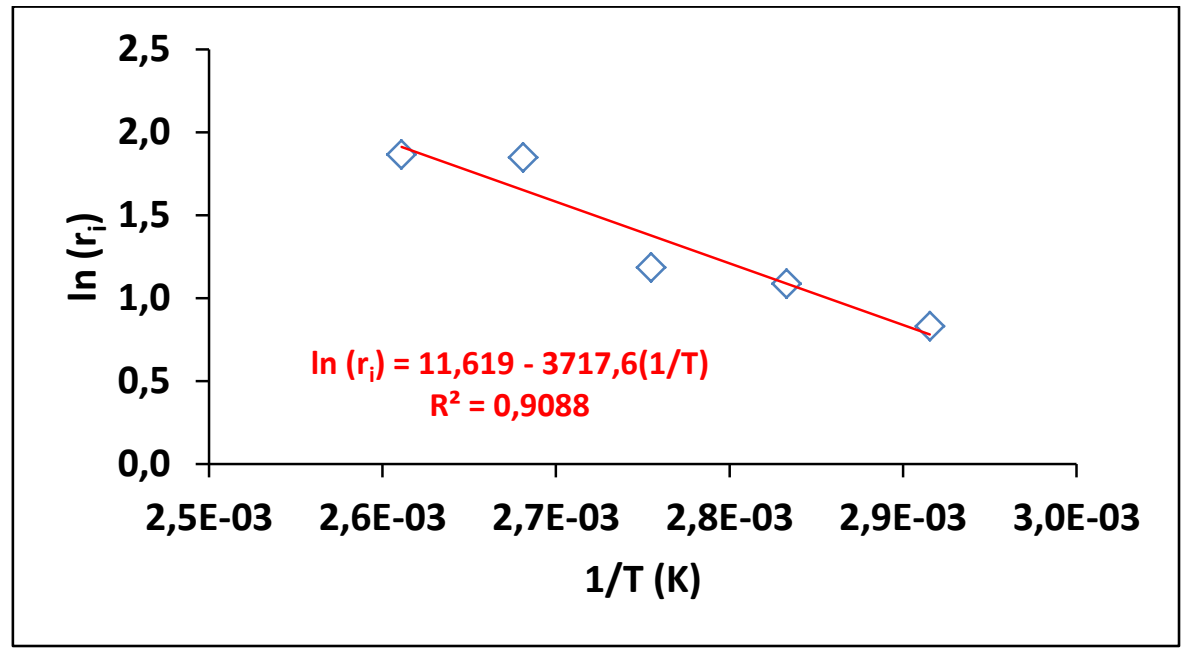

Figura 5.5. Determinación de la energía de activación aparente en la APH de glucosa con $\mathrm{Ru}(3 \%) / \mathrm{C}$.

De los resultados obtenidos del ajuste lineal de los datos experimentales se obtuvo una energía de activación aparente de $30,8 \mathrm{~kJ} / \mathrm{mol}(7,38 \mathrm{Kcal} / \mathrm{mol})$. Este valor es similar a los reportados en bibliografía y superior a la energía de activación de difusión en líquidos (12-21 kJ/mol) (Déchamp N. y col., 1995), confirmando así que los datos de velocidad se obtienen bajo control de cinética química. En este sentido, también Brahme y colaboradores obtuvieron valores de energía de activación de 43,9 $\mathrm{kJ} / \mathrm{mol}(10,5 \mathrm{kcal} / \mathrm{mol})$ y $5,86 \mathrm{~kJ} / \mathrm{mol}(1,4 \mathrm{kcal} / \mathrm{mol})$ para los rangos de temperatura de $77-100^{\circ} \mathrm{C}$ y $100-145,5^{\circ} \mathrm{C}$ respectivamente, empleando $10 \mathrm{~g} / \mathrm{L}$ de catalizador Niquel Raney y una velocidad de agitación de 575 rpm (Brahme P.H. y Doraiswamy L. K., 
1976). También valores similares se han informado en estudios efectuados con otros monosacáridos. Así, Li y colaboradores (Li H. y col. 2008) (Li H. y col. 2008) reportaron que la energía de activación aparente (Ea) de la hidrogenación de maltosa en un catalizador Ru-P fue de $27 \mathrm{~kJ} / \mathrm{mol}(6.45 \mathrm{Kcal} / \mathrm{mol}$ ) y para Ru-B fue de $32 \mathrm{~kJ} / \mathrm{mol}$ (7.65 Kcal $/ \mathrm{mol})$, empleando una solución de maltosa de $40 \% \mathrm{p} / \mathrm{v}, 90^{\circ} \mathrm{C}, 2 \mathrm{MPa}$ de presión y agitación a $1200 \mathrm{rpm}$.

\subsubsection{4.- Influencia de la presión de $\mathrm{H}_{2}$}

Se estudió también la influencia de la presión parcial de hidrógeno en la cinética de la hidrogenación de glucosa con el catalizador de $\mathrm{Ru}(3 \%) / \mathrm{C}$, variándola entre 0,5 $\mathrm{MPa}$ y $2 \mathrm{MPa}$ (mantenida constante durante la reacción); a $90^{\circ} \mathrm{C}$ de temperatura y manteniendo constante las demás variables. Los resultados de estos ensayos se muestran en la figura 5.6, mientras que en la tabla 5.6 se muestran las velocidades iniciales de reacción.

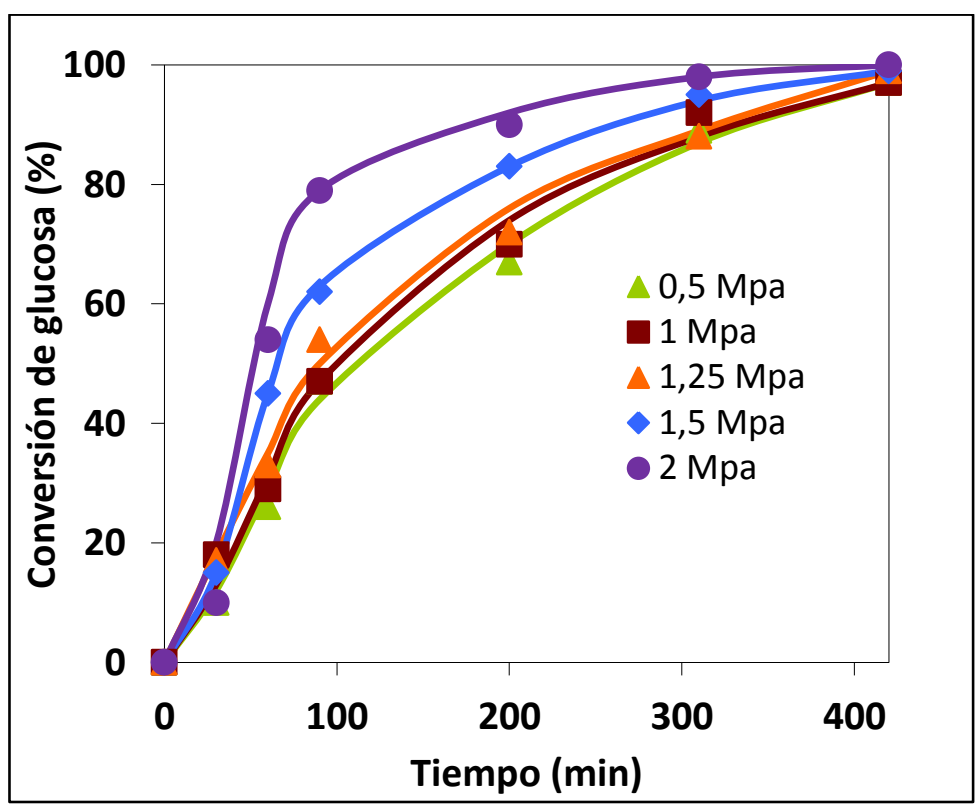

Figura 5.6. Evaluación de la presión de $\mathrm{H}_{2}$ sobre APH de glucosa con $\mathrm{Ru}(3 \%) / \mathrm{C}$.

En todos los casos se observa que la reacción alcanza prácticamente conversión total en el tiempo evaluado, aumentando la velocidad de reacción con el aumento de presión, como era de esperarse. Se puede remarcar también, que al igual que con las pruebas anteriores, la variación de la presión de $\mathrm{H}_{2}$ no produce cambios en la selectividad de la reacción, obteniéndose como único producto el sorbitol. 
Tabla 5.6. Efecto de la presión de $\mathrm{H}_{2}$ sobre la actividad del catalizador $\mathrm{Ru}(3 \%) / C$ en la APH de glucosa.

\begin{tabular}{ccc}
\hline Presión de $\mathrm{H}_{\mathbf{2}}$ (MPa) & Conversión (\%)* & $\mathbf{r}_{\mathrm{i}}\left(\mathbf{m m o l e s}_{\mathrm{conv}} \mathbf{g}_{\mathrm{Ru}}{ }^{-1} \mathbf{m i n}^{-1}\right)^{* *}$ \\
\hline $\mathbf{0 , 5 0}$ & 97 & 2,90 \\
$\mathbf{1 , 0 0}$ & 97 & 2,99 \\
$\mathbf{1 , 2 5}$ & 99 & 3,27 \\
$\mathbf{1 , 5 0}$ & 99 & 5,54 \\
$\mathbf{2 , 0 0}$ & 100 & 6,45 \\
\hline
\end{tabular}

* Conversión a 7 horas de reacción

${ }^{* *} \mathrm{r}_{\mathrm{i}}$ : (velocidades iniciales calculadas para un $10 \%$ de conversión)

Si se considera para la expresión de la velocidad de reacción una ecuación del tipo ley potencia de la forma:

$$
r_{i}=k \cdot\left(C_{g l u}\right)^{n} \cdot\left(P_{H 2}\right)^{m}
$$

Aplicando logaritmo natural a toda la expresión se llega a:

$$
\ln \left(r_{i}\right)=\ln \left[k \cdot\left(C_{g l u}\right)^{n}\right]+m \cdot \ln \left(P_{H 2}\right)
$$

Si se grafica $\ln \left(r_{i}\right)$ en función de $\ln \left(P_{H 2}\right)$ y ajustando los puntos con una ecuación lineal se puede determinar el orden de reacción $(\mathrm{m})$ para el reactivo gaseoso a partir de la pendiente de la recta obtenida. En la figura 5.7 dicho gráfico del $\ln \left(r_{i}\right)$ en función de $\ln \left(P_{\mathrm{H}_{2}}\right)$. El ajuste lineal de los datos obtenidos muestra un orden de reacción respecto a la presión de $\mathrm{H}_{2}$ de 0,5862 .

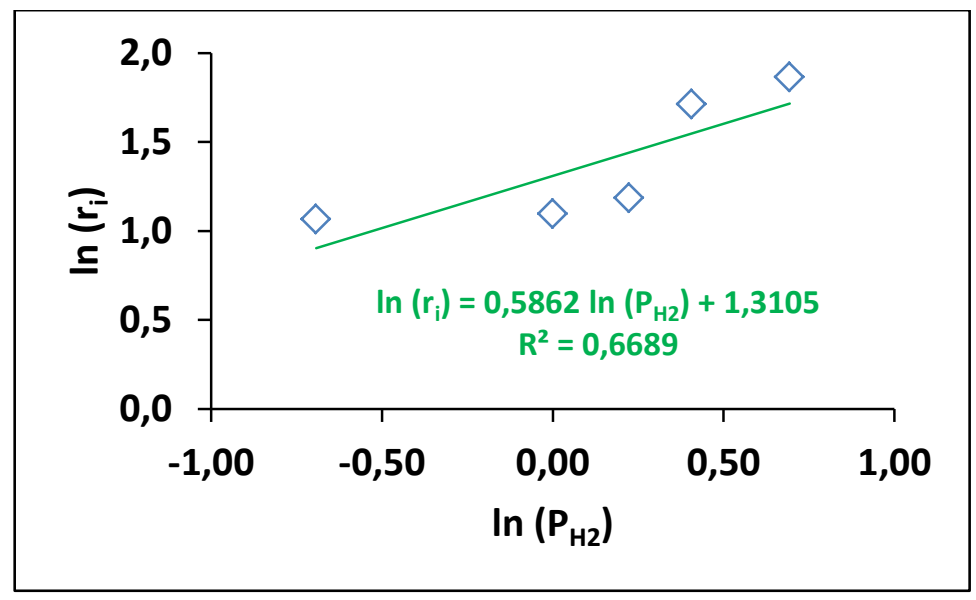

Figura 5.7. Determinación del orden de reacción para el $\mathrm{H}_{2}$ en la APH de glucosa con $\mathrm{Ru}$ $(3 \%) / C$. 


\subsubsection{5.- Influencia de la concentración inicial de glucosa}

Dentro del sistema pseudohomogéneo propuesto, solo resta determinar el orden de reacción con respecto a la concentración de glucosa, es decir ver la influencia de la variación de dicha concentración en la velocidad inicial de reacción. Para ellos, al igual que en las experiencias anteriores, se realizaron experimentos modificando la variable de interés, manteniendo las demás en forma constante, y ver como resulta afectado el comportamiento catalítico.

La concentración inicial de glucosa se varió en 4 niveles diferentes $(0,033 \mathrm{M}$, 0,066 M, 0,1 M y 0,133 M), las cuales corresponden a 0,3, 0,6, 0,9 y 1,2 gramos de glucosa en $50 \mathrm{~cm}^{3}$. de solvente respectivamente. Los resultados de conversión en función del tiempo obtenidos en estas experiencias se muestran en la Figura 5.8, mientras que en la Tabla 5.7 se presentan las velocidades iniciales de hidrogenación de glucosa con el catalizador de $\mathrm{Ru}(3 \%) / \mathrm{C}$.

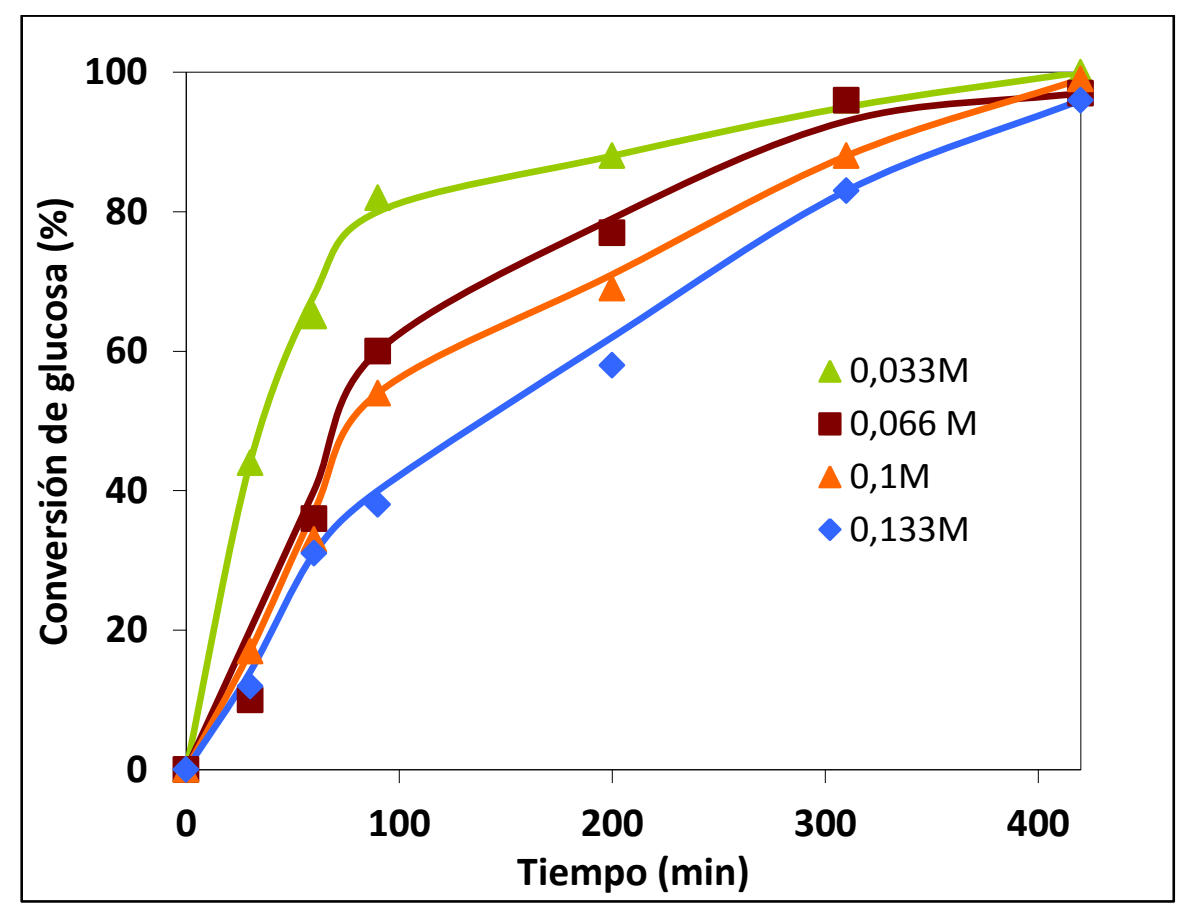

Figura 5.8. Evaluación de la concentración inicial de glucosa sobre APH con Ru (3\%)/C 
Tabla 5.7. Efecto de la concentración inicial de glucosa sobre la actividad del catalizador $\mathrm{Ru}(3 \%) / \mathrm{C}$ en la APH de glucosa.

\begin{tabular}{ccc}
\hline $\begin{array}{c}\text { Concentración inicial de glucosa } \\
\boldsymbol{C}_{\boldsymbol{g l u} \mathbf{0}}^{\mathbf{0}}(\mathrm{mol} / \mathrm{L})\end{array}$ & Conversión (\%)* & $\mathbf{r}_{\mathrm{i}}\left(\mathbf{m m o l e s}_{\mathrm{conv}} \mathrm{g}_{\mathrm{Ru}}{ }^{-\mathbf{1}} \mathbf{m i n}^{-\mathbf{1}}\right)^{* *}$ \\
\hline $\mathbf{0 , 0 3 3}$ & 100 & \\
\hline $\mathbf{0 , 0 6 6}$ & 99 & 10,87 \\
$\mathbf{0 , 1}$ & 99 & 3,76 \\
$\mathbf{0 , 1 3 3}$ & 96 & 3,27 \\
\hline
\end{tabular}

* Conversión a 7 horas de reacción

${ }^{* *} r_{\mathrm{i}}$ : (velocidades iniciales calculadas para un $10 \%$ de conversión)

Nuevamente considerando que la velocidad de reacción cumple con la forma de una ecuación tipo ley de potencia:

$$
r_{i}=k \cdot\left(C_{g l u}\right)^{n} \cdot\left(P_{H 2}\right)^{m}
$$

Aplicando el logaritmo y reacomodando convenientemente los términos se obtiene:

$$
\ln \left(r_{i}\right)=\ln \left[k \cdot\left(P_{H 2}\right)^{m}\right]+n \cdot \ln \left(C_{g l u}\right)
$$

Graficando el $\ln \left(r_{i}\right)$ en función del $\ln \left(C_{g l u}\right)$ y realizando una regresión lineal de los puntos obtenidos es posible determinar el orden de reacción (n) correspondiente a la concentración de glucosa. En la Figura 5.9 se presenta el logaritmo de la velocidad inicial de reacción en función del logaritmo de la concentración inicial de glucosa. Del ajuste lineal de los resultados se obtiene un orden de reacción respecto a la glucosa de $-1,0105$.

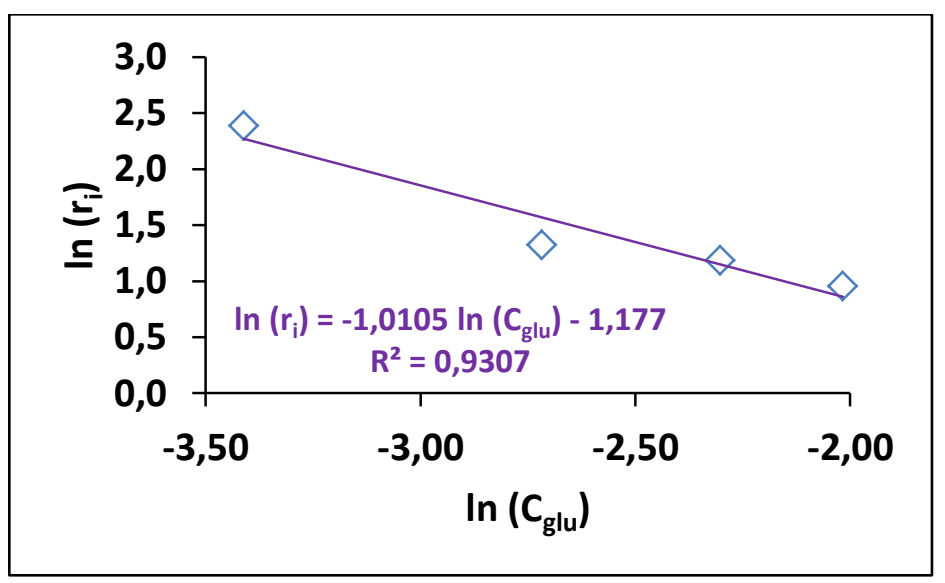

Figura 5.9. Determinación del orden de reacción para la glucosa en su APH con Ru (3\%)/C. 


\section{4.- Estabilidad del catalizador Ru (3\%)/C}

Se evaluó la posibilidad de reutilización del catalizador luego de ciclos consecutivos de trabajo, teniendo en cuenta que este es un aspecto muy importante para que un catalizador pueda ser empleado industrialmente.

Las condiciones de reacción empleadas fueron las mismas que las que se utilizaron en las secciones anteriores: $90^{\circ} \mathrm{C}, 0,90$ gramos de glucosa, $250 \mathrm{mg}$ de catalizador (cargado en el reactor para el primer uso), presión de $\mathrm{H}_{2}$ de 1,25 MPa, velocidad de agitación $625 \mathrm{rpm}$ y $50 \mathrm{~cm}^{3}$ de agua ultra pura como solvente.

Se llevaron a cabo 5 ensayos como las informadas anteriormente, pero empleando siempre el mismo catalizador cargado en la primera. Es decir, se hizo una experiencia similar a las anteriores en las mismas condiciones experimentales, y una vez finalizada ésta luego de 7 horas de reacción, se separó el catalizador, se secó en estufa a temperatura suave $\left(60^{\circ} \mathrm{C}\right)$ y se lo reutilizó; cargando el reactor nuevamente (luego de su lavado) con 0,90 gramos de sustrato y $50 \mathrm{~cm}^{3}$ de agua. Esto se repitió 4 veces. La figura 5.10 muestra los resultados obtenidos.

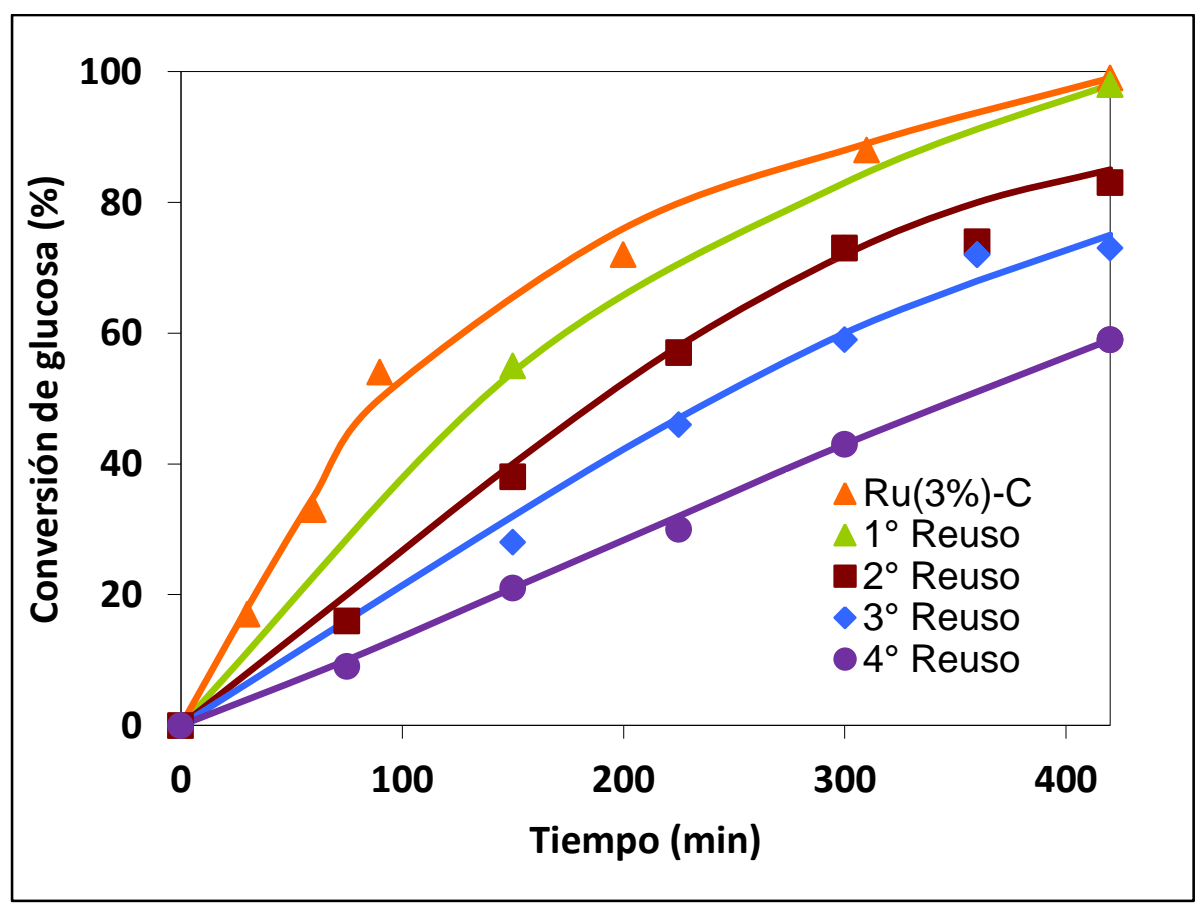

Figura 5.10. Reutilización del catalizador de Ru (3\%)/C 
Luego de la primera reutilización, se observa que la actividad del catalizar continúa siendo alta llegando a un 98\% de conversión. Luego de utilizado por tercera vez, la actividad sufre una disminución para el tiempo evaluado, aunque se mantiene por encima del $80 \%$ de conversión. A partir del tercer reúso la conversión cae por debajo del $75 \%$ para las 7 horas de reacción evaluadas. Sin embargo, esta modificación en los valores de conversión está asociada con el cambio de relación en las proporciones sustrato/catalizador; aumentando en cada ciclo debido a la pérdida de masa de sistema catalítico entre cada etapa sucesiva de extracción y secado. En la tabla 5.8 figuran las velocidades iniciales de reacción para cada reúso, calculadas por unidad de masa de catalizador. Como puede observarse, no hay variación apreciable entre ellas, a excepción del último ciclo. Teniendo en consideración estos valores, podría considerarse que el sistema catalítico no evidenciaría desactivación.

La disminución calculada en la velocidad de reacción del $4^{\circ}$ reúso podría ser una evidencia de adsorción fuerte de glucosa y/o sorbitol, sin que esto implique una desactivación definitiva del catalizador por envenenamiento irreversible.

Tabla 5.8. Actividad del catalizador Ru (3\%)/C en la APH de glucosa en distintos ciclos de utilización

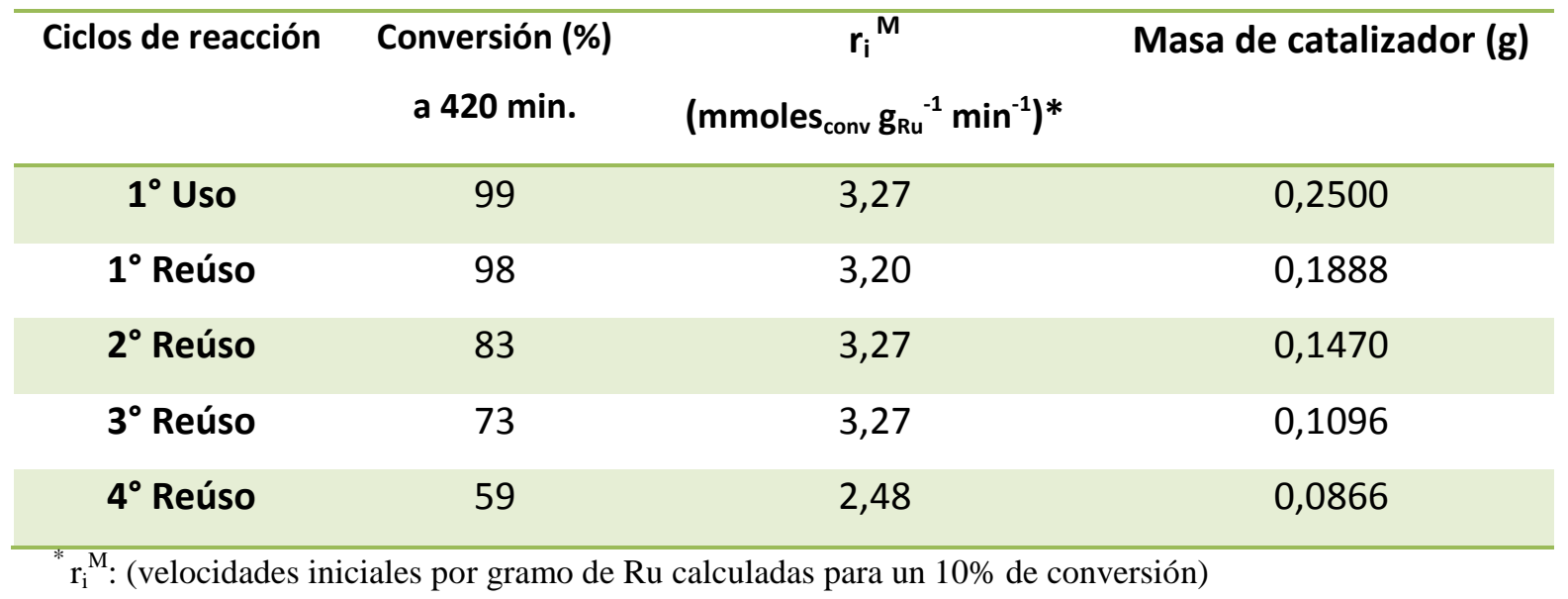




\section{5.- Conclusiones}

Se realizaron ensayos de hidrogenación de glucosa en fase acuosa utilizando catalizadores de $\mathrm{Ru} / \mathrm{C}$, variando la carga metálica de 0,5 a $3 \% \mathrm{p} / \mathrm{p}$. El catalizador con mayor contenido metálico presentó conversión prácticamente total y selectividad del $100 \%$ a al polialcohol correspondiente (sorbitol).

Se emplearon criterios analíticos para identificar la existencia de limitaciones difusionales. Para ello, se comparó la velocidad de reacción con las velocidades máximas de transporte en las etapas físicas, mediante el cálculo de coeficientes de transferencia y difusividades. Los criterios basados en estas comparaciones demostraron la ausencia de limitaciones importantes de transporte de masa.

También se realizaron pruebas experimentales, empleando el catalizador de $\mathrm{Ru}(3 \%) / C$, que demostraron la ausencia de limitaciones de transporte de masa en concordancia con los criterios analíticos.

Se estudió el efecto de la temperatura lo que permitió determinar un valor para la energía de activación de 30,87 kJ/mol (7,38 Kcal/mol). Se estudió además, el efecto de la presión de $\mathrm{H}_{2}$, determinándose un orden de reacción de 0,5862 para este reactivo, mientras que a partir del estudio de la variación de la concentración inicial de glucosa se estableció un orden de reacción de -1,0105 para el monosacárido.

Se estudió también la estabilidad del catalizador de $\mathrm{Ru}(3 \%) / C$. el catalizador mantuvo el valor de velocidad inicial de reacción luego de 4 ciclos de uso. La disminución en la conversión observada en cada reciclo puede deberse a la adsorción fuerte de glucosa y/o sorbitol sobre el catalizador, sin que esto implique una desactivación definitiva del catalizador por envenenamiento irreversible. 


\section{CAPÍTULO 6}

\section{ESTUDIO DE HIDROGENACIÓN DE MONO Y DISACÁRIDOS CON CATALIZADORES DE RUTENIO SOPORTADO}


En este capítulo se presenta el estudio de la reacción en fase acuosa (APH) de monosacáridos (glucosa y xilosa) y el disacárido celobiosa (sustrato modelo de la fragmentación de celulosa) con catalizadores de Ru monometálico sobre diferentes soportes. Se analiza la influencia de la naturaleza del soporte, así como su interacción con el Ru, sobre la actividad y selectividad de los catalizadores preparados. 


\section{1.- Introducción}

Como se desarrolló a comienzos de este trabajo, el uso de materias primas renovables y el desarrollo de diferentes estrategias para la valorización de la biomasa, junto con la catálisis heterogénea, son una alternativa interesante para la sustitución del petróleo en la obtención de intermediarios y productos químicos finales de alto valor agregado (Li N. y col., 2011). La celulosa es el carbohidrato más abundante y no comestible, por esta razón, se espera que sea el primer objetivo de la química de los recursos de la biomasa (Negahdar L., Delidovich I. y Palkovits R., 2016). Mediante la degradación de la biomasa celulósica, pueden obtenerse mono-, di- y oligosacáridos, que a su vez pueden ser transformados en productos valiosos o intermediarios, tales como glucosa, xilosa, furfural, etc (Climent M.J., Corma A. y Iborra S., 2014). Dentro de los productos químicos más importantes derivados de la biomasa celulósica se encuentran los alcoholes de azúcar. Los polisacáridos (celulosa, hemicelulosa, inulina, etc.) se hidrolizan, típicamente usando catalizadores ácidos, en azúcares monoméricos y estos, a su vez, pueden someterse además a reacciones de hidrogenación en presencia de catalizadores metálicos soportados para producir alcoholes de azúcar (Tathod A.T. y Dhepe P.L., 2015).

Convencionalmente, la hidrogenación catalítica de los azúcares monoméricos se lleva a cabo con catalizadores a base de níquel, por ejemplo, Ni Raney (Hoffer B.W. y col., 2003). Si bien este catalizador demostró poseer una buena actividad catalítica, tiene el inconveniente de su lixiviación y baja selectividad, motivo por el cual se han investigado otros catalizadores basados en metales tales como Co, Pt, Pd, Rh y Ru (Li H., Li H. y Deng J.F., 2002).

Se ha encontrado que los catalizadores a base de rutenio superan a los catalizadores a base de níquel debido a su alta actividad, requerimiento de menor carga y menor desactivación (van Gorpa K. y col., 1999; Hoffer B.W. y col., 2003; Kusserow B., Schimpf S. y Claus P., 2003). Es por ello, que aunque sea mucho más caro que el níquel, puede ser de interés para usos industriales, ya que es más activo y no muestra lixiviación.

La actividad de los catalizadores a base de rutenio ha demostrado ser altamente dependiente del material sobre el cual se lo soporta (Crezee E.B. y col., 
2003; Zhang J. y col., 2011). En este sentido, los materiales a base de zirconio son soportes prometedores para la valorización de la biomasa en sustancias químicas y combustibles (Aboulayt A. y col., 2017).

En este apartado se reporta la utilización de la serie de catalizadores preparados de Ru monometálicos soportados, descriptos en el capítulo 4 (sobre C, A, Z, ZP, ZP-A), en la hidrogenación en fase acuosa de monosacáridos (xilosa y glucosa) y del disacárido celobiosa, sustrato modelo de la fragmentación de celulosa. Los sustratos empleados para estos estudios fueron de origen comercial.

La preparación y caracterización de los catalizadores fueron detalladas en el capítulo 4. Es por esto que en la Tabla 6.1 sólo se resume algunas características de los sistemas preparados, a fin de tener presentes los datos de las propiedades texturales e identificación de fases, tratando de relacionar la estructura de los mismos con su comportamiento catalítico.

Tabla 6.1. Principales características de los catalizadores de Ru estudiados.

\begin{tabular}{|c|c|c|c|c|c|c|}
\hline Catalizador & $\begin{array}{c}\text { Área } \\
\text { superficial } \\
\text { BET }\left(\mathrm{m}^{2} / \mathrm{g}\right)\end{array}$ & $\begin{array}{l}\text { Volumen } \\
\text { de poro } \\
\left(\mathrm{cm}^{3} / \mathrm{g}\right)\end{array}$ & $\begin{array}{l}\text { Diámetro } \\
\text { de poro } \\
\text { (A) }\end{array}$ & $\begin{array}{c}\text { Fase } \\
\text { cristalina }\end{array}$ & $D_{\text {va }}(n m)$ & $\begin{array}{l}\text { Dispersión } \\
\text { (\%) }^{(1)}\end{array}$ \\
\hline $\mathrm{Ru} / \mathrm{C}$ & 1011 & 0,53 & 26 & Amorfa & 1,12 & 82 \\
\hline $\mathrm{Ru} / \mathrm{A}$ & 216 & 0,45 & 75 & Amorfa & 2,85 & 32 \\
\hline $\mathrm{Ru} / \mathrm{Z}$ & 24 & 0,10 & 174 & $\begin{array}{c}\mathrm{m}-\mathrm{ZrO}_{2} \text { and t- } \\
\mathrm{ZrO}_{2}\end{array}$ & $-(2)$ & _(2) \\
\hline$R u / Z-A$ & 166 & 0,43 & 96 & $\mathrm{t}-\mathrm{ZrO}_{2}$ & 1,42 & 64 \\
\hline $\mathrm{Ru} / \mathrm{PZ}$ & 40 & 0,16 & 208 & $\begin{array}{l}\text { Fosfato de } \\
\text { Zirconio }\end{array}$ & 5,7 & 16 \\
\hline Ru/ZP-A & 178 & 0,50 & 112 & amorfa & 3,08 & 30 \\
\hline
\end{tabular}

\section{2.- Hidrogenación de glucosa}

La hidrogenación de D-glucosa a D-sorbitol parece una reacción simple, pero en realidad, la D-glucosa no solamente se convierte de manera selectiva en D-sorbitol, sino que también puede dar muchos otros subproductos (como se muestra en la figura 6.1). Algunos de estos subproductos pueden provocar, incluso, la desactivación del catalizador. Entre las posibles reacciones competitivas, el reordenamiento Lobry de Bruyn-Alberda van Ekenstein de la D-glucosa da lugar a la formación de D-manosa y D- 
fructosa. Aldehídos (gliceraldehído, formaldehído) y cetonas (dihidroxiacetona) se podrían originar por escisión en medio alcalino de las moléculas de azúcar. La hidrogenación en fase líquida de D-glucosa conduce en general como producto principal a D-sorbitol y como subproducto principal a D-manitol. La forma de ajustar la selectividad al producto deseado pasa por una correcta selección del metal activo y del soporte catalítico.

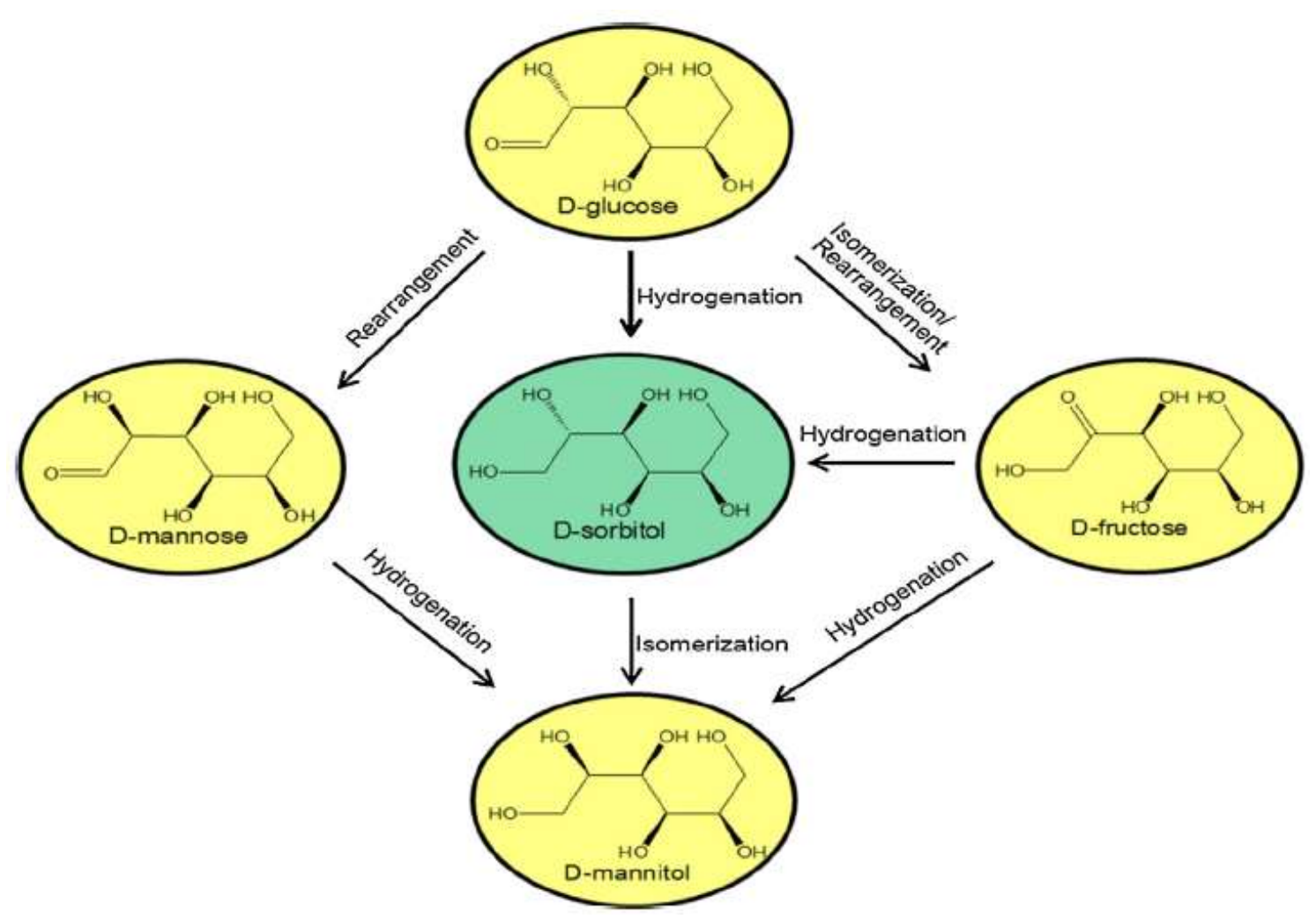

Figura 6.1. Posibles transformaciones de glucosa (Extraída de Mishra D. K. y col., 2014)

El objetivo principal que nos hemos planteado al estudiar la hidrogenación en fase acuosa de D-glucosa, es obtener selectivamente D-sorbitol. En 2004, el Departamento de Energía de los EE. UU. identificó al D-sorbitol como uno de los 12 productos químicos de valor agregado más importantes que se pueden obtener de la biomasa, como fuente potencial de alcanos para biocombustibles líquidos o como "un componente sobresaliente para la obtención de productos químicos básicos", especialmente a través de su deshidratación a isosorbida (Vilcocq L y col., 2013). Los ésteres $\mathrm{y}$ otros derivados del $\mathrm{D}$-sorbitol son también importantes aditivos $\mathrm{e}$ intermediarios en las industrias de los cosméticos y productos farmacéuticos, siendo la 
molécula un sustituto clave del azúcar en la industria de los alimentos y bebidas, con una producción mundial anual de aproximadamente 800000 toneladas (Zhang X. y col., 2016). El D-Sorbitol se obtiene comúnmente a través de la hidrogenación de D-glucosa, empleando catalizadores a base de $\mathrm{Ni}, \mathrm{Ru}, \mathrm{Pt}$ y $\mathrm{Rh}$, soportados sobre óxidos, distintos tipos de carbón, polímeros, hidrotalcitas y zeolitas (Mishra D.K. y col., 2014; Perrard A. y col., 2007).

Los procesos comerciales existentes emplean catalizadores de Níquel Raney o $\mathrm{Ru}$, soportados en carbón. Sin embargo, con el primero de ellos se obtiene una selectividad relativamente baja, además del hecho de que es propenso a la desactivación progresiva en el transcurso de la reacción y a la contaminación del producto, mientras que el rutenio es susceptible de envenenamiento por impurezas orgánicas fuertemente adsorbidas sobre su superficie (Kusserow B., Schimpf S. y Claus P., 2003).

Obviamente, la existencia de un proceso catalítico comercial no impide la búsqueda de mejoras en el proceso y en el avance del conocimiento científico fundamental. Es por ello que en esta Tesis Doctoral se propuso continuar explorando acerca del papel de los soportes básicos y de las fases activas con el objetivo de llegar selectivamente a D-sorbitol en condiciones de reacción más suaves que las reportadas en la literatura.

\subsection{1.- Experimental}

Los ensayos de hidrogenación se llevaron a cabo en un reactor tipo autoclave (Berghof BR 100, $100 \mathrm{~cm}^{3}$ ) a $90^{\circ} \mathrm{C}$ y $1,25 \mathrm{MPa} \mathrm{H}_{2}$ durante $7 \mathrm{~h}$, empleando 0,25 g de catalizador; condiciones suaves para una reacción de hidrogenación en fase acuosa, y menores a las normalmente reportadas en bibliografía (Lee J., Kim Y.T. y Huber G.W., 2014). En cada ensayo se utilizaron $0,90 \mathrm{~g}$ de sustrato (glucosa) y $50 \mathrm{~cm}^{3}$ de agua como solvente. Las muestras de reacción fueron analizadas por HPLC utilizando un equipo UHPLC DIONEX UltiMate 3000 con detector de índice de refracción (RI) a $40^{\circ} \mathrm{C}$ después de la separación en una columna de exclusión iónica Phenomenex Rezex $\mathrm{RCM} \mathrm{Ca}^{+2}$ Monosaccharide $(300 \times 7,8 \mathrm{~mm})$ a $80^{\circ} \mathrm{C}$. Se utilizó agua milli Q como fase móvil y un caudal de $0,6 \mathrm{~cm}^{3} / \mathrm{min}$. Los productos fueron identificados por comparación con patrones puros. 
La conversión de sustrato y la selectividad de los productos fueron calculadas utilizando las siguientes expresiones:

$$
x(\%)=\frac{C^{0}-C^{t}}{C^{0}} 100
$$

Donde $\mathrm{X}$ es la conversión de sustrato, $\mathrm{C}^{0}$ es la concentración molar inicial de sustrato y $\mathrm{C}^{\mathrm{t}}$ su concentración molar en el tiempo $\mathrm{t}(\mathrm{min})$; ambos determinados por cromatografía.

La selectividad para el compuesto i $\left(\mathrm{S}_{\mathrm{i}}\right)$ se determinó como se indica en la siguiente ecuación:

$$
S(\%)_{i}=\frac{C_{i}^{\mathrm{t}}}{\sum_{i=1}^{n} C_{i}^{\mathrm{t}}} 100
$$

Donde $\mathrm{C}_{\mathrm{i}}^{\mathrm{t}}$ es la concentración molar del compuesto i en el tiempo t (min).

La velocidad inicial de conversión $\left(r_{i}\right)$ se definió como los milimoles de reactivo consumidos, por gramo de metal de base y por min; y considerando los datos en $x$ $\leq 10 \%$.

\subsection{2.- Resultados y discusión}

Los seis sistemas preparados en el laboratorio se ensayaron en la hidrogenación de glucosa (figura 6.2).

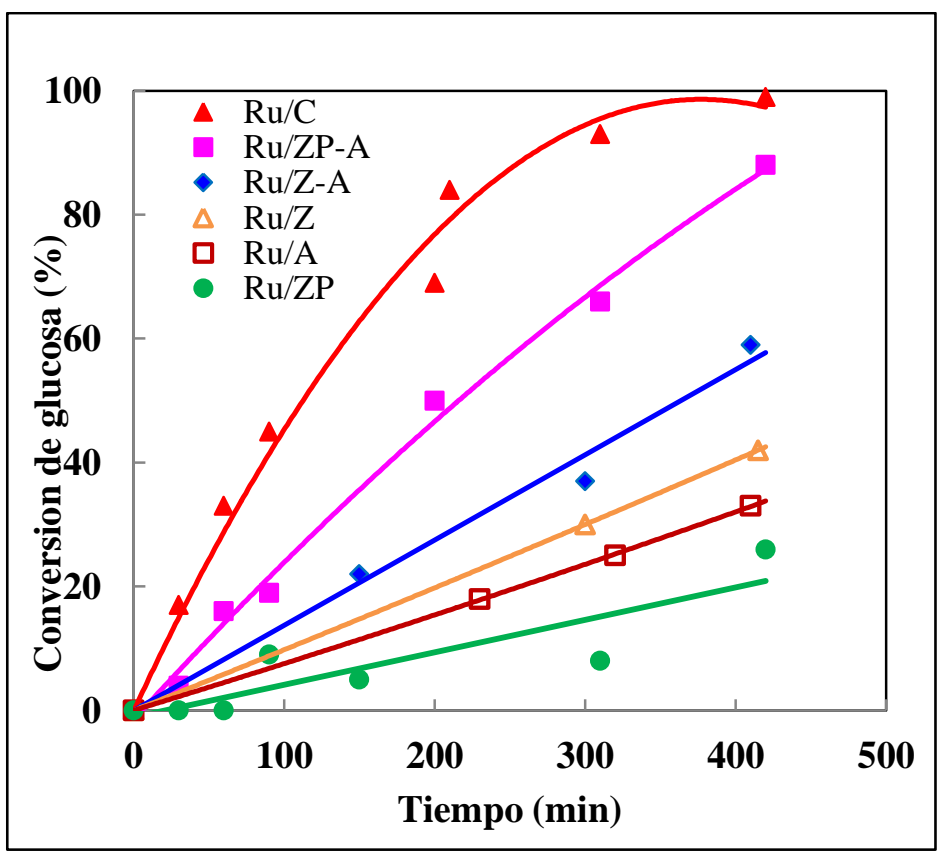

Figura 6.2. Conversión de glucosa con los seis catalizadores preparados. $\left(T=90^{\circ} \mathrm{C}, \mathrm{P}_{\mathrm{H} 2}=1,25\right.$ $\mathrm{MPa}$, glucosa $=0,9 \mathrm{~g}$, catalizador $=250 \mathrm{mg}$, agua $=50 \mathrm{ml}$ ) 
El sistema $\mathrm{Ru} / \mathrm{C}$ fue el que presentó mayor actividad, obteniéndose una conversión del 99\% luego de 7 h de reacción. Para el mismo tiempo de reacción se obtuvieron conversiones más bajas con el resto de los catalizadores (tabla 6.2). También se muestran las velocidades iniciales obtenidas para los seis catalizadores. Las mismas se calcularon para valores de tiempo de reacción a 10\% de conversión. En el caso del catalizador soportado sobre carbón, la velocidad inicial resultó de 2 a 13 veces superior que para los demás sistemas preparados.

Tabla 6.2. Conversiones obtenidas en la hidrogenación de glucosa con catalizadores de Ru soportados.

\begin{tabular}{ccc}
\hline Catalizador & Conversión (\%) & $\mathbf{r}_{\mathbf{i}}^{(\mathbf{1})}$ \\
\hline $\mathbf{R u} / \mathbf{C}$ & 99 & 3,27 \\
$\mathbf{R u} / \mathbf{A} u / \mathbf{Z}$ & 33 & 0,50 \\
$\mathbf{R u} / \mathbf{Z}-\mathbf{A}$ & 42 & 0,59 \\
$\mathbf{R u} / \mathbf{Z P}$ & 59 & 0,87 \\
\hline $\mathbf{R u} / \mathbf{Z P}-\mathbf{A}$ & 26 & 0,25 \\
\hline${ }^{(1)} \mathrm{r}_{\mathrm{i}}:$ mmoles $_{\text {conv }} \mathrm{g}_{\mathrm{Ru}}{ }^{-1} \mathrm{~min}^{-1}$ (velocidades iniciales calculadas para un 10\% de conversión)
\end{tabular}

La mayor conversión observada para Ru/C podría deberse, en principio, a que dicho sistema posee un tamaño de partículas menor y una mayor dispersión de la fase metálica, respecto a los demás catalizadores. Los catalizadores soportados sobre Z-A, A y ZP presentan un comportamiento que va en este mismo sentido.

Sin embargo resulta llamativo el caso del catalizador Ru/ZP-A que teniendo una dispersión del 30\% (menor a las de Ru/Z-A y Ru-A) alcanzó una conversión del 88\%. Esto hace evidente que la actividad de los catalizadores, además de la dispersión metálica, también depende de las características del soporte.

Los sistemas soportados sobre alúmina (Ru/ZP-A y Ru/Z-A) alcanzaron mayores conversiones que los catalizadores másicos (Ru/ZP y Ru/Z).

Analizando los resultados, el orden que siguen los catalizadores según su actividad resulta coincidente con el observado para los ensayos de hidrogenación de furfural realizados en esta tesis y que posteriormente serán discutidos en el capítulo 7.

En reportes de literatura se ha especulado que el grado de desorden de los catalizadores se incrementa agregando fósforo, lo que facilita el flujo de hidrógeno 
durante el reacción (Li H. X., Wang W. J. y Deng J. F., 2000). Por otra parte Zhang y col. (Zhang J. y col., 2013) realizaron estudios empleando una aleación amorfa de NiMoAl, la cual exhibió conversión completa de glucosa y selectividad de 99\% a sorbitol. Los autores atribuyen los elevados valores de actividad obtenidos al agregado de Mo, el cual generó un aumento del grado de desorden, evitando la cristalización del Ni. Este comportamiento se dirige en el mismo sentido que el observado por nuestro sistema Ru/ZP-A en cuanto a que una superficie amorfa favorecería la actividad catalítica.

También, Hui Li y colaboradores (Li H. y col., 2008) estudiaron un catalizador de Ru-P amorfo, preparado por reducción química de cloruro de rutenio con hipofosfito $\left(\mathrm{H}_{2} \mathrm{PO}_{2}{ }^{-}\right)$, en la hidrogenación en fase líquida de maltosa. En sus trabajos, compararon también el catalizador amorfo con uno de Ru-P tratado a $600^{\circ} \mathrm{C}$ en flujo de $\mathrm{N}_{2}$ por $2 \mathrm{~h}$, el cual presentó cierto grado de cristalinidad. A pesar del menor grado de dispersión del Ru, Ru-P exhibió una mayor actividad intrínseca que el catalizador Ru-B (también preparado por los autores con una técnica similar). Para la reacción estudiada, determinaron una energía de activación aparente (Ea) de 27 kJ/mol para Ru-P, más baja que la obtenida sobre Ru-B (32 kJ/mol), sugiriendo que los sitios catalíticos de Ru en Ru-P eran más activos que aquellos en Ru-B. Los autores argumentan que este comportamiento podría atribuirse a la mayor cantidad de sitios activos insaturados resultantes de la aleación de Ru con P y que podría fortalecer la adsorción de reactivos y favorecer la actividad hidrogenante (Yoshida S. y col., 1984; Angel G. D. y Benitez J. L., 1994). Por otro lado, Makkee y col. (Makkee M., Kieboom A. P. G. y Van Bekkum H., 1985) confirmaron que la hidrogenación de fructosa y glucosa procede a través de la forma de anillo más que en la estructura lineal de la cetona o aldehído. Beenackers y otros (Beenackers J. A. W. M., Kuster B. F. M. y Van der Baan H. S., 1985) mostraron que, tras la adsorción de glucosa en metales, se genera una especie ionizada (es decir, anión de glucosa) susceptible de ataque por hidrógeno adsorbido disociativamente en sitios metálicos vecinos, iniciando la reacción. En los estudios de XPS mostrados por los autores, Ru en Ru-P exhibió una relativamente menor densidad electrónica de la banda d que en Ru-B. Tal deficiencia de electrones en el sitio activo de Ru podría adsorber fuertemente el átomo de $\mathrm{O}$ en el sacárido, activando el enlace C-O para la hidrogenación llevando a la actividad intrínseca más alta. 
En cuanto a la selectividad (ver figura 6.1), se obtuvo sorbitol como principal producto para los seis catalizadores y no se observaron reacciones de deshidratación, en la hidrogenación de glucosa. Este resultado podría estar en relación con las temperaturas de reacción empleadas en las reacciones.

Tabla 6.3.Selectividades obtenidas en la hidrogenación de glucosa con catalizadores de Ru soportados

\begin{tabular}{ccc}
\hline Catalizador & $\begin{array}{c}\text { Selectividad a } \\
\text { sorbitol (\%) }\end{array}$ & $\begin{array}{c}\text { Selectividad a } \\
\text { otros (\%) }\end{array}$ \\
\hline $\mathrm{Ru} / \mathrm{C}$ & $\approx 100$ & 0 \\
$\mathrm{Ru} / \mathrm{A}$ & $\approx 100$ & 0 \\
$\mathrm{Ru} / \mathrm{Z}$ & 98,13 & 1,87 \\
$\mathrm{Ru} / \mathrm{Z}-\mathrm{A}$ & $\approx 100$ & 0 \\
$\mathrm{Ru} / \mathrm{ZP}$ & $\approx 100$ & 0 \\
$\mathrm{Ru} / \mathrm{ZP}-\mathrm{A}$ & 97,49 & 2,50 \\
\hline
\end{tabular}

Lazaridis y colaboradores (Lazaridis P. A. y col., 2015) investigaron la performance de los catalizadores soportados $\mathrm{Ru}$ y $\mathrm{Pt} / \mathrm{C}$ con diferente cargas metálicas (1-5\% en peso) y medios reductores $\left(\mathrm{NaBH}_{4}\right.$ y $\left.\mathrm{H}_{2}\right)$ en la hidrogenación de glucosa a 1,6 $\mathrm{MPa} \mathrm{H}_{2}$ y $180^{\circ} \mathrm{C}$. Estos autores propusieron que una temperatura más alta podría promover reacciones de hidrogenólisis hacia alcoholes de azúcar más pequeños (es decir, glicerol) disminuyendo así la selectividad hacia el sorbitol. Esto lo verificaron principalmente para los catalizadores $\mathrm{Ru} / \mathrm{C}$ y en menor medida para los catalizadores de Pt/C. Los otros productos principales formados fueron 1,2,5,6-hexanetetrol (alcohol de azúcar (6), arabinitol (alcohol C5), treitol y/o meso-eritritol (alcohol C4), glicerol y 1,2-propanodiol (alcoholes C3). La selectividad a sorbitol con el catalizador de Ru/C al $1 \%$ de carga metálica reducido con $\mathrm{NaBH}_{4}$ (Ru/C-B) fue del 54\%, mientras que 1,2,5,6hexanetetrol, 1,2-propanodiol y glicerol también se formaron con valores de selectividad de $\sim 6 \%, 20 \%$ y $17 \%$ respectivamente. El aumento del contenido de metal favoreció la hidrogenación de glucosa hacia sorbitol $(73 \%$ de selectividad con el catalizador Ru/C-B a 3\% de carga metálica) con la formación paralela de arabinitol (12\% de selectividad) y en menor medida glicerol, 1,2-propanodiol y azúcares C4 (aprox. 3-6\% de selectividad). Al aumentar aún más la carga de Ru (a 5\%) la formación de arabinitol aumentó a aproximadamente $25 \%$ con una consecuente disminución de 
la selectividad de sorbitol al 55\%. Respecto a la selectividad y rendimiento de sorbitol para los catalizadores $\mathrm{Ru} / \mathrm{C}-\mathrm{H}$ (reducido con $\mathrm{H}_{2}$ a $350^{\circ} \mathrm{C}$ ), se observó un comportamiento similar, siendo el catalizador $\mathrm{Ru} / \mathrm{C}-\mathrm{H} 3 \%$ en peso más selectivo (89\% de selectividad) que el catalizador reducido $\mathrm{NaBH}_{4}$ correspondiente. En el caso de los catalizadores usados en esta tesis, no se observó ninguna de estas reacciones secundarias indicando la selectividad de los sistemas preparados.

El mecanismo de formación de sorbitol generalmente aceptado implica la adsorción disociativa de $\mathrm{H}_{2}$ molecular en metales como $\mathrm{Pt}, \mathrm{Ru}, \mathrm{Ni}$, y la posterior adición del par de átomos de hidrógeno al grupo hemiacetal de glucosa, que conduce a la escisión del enlace C-O y la formación del grupo hidroxilo (-OH) (Ruppert A.M., Weinberg K. y Palkovits R., 2012). Esta etapa de reacción se produce fácilmente en metales específicos y sistemas catalíticos a temperaturas de reacción de aprox. 100$120^{\circ} \mathrm{C}$ y presiones de $\mathrm{H}_{2}$ aproximadamente de 3-8 $\mathrm{MPa}$, como se ha demostrado previamente en estudios dirigido a la maximización de la selectividad y el rendimiento de sorbitol. (Lazaridis P.A. y col., 2015);Ruppert A.M., Weinberg K. y Palkovits R.,2012; A. Negoi, y col, 2014). La acidez del soporte además, es un aspecto positivo para la reacción ya que como se ve en la figura 6.3 un ion hidronio puede transferir un protón al anillo 05 seguido de la rotura del enlace C1-05. Una molécula de agua vecina se lleva el protón de $\mathrm{HC1}^{+}-\mathrm{OH}$ forma un aldehído $\mathrm{HC}=\mathrm{O}$. Así una estructura de anillo de la glucopiranosa cíclica se transforma en una conformación aldosa de cadena abierta (Qian X., 2013).
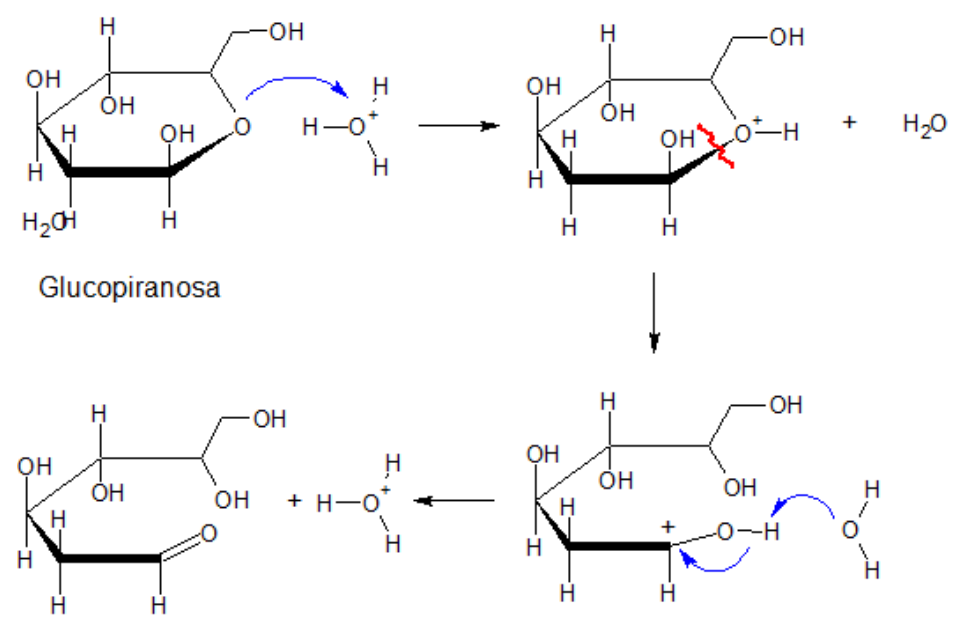

Aldosa

Figura 6.3. Mecanismo de apertura de glucopiranosa cíclica en medio ácido. 


\section{3.- Hidrogenación de xilosa}

\subsection{1.- Introducción}

La hidrogenación catalítica de la xilosa se ha estudiado y utilizado ampliamente para producir xilitol, una molécula plataforma muy importante, que se puede transformar en una variedad de productos químicos (Wyman C.E., Decker S.R., Himmel M.E. y col., 2004; Corma A. Iborra S. y Velty A., 2007; Fukuoka A. y Dhepe P.L., 2007). El xilitol, un alcohol de azúcar de cinco átomos de carbono, es un excelente edulcorante, similar a la sacarosa, que endulza casi el doble que el sorbitol y aproximadamente tres veces más que el manitol, y se encuentra en una pequeña cantidad en la naturaleza (Olinger P.M. y Pepper T., 2001). El xilitol tiene otras propiedades interesantes tales como anticancerígeno, a la vez que posee una amplia gama de aplicaciones en industrias de alimentos, farmacéutica, cosmética y resinas sintéticas (Mishra D.K y Dabbawala A.A., 2013a).

La hidrogenación catalítica en fase líquida de la xilosa, en principio, parece simple, pero la formación de pequeñas cantidades de subproductos, por ej. xilulosa (a través de isomerización) complica el proceso. La xilulosa se puede hidrogenar además a arabinitol y xilitol (Figura 6.4). Además, en algunos casos bajo condiciones severas (a altas temperaturas y altas concentraciones de álcali) existe la posibilidad de formación de furfural y ácido xilónico como subproductos. Es sabido que la reacción de Cannizzaro catalizada por álcali es normalmente responsable para la formación de ácido xilónico. En general, las condiciones de reacción son elegido de tal manera que la formación de ácido xilónico y furfural quede impedida (Yadav M., Mishra D. K., Hwang J., 2012). Por lo tanto, los principales subproductos son xilulosa y arabinitol, pudiéndose ser suprimida su generación mediante el uso de baja temperatura y alta presión de hidrógeno (Mikkola J.P., y col., 2000). 


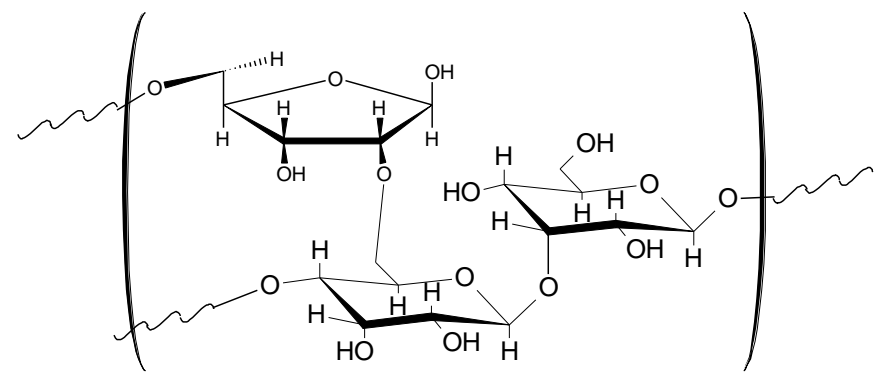

hemicelulosa

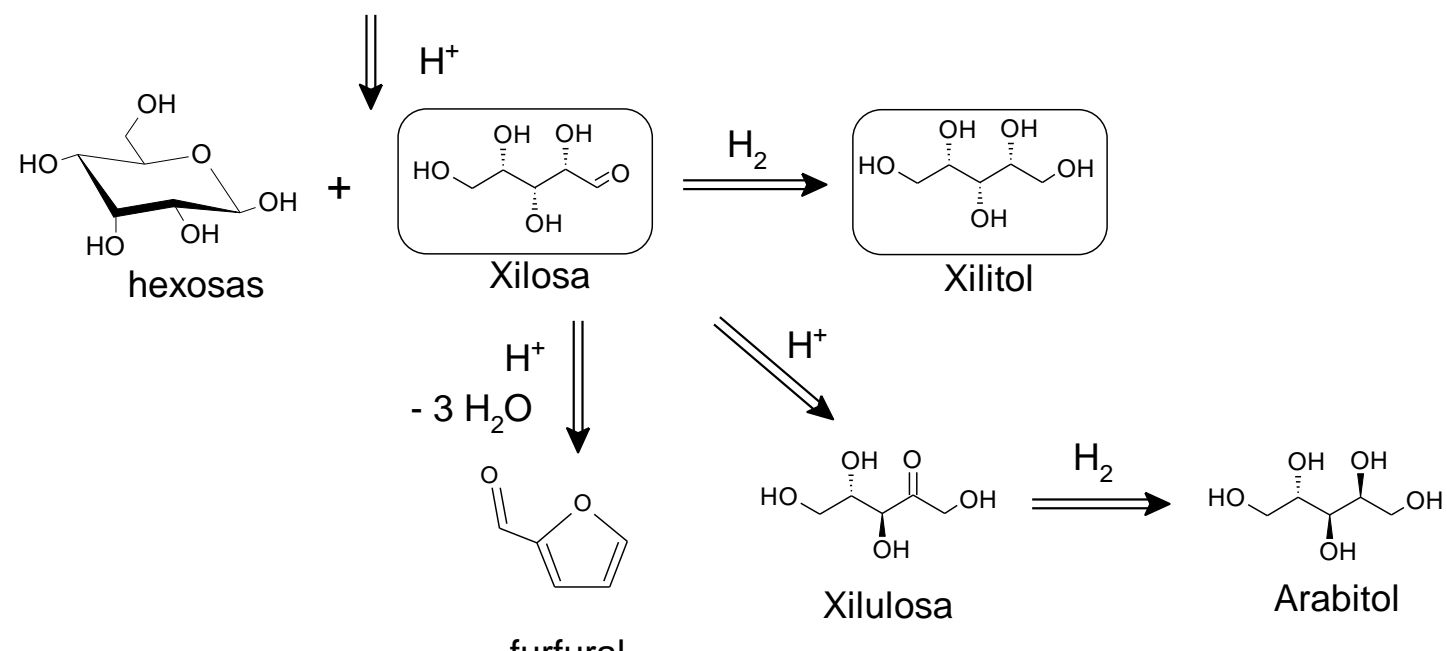

furfural

Figura 6.4. Transformaciones principales y secundarias en la hidrogenación de xilosa

\subsection{2.- Resultados y discusión}

Las condiciones experimentales en las que se realizaron los ensayos son las mismas que las utilizadas en la hidrogenación de glucosa, descriptas en el apartado 6.2.1. (Experimental).

Para la hidrogenación en fase líquida de xilosa a xilitol se esperaba un comportamiento similar al observado en la hidrogenación de glucosa a sorbitol presentada anteriormente, no obstante, las actividades obtenidas fueron diferentes; además de observarse la formación de una pequeña cantidad del subproducto arabitol. Este resultado hace que el proceso sea más complicado, ya que se requiere una etapa adicional para lograr la purificación del xilitol. A pesar de esto, los resultados obtenidos con el catalizador Ru/ZP-A son muy alentadores, ya que fue posible hidrogenar xilosa alcanzando una conversión de casi $100 \%$ con una selectividad a xilitol superior al $99 \%$. 
En la figura 6.5 se presentan los resultados de conversión de xilosa en función del tiempo de reacción para los catalizadores de Ru monometalicos ensayados.

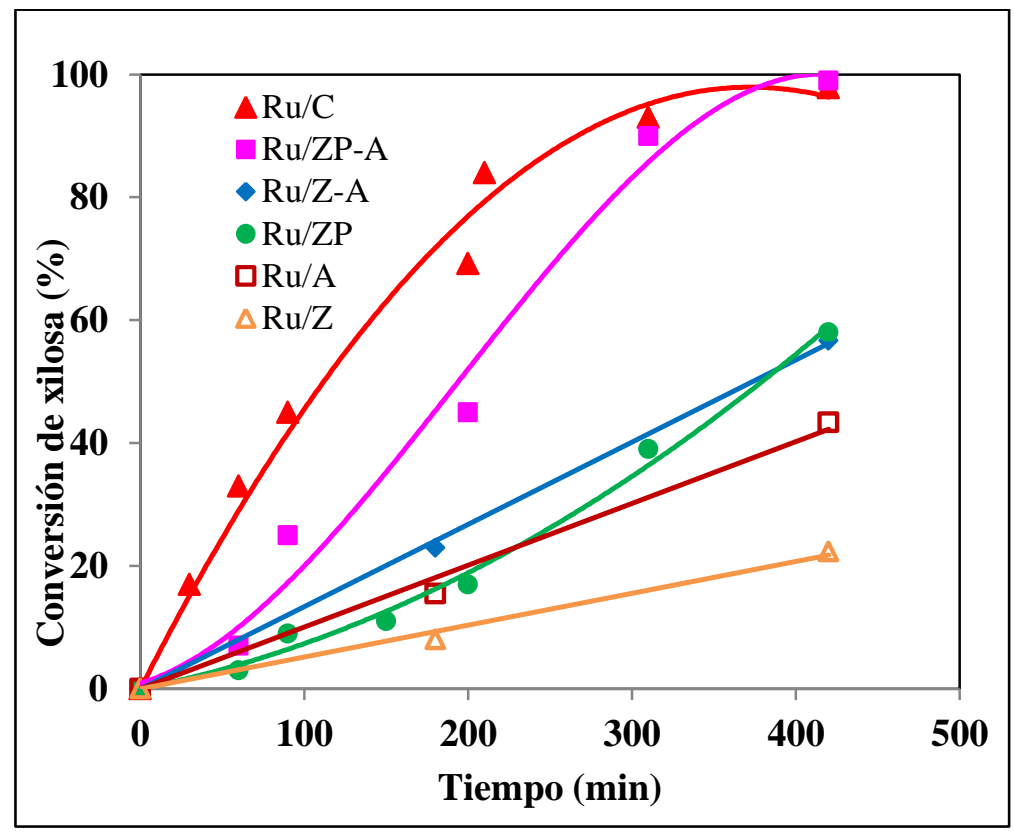

Figura 6.5. Conversión de xilosa $\left(\mathrm{T}=90^{\circ} \mathrm{C}, \mathrm{P}_{\mathrm{H} 2}=1,25 \mathrm{MPa}\right.$, xilosa $=0,9 \mathrm{~g}$, catalizador $=250 \mathrm{mg}$, agua $=50 \mathrm{ml}$ )

La actividad de los catalizadores resultó altamente dependiente del soporte. Con el catalizador de Ru/C se obtuvo una conversión del $98 \%$ y la velocidad de reacción fue la más alta exhibida entre los sistemas catalíticos, siendo entre 1,6 y 9,5 veces mayor que las de los demás, como puede verse en la tabla 6.4. Siguiendo a este catalizador los sistemas Ru/Z-A, Ru/A presentaron valores de conversión menores, en correspondencia con el grado de dispersión metálica, mientras que Ru/Z fue el que obtuvo la menor conversión.

Tabla 6.4. Conversiones obtenidas en la hidrogenación de xilosa con catalizadores de Ru soportados.

\begin{tabular}{ccccc}
\hline Catalizador & Conversión (\%) & $\mathbf{r}_{\mathbf{i}}^{(\mathbf{1})}$ & $\mathbf{D}_{\text {va }}(\mathbf{n m})$ & Dispersión (\%) $^{(\mathbf{2})}$ \\
\hline $\mathrm{Ru} / \mathrm{C}$ & 98 & 3,26 & 1,12 & 82 \\
$\mathrm{Ru} / \mathrm{A}$ & 43 & 0,65 & 2,85 & 32 \\
$\mathrm{Ru} / \mathbf{Z}$ & 22 & 0,33 & $-{ }^{(3)}$ & $-{ }^{(3)}$ \\
$\mathrm{Ru} / \mathrm{Z}-\mathrm{A}$ & 57 & 0,87 & 1,42 & 64 \\
$\mathrm{Ru} / \mathrm{ZP}$ & 58 & 0,51 & 5,70 & 16 \\
$\mathrm{Ru} / \mathrm{ZP}-\mathrm{A}$ & 99 & 1,98 & 3,08 & 30 \\
\hline
\end{tabular}

(1) $\mathrm{r}_{\mathrm{i}}$ : $\mathrm{mmoles}_{\text {conv }} \mathrm{g}_{\mathrm{Ru}}{ }^{-1} \mathrm{~min}^{-1}$ (velocidades iniciales calculadas para un $10 \%$ de conversión)

(2) Calculada como $D_{R u}=\frac{0,91}{d_{T E M}}$ 
Por otra parte, estos catalizadores mostraron valores de selectividad a xilitol siguiendo el orden $\mathrm{Ru} / \mathrm{A}>\mathrm{Ru} / \mathrm{Z}-\mathrm{A}>\mathrm{Ru} / \mathrm{Z}$ (tabla 6.5) y menores a $\mathrm{Ru} / \mathrm{C}$. Esto podría estar relacionado con el diferente grado de acidez de los soportes. (Mishra D. K., Dabbawala A.A. y Hwang J. S,2013b).

Resultan particulares los comportamientos observados con los sistemas fosfatados. A pesar de los menores valores de dispersión Ru/ZP-A y Ru/ZP exhibieron una conversión del $99 \%$ y $58 \%$ respectivamente en las $7 \mathrm{~h}$ de reacción ensayadas, con una selectividad a xilitol cercana al $100 \%$ en ambos casos. Ambos catalizadores presentaron un período de inducción al comienzo de la reacción, siendo más notorio en el caso del soporte másico (ZP)

Tabla 6.5. Selectividades obtenidas en la hidrogenación de xilosa con catalizadores de Ru soportados.

\begin{tabular}{cccc}
\hline Catalizador & $\begin{array}{c}\text { Selectividad a } \\
\text { xilitol (\%) }\end{array}$ & $\begin{array}{c}\text { Selectividad a } \\
\text { arabinitol (\%) }\end{array}$ & $\begin{array}{c}\text { Selectividad a } \\
\text { otros (\%) }\end{array}$ \\
\hline $\mathrm{Ru} / \mathrm{C}$ & 98,7 & 0,8 & 0,5 \\
$\mathrm{Ru} / \mathrm{A}$ & 95,6 & 0 & 4,4 \\
$\mathrm{Ru} / \mathrm{Z}$ & 90,7 & 1,8 & 7,5 \\
$\mathrm{Ru} / \mathrm{Z}-\mathrm{A}$ & 93,4 & 2,3 & 4,3 \\
$\mathrm{Ru} /$ ZP & $\approx 100$ & 0 & 0 \\
$\mathrm{Ru} /$ ZP-A & $\approx 100$ & 0 & 0 \\
\hline
\end{tabular}

En relación a este comportamiento podemos mencionar que Yadav y colaboradores (Yadav M., Mishra D. K. y Hwang J., 2012) informaron también la obtención de altos valores de conversión y selectividades en sistemas preparados a base de $\mathrm{Ru}$ siendo mayores para el caso de $\mathrm{Ru}(1,0 \%) / \mathrm{NiO}(5,0 \%)-\mathrm{TiO}_{2}$ respecto a $\mathrm{Ru}$ $(1,0 \%) / \mathrm{TiO}_{2}$ a pesar de la menor dispersión del primero respecto al segundo. En el mecanismo propuesto para la hidrogenación de xilosa, el átomo de $\mathrm{O}$ del grupo carbonilo se adsorbe en la superficie del catalizador junto con la adsorción del átomo de $\mathrm{O}$ en el grupo hidroxilo adyacente al grupo carbonilo sobre el catalizador (Lee J., Kim Y. T. y Huber G. W., 2012). 


\section{4.- Hidrogenación de celobiosa}

También se realizaron ensayos de estos sistemas catalíticos empleando celobiosa (Figura 6.6) como sustrato. Este compuesto es un disacárido formado por dos moléculas de glucosa unidas por medio de lo que se conoce como enlace $\mathrm{O}$ glucosídico, a través de los grupos hidroxilo del carbono 1 en posición beta de una glucosa y del carbono 4 de la otra glucosa. Por ello, la celobiosa también se llama betaD-glucopiranosil-(1-4)-beta-D-glucopiranosa y constituye un sustrato modelo de la fragmentación de celulosa.

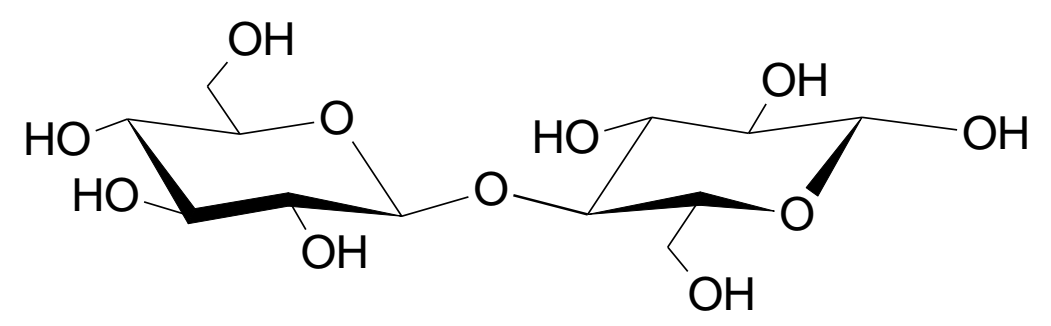

Figura 6.6. Estructura de celobiosa

La celobiosa fue seleccionada como una molécula modelo simple de celulosa, para el estudio del comportamiento de nuestros sistemas catalíticos frente a los polisacáridos. Los ensayos se realizaron en las mismas condiciones que para los monosacáridos $\left(90^{\circ} \mathrm{C}\right.$ y $1,25 \mathrm{MPa} \mathrm{H}_{2}$ durante $7 \mathrm{~h}, 0,25 \mathrm{~g}$ de catalizador; 0,90 g de celobiosa y $50 \mathrm{~cm}^{3}$ de agua).

La figura 6.7 presenta las conversiones obtenidas con los cuatro catalizadores a base de $\mathrm{ZrO}_{2}$. Estos catalizadores se seleccionaron teniendo en cuenta su mayor grado de acidez. Junto con ellos, se presenta también los resultados obtenidos con el catalizador de Ru/C (de menor acidez) a modo comparativo. Los resultados indican que los sitios metálicos de Ru hidrogenan eficientemente celobiosa a celobitol (3- $\beta$ Dglucopiranosil- D-glucitol), siendo el grado de conversión dependiente de la dispersión de la fase metálica. Se observan bajos valores de conversión para los casos de los soportes másicos (19\% para Z y $8 \%$ para ZP), mientras que dicho valor aumentó al depositarlos sobre alúmina (92\% para Z-A y $80 \%$ para ZP-A). El catalizador de Ru/C fue el que obtuvo la mayor conversión (96\%). 


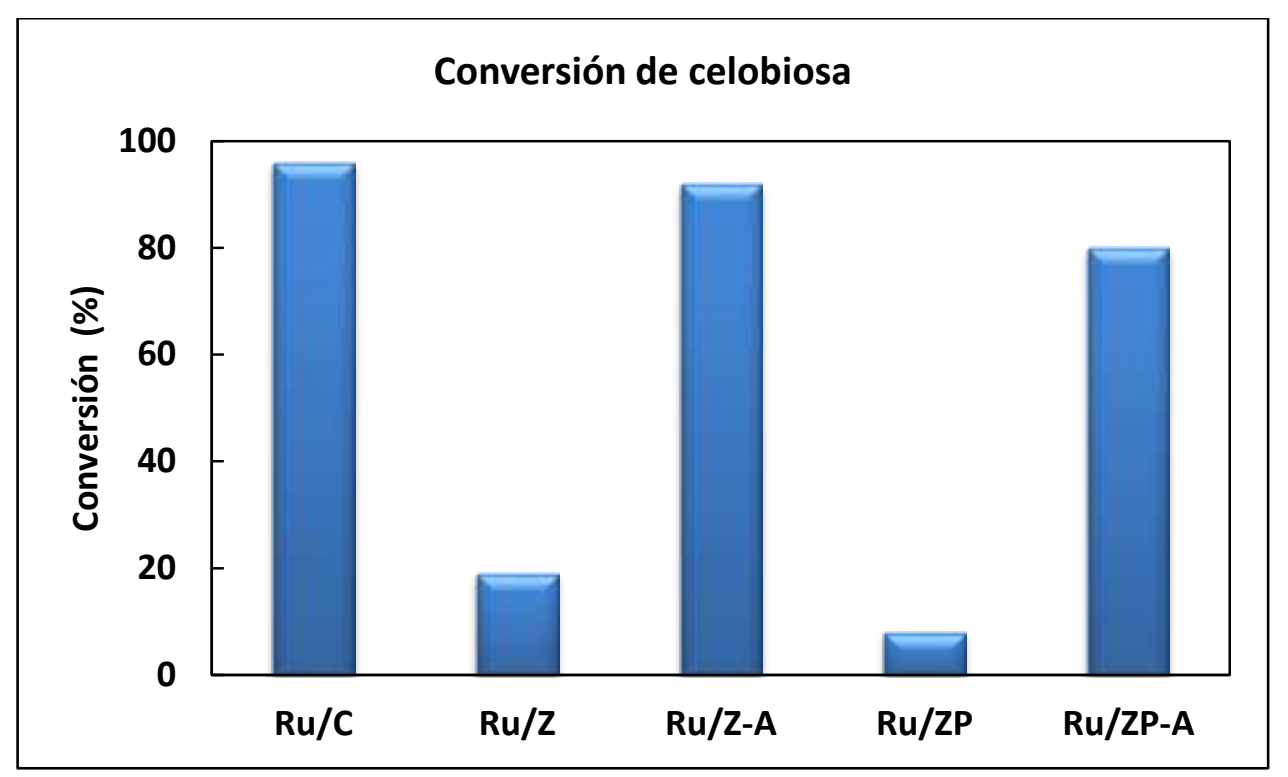

Figura 6.7. Conversiones obtenidas en la hidrogenación en fase acuosa de celobiosa. $\left(T=90^{\circ} \mathrm{C}\right.$, $P_{\mathrm{H} 2}=1,25 \mathrm{MPa}$, celobiosa $=0,9 \mathrm{~g}$, catalizador $=250 \mathrm{mg}$, agua $=50 \mathrm{ml}$ )

De las posibles vías de transformación, mostradas en la figura 6.8 , el 3- $\beta-D-$ glucopiranosil-D-glucitol fue el único producto observado.

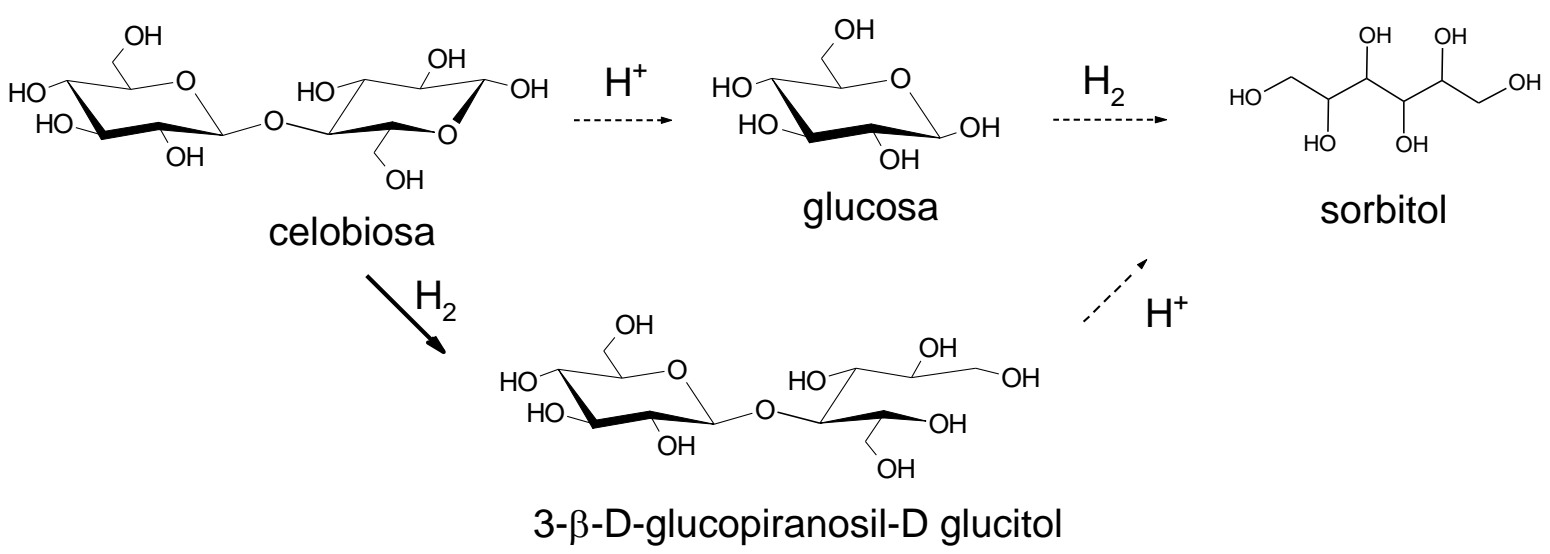

Figura 6.8. Posibles reacciones de celobiosa

Este resultado indica que la reacción transcurre a través de la apertura del enlace C1O-C5 en un monómero de glucosa de la molécula de celobiosa a través de hidrogenólisis, seguida de la hidrogenación a 3- $\beta$-D-glucopiranosil-D-glucitol, ambos en los sitios Ru (Niu Y. y col, 2014). El hecho de que no se haya observado la presencia de glucosa ni sorbitol, indica que el enlace 1,4-glicosídico no pudo ser hidrolizado. 
Dos factores pueden contribuir a esto: por un lado la estructura relativamente voluminosa de la celobiosa puede impedir estéricamente la adsorción de la molécula en el sitio ácido del catalizador a través de su enlace 1,4-glicosídico. La celobiosa tiene ocho grupos alcoholes libres $(\mathrm{OH})$, un enlace acetal y un enlace hemiacetal, los cuales dan lugar a fuertes enlaces de hidrógeno inter e intramoleculares. Estos fuertes enlaces de hidrógeno y dos anillos rígidos de glucosa hacen menos posible la rotación y flexión del de los mismos, por lo tanto, el enlace C-O-C es menos accesible a la superficie del catalizador. Este fuerte impedimento estérico también ha sido reportado por otros (Niu Y. y col., 2014; Yoon E.Y., 2001). Por otro lado, y más probablemente, la acidez de los soportes no haya sido suficiente para escindir el enlace glicosídico C-O-C.

\section{5.- Hidrólisis enzimática para la obtención de azúcares}

Como se ha mencionado previamente, la celulosa, se compone exclusivamente de cadenas de glucosa no ramificadas unidas (entre 38 y $50 \%$ del peso seco) (Fan L.T., Gharpuray M.M. y Lee Y.H., 1987). La transformación de la celulosa en azúcares (para luego ser hidrogenados) y productos bioderivados, se puede llevar a cabo mediante procesos de fermentación, a través de métodos químicos o una combinación de ambos. Esta última elección, la combinación de reacciones biocatalíticas y quimiocatalíticas que conducen a procesos de una sola etapa en medio acuoso, representa un concepto económica y ecológicamente atractivo (Gröger H. y Hummel W., 2014).

La Figura 6.9 representa la estructura química de la celulosa y los productos que pueden obtenerse mediante una combinación de la estrategia de dos pasos en one-pot basada en el uso de un catalizador enzimático seguido de un paso quimiocatalítico. 


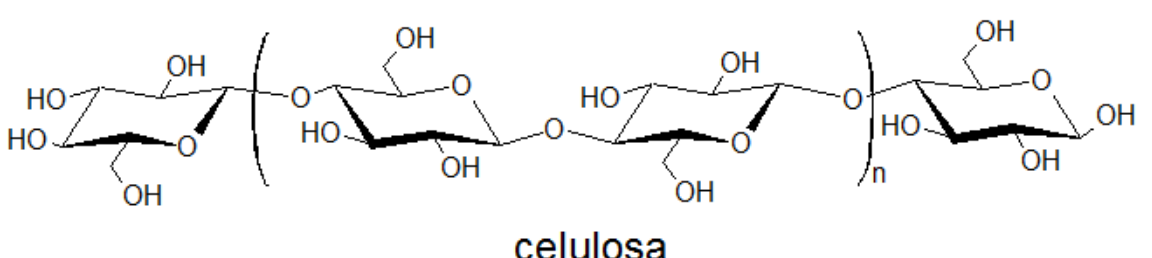

celulosa
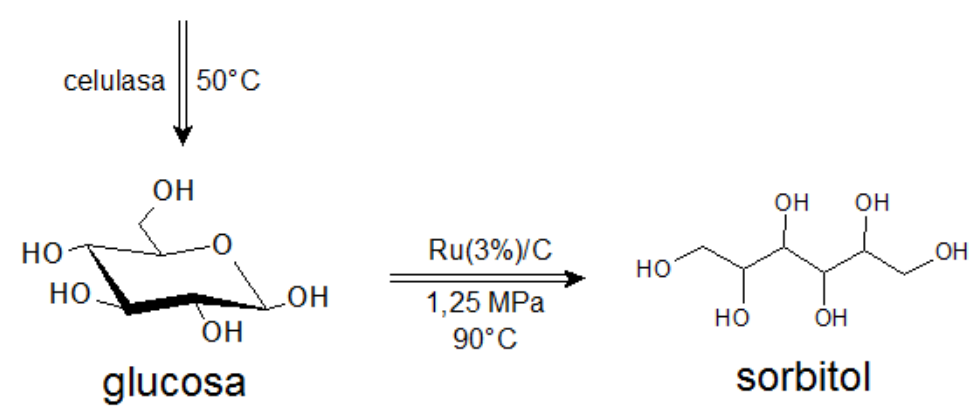

Figura 6.9. De la celulosa a la glucosa y sorbitol a través de una estrategia de dos pasos en one-pot.

La producción de glucosa a través de la hidrólisis enzimática de la celulosa requiere un paso de pretratamiento para "liberar" los carbohidratos de sus impedimentos estructurales, de modo que el material se vuelva más accesible al ataque enzimático (Fan L.T., Gharpuray M.M. y Lee Y.H., 1987). Se realizó un ensayo hidrólisis se llevó a cabo en condiciones suaves $(\mathrm{pH}=4,8$ controlado con buffer cítrico/citrato, 50 드. agitación suave) usando una enzima comercial Aspergillus sp. celulasa (Sigma-Aldrich) como catalizador. La dosificación enzimática utilizada fue de 14,5 UI/g de celulosa, sin embargo para el tiempo de reacción utilizado (18 h), no se obtuvieron rendimientos significativos de glucosa.

Previamente para determinar la dosificación de la celulasa se determinó la actividad enzimática según Unidades de Papel de Filtro (FPU) siguiendo el protocolo determinado por IUPAC (Ghose T.K., 1987), midiendo azúcares reductores por el método del ácido dinitrosalicílico (DNS) (SIGMA-ALDRICH).

Para ello, se llevaron a cabo una serie de reacciones empleando diferentes diluciones de la enzima y posteriormente se midió la absorbancia espectrofométricamente para determinar la cantidad de glucosa (expresada como azúcares reductores). Para estas reacciones se utilizó:

- Buffer de reacción: buffer cítrico-citrato 0,05M pH 4,8

- Sustrato: celulosa $2 \% \mathrm{p} / \mathrm{v}$ en buffer de reacción 
- Diluciones de la enzima: en buffer de reacción (se deben realizar al menos 2 diluciones de la enzima que deben liberar una un poco más de 0,5 mg de glucosa y otra un poco menos en las condiciones de reacción.

- Condiciones de reacción: $30 \mathrm{~min}$ a $50^{\circ} \mathrm{C}$ (baño termostático) y $\mathrm{pH} \mathrm{4,8}$ (buffer)

- Mezcla de reacción: $0,5 \mathrm{~cm}^{3}$ de la dilución de enzima $+0,5 \mathrm{~cm}^{3}$ de solución de celulosa. Se mezcló bien e incubó a $50^{\circ} \mathrm{C}$ durante $30 \mathrm{~min}$.

- Pasado el tiempo de reacción, se retiraron del baño y se agregaron 3 $\mathrm{cm}^{3}$ del reactivo DNS para determinar azúcares reductores (glucosa).

- Se colocó a ebullición durante 5 min en baño a $100^{\circ} \mathrm{C}$ y luego se transfirió a baño de agua fría para enfriar.

- Se agregaron $20 \mathrm{~cm}^{3}$ de agua destilada y se mezcló completamente por inversión del tubo varias veces.

- Se midió la absorbancia (Abs) a $540 \mathrm{~nm}$ y empleando una curva de calibración se determinó la concentración de glucosa.

En la tabla 6.6 se resumen las mezclas preparadas.

Tabla 6.6. Soluciones para determinación de actividad enzimática

\begin{tabular}{|l|c|c|c|c|}
\cline { 2 - 5 } \multicolumn{1}{c|}{} & Enzima $^{\#}$ & Zero & Blanco Enz & Std Glucosa* \\
\hline Solución de enzima & $0,5 \mathrm{~cm}^{3}$ & --- & --- & --- \\
\hline Solución de celulosa & $0,5 \mathrm{~cm}^{3}$ & $0,5 \mathrm{~cm}^{3}$ & $0,5 \mathrm{~cm}^{3}$ & $0,5 \mathrm{~cm}^{3}$ \\
\hline Incubación a $50^{\circ} \mathrm{C}$ & $30 \mathrm{~min}$ & $30 \mathrm{~min}$ & $30 \mathrm{~min}$ & $30 \mathrm{~min}$ \\
\hline reactivo DNS & $3 \mathrm{~cm}^{3}$ & $3 \mathrm{~cm}^{3}$ & $3 \mathrm{~cm}^{3}$ & $3 \mathrm{~cm}^{3}$ \\
\hline Buffer citrato & --- & $0,5 \mathrm{~cm}^{3}$ & --- & --- \\
\hline Sc de enzima & --- & --- & $0,5 \mathrm{~cm}^{3}$ & --- \\
\hline Sc de glucosa estándar & --- & --- & --- & $0,5 \mathrm{~cm}^{3}$ \\
\hline \multicolumn{5}{|r|}{ MEZCLAR BIEN, HERVIR $5 \mathrm{~min}$ y agregar $20 \mathrm{~cm}^{3}$ de agua destilada } \\
\hline
\end{tabular}

\#determinaciones por triplicado

*determinaciones por duplicado

Para la curva de calibración de glucosa, se prepararon una serie de estándares, los cuales fueron medidos por el método de DNS (Miller G.L., 1959). Para esto se empleó: 
- Solución de DNS (ácido dinitrosalicílico): 0,75 gr DNS + 1,4 gr NaOH en $100 \mathrm{~cm}^{3}$ de agua destilada. Disolver y luego agregar: $21,61 \mathrm{gr}$ de tartrato de $\mathrm{Na}$ y K; $0,54 \mathrm{~cm}^{3}$ de fenol: 0,59 gr de metabisulfito de $\mathrm{Na}$.

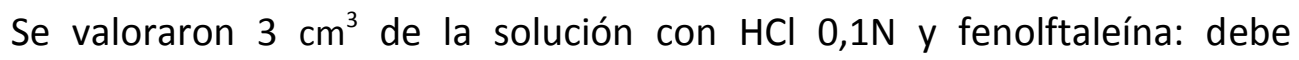
consumir 5-6 $\mathrm{cm}^{3}$ de $\mathrm{HCl}$, sino agregar $\mathrm{NaOH}\left(2 \mathrm{~g}\right.$ por $\mathrm{cm}^{3}$ de $\mathrm{HCl} 0,1 \mathrm{~N}$ adicionado de más).

- Estándar de glucosa: Solución Stock de glucosa $2 \mathrm{mg} / \mathrm{cm}^{3}$

Tabla 6.7. Soluciones estándar de glucosa

\begin{tabular}{|c|c|c|c|c|}
\hline & Stock & buffer & $\mathrm{glu} / \mathrm{cm}^{3}$ & $\mathrm{glu} / 0,5 \mathrm{~cm}^{3}$ \\
\hline Sin diluir & & & $2 \mathrm{mg} / \mathrm{cm}^{3}$ & $1 \mathrm{mg}$ \\
\hline $1 / 1,5$ & $1 \mathrm{~cm}^{3}$ & $0,5 \mathrm{~cm}^{3}$ & $1,33 \mathrm{mg} / \mathrm{cm}^{3}$ & $0,67 \mathrm{mg}$ \\
\hline $1 / 2$ & $1 \mathrm{~cm}^{3}$ & $1 \mathrm{~cm}^{3}$ & $1 \mathrm{mg} / \mathrm{cm}^{3}$ & $0,5 \mathrm{mg}$ \\
\hline $1 / 3$ & $0,5 \mathrm{~cm}^{3}$ & $1 \mathrm{~cm}^{3}$ & $0,67 \mathrm{mg} / \mathrm{cm}^{3}$ & $0,33 \mathrm{mg}$ \\
\hline $1 / 4$ & $0,5 \mathrm{~cm}^{3}$ & $1,5 \mathrm{~cm}^{3}$ & $0,5 \mathrm{mg} / \mathrm{cm}^{3}$ & $0,25 \mathrm{mg}$ \\
\hline
\end{tabular}

Reacción: se colocan en tubo de ensayo $1 \mathrm{~cm}^{3}$ de muestra $+3 \mathrm{~cm}^{3}$ del reactivo DNS. Se coloca en baño de agua a $100^{\circ} \mathrm{C}$ durante $5 \mathrm{~min}$. Se enfría a temperatura ambiente y se leer absorbancia a 540 empleando agua para ajustar el cero. En la figura 6.10 se pueden observar las muestras patrones de glucosa preparadas para ser medidas, ordenadas de mayor (izquierda) a menor (derecha) concentración.

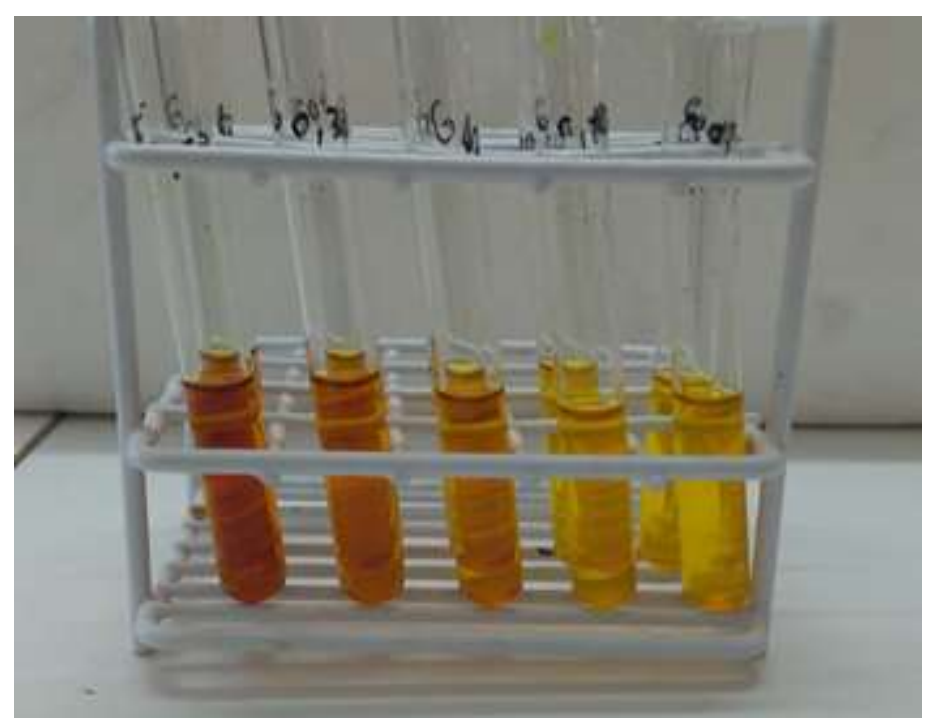

Figura 6.10. Estándares de glucosa con reactivo DNS 
A partir de estos se ensayos se determinó que la actividad de enzima fue de = $0,29 \mathrm{UI} / \mathrm{cm}^{3}$ de solución de enzima determinada según FPU.

En $3 \mathrm{~cm}^{3}$ de solución de enzima que usamos en reacción de hidrólisis $=3^{*} 0,29=0,87 \mathrm{UI}$ Solución de celulosa $=2 \% \mathrm{p} / \mathrm{v}=2 \mathrm{~g}$ en $100 \mathrm{~cm}^{3}$. En $3 \mathrm{~cm}^{3}=3 * 2 / 100=0,06 \mathrm{~g}$ de celulosa

0,06 g de ceulosa 0,87 UI de enzima

$1 \mathrm{~g}$ de celulosa $\mathrm{x}=14,5 \mathrm{UI} / \mathrm{g}$ de celulosa

La cantidad de glucosa obtenida luego de la hidrólisis resultó en muy bajo rendimiento, por lo que no se pudo efectuar el paso siguiente a su hidrogenación con el catalizador metálico.

En estudios posteriores se decidió evaluar la producción de enzimas lignocelulolíticas a partir del cultivo fúngico de Chaetomium globosum LPSC 259 y su utilización para la transformación de biomasa residual de la región noroeste de la provincia de Buenos Aires.

\subsection{1.- Transformación fúngica de los restos de Festuca sp. bajo condiciones de fermentación en estado sólido}

El material de partida fue fraccionado en segmentos y alícuotas de 2 gramos (peso seco) se colocaron en Erlenmeyers de $250 \mathrm{~cm}^{3}$.

Se llevó a cabo la incubación de los restos foliares de Festuca sp. que fueron hidratados al $70 \%$ de humedad (adicionando a cada Erlenmeyer $3 \mathrm{~cm}^{3}$ de agua) y pretratados con calor (autoclave a $121{ }^{\circ} \mathrm{C}$ durante 30 minutos) y en presencia del hongo durante 15 días a $24^{\circ} \mathrm{C}$ en oscuridad (Figura 6.11 y 6.12).

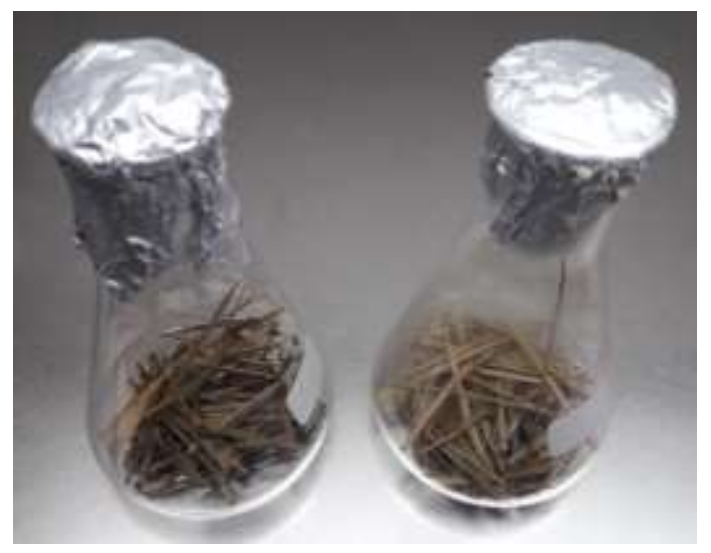

Figura 6.12. Sistema de tratamiento de los restos foliares al comienzo de la incubación. 


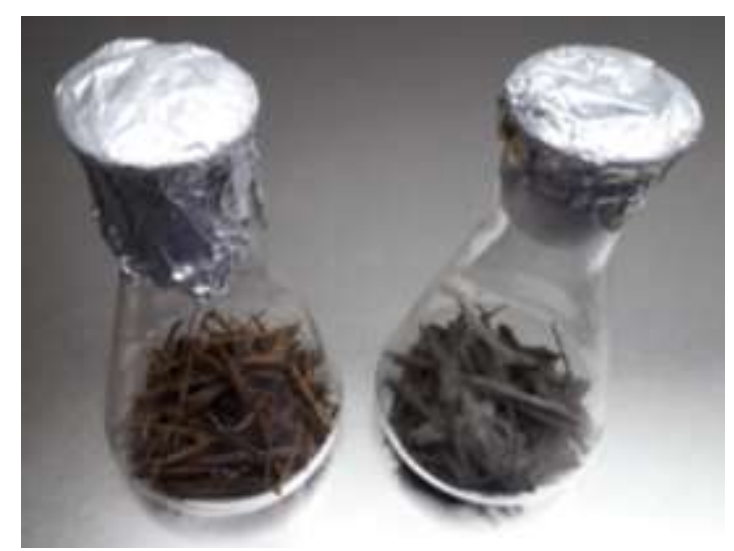

Figura 6.13. Sistema de tratamiento de los restos foliares a los 15 días de la incubación (Erlenmeyer control, izquierda; Erlenmeyer inoculado con el hongo, derecha).

La inoculación del hongo se realizó aplicando una suspensión de micelio y esporas obtenida a partir de cultivos agarizados del hongo sobre el sustrato siguiendo a Saparrat y col. (2010). Paralelamente se realizó un tratamiento control incubado bajo las mismas condiciones (conteniendo los mismos restos foliares de Festuca sp. hidratados al $70 \%$ de humedad y pretratados con calor pero sin inoculación - solo se adicionó al sistema un volumen de agua equivalente al volumen de inóculo aplicado al tratamiento con el hongo). Se hicieron cuatros réplicas (Erlenmeyers) del tratamiento inoculado y 4 adicionales control (sin inoculación). Adicionalmente, a los 7 días de incubación, cada Erlenmeyer fue suplementado con $3 \mathrm{~cm}^{3}$ de agua.

\subsection{2.- Procesamiento de la biomasa pretratada y colonizada con el hongo}

El contendido de cada Erlenmeyer se colocó en tubos-falcon de $50 \mathrm{~cm}^{3}$ que posteriormente se congelaron a $-20^{\circ} \mathrm{C}$.

La fracción soluble en agua se obtuvo agregando $20 \mathrm{~cm}^{3}$ de agua a las muestras y agitando a $25 \mathrm{rpm}$. por 2 horas a $4^{\circ} \mathrm{C}$. Posteriormente se separó la fracción líquida, se centrifugó a 8000 x g y $4^{\circ} \mathrm{C}$ durante 15 minutos y filtró en membrana para $10 \mathrm{kD}$ con el objeto de separar los complejos enzimáticos y aquellos compuesto solubles de elevado peso molecular (Figura 6.14). El filtrado se utilizó como sustrato para su hidrogenación con un catalizador de $\mathrm{Ru} / \mathrm{C}$ a $90^{\circ} \mathrm{C}$ y $1,25 \mathrm{MPa}$ de $\mathrm{H}_{2}$ y se analizó por HPLC para cuantificar la glucosa obtenida. 


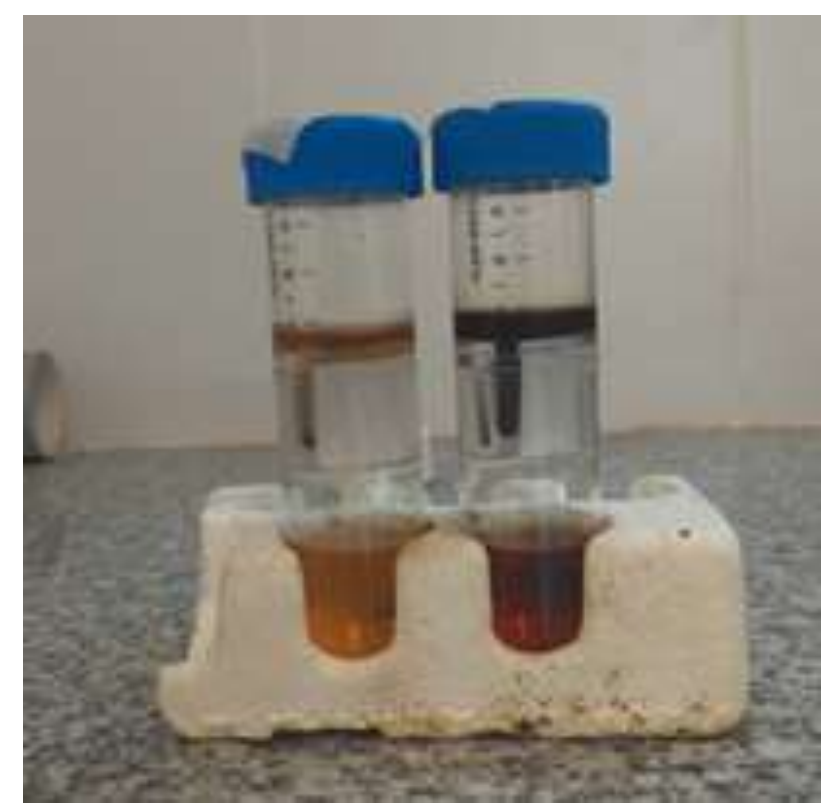

Figura 6.14. Filtrado de fracción líquida extraída del cultivo fúngico

La cantidad de glucosa obtenida a partir de la hidrólisis de biomasa no resultó en un valor significativo. Esto podría deberse a que el período de cultivo del hongo resultó demasiado extenso, resultando en el consumo del monosacárido producido, como fuente de carbono para su propio crecimiento. 


\section{6.- Conclusiones}

La actividad de los catalizadores estudiados resultó altamente dependiente del soporte en las hidrogenaciones en fase acuosa de glucosa, xilosa y celobiosa.

Los sistemas soportados sobre alúmina (Ru/ZP-A y Ru/Z-A) alcanzaron mayores conversiones que los catalizadores másicos. La elevada superficie específica y el mayor volumen de poro del soporte ZP-A desempeñan un papel fundamental a la hora de obtener una mejora en la performance catalítica.

En cuanto a la selectividad, se obtuvo para los seis catalizadores sorbitol como único producto y no se observaron reacciones de deshidratación, en la hidrogenación de glucosa.

En la hidrogenación de xilosa el producto mayoritario fue xilitol y se obtuvo una pequeña cantidad de arabinitol en los catalizadores $\mathrm{Ru} / \mathrm{C}, \mathrm{Ru} / \mathrm{Z}$ y $\mathrm{Ru} / \mathrm{Z}-\mathrm{A}$. El catalizador Ru/ZP-A presentó la mayor conversión (casi 100\%) y selectividad a xilitol (superior a 99\%).

Los sitios metálicos de Ru pueden hidrogenar el disacárido celobiosa a celobitol (3- $\beta$-Dglucopiranosil- D-glucitol). La conversión aumenta en relación al aumento de la dispersión metálica. Los sistemas Ru/C, Ru/Z-A y Ru/ZP-A presentaron los mayores valores de conversión. Sin embargo, la acidez de los soportes en ningún caso fue suficiente para escindir el enlace glicosídico C-O-C. 


\section{CAPÍTULO 7}

\section{ESTUDIO DE HIDROGENACIÓN DE FURFURAL CON CATALIZADORES DE RUTENIO SOPORTADO}


En este capítulo se presenta el estudio de la influencia de la naturaleza del soporte, así como su interacción con el Ru, sobre la actividad y selectividad de los catalizadores preparados en la hidrogenación en fase acuosa de furfural. Posteriormente se presenta el estudio del efecto del agregado de Sn como promotor mediante técnicas de QOMS/M a un catalizador de Ru monometálico.

Finalmente se presenta el estudio de la conversión catalítica de furfural proveniente de la pirólisis de cáscaras de semillas de girasol para producir bio-alcohol furfurílico, evaluando la performance en cuanto a la hidrogenación de los catalizadores de $R u / C$ y $R u S n_{0.4} / C$. 


\section{1.- Introducción}

Como se ha descripto en el Capítulo 1, el furfural es un producto obtenido de la biomasa por deshidratación térmica de azúcares. Este compuesto posee gran potencial como plataforma química renovable para la producción de bioproductos y biocombustibles (Cai C.M. y col., 2014), entre los cuales se encuentran el furano y el ácido furoico. Estos productos se usan para incrementar el octanaje de gasolinas y como materia prima y productos intermedios para síntesis de medicamentos y perfumes, respectivamente. También hay rutas catalíticas que, a partir del furfural, permiten la síntesis de poliamidas, caucho y diferentes tipos de Nylon, muchos de ellos con aplicación industrial y que actualmente se derivan de la industria petroquímica (Kamm B., Gruber P.R. y Kamm M., 2005).

En este trabajo de Tesis se ha planteado la valorización de furfural mediante su hidrogenación catalítica con la finalidad de obtener selectivamente alcohol furfurílico. Esta reacción es un claro ejemplo de como pueden obtenerse diferentes compuestos de acuerdo al tipo de catalizador utilizado.

La molécula de furfural posee un conjunto de dobles enlaces $\mathrm{C}=\mathrm{C}$ conjugados en el anillo furánico y el enlace $\mathrm{C}=\mathrm{O}$ del grupo funcional carbonilo, siendo así miembro del grupo de los aldehídos $\alpha, \beta$-insaturados. Estos grupos funcionales son factibles de hidrogenarse dependiendo del tipo de interacción entre el reactivo y la superficie del catalizador, dando lugar a un sistema de reacciones amplio y complejo (Figura 7.1). La hidrogenación del enlace $\mathrm{C}=\mathrm{O}$ da lugar al alcohol insaturado (alcohol furfurílico o FFA), mientras que la hidrogenación de los enlaces $\mathrm{C}=\mathrm{C}$ dan lugar al aldehído saturado (THFF). Ambas son reacciones paralelas, y por tanto competitivas. Posteriormente la formación del alcohol saturado (alcohol tetrahidrofurfurílico o THFA) es consecutiva a la formación de alcohol furfurílico o de tetrahidrofurfural.

También existe la posibilidad de que se produzca en paralelo la decarbonilación de furfural para dar lugar a furano. Otra reacción indeseable es la hidrogenólisis del enlace $\mathrm{C}=\mathrm{O}$ en el furfural que produciría 2-metilfurano. Por lo tanto, si el objetivo es obtener selectivamente el alcohol insaturado en la hidrogenación de furfural, debe favorecerse la velocidad de hidrogenación del grupo funcional $C=0$ frente a las demás rutas. 


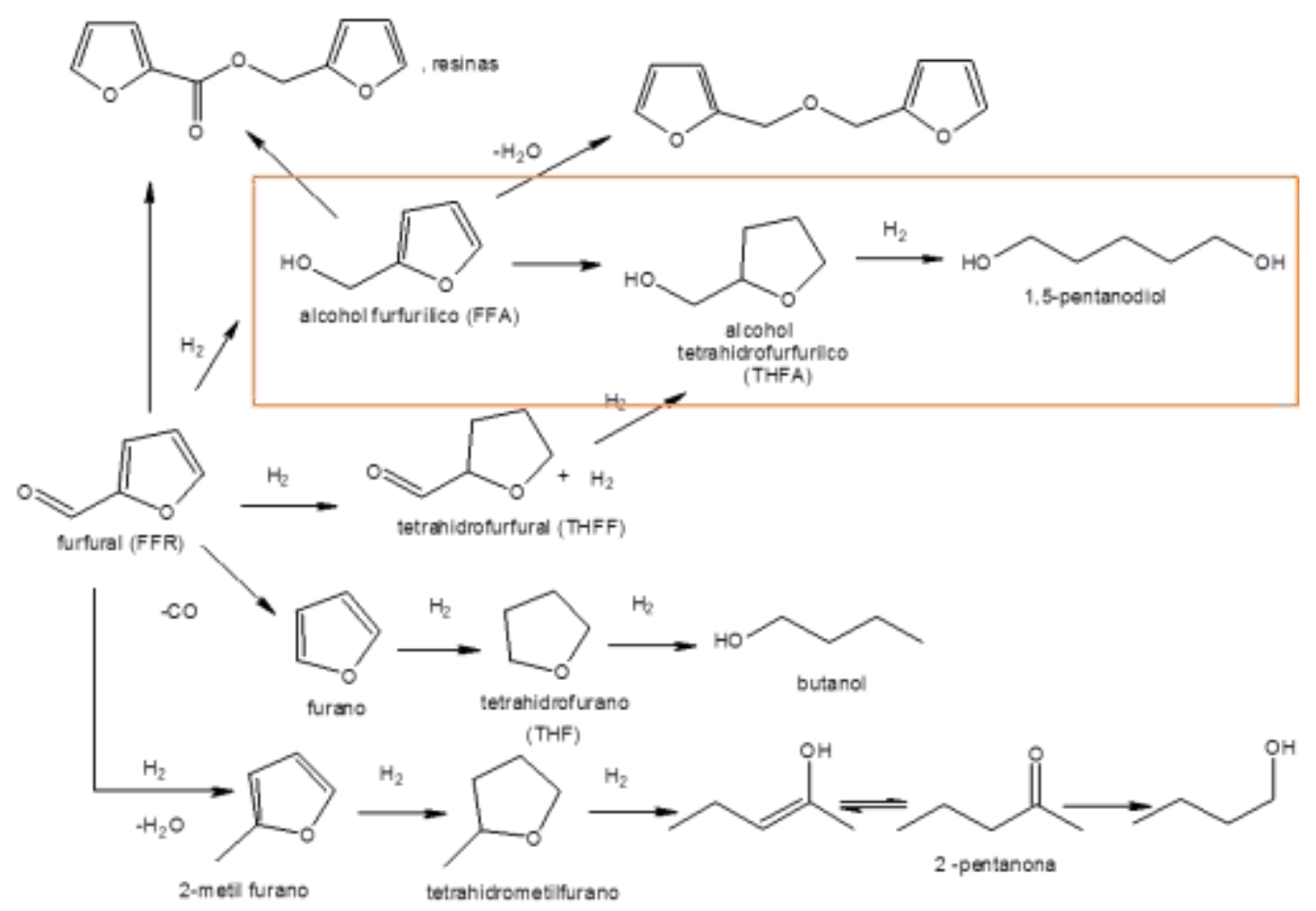

Figura 7.1. Productos de hidrogenación del furfural.

Si bien el alcohol insaturado es el producto más buscado, este compuesto resulta también el más difícil de obtener. Generalmente es más fácil la hidrogenación del doble enlace $\mathrm{C}=\mathrm{C}$ (Energía de enlace $=615 \mathrm{~kJ} / \mathrm{mol}(147 \mathrm{Kcal} / \mathrm{mol}))$ que la del grupo $\mathrm{C}=\mathrm{O}$ (Energía de enlace $=711 \mathrm{~kJ} / \mathrm{mol}(170 \mathrm{Kcal} / \mathrm{mol}))($ Rojas $\mathrm{H}$. y col., 2008).

Sin embargo, las cetonas y aldehídos $\alpha, \beta$-insaturados pueden ser hidrogenados selectivamente a los alcoholes insaturados, siempre que las reacciones sean llevadas a cabo sobre ciertos catalizadores a temperatura y presión suficientemente baja. (Ide M. S. y col., 2012). Así, este tipo de reacciones también resulta un reto termodinámico interesante.

En estos compuestos, el impedimento estérico asociado con grupos sustituyentes voluminosos cercanos al enlace $C=C$ también juega un papel importante en la determinación de la selectividad (Torres G.C. y col., 1999; Von Arx M., Mallat T y Baker A., 1999) Sin embargo, esto solo no puede explicar por qué hay una falta de selectividad al alcohol insaturado para la mayoría de las reacciones de hidrogenación de cetonas $\alpha$, $\beta$-insaturadas sobre catalizadores de Pd, Pt y Ru, (Marinelli T., Nabuurs S. y Ponec V., 1995; Milone C. y col., 2003; Margitfalvi J. y col., 2002), ya que estos metales en ocasiones pueden hidrogenar selectivamente aldehídos $\alpha, \beta$-insaturados 
con similares impedimentos estéricos cerca el enlace $\mathrm{C}=\mathrm{C}$. Así, resultan diversos los factores que influyen en el direccionamiento de la reacción. Entre ellos podemos mencionar la importancia que ejercen el tipo de metal catalítico empleado, el tamaño de partículas, el soporte del catalizador y la presencia de promotores.

Entre los metales que se han estudiado en bibliografía, el paladio parece ser el más selectivo en la formación de aldehídos saturados (Steffan, M y col., 2007; Lashdaf, M.; y col.) y rutenio (Lashdaf, M y col., 2003; Mercadante, L., 1996) y platino (Englisch, M., Ranade, V. S. y Lercher J. A., 1997; Dandekar, A. y Vannice, M. A., 1999) son moderadamente selectivos hacia la formación de los alcoholes insaturados.

Respecto al tamaño de partículas, se ha reportado que partículas de mayor tamaño aumentarían la selectividad al alcohol insaturado respecto a partículas más pequeñas. Sin embargo es importante tener en cuenta que el grado de sustitución en los aldehídos $\alpha$, $\beta$-insaturados también se ha demostrado que afecta en gran medida la selectividad (Ide M. S. y col., 2012). En relación a esto, en la hidrogenación de varios aldehídos $\alpha, \beta$-insaturados, Galvagno y col. (Galvagno S. y col., 1991; Galvagno, S. y col., 1993) observaron que la selectividad al alcohol insaturado fue mayor para el citral que el cinamaldehído sobre catalizadores de Ru/C que variaban en tamaño de partícula de 2 a $12 \mathrm{~nm}$. Estos resultados fueron respaldados por el trabajo de Mercadante y col. con partículas menores de $8 \mathrm{~nm}$. Aumentando el tamaño de partícula de Ru de 8 a $27 \mathrm{~nm}$ tanto en $\mathrm{Ru} / \mathrm{C}$ como en $\mathrm{Ru} / \mathrm{Al}_{2} \mathrm{O}_{3}$ se aumentó la selectividad al alcohol insaturado durante la hidrogenación de cinamaldehído, mientras que no se observó ningún efecto sobre la selectividad en la hidrogenación de citral. (Mercadante L. y col., 1996). Esto deja en evidencia que en ocasiones el efecto de un factor está condicionado a los demás intervinientes.

Además del tipo de metal y la presencia de grupos sustituyentes en la molécula reactiva, la composición del soporte y la presencia de promotores también pueden influenciar la performance de las reacciones de hidrogenación (Ide M. S. y col., 2012) Por ejemplo, Mercadante y col indicaron que un catalizador $\mathrm{Ru} / \mathrm{C}$ fue aproximadamente $20 \%$ más selectivo para el alcohol insaturado que un catalizador de $\mathrm{Ru} / \mathrm{Al}_{2} \mathrm{O}_{3}$ para la hidrogenación de cinamaldehído. (Mercadante L. y col., 1996). 
También, Lashdaf y col. observaron una mayor selectividad durante esta reacción en $\mathrm{Ru} / \mathrm{SiO}_{2}$ comparado con $\mathrm{Ru} / \mathrm{Al}_{2} \mathrm{O}_{3}$. (Lashdaf, M. y col., 2003).

Teniendo en cuenta estos antecedentes, en este trabajo de Tesis se llevaron a cabo investigaciones sobre la hidrogenación de furfural. En una primera etapa se presentarán, en este capítulo, los estudios realizados en la hidrogenación de furfural empleando catalizadores monometálicos heterogéneos a base de Ru soportados.

También, en la literatura se encuentran numerosos estudios dedicados a mejorar la selectividad hacia el alcohol insaturado mediante diversos procedimientos: control fino de los tamaños y/o las caras cristalinas expuestas de las nanopartículas metálicas activas, (Zhu Y. y Zaera F., 2014; Serrano-Ruiz J. y col., 2008), aprovechamiento de restricciones estéricas impuestas por el entorno del sitio activo (Guo Z. y col., 2014) o modificando el metal de base con un segundo componente metálico (Liu Z. y col., 2013; Merlo A. B. y col., 2010). Siguiendo esta última estrategia, Vilella M.J., De Miguel S.R. y colaboradores investigaron la hidrogenación de citral en fase líquida llevada a cabo a $70^{\circ} \mathrm{C}$ y presión atmosférica sobre catalizadores de Pt y PtSn soportados tanto en polvo de carbón activado (C) como en fieltro (ACf); encontrando que la adición de Sn a los catalizadores de Pt aumenta la velocidad de reacción de la hidrogenación de citral, siendo esta influencia más importante para los catalizadores basados en carbono. La adición de Sn mejoró notablemente la selectividad a alcoholes insaturados dobles (nerol y geraniol) para ambas series de catalizadores (Vilella I.M.J. y col, 2005).

Este último camino fue el seleccionado para el desarrollo de esta tesis. Como bien sabemos, el comportamiento catalítico de sistemas bimetálicos depende del tamaño de las partículas metálicas, la interacción entre ellas y con el soporte, otros componentes del catalizador, etc. A su vez, el segundo metal puede influenciar al primero a través de interacciones electrónicas o modificando la arquitectura del sitio activo (Basset J. M. y col., 2009 y referencias allí citadas).

De particular interés son los catalizadores bimetálicos preparados por una secuencia de reacciones superficiales, lo que resulta en un sistema en el que ambos metales tienen una fuerte interacción. Una de las estrategias propuestas para obtener estos catalizadores se desarrolló en la escuela rusa encabezada por el Prof. Yermakov, 
y consiste en el anclaje de un complejo de un metal noble sobre cationes metálicos de un metal oxofílico unidos a un soporte (Lefebvre L., Candy J. P. y Basset J. M., 1999). El procedimiento de preparación implica varios pasos, el primero es la interacción de un compuesto organometálico del metal de base con los grupos hidroxilo superficiales de la sílice. El segundo metal es generalmente uno del grupo 8 (por ejemplo, Ni, Pd, Pt, etc.). La unión entre los dos metales debe ser lo suficientemente fuerte como para mantener el complejo bimetálico intacto después de la activación del catalizador. Aunque es posible obtener sistemas estables y altamente dispersos, también se obtienen partículas monometálicas, originadas por la interacción de los compuestos organometálicos utilizados con el soporte.

Un método de preparación de catalizadores bimetálicos soportados altamente dispersos que se desprende del anterior, implica la reacción de complejos metálicos con "clusters" metálicos soportados. El método se basa en la idea de que mediante una elección cuidadosa del complejo metálico y el control de los parámetros de reacción, puede ser posible hacer que el complejo metálico reaccione selectivamente con el metal soportado, pero no con la superficie de soporte (Lefebvre L., Candy J. P. y Basset J. M., 1999). Esta aproximación al tema es la que da lugar a las denominadas técnicas de la Química Organometálica de Superficies sobre Metales (QOMS/M).

La aplicación de estas técnicas nos permite controlar las distintas etapas de preparación de los sistemas catalíticos, dando lugar a sólidos reproducibles desde el punto de vista de la estructura y de su performance. Según lo desarrollado en el capítulo IV, estas técnicas consisten en la reacción entre un metal de transición M (en el caso de este trabajo, el metal utilizado fue el $\mathrm{Ru}$ ), soportado y un compuesto organometálico $\mathrm{M}^{\prime}\left(\mathrm{C}_{4} \mathrm{H}_{9}\right)_{4}\left(\mathrm{M}^{\prime}=\mathrm{Sn}\right)$ en atmósfera de $\mathrm{H}_{2}$, donde deben ser tenidos en cuenta distintos aspectos operativos (temperatura, naturaleza del soporte, estado físico del compuesto organometálico y del precursor monometálico), ya que de ellos van a depender los productos de reacción (Ferretti O. A. y Casella M. L.; 1995). 


\section{2.- Condiciones experimentales}

Las reacciones de hidrogenación de furfural (FF) en fase líquida fueron realizadas en un reactor tipo autoclave (Berghof BR-100) a 1,25 MPa de presión de $\mathrm{H}_{2}$, $90^{\circ} \mathrm{C}$ de temperatura y empleando $0,25 \mathrm{~g}$ de catalizador. En cada ensayo se utilizaron $0,45 \mathrm{~cm}^{3}$ de furfural (Aldrich, 99\%) y $50 \mathrm{~cm}^{3}$ de agua como solvente. El diseño del equipo de reacción fue descripto en el capítulo 2.

Las condiciones de reacción fueron establecidas a partir de los análisis, de las diferentes variables operativas, realizados en estudios previos efectuados por nuestro grupo de trabajo así como en trabajos reportados en bibliografía. (Merlo A. B. y col., 2009; Merlo A. B. y col., 2010).

Dichas condiciones se eligieron con el objetivo de obtener un catalizador que pueda reemplazar al catalizador comercial $\mathrm{Cu}-\mathrm{Cr}$ utilizado en la industria y que permita hidrogenar selectivamente el furfural a alcohol furfurílico en fase líquida utilizando condiciones suaves (más moderadas que en el proceso industrial estándar; $160^{\circ} \mathrm{C}$ y 4 MPa de $\mathrm{H}_{2}$ ) y ambientalmente amigables.

La evolución de la reacción fue seguida por cromatografía gaseosa en un cromatógrafo Varian CP-3800 provisto de una columna capilar CP Wax 52 CB (30 m; 0,3 $\mathrm{mm}$ d.i.) y un detector FID. Los productos de reacción fueron identificados utilizando un equipo GC/MS HP5890 equipado con una columna HP5-MS (30 m, 0.25 $\mathrm{mm}$ d.i.).

La conversión del furfural y la selectividad de los productos fueron calculadas utilizando las siguientes expresiones:

$$
x(\%)_{F F}=\frac{C_{F F}^{0}-C_{F F}^{t}}{C_{F F}^{0}} 100
$$

Donde $\mathrm{X}_{\mathrm{FF}}$ es la conversión de furfural, $\mathrm{C}_{\mathrm{FF}}^{0}$ es la concentración molar inicial de furfural y $C_{F F}^{t}$ su concentración molar en el tiempo $t$ (min); ambos determinados por cromatografía.

La selectividad para el compuesto i $\left(\mathrm{S}_{\mathrm{i}}\right)$ se determinó como se indica en la siguiente ecuación: 


$$
S(\%)_{i}=\frac{C_{i}^{\mathrm{t}}}{\sum_{i=1}^{n} C_{i}^{\mathrm{t}}} 100
$$

Donde $\mathrm{C}_{\mathrm{i}}^{\mathrm{t}}$ es la concentración molar del compuesto i en el tiempo t (min).

La velocidad inicial de conversión de furfural $\left(r_{i}\right)$ se definió como los milimoles de reactivo consumidos, por gramo de metal de base y por min; y considerando los datos en los que $\mathrm{X}_{\mathrm{FF}} \leq 10 \%$.

\section{3.- Hidrogenación con catalizadores monometalicos}

En la figura 7.2 se presentan los resultados de conversión de furfural en función del tiempo de reacción para los catalizadores de Ru monometalicos preparados (3\% en peso) sobre distintos soportes: $\mathrm{Ru} / \mathrm{C}, \mathrm{Ru} / \mathrm{A}, \mathrm{Ru} / \mathrm{Z}, \mathrm{Ru} / \mathrm{ZP}, \mathrm{Ru} / \mathrm{Z}-\mathrm{A}$ y $\mathrm{Ru} / \mathrm{ZP}-\mathrm{A}$ (la nomenclatura utilizada corresponde a la informada en la Tabla 3.1).

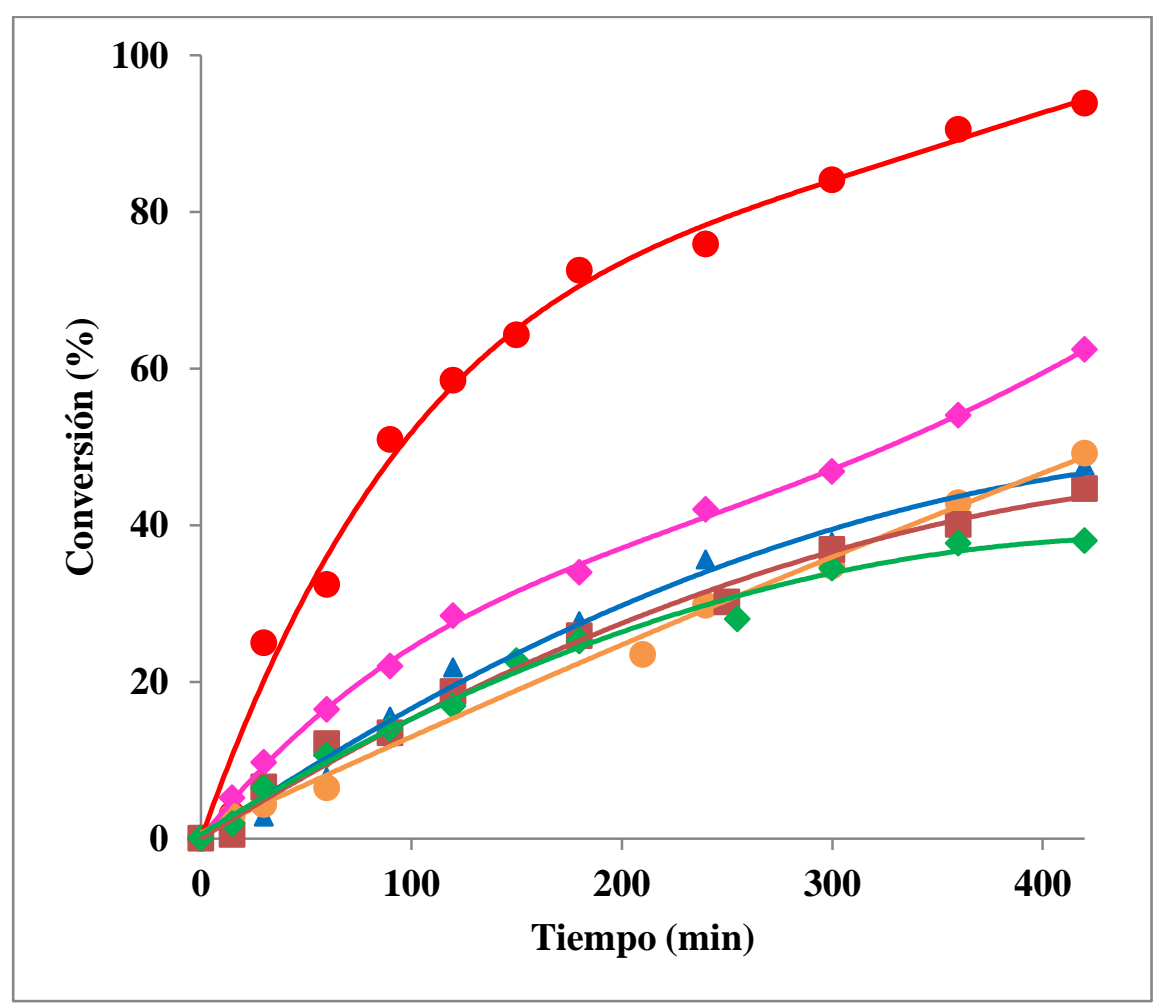

Figura 7.2. Hidrogenación de furfural empleando diferentes catalizadores monometálicos:

(•) Ru/C, (†) Ru/ZP-A, (A) Ru/Z-A, (•) Ru/Z, (ロ) Ru/A, (†) Ru/ZP

Como puede observarse, todos lo catalizadores resultaron activos en la hidrogenación de furfural bajo las condiciones experimentales ensayadas. El sistema 
$\mathrm{Ru} / \mathrm{C}$ fue el que presentó mayor actividad, obteniéndose una conversión del 94\% luego de 7 hs de reacción. Para el mismo tiempo de reacción se obtuvieron conversiones más bajas con el resto de los catalizadores (tabla 7.1). También se muestran las velocidades iniciales obtenidas para los seis catalizadores. Las mismas se calcularon para valores de tiempo de reacción a $10 \%$ de conversión. En el caso del catalizador soportado sobre carbón, la velocidad inicial resultó de 2 a 4 veces superior que para los demás sistemas preparados.

Tabla 7.1. Conversión luego de $7 \mathrm{~h}$ de reacción y velocidades iniciales en la hidrogenación de furfural con todos los catalizadores de Ru estudiados.

\begin{tabular}{|c|c|c|c|c|}
\hline Catalizador & Conversión (\%) & $r_{i}^{(1)}$ & $D_{\mathrm{va}}(\mathrm{nm})$ & Dispersión $(\%)^{(2)}$ \\
\hline $\mathrm{Ru} / \mathrm{C}$ & 94 & 4,7 & 1,12 & 82 \\
\hline $\mathrm{Ru} / \mathrm{A}$ & 45 & 1,2 & 2,85 & 32 \\
\hline $\mathrm{Ru} / \mathrm{Z}$ & 49 & 1,1 & $-{ }^{(3)}$ & $-(3)$ \\
\hline $\mathrm{Ru} / \mathrm{Z}-\mathrm{A}$ & 48 & 1,1 & 1,42 & 64 \\
\hline Ru/ZP & 38 & 1,4 & 5,70 & 16 \\
\hline $\mathrm{Ru} / \mathrm{ZP}-\mathrm{A}$ & 62 & 2,3 & 3,08 & 30 \\
\hline \multicolumn{5}{|c|}{ (1) $r_{i}:$ mmoles $_{\text {conv }} \mathrm{g}_{\mathrm{RU}}^{-1} \min ^{-1}$ (velocidades iniciales calculadas para un $10 \%$ de conversión) } \\
\hline (2) Calcula & $\mathrm{mo} D_{R u}=\frac{0.91}{d_{T E M}}$ & & & \\
\hline
\end{tabular}

La mayor conversión observada para Ru/C podría deberse, en principio, a que dicho sistema posee un tamaño de partículas menor y una mayor dispersión de la fase metálica, respecto a los demás catalizadores. Los catalizadores soportados sobre Z-A, A y ZP presentan un comportamiento que va en este mismo sentido, aunque el último de ellos presenta una mayor velocidad inicial de reacción. Esto podría indicar que la conversión final alcanzada por este catalizador puede estar limitada por interacción fuerte de algún compuesto que reduciría la disponibilidad de sitios activos. Sin embargo, Ru/Z-A también presenta mayor dispersión que los demás sistemas catalíticos aunque la actividad obtenida es similar a los mismos (el doble de dispersión que $\mathrm{Ru} / \mathrm{A}$ por ejemplo, aunque sólo un $6 \%$ de incremento en la conversión respecto a ese sistema catalítico). Ru/ZP-A, por su parte, presenta una dispersión similar a Ru/A 
( $30 \%$ y $32 \%$ respectivamente) y menor a la mitad de la de Ru/Z-A, aunque el valor de conversión resultó considerablemente mayor que la obtenida con estos últimos catalizadores (más de un $37 \%$ mayor respecto a Ru/Z-A y $29 \%$ respecto a Ru-A). Así, los resultados encontrados en este trabajo de tesis, parecen indicar que la actividad catalítica no solo depende del tamaño de partícula y la dispersión metálica.

Trabajos previos sobre hidrogenación de aldehídos $\alpha, \beta$-insaturados a presión atmosférica han reportado independencia de la actividad catalítica específica respecto al tamaño de partícula para catalizadores de Ru soportados sobre carbón activado y alúmina ensayados con cinamaldehído y citral como sustratos. (Galvagno S. y col., 1991; Galvagno S. y Milone C., 1993; Galvagno S. y col, 1993).

Las actividades observadas para los catalizadores ensayados parecen estar influenciadas además por efecto de la composición del soporte y/o su acidez, sobre los sitios activos metálicos. En este sentido, varios autores han encontrado que, empleando catalizadores de $\mathrm{Pt}$, la actividad en reacciones de hidrogenación y de hidrogenólisis aumenta cuando la acidez del soporte aumenta (Ramaker D. E. y col., 2001; Stakheev A. Y. y col., 2007). En un soporte más ácido, es decir, sobre un soporte que contiene átomos de oxígeno cuya carga formal negativa (o carácter iónico) es baja, la densidad de electrones de las nanopartículas de Pt se dirigen hacia la interfaz soporte-metal. La densidad de electrones en la superficie del metal y por lo tanto la donación electrónica hacia los adsorbatos disminuye (Mojet B. L. y col., 1999; Stakheev A. Y. y col., 2007), lo que lleva a que las moléculas se encuentren menos fuertemente adsorbidas (Stakheev A. Y. y col., 2007). Esto resulta en una mayor actividad de los catalizadores ácidos en reacciones que involucran hidrógeno. Este modelo podría explicar el comportamiento observado sobre los catalizadores fosfatados (Handjani S. y col., 2011). Esto hace evidente que hay 2 factores a considerar: la dispersión y la característica del soporte.

En cuanto a la distribución de productos en la hidrogenación de furfural también se observaron diferentes comportamientos en los catalizadores monometálicos soportados.

La tabla 7.2 presenta las selectividades obtenidas a $10 \%$ de conversión y al final de reacción. 
Tabla 7.2. Selectividades obtenidas para la hidrogenación de furfural con diferentes catalizadores de Ru.

\begin{tabular}{|c|c|c|c|c|c|c|c|c|c|c|}
\hline \multirow{2}{*}{ Catalizador } & \multicolumn{5}{|c|}{ Selectividad (\%) ** } & \multicolumn{5}{|c|}{ Selectividad (\%) *** } \\
\hline & THF & THFF & THFA & FFA & Otros & THF & THFF & THFA & FFA & Otros \\
\hline $\mathrm{R} / \mathrm{C}$ & 0 & 0 & 0,7 & 99,3 & 0 & 2,2 & 0 & 2,5 & 41,6 & 53,5 \\
\hline $\mathrm{Ru} / \mathrm{A}$ & 0 & 0 & 1,3 & 98,7 & 0 & 0,1 & 0,1 & 0,85 & 74,1 & 24,7 \\
\hline $\mathrm{Ru} / \mathrm{Z}$ & 0,4 & 0 & 0 & 98,5 & 1,1 & 0 & 0,2 & 2,4 & 75,8 & 21,6 \\
\hline Ru/Z-A & 0,5 & 0 & 1,7 & 97,4 & 0,4 & 0,3 & 0 & 2,75 & 76,2 & 21,4 \\
\hline $\mathrm{Ru} / \mathrm{ZP}$ & 0 & 0 & 1,6 & 90,0 & 7,0 & 0 & 0 & 0,77 & 93,13 & 6,1 \\
\hline Ru/ZP-A & 0 & 0 & 1,2 & 90,1 & 8,7 & 0 & 0 & 1,12 & 95,73 & 3,11 \\
\hline \multicolumn{11}{|c|}{${ }^{*} r_{i}:$ mmoles $_{\text {conv }} g_{R U}^{-1} \min ^{-1}$ (velocidades iniciales calculadas para un $10 \%$ de conversión) } \\
\hline \multicolumn{11}{|c|}{ ** Selectividades obtenidas para $10 \%$ de conversión. } \\
\hline \multicolumn{11}{|c|}{ *** Selectividades para conversión obtenida al final de reacción (420 min). } \\
\hline
\end{tabular}

El producto mayoritario al inicio de la reacción fue el alcohol furfurílico (FFA), resultando de la hidrogenación de enlace $\mathrm{C}=\mathrm{O}$. Se obtuvieron selectividades mayores a $90 \%$ para este producto a un $10 \%$ de conversión, en todos los casos ensayados. En el caso de Ru/C que resultó ser el más activo, se observó en primera instancia la producción de FFA casi como único producto de reacción obteniéndose un valor de selectividad superior al 99\%, a 25\% de conversión en los primeros 30 minutos de reacción. Sin embargo, la distribución de productos se modificó notoriamente con el avance de la reacción, obteniéndose una selectividad a FFA menor a $42 \%$ al final de la reacción luego de 420 minutos y viéndose la aparición de diferentes productos, agrupados en la tabla 4.2 como "otros". Entre ellos se pueden encontrar el 1,5pentanodiol y/o el éster de condensación, ambos formados a partir del FFA. Esto puede notarse en el gráfico de distribución de productos de hidrogenación (Figura 7.3 (a)), donde luego de pasar por un máximo, la proporción de FFA disminuye en el medio de reacción. Un comportamiento semejante exhiben los catalizadores soportados sobre Z, A y ZA (Figura X.3 (b), (c) y (d) respectivamente). En estos casos, la selectividad a FFA permanece en un valor más alto al final de la reacción (alrededor del 75\%), sin 
embargo esto puede ser debido a la menor actividad presentada, ya que luego de 7 horas de reacción la hidrogenación de furfural no superó el 50\% de conversión.

En los soportes fosfatados, el comportamiento resultó diferente, ya que la selectividad a FFA para $10 \%$ de conversión fue menor que los demás catalizadores descriptos previamente. Sin embargo al final de la reacción fueron los más selectivos a FFA. Esta mayor selectividad al alcohol insaturado podría estar relacionada con el mayor tamaño de partícula que presentan estos catalizadores, en acuerdo con observaciones previas sobre otros catalizadores en la hidrogenación de aldehídos $\alpha, \beta$ insaturados. (Mercadante L., 1996; Nitta Y., Ueno K. y Imanaka T., 1989). Resultados similares han sido explicados por Gallezot y col. ( Gallezot P., Giroir-Fendler A. y Richard P., 1981) teniendo en cuenta que en la superficie plana de una partícula grande de metal, el aldehído insaturado se inclina hacia fuera de la superficie debido a una interacción repulsiva que se produce entre el anillo aromático y el metal, protegiendo el doble enlace $\mathrm{C}=\mathrm{C}$ de la hidrogenación.

Según resultados publicados por otros autores (Sitthisa S., Na W. y Resasco D.E., 2011), en metales del grupo VIII, los aldehídos tienden a adsorberse con el grupo carbonilo paralelo a la superficie $\left(\eta^{2}(C, O)\right)$, configuración que favorece la hidrogenación de dicho grupo a FFA.

Como es sabido, la probabilidad de hidrogenar el enlace $\mathrm{C}=\mathrm{C} \circ \mathrm{C}=\mathrm{O}$ de los aldehídos $\alpha, \beta$-insaturados, lo cual rige la selectividad final al alcohol insaturado alcohol, depende críticamente del modo de adsorción de la molécula sobre el catalizador y, en última instancia, de la estructura electrónica de la superficie metálica. La estructura local de los metales puede modificarse por especies donantes de electrones que interactúan con los átomos de superficie (efecto de ligando electrónico). Una mayor densidad de carga en los átomos metálicos superficiales podría, por una parte, disminuir la energía de enlace de $\mathrm{C}=\mathrm{C}$ a través de un aumento de la interacción repulsiva de electrones y, por otro lado, favorecer la retrodonación con el $\pi *$ co-orbital y la hidrogenación de $\mathrm{C}=\mathrm{O}$ con respecto a $\mathrm{C}=\mathrm{C}$. Por lo tanto, la presencia de sitios ácidos de Lewis, donadores de electrones interactuando con partículas metálicas activaría el grupo carbonilo y deberían mejorar la selectividad al alcohol insaturado. (Gallezot P. y Richard D., 1998). 
Puede concluirse así que la mayor selectividad a FFA puede estar asociada al tamaño de partícula metálica por un lado y a la acidez del soporte por otro. En partículas grandes y soportes ácidos como los fosfatados, la selectividad a FFA se ve favorecida, mientras que el metal depositado sobre carbón, que presenta partículas más pequeñas la selectividad a FFA fue mucho menor. Esto también puede observarse en los gráficos de distribución de productos para los catalizadores (Figura 7.3), donde se aprecia que para $\mathrm{Ru} / \mathrm{C}$ por ejemplo la proporción de otros productos aumenta significativamente hacia el final de la reacción, mientras que para Ru/ZP-A la proporción de FFA aumenta a medida que avanza la reacción.

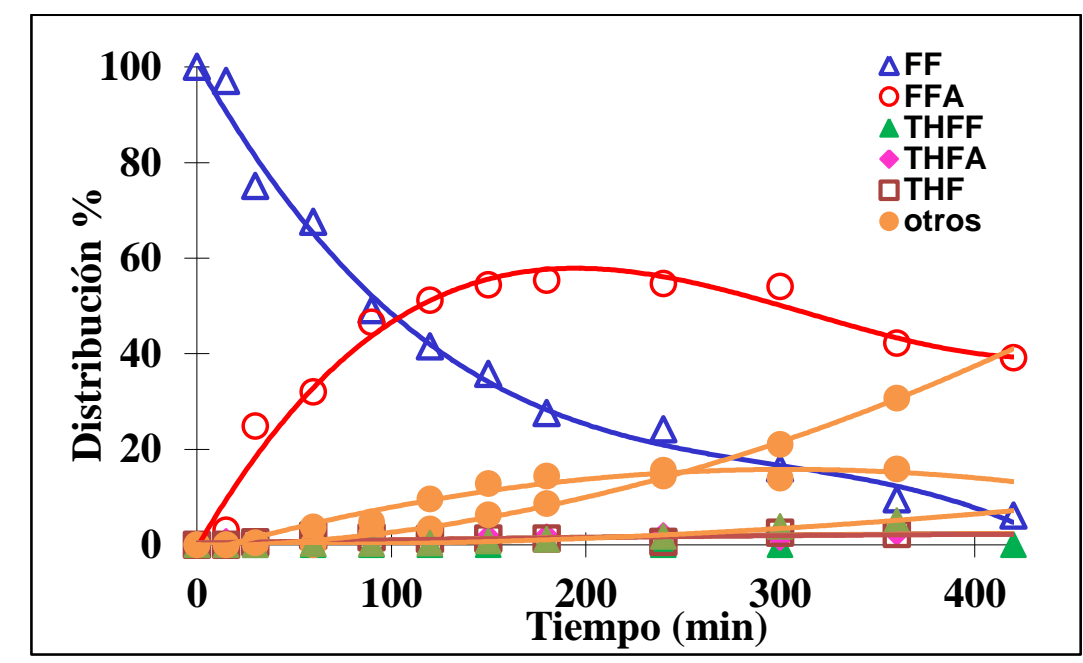

(a) $\mathrm{Ru} / \mathrm{C}$

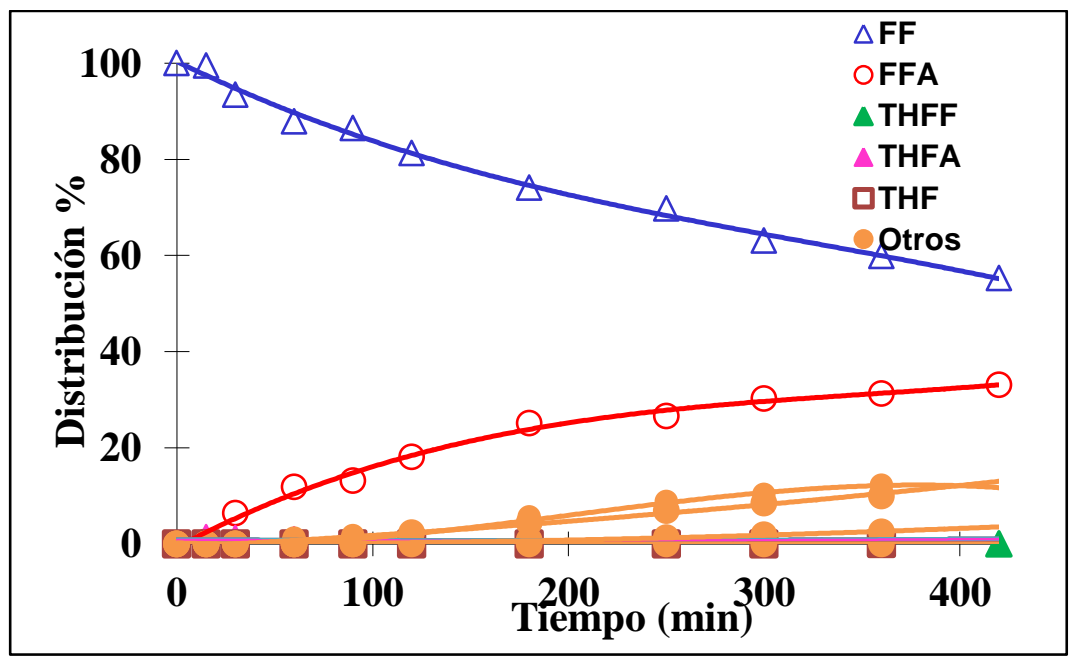

(b) Ru/A

Figura 7.3. Distribución de productos de hidrogenación de furfural (FF). (a) Ru/C, (b) Ru/A 


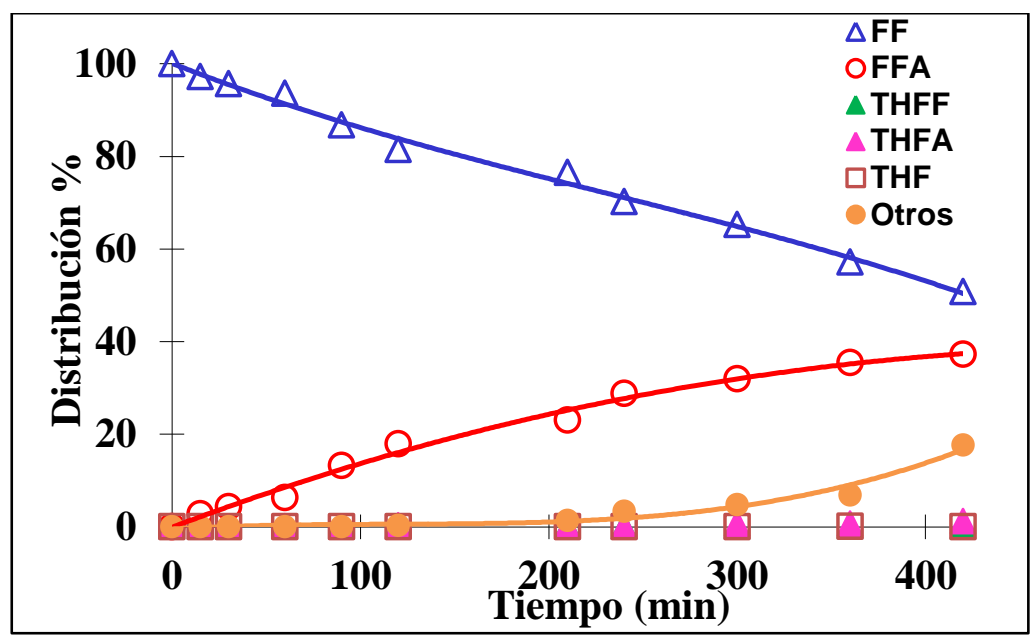

(c) $\mathrm{Ru} / \mathrm{Z}$

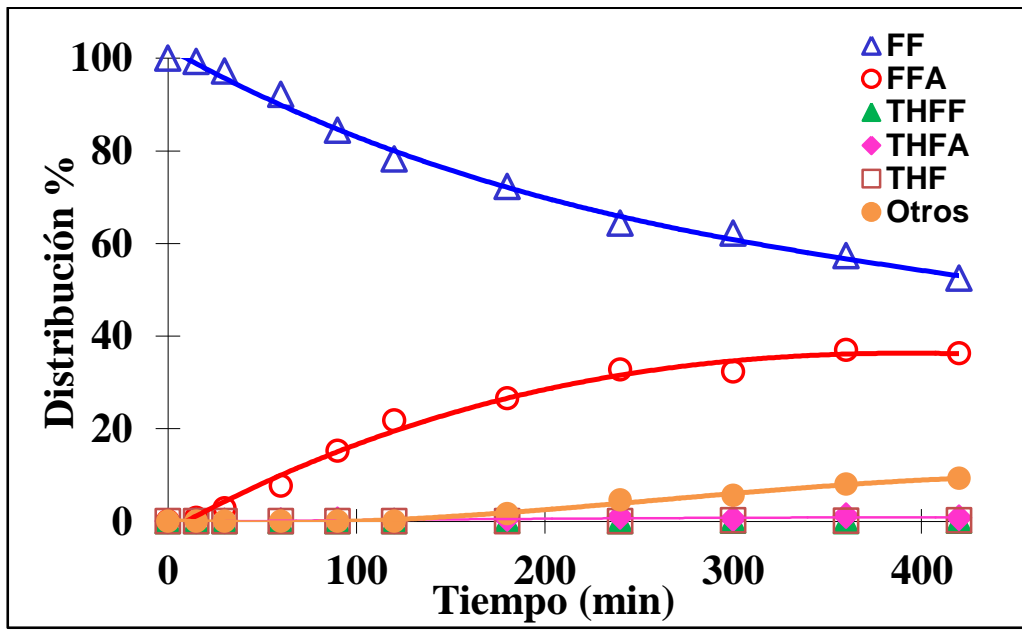

(d) Ru/Z-A

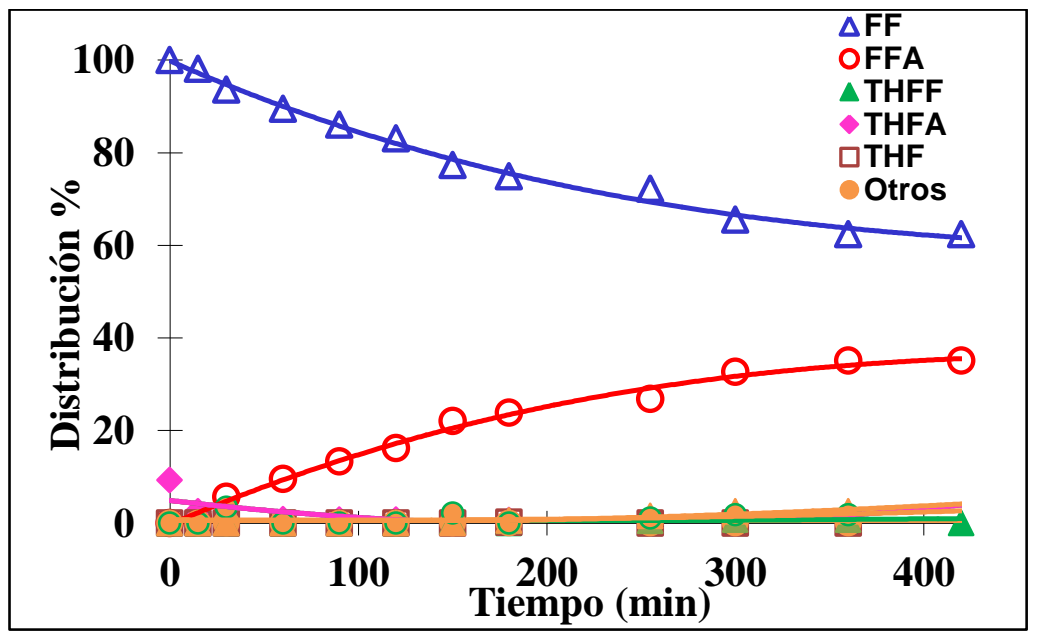

(e) Ru/ZP

Figura 7.3 (cont.) Distribución de productos de hidrogenación de furfural (FF). (c) Ru/Z, (d) $\mathrm{Ru} / \mathrm{Z}-\mathrm{A}$, (e) Ru/ZP 


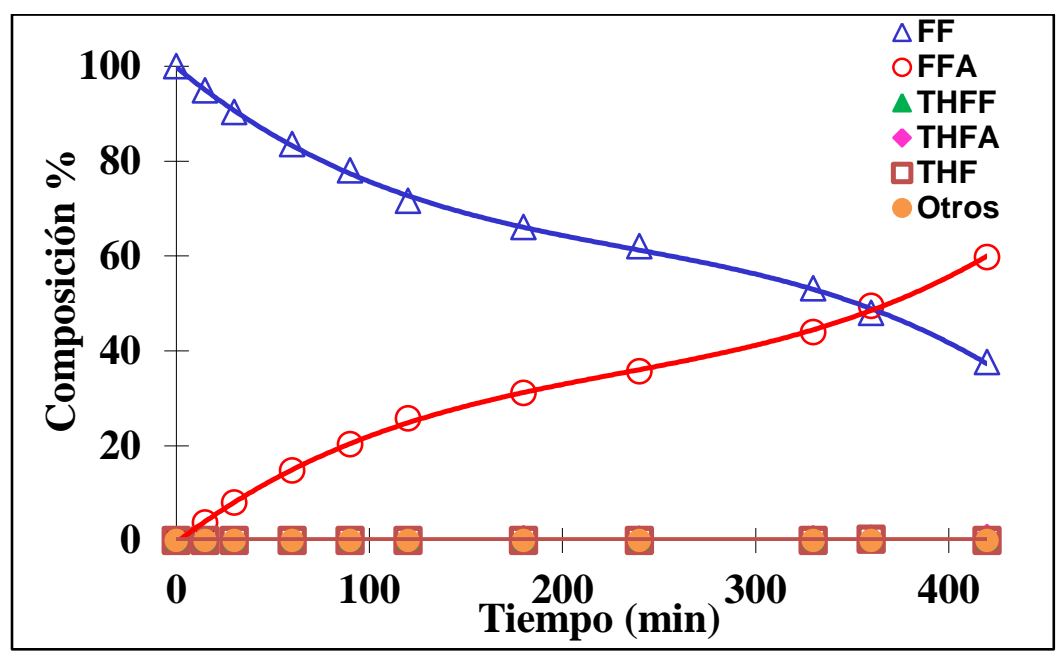

(f) Ru/ZP-A

Figura 7.3 (cont.). Distribución de productos de hidrogenación de furfural (FF). (f) Ru/ZP-A

Debido a que el catalizador de Ru/C presentó elevada actividad, aunque resultó poco selectivo a FFA al final de la reacción se decidió evaluar una serie de catalizadores bimetálicos RuSn/C en la hidrogenación de furfural. Se espera que el agregado de Sn como metal promotor mejore esta selectividad, teniendo en cuenta lo observado en los estudios de hidrogenación de trans-2-pentenal descriptos en el capítulo 4.

\section{4.- Hidrogenación con catalizadores bimetálicos}

Como ya se describió en el capítulo 4, se prepararon catalizadores bimetálicos a base de Ru soportado empleando Sn como metal promotor, agregado mediante técnicas QOMS/M. Si bien el procedimiento detallado para su obtención ya fue desarrollado previamente, en la Tabla 7.3 se resumen nuevamente los catalizadores bimetálicos preparados y las condiciones de reacción empleadas en cada caso, a modo de resumen y para facilitar la lectura en el presente capítulo. 
Tabla 7.3. Condiciones de reacción empleadas en la preparación de los catalizadores bimetálicos mediante técnicas QOMS/M. La concentración inicial y final de $\mathrm{SnBu}_{4}$ fue medida por cromatografía de gases.

\begin{tabular}{|c|c|c|c|c|c|c|c|}
\hline Cat. & $\mathrm{T}\left({ }^{\circ} \mathrm{C}\right)^{(1)}$ & $M(g)^{(2)}$ & $\begin{array}{l}\text { Tiempo } \\
\text { de reac. } \\
\text { (h) }\end{array}$ & $\begin{array}{l}\text { Tiempo } \\
\text { de reac. } \\
\text { total (h) }\end{array}$ & $\begin{array}{c}\mathrm{C}_{\mathrm{i}} \\
(\mathrm{mmol} \mathrm{L} \\
\left.\mathbf{L}^{-1}\right)^{(3)}\end{array}$ & $\begin{array}{c}\mathrm{C}_{\mathrm{f}} \\
\left.(\mathrm{mmol} \mathrm{L})^{-1}\right)^{(3)}\end{array}$ & $\mathrm{Sn} / \mathrm{Ru}^{(4)}$ \\
\hline $\operatorname{RuSn}_{0.1} / \mathrm{C}$ & 90 & 1,5 & 4,5 & 5,5 & 4,2 & 1,1 & 0,14 \\
\hline $\mathrm{RuSn}_{0.4} / \mathrm{C}$ & 120 & 3,0 & 4 & 5,5 & 60,8 & 54,1 & 0,45 \\
\hline $\mathrm{RuSn}_{0.8} / \mathrm{C}$ & 150 & 2,0 & 4,5 & 5,5 & 19 & 7,1 & 0,80 \\
\hline \multicolumn{8}{|c|}{${ }^{(1)}$ Temperatura de Reacción } \\
\hline \multicolumn{8}{|c|}{ (2) Masa de catalizador monometálico empleado } \\
\hline \multicolumn{8}{|c|}{ 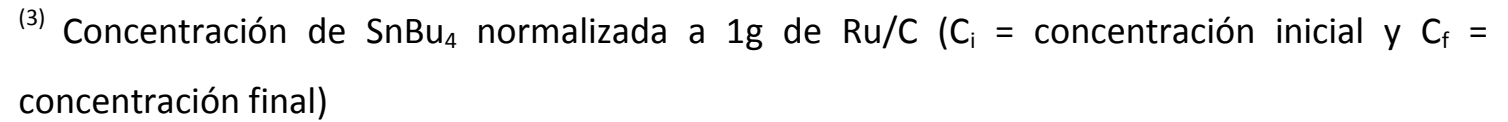 } \\
\hline
\end{tabular}

Las reacciones de hidrogenación de furfural se llevaron a cabo con Ru/C, $\mathrm{RuSn}_{0.4} / \mathrm{C}$ y $\mathrm{RuSn}_{0.8} / \mathrm{C}$. El catalizador $\mathrm{RuSn}_{0.1} / \mathrm{C}$ no se ensayó en esta reacción ya que a partir de lo observado en la reacción test con trans-2-pentenal expuesta en el capítulo 4, se observó que este sistema no presentó un cambio significativo en la selectividad respecto al catalizador monometálico.

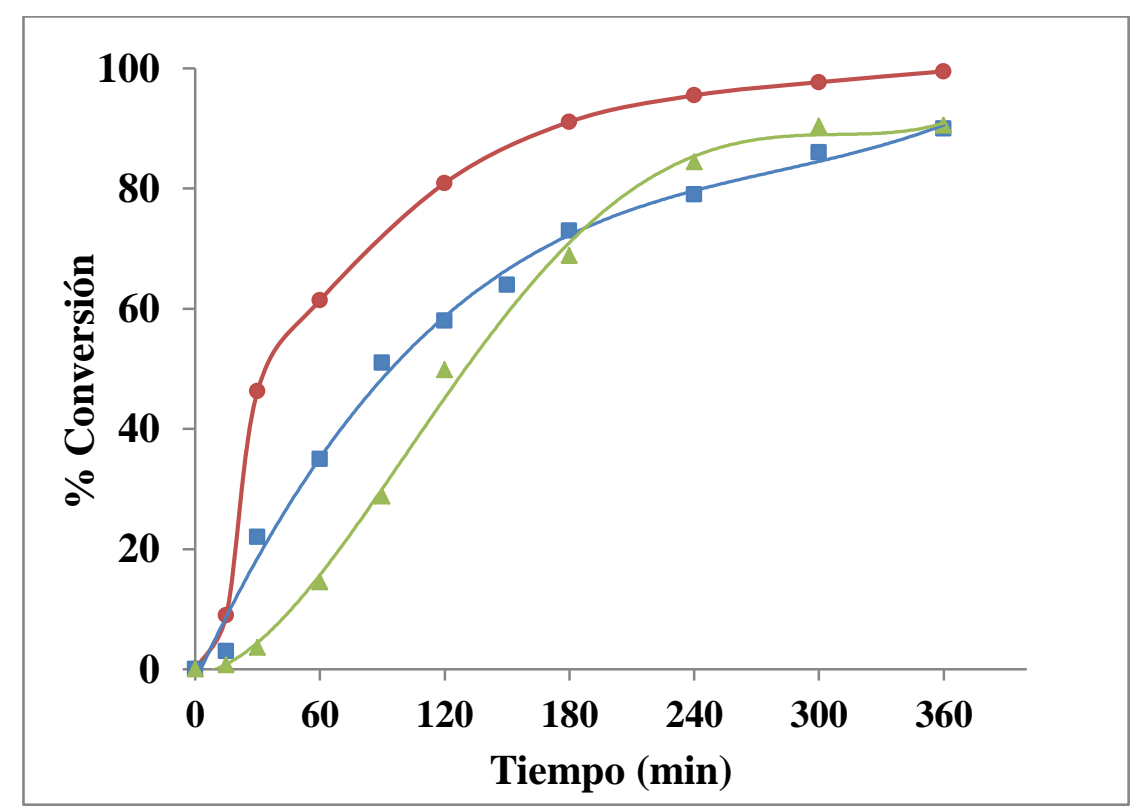

Figura 7.4. Conversión de furfural: (•) $\mathrm{RuSn}_{0.4} / \mathrm{C}$, (口) Ru/C y ( $\triangle$ ) RuSn $n_{0.8} / \mathrm{C}\left(90^{\circ} \mathrm{C}\right.$ y $1.25 \mathrm{MPa}$ $\mathrm{H}_{2}$ ). 
En la figura 7.4, se observa la conversión de furfural como función del tiempo para los catalizadores estudiados. La conversión alcanzó valores entre 85 y 95\% después de 400 minutos de reacción, indicando que los tres catalizadores ensayados eran activos. Estos resultados son prometedores, teniendo en cuenta especialmente que las condiciones utilizadas en los ensayos son más suaves que las normalmente encontradas en literatura. Se estimaron además, las velocidades iniciales de conversión de furfural $\left(r_{i}, \mathrm{mmol}_{\mathrm{FF}} \mathrm{gRu}^{-1} \mathrm{~min}^{-1}\right)$ a partir de la pendiente de las rectas obtenidas de $X_{F F}$ Vs. tiempo (figura 7.4) considerando los datos en $X_{F F} \leq 10 \%$. En el caso del catalizador $\mathrm{RuSn}_{0.8} / \mathrm{C}, \mathrm{r}_{\mathrm{i}}$ se calculó después de la corrección del periodo de inducción.

Las velocidades de reacción iniciales $\left(r_{i}\right)$ y los turnover frequencies (TOF) y conversión para los tres sistemas catalíticos estudiados, Ru/C, RuSn ${ }_{0.4} / C$ y $\mathrm{RuSn}_{0.8} / \mathrm{C}$, se presentan en la Tabla 7.4.

Tabla 7.4. Conversiones obtenidas en la hidrogenación de furfural con catalizadores bimetálicos de RuSn $/ \mathrm{C}$.

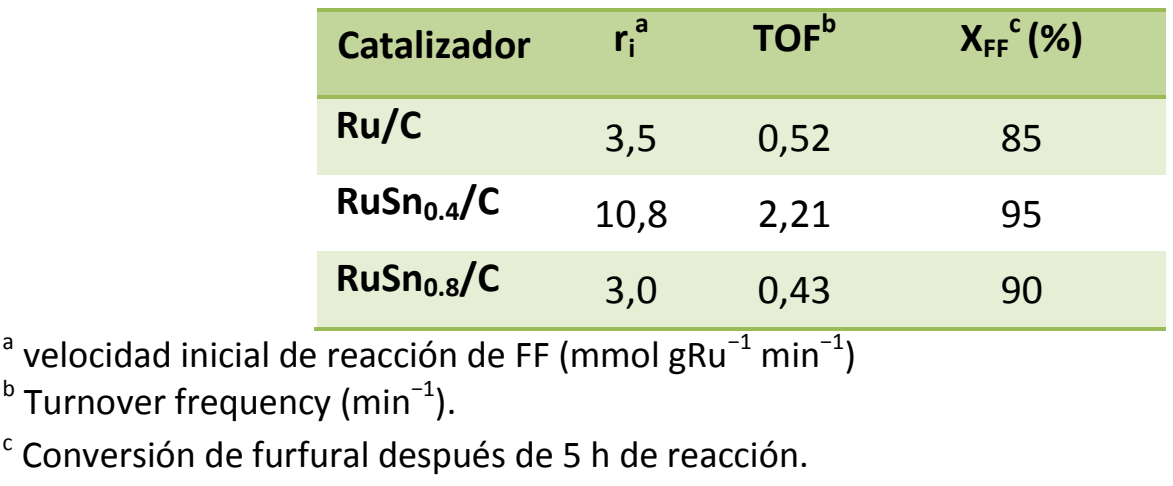

Lee y col. (Lee J., Kim Y.T. y Huber G.W., 2014) midieron la velocidad de reacción por sitio para la hidrogenación en fase acuosa $(\mathrm{APH})$ de furfural sobre varios catalizadores bimetálicos soportados en alúmina ( $\mathrm{Pd}-\mathrm{Ni}, \mathrm{Pd}-\mathrm{Co}, \mathrm{Pd}-\mathrm{Fe}, \mathrm{Ru}-\mathrm{Ni}, \mathrm{Ru}-\mathrm{Co}$, Ru-Fe, Pt-Ni, Pt-Co y Pt-Fe) usando un reactor de alto rendimiento (HTR). Aunque no informan los valores de conversión obtenidos, los autores reportan haber obtenido altas velocidades de reacción en los catalizadores estudiados. Sin embargo, la temperatura de reacción empleada fue mayor a la aquí utilizada y la presión fue más de 4 veces superior $\left(100^{\circ} \mathrm{C}, 5,41 \mathrm{MPa}\right.$, y $4,8 \%$ en peso de soluciones de furfural). Sus 
resultados demuestran que la actividad de los catalizadores bimetálicos para la hidrogenación de un grupo carbonilo puede llegar a ser 110 veces mayor que los catalizadores monometálicos. En el caso de los resultados obtenidos en este trabajo de tesis, si bien al pasar del catalizadores de $\mathrm{Ru} / \mathrm{C}$ al catalizador $\mathrm{RuSn_{0.4 }} / \mathrm{C}$ la velocidad inicial prácticamente se triplica (de 3,5 a 10,8 para $\mathrm{Ru} / \mathrm{C}$ y $\mathrm{RuSn}_{0.4} / \mathrm{C}$, respectivamente), un nuevo aumento en la cantidad de Sn agregado provoca una disminución en la velocidad inicial de reacción.

Por otra parte, en los estudios mencionados, Lee y col. observaron que la adición de Fe y Co a un catalizador de Ru monometálico aumentó la actividad hasta 2 veces para la hidrogenación del furfural. La adición de Ni al catalizador monometálico de Ru disminuyó la actividad en un 19\%, mientras que la adición de $\mathrm{Ni}$, Co y Fe a un catalizador de Pt aumentó la velocidad de reacción, siendo los catalizadores bimetálicos de $\mathrm{Pt}-\mathrm{Fe}$, los más activos. El catalizador de $\mathrm{Pt}_{1} \mathrm{Fe}_{3}$ fue 16 veces más activo que el catalizador de $\mathrm{Pt}$ al $3 \%$ en peso. El catalizador de $\mathrm{Pt}_{1} \mathrm{Co}_{3}$ fue 9 veces más activo que el catalizador monometálico. El catalizador de $\mathrm{Pt}_{1} \mathrm{Ni}_{1}$ tuvo una velocidad de hidrogenación más alta que el catalizador de Pt al 3\% en peso pero una tasa de hidrogenación más baja que el catalizador de $20 \%$ en peso de Ni. Los catalizadores bimetálicos basados en Pd produjeron alcohol furfurílico $(88,5$ a $93,1 \%)$ y THFA $(6,9$ a 11,5\%) a partir de furfural. Los catalizadores bimetálicos basados en Ru llevaron a la obtención de THFA con pequeñas proporciones (0,2 a 3,6\%). Los catalizadores bimetálicos basados en Pt producen solo alcohol furfurílico.

En otros estudios, Mironenko y col. (Mironenko R.M. y col., 2015) utilizaron catalizadores monometálicos de $\mathrm{Pd}$ y Ru con un contenido metálico de 1,5\% en peso depositados sobre soportes de carbono (nanotubos de carbono de paredes múltiples (CNT) y carbón negro (CB)). Los catalizadores de rutenio soportados se obtuvieron por impregnación con humedad incipiente de los soportes de carbono con soluciones acuosas de complejos de cloruro de rutenio (IV), mientras que los catalizadores de paladio los prepararon mediante la adsorción de complejos de cloruro de paladio (II) a partir del exceso de solución. Estos autores estudiaron los catalizadores en la hidrogenación en fase acuosa del furfural a diferentes temperaturas (50 y $90^{\circ} \mathrm{C}$ ) y presiones de hidrógeno $(0,5$ y $2,0 \mathrm{MPa})$. Bajo condiciones suaves $\left(50^{\circ} \mathrm{C}, 0,5 \mathrm{MPa}\right)$, en 
presencia del catalizador de $\mathrm{Pd} / \mathrm{CB}$ al $1,5 \%$, si bien dio como resultado una alta selectividad a alcohol furfurílico (99\%), la conversión de furfural alcanzada fue del $29 \%$. Al aumentar la presión (a la temperatura de $50^{\circ} \mathrm{C}$ ) a $2 \mathrm{MPa}$ la conversión aumentó a un poco más del $43 \%$. Solo luego de la elevación de la temperatura a $90^{\circ} \mathrm{C}$ junto con una presión de $2 \mathrm{MPa}$ se produjo un aumento significativo de la velocidad de reacción y la conversión. Asimismo, con esto, la selectividad para el alcohol furfurilo disminuyó sustancialmente, hasta el 52\%. El alcohol tetrahidrofurfurilico fue el que prevaleció entre los subproductos.

Los catalizadores de rutenio ensayados por estos autores, por otro lado, mostraron una baja actividad en la hidrogenación de furfural en esas condiciones elegidas de reacción, siendo la conversión de furfural menor al 14\%.

Los valores $r_{i}$ obtenidos en el caso de la hidrogenación en fase acuosa (APH) de furfural en este trabajo de tesis son muy inferiores a los obtenidos con catalizadores a base de platino soportado sobre $\mathrm{SiO}_{2}$ y utilizando 2-propanol como disolvente, como puede verse en los resultados obtenidos por Merlo A.B. y col. presentados en la Tabla 7.5. Por otra parte, el empleo de este solvente llevó a la formación, aunque en bajo porcentaje, de un éter (2-isopropoximetil-furano), compuesto formado entre el alcohol furfurílico y el 2-propanol (Merlo A. B. y col., 2009).

Tabla 7.5. Velocidades de reacción y selectividad a FFA a $480 \mathrm{~min}$ para la hidrogenación de furfural en 2-propanol.

\begin{tabular}{|c|c|c|}
\hline Catalizador & $r_{i}^{a}\left(m m o l ~ g_{P t}^{-1} \min ^{-1}\right)$ & $\mathrm{S}_{\mathrm{FFA}} \%^{\mathrm{b}}$ \\
\hline Pt & 22,8 & 98,7 \\
\hline $\mathrm{PtSn}_{0.3}$ & 138 & 96,18 \\
\hline $\mathrm{PtSn}_{0.6}$ & 109,2 & 96,89 \\
\hline $\mathrm{PtSn}_{0.8}$ & 97,8 & 98,24 \\
\hline $\mathrm{PtSn}_{1.0}$ & 69 & 98,20 \\
\hline
\end{tabular}

a velocidad de reacción estimada entre $0 \%$ y $10 \%$ de conversión

${ }^{b}$ Selectividad a alcohol furfurílico

Los estudios realizados por dichos autores con otros solventes (empleando el catalizador monometáico), mostraron menores valores de conversión (Tabla 7.6). 
Tabla 7.6. Conversiones obtenidas a 480 minutos de reacción en la hidrogenación de furfural con $\mathrm{Pt} / \mathrm{SiO}_{2}$ para los distintos solventes.

\begin{tabular}{|c|c|c|}
\hline Catalizador & Solvente & Conversión \% \\
\hline \multirow{4}{*}{$\mathrm{Pt} / \mathrm{SiO}_{2}$} & 2-propanol & 46 \\
\hline & Etanol & 36 \\
\hline & Tolueno & 15 \\
\hline & n-heptano & 13 \\
\hline
\end{tabular}

Las características del agua como disolvente, en este caso su polaridad, pueden influir fuertemente en la actividad catalítica durante la hidrogenación. Por ejemplo, el agua afecta la solubilidad del hidrógeno en los medios de reacción y compite con el furfural por la adsorción en el catalizador. Este último hecho podría ser el responsable de una adsorción del furfural menos eficiente sobre los sistemas evaluados y consecuentemente, de su menor velocidad de hidrogenación. También podría ser la causa de la existencia de un período de inducción en la evolución de la conversión de $\mathrm{FF}$, el cual es particularmente apreciable en el catalizador con el contenido más alto de Sn. Los efectos del agua sobre la hidrogenación catalítica de FF han sido sistemáticamente estudiados por varios autores, aunque no se han obtenido resultados homogéneos.

Así, Chen X y colaboradores investigaron nanoláminas de nitruro de carbono grafítico para desarrollar soportes de catalizadores de Pt eficaces para la hidrogenación selectiva de furfural a alcohol furfurílico en agua. A fin de estudiar el efecto de los solventes sobre el rendimiento catalítico del 5\% de Pt@TECN, agua, etanol, tolueno, isopropanol y octano se usaron como solventes para la hidrogenación de furfural. Los resultados se resumen en la Tabla 7.7.

Tabla 7.7. Efecto del solvente en la hidrogenación de furfural sobre $5 \%$ de Pt@TECN.

\begin{tabular}{lccccc}
\multicolumn{1}{c}{ Solvente } & Conv (\%) & $\mathrm{S}_{\mathrm{FFA}} \%$ & $\mathrm{~S}_{\text {Furano }}(\%)$ & $\mathrm{S}_{\mathrm{SP}}{ }^{\mathrm{a}}$ & Polaridad del solvente \\
\hline Agua & $>99$ & $>99$ & 0 & 0 & 10,2 \\
Etanol & 67,4 & 70,5 & 0 & 29,5 & 4,3 \\
Tolueno & 51,2 & 95,6 & 4,4 & 0 & 2,4 \\
Isopropanol & 91,5 & 96,7 & 0 & 3,3 & 3,9 \\
Octano & 8,3 & $65 ., 8$ & 34,2 & 0 & 0 \\
\hline
\end{tabular}

a 2-furaldehído dietil acetal (etanol) y 2-isopropoximetilfurano (isopropanol) expresado como Producto solvente (SP). 
A pesar de que el mecanismo del efecto del solvente no ha sido claramente explicitado, se ha considerado que la actividad probablemente se correlacione con la polaridad del solvente (Mao, H. y col., 2011)

Las diferencias en los sitios metálicos de $\mathrm{Ru}$ expuestos en nuestros tres catalizadores estudiados se tuvieron en cuenta a través de los valores de TOF (Tabla 7.4). La adición de estaño en una relación atómica $\mathrm{Sn} / \mathrm{Ru}$ de 0,4 condujo a un aumento en la actividad catalítica. Este resultado podría atribuirse al hecho de que el estaño reduce la intensidad de adsorción de hidrógeno en la superficie del rutenio, aumentando la disponibilidad de sitios de hidrogenación. Esta explicación ha sido propuesta, entre otros, por Zhang y colaboradores, quienes propusieron que la reactividad de catalizadores de platino en la hidrogenación de furfural podría ser mejorada por la disminución de la fuerza de adsorción de $\mathrm{H}_{2}$ mediante la adición de $\mathrm{Ni}$ y/o Cu (Zhang C., Lai Q. y Holles J.H., 2017). Por otro lado, tal como se ha demostrado por XPS y presentado en el capítulo 4, en los catalizadores bimetálicos se observó la presencia de estaño iónico, el cual actúa como un ácido de Lewis, polarizando el enlace $\mathrm{C}=\mathrm{O}$ del furfural y facilitando su hidrogenación. Una mayor concentración de estaño no mejora el rendimiento catalítico. Así, parece haber un compromiso entre la dilución de los sitios Ru, activos para la hidrogenación, y el efecto promotor de Sn. La fase RuSn inferida a partir de los resultados XPS, es muy importante para la actividad en la hidrogenación del FF. Sin embargo, cuando la proporción del Sn (0) aumenta (catalizador $\mathrm{RuSn}_{0.8}$ ) la actividad disminuye, por lo que la formación de la fase RuSn debe mantenerse relativamente baja con respecto al metal activo, de modo que el rendimiento catalítico no se vea afectado. En este mismo sentido, Wang y colaboradores han demostrado, mediante cálculos utilizando la teoría de densidad funcional (DFT), que la reactividad del furfural depende del cubrimiento de la superficie con hidrógeno, pasando por un máximo a valores intermedios de cobertura. Como describen los autores, son cuatro las conformaciones típicas en las que el sustrato puede adsorberse: plana, dos de tipo inclinado, y vertical. Esta última, sostienen, no es la más estable para el catalizador estudiado ( $P d(111))$, dado la muy baja energía de adsorción. La conformación plana de furfural (flat, figura 7.5), por otra parte, interactúa tanto con su anillo como con el grupo carbonilo. Respecto a las 
conformaciones inclinadas, se pueden reconocer: una en la cual los dos carbonos del anillo furanico pueden unirse al metal y el grupo - $\mathrm{CHO}$ está ligeramente inclinado desde la superficie (Tilted-2, figura 7.5) y otro en el que el grupo - $\mathrm{CHO}$ y un átomo de carbono del anillo furanico se unen al metal y el anillo de furanico está ligeramente inclinado hacia afuera de la superficie (Tilted-1, figura 7.5)

A grados de cubrimiento superficial bajos, la conformación más estable es la plana debido a la maximización de la cantidad de enlaces con la superficie y las fuertes fuerzas de dispersión. En grados de cubrimiento altos, la conformación plana no es factible debido a la aglomeración en la superficie. En cambio, en este caso las conformaciones inclinadas se convierten en las más estables.

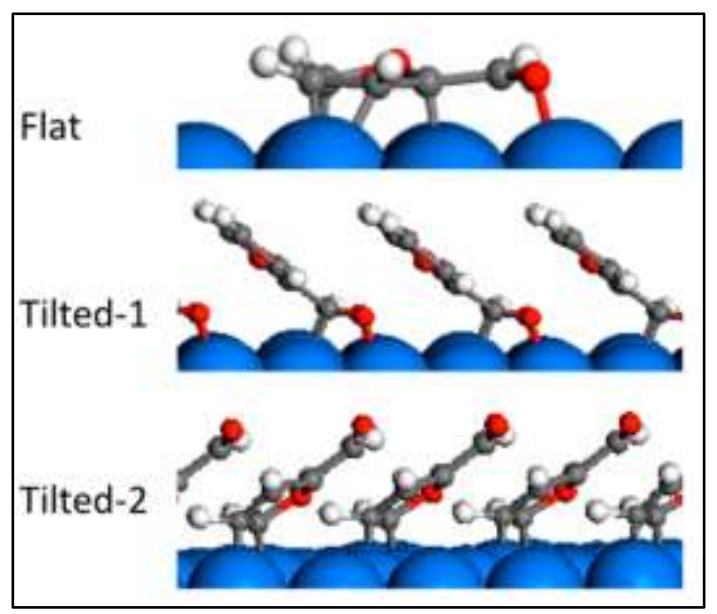

Figura 7.5. Tipos de adsorción de furfural sobre la superficie catalítica (Extraída de Wang S.G., Vorotnikov V. y Vlachos D. G., 2015)

El furfural se une fuertemente al metal descubierto y la fuerza de adsorción disminuye al aumentar el grado de cubrimiento superficial con hidrógeno. Un aumento de esto último induce un cambio conformacional de furfural desde la forma plana a coberturas bajas a inclinado en coberturas más altas (Wang S.G., Vorotnikov V. y Vlachos D. G., 2015). Este cambio se produciría hasta un cierto grado donde luego la adsorción e interacción de furfural con los sitios metálicos se vea dificultada. Este comportamiento podría también observarse con el cubrimiento de la superficie catalítica por parte de un segundo metal como el Sn.

Para explicar los valores de selectividad obtenidos en los estudios realizados en esta tesis, en la Figura 7.6 se muestra una vía de reacción simplificada para la 
hidrogenación de furfural. La hidrogenación del enlace $\mathrm{C}=\mathrm{O}$ de FF y del anillo de furano da lugar al alcohol furfurílico (FFA) y tetrahidrofurfural (THFF), respectivamente. La hidrogenación adicional de cualquiera de estos dos compuestos genera alcohol tetrahidrofurfurílico (THFA). Además, muchas otras reacciones pueden tener lugar, tales como la hidrogenolisis del enlace $\mathrm{C}=\mathrm{O}$, decarbonilación, apertura de anillo de furano, etc. También, productos de condensación de alto peso molescular han sido informados en algunos casos (Zheng H.Y. y col., 2006; Delbecq F. y Sautet P., 1995).

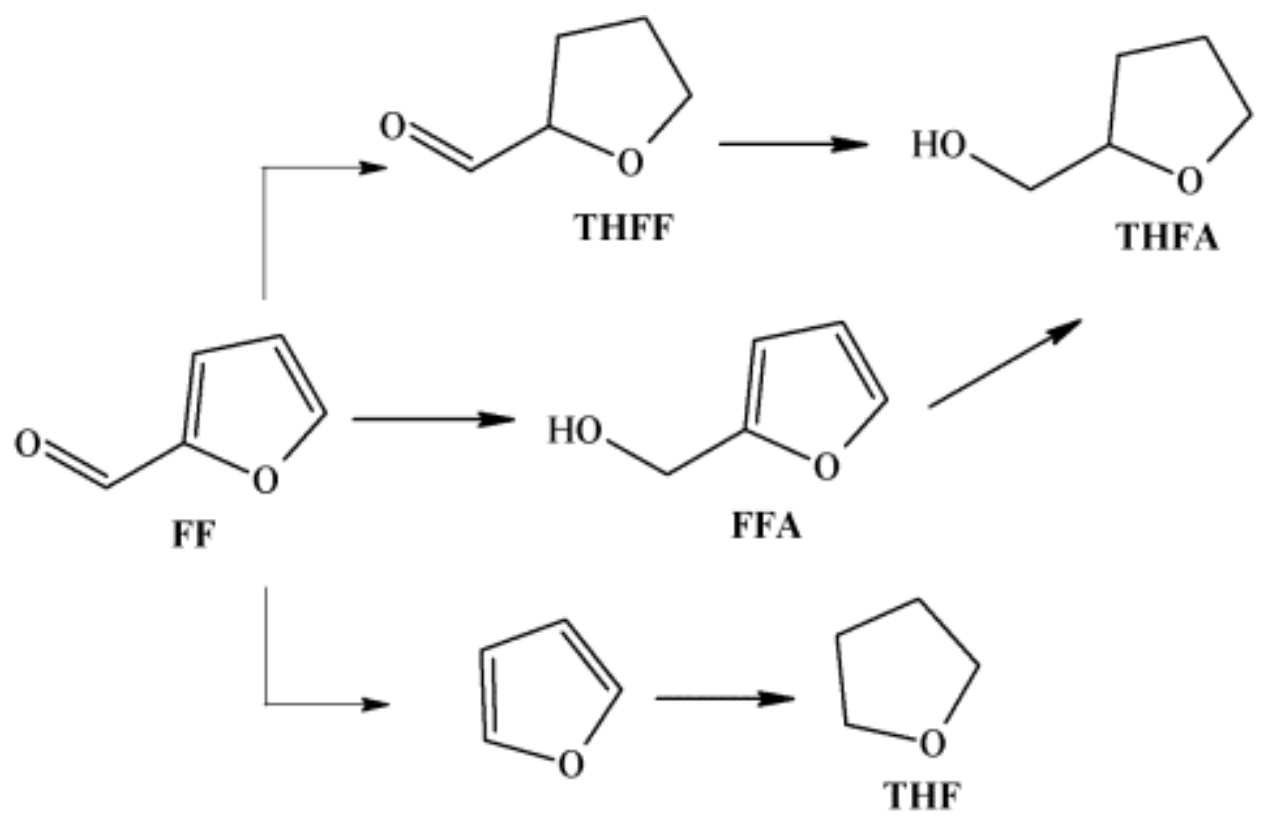

Figura 7.6. Vía esquemática simplificada para la hidrogenación del furfural.

La Tabla 7.8 muestra los valores de selectividad para los diferentes productos de reacción obtenidos con los catalizadores $\mathrm{Ru} / \mathrm{C}$, $\mathrm{RuSn}_{0.4} / \mathrm{C}$ y $\mathrm{RuSn}_{0.8} / \mathrm{C}$ correspondientes a la máxima conversión alcanzada por cada uno de ellos. El catalizador monometálico presentó una baja selectividad a FFA (47\% a $85 \%$ conversión). Este resultado se debe a la formación de productos indeseables, entre los cuales se pueden mencionar THFA, ciclopentanona (obtenida por reordenación del anillo de furano por efecto de agua) y 1,5-pentanodiol. 
Tabla 7.8 Selectividades de R/C, $\mathrm{RuSn}_{0.4} / \mathrm{C}, \mathrm{RuSn}_{0.8} / \mathrm{C}$ en hidrogenación de FF

\begin{tabular}{|c|c|c|c|c|c|c|}
\hline \multirow[t]{2}{*}{ Catal. } & \multirow[t]{2}{*}{$\mathrm{S}_{\mathrm{FFA}}{ }^{\mathrm{a}}(\%)$} & \multicolumn{5}{|c|}{$S_{i}^{b}(\%)$} \\
\hline & & THF & THFF & THFA & FFA & Otros \\
\hline $\mathrm{R} / \mathrm{C}$ & 99 & 2 & 0 & 15 & 47 & 36 \\
\hline $\mathrm{RuSn}_{0.4} / \mathrm{C}$ & 91 & 0 & 1 & 1 & 90 & 8 \\
\hline $\mathrm{RuSn}_{0.8} / \mathrm{C}$ & 95 & 0 & 2 & 25 & 62 & 11 \\
\hline
\end{tabular}

${ }^{a}$ Selectividad a alcohol furfurilico a $10 \%$ de conversión de furfural.

b Selectividad al producto i a máxima conversión (THF =tetrahidrofurano; THFF= tetrahidrofurfural; THFA = alcohol tetrahidrofurfurilico; FFA= alcohol furfurilico).

En cuanto a los sistemas bimetálicos, los resultados de la selectividad para FFA son mucho mayores, especialmente en el caso del catalizador RuSn $n_{0.4} / \mathrm{C}$. Estos sugieren que la hidrogenación del furfural procede a través de diferentes intermediarios adsorbidos, dependiendo de la naturaleza de la superficie catalítica. Delbecq y Sautet han modelado la adsorción de varios aldehídos $\alpha$, $\beta$-insaturados (acroleína, crotonaldehído, prenal y cinamaldehído) utilizando la aproximación de Hückel en cristales de platino y de paladio. Las posibles estructuras de adsorción de aldehídos $\alpha$ $\beta$-insaturados son numerosas ya que cada doble enlace puede interactuar con la superficie en varias configuraciones (Figura 7.7).
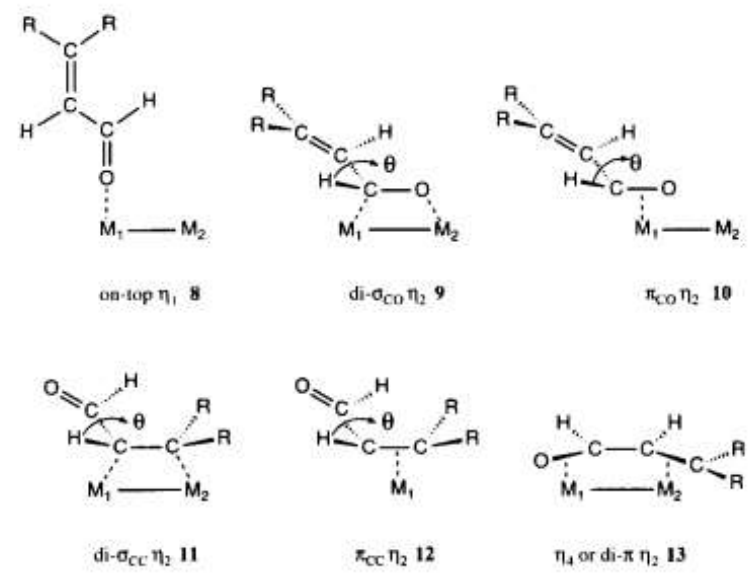

$\alpha-\beta$ unsarurated aldehydes

Figura 7.7. Posibles modos de adsorción para aldehídos $\alpha, \beta$-insaturados (extraído de Delbecq F. y Sautet P., 1995)

Su número incluso es mayor para aleaciones, como puede darse en catalizadores bimetálicos, en comparación con un metal puro, ya que los átomos de la 
superficie que participan en la adsorción pueden ser uno u otro. En sus trabajos los autores presentan configuraciones para sistemas PtSn (Figura 7.8).

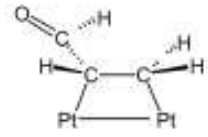

di- $\sigma_{\mathrm{CC}}$ trans

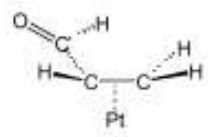

$\pi_{\mathrm{CC}}$ trans

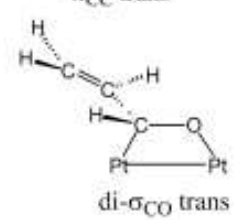

di $-\sigma_{\mathrm{CO}}$ trans

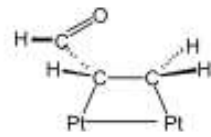

di- $\sigma_{C C}$ cis

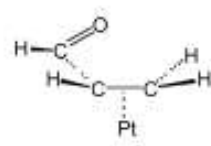

$\pi_{\mathrm{CC}} \mathrm{cis}$

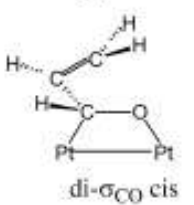

di $-\sigma_{C O}$ cis

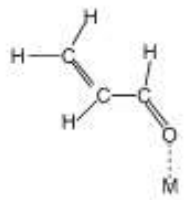

atop
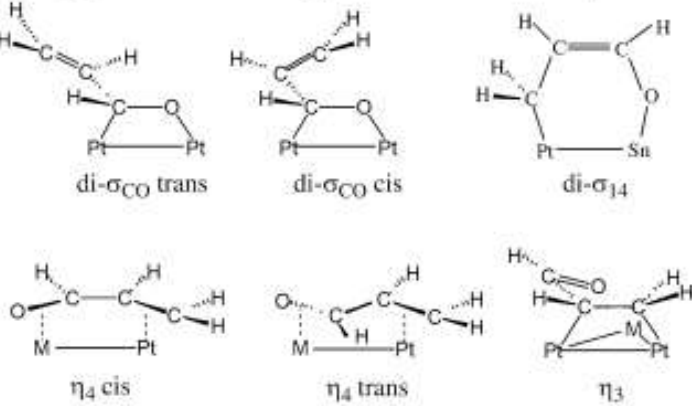

$\eta_{3}$

Figura 7.8. Posibles modos de adsorción en sistema PtSn (extraído de Delbecq F. y Sautet P., 2003)

Como generalidad, estos estudios orientados a explicar la selectividad durante la hidrogenación de los aldehídos $\alpha, \beta$ - insaturados sugieren que la adsorción competitiva de los grupos $\mathrm{C}=\mathrm{C}$ y $\mathrm{C}=\mathrm{O}$ depende de la expansión radial de los orbitales $d$ del metal (Delbecq F. y Sautet P., 1995). Así, cuanto mayor es su expansión, mayor es la repulsión electrónica con el enlace $\mathrm{C}=\mathrm{C}$ y menor es la probabilidad de adsorción a través de una geometría planar. Esto conduce a una mayor selectividad hacia la hidrogenación del enlace $\mathrm{C}=\mathrm{O}$. El ancho de banda $d$ de $\mathrm{Ru}$ es menor que el correspondiente a metales como Pt o Ir, entonces se espera que en este caso, la adsorción de la molécula de furfural a través del grupo carbonilo no esté favorecida, obteniendo así una baja selectividad al alcohol insaturado, tal como efectivamente ocurre con el catalizador de Ru/C ensayado en nuestro caso (Tabla 7.8, $\mathrm{S}_{\mathrm{FFA}}=47 \%$ )

Una forma muy conocida de mejorar la selectividad hacia la hidrogenación del grupo carbonilo es promover el metal base con un segundo metal (Delbecq F. y Sautet P. 2003; Neri G. y col., 1996). En este sentido, la modificación de los sitios activos de rutenio mediante la adición de estaño favorecería la aparición de especies adsorbidas 
que conducen a la hidrogenación preferencial del grupo carbonilo (on-top $\eta_{1}$, di- $\sigma_{c o} \eta_{2}$ y $\pi_{\mathrm{co}} \eta_{2}$ ) con el consiguiente aumento de la selectividad hacia el FFA.

De acuerdo con los resultados de XPS, los efectos electrónicos ejercidos por el estaño en el rutenio son también importantes. Esto es posible gracias a la creación de un nuevo tipo de sitio activo, como consecuencia de la interacción específica entre $\mathrm{SnBu}_{4}$ y el Ru soportado y reducido. La proximidad de ambos metales demostrada por los resultados de reducción a temperatura programada (TPR), apoya esta hipótesis (ver Figura 4.7, capítulo 4). Comportamientos que van en este sentido han sido reportados por Irene Vilella I.M.L, de Miguel S.R. y col. en la hidrogenación de citral con catalizadores de PtSn (Vilella I.M.L, y col., 2003).

La Tabla 7.8 muestra también a fines comparativos, la selectividad hacia el producto deseado, alcohol furfurílico, para dos niveles de conversión diferentes. Se puede ver que la selectividad hacia FFA para el catalizador de $\mathrm{RuSn}_{0.4} / \mathrm{C}$ permanece alta, a lo largo del experimento. Esto también puede observarse en los gráficos de distribución de productos para los tres catalizadores (Figura 7.9), donde se aprecia que para $\mathrm{Ru} / \mathrm{C}$ y $\mathrm{RuSn}_{0,8} / \mathrm{C}$ la proporción de otros productos aumenta significativamente hacia el final de la reacción. Tal como se observó con la actividad de los catalizadores, una mayor adición de estaño reduce la selectividad a FFA, lo cual podría ser debido a la modificación de los sitios activos.

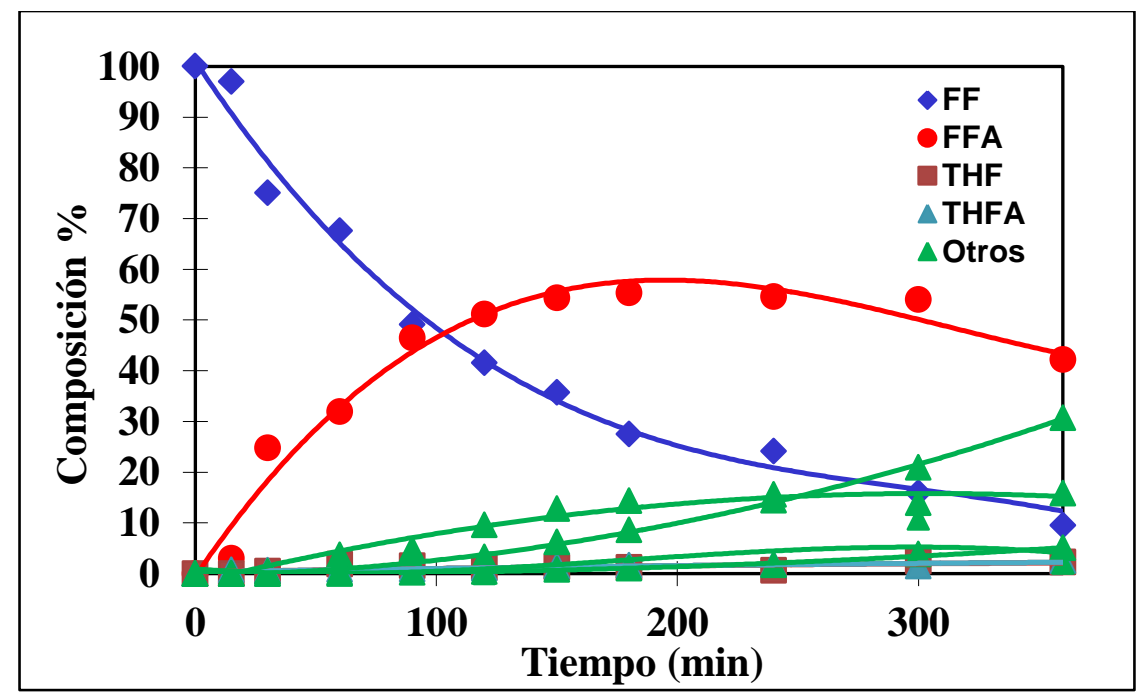

(a) Ru/C 


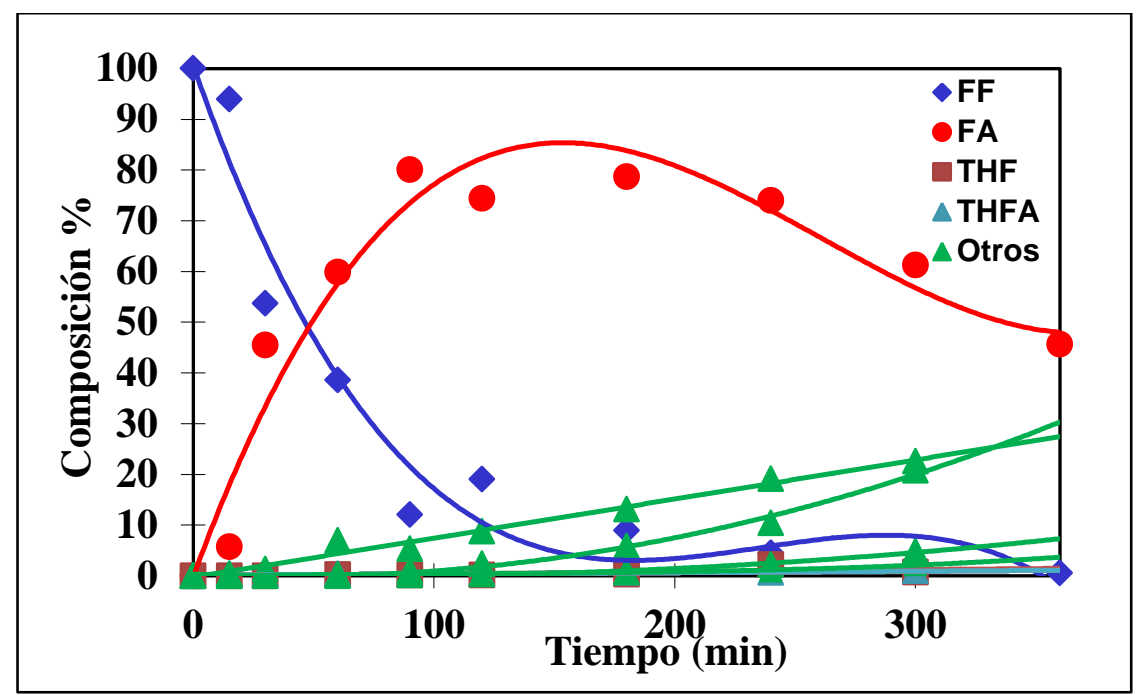

(b) $\mathrm{RuSn}_{0,4} / \mathrm{C}$

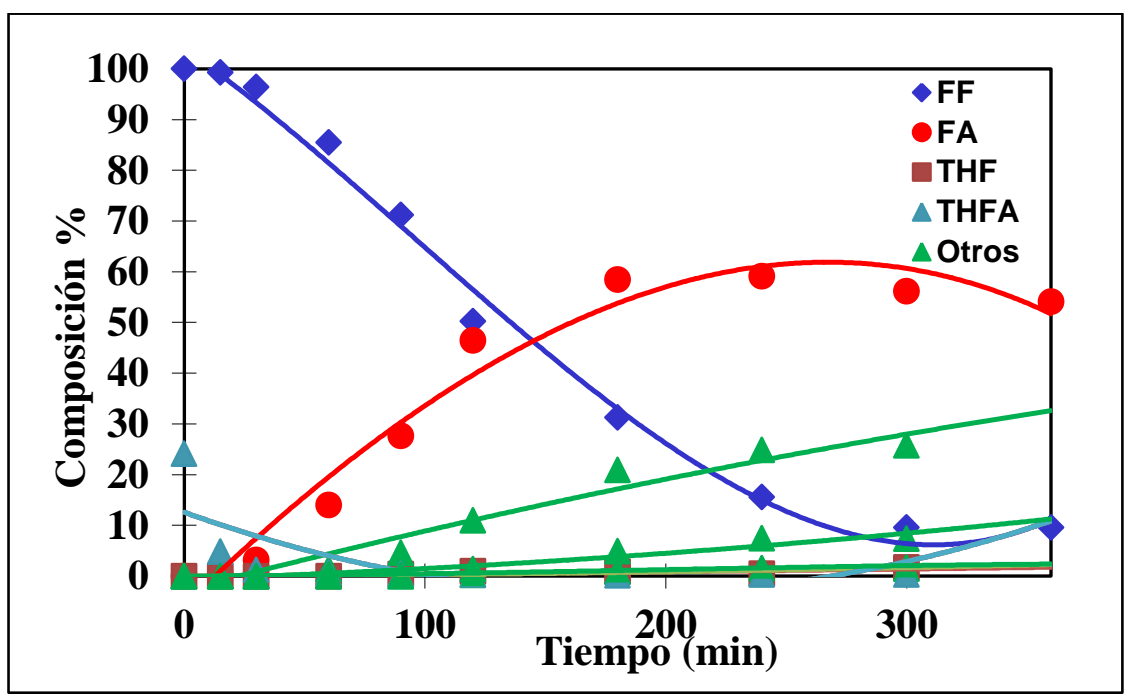

(c) $\mathrm{RuSn}_{0,8} / \mathrm{C}$

Figura 7.9. Distribución de productos de hidrogenación de furfural. (a) $\mathrm{Ru} / \mathrm{C}$, (b) $\mathrm{RuSn}_{0.4} / \mathrm{C}$, (c) $\mathrm{RuSn}_{0.8} / \mathrm{C}$

\section{5.- Reutilización de los catalizadores}

Una propiedad importante de los catalizadores heterogéneos, además de su actividad y selectividad, es la posibilidad de reutilización que hace factible su aplicación práctica en diferentes ciclos catalíticos, haciéndolos económicamente atractivos.

Así es que resultó interesante analizar el comportamiento de los catalizadores $\mathrm{Ru} / \mathrm{C}$, $\mathrm{RuSn}_{0.4} / \mathrm{C}$ y $\mathrm{RuSn}_{0.8} / \mathrm{C}$ en sucesivas reacciones de hidrogenación. Para ello, se llevaron a cabo una serie de experimentos en los que, después de 420 minutos de reacción (bajo las mismas condiciones experimentales explicadas previamente), el catalizador se lavó con agua destilada y se reutilizó hasta completar tres ciclos de hidrogenación. 
Como se muestra en las figuras 7.10, 7.11 y 7.12, se observó una caída significativa en la conversión de furfural después de reutilizar dos veces todos los catalizadores.

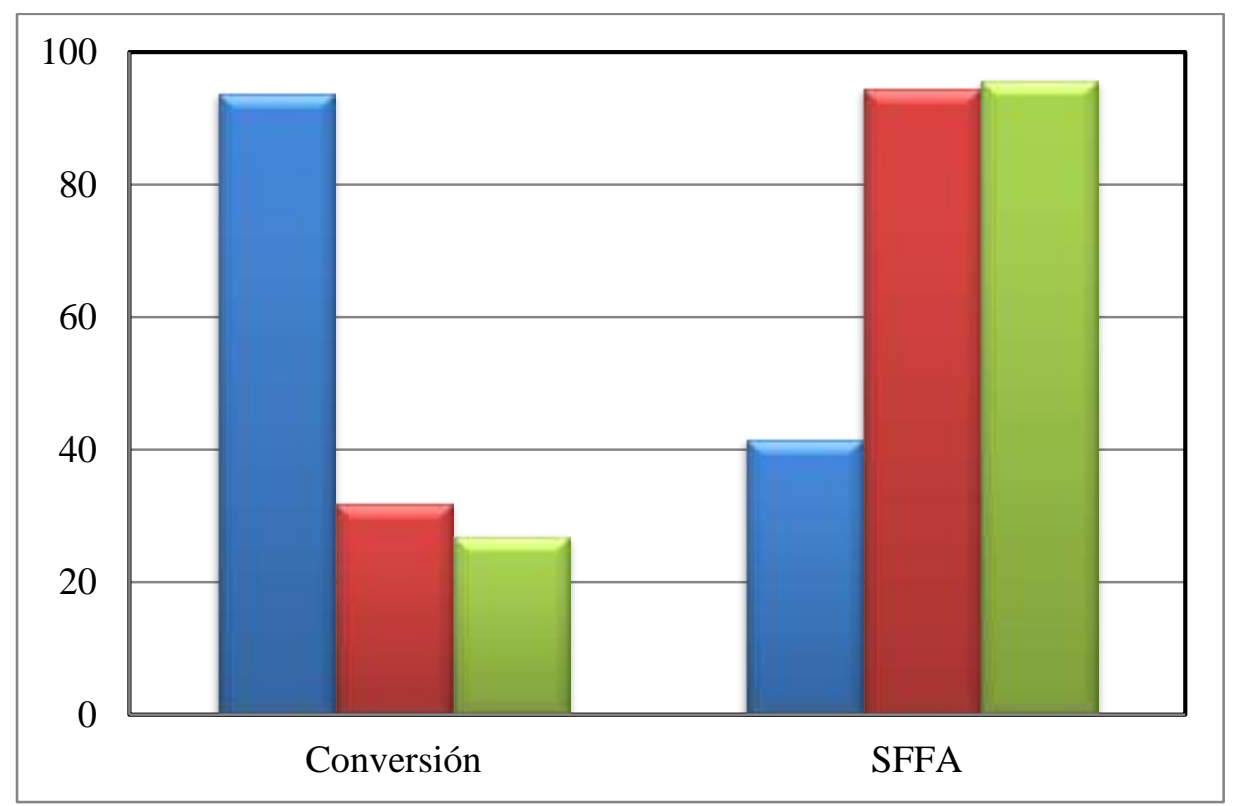

Figura 7.10. Conversión y selectividad a alcohol furfurílico (FFA) de Ru/C ((घ) catalizador fresco; $(\square) 1^{\circ}$ reúso y $(\square) 2^{\circ}$ reúso).

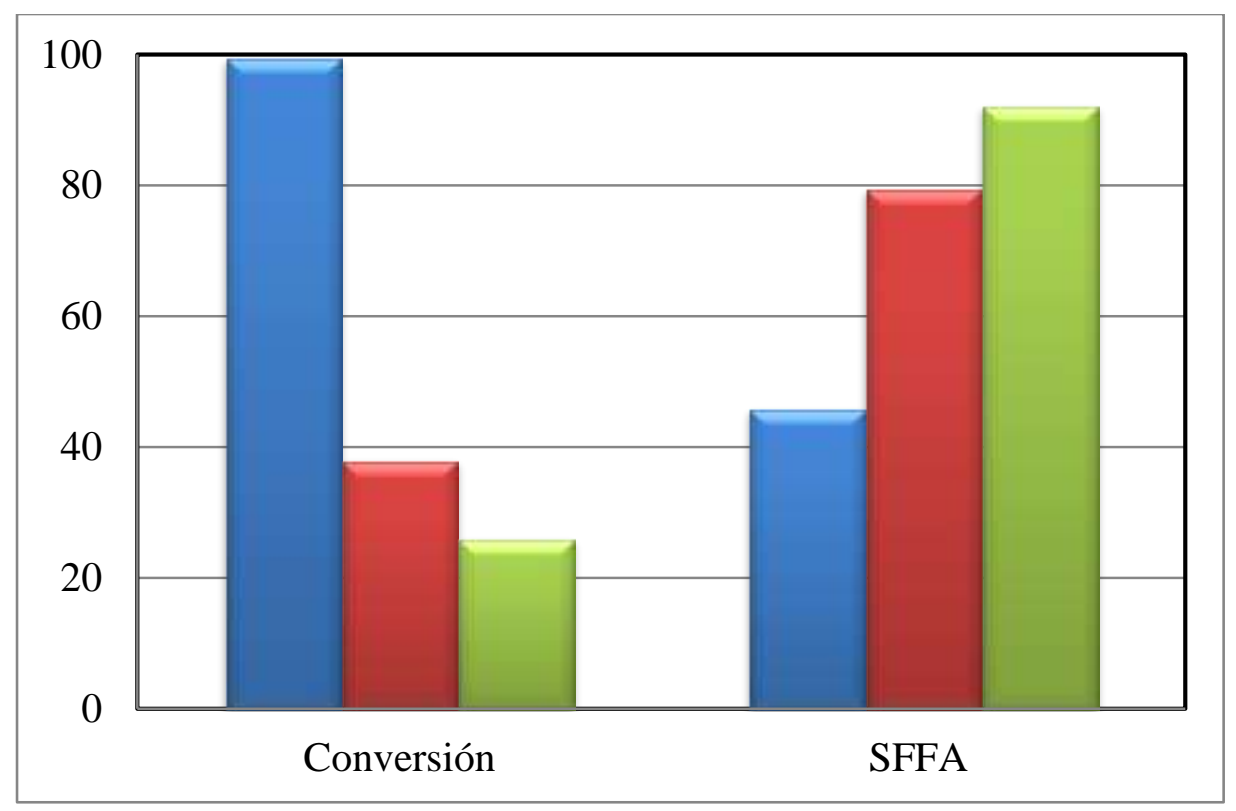

Figura 7.11. Conversión y selectividad a alcohol furfurílico (FFA) de) $\mathrm{RuSn}_{0.4} / \mathrm{C}$ ( $\square$ ) catalizador fresco; $(\square) 1^{\circ}$ reúso y $(\square) 2^{\circ}$ reúso). 


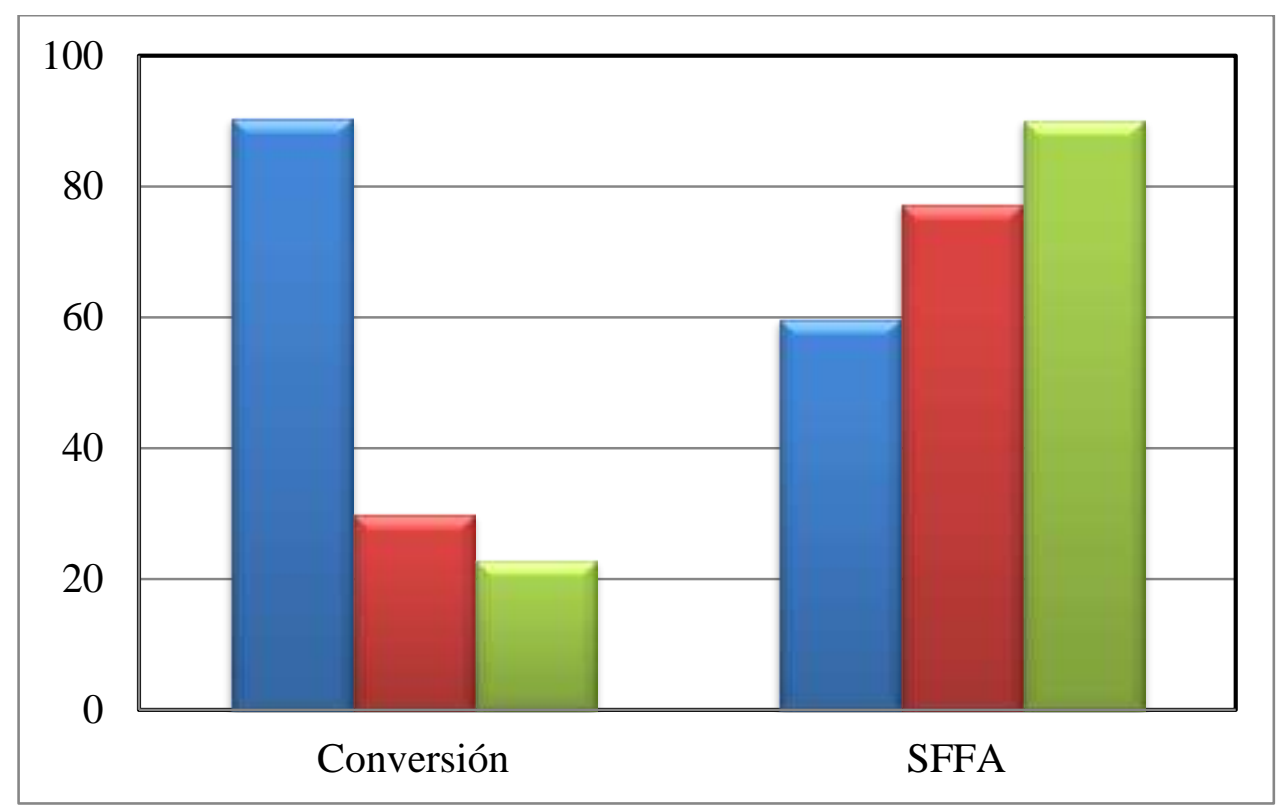

Figura 7.12. Conversión y selectividad a alcohol furfurílico (FFA) de $\mathrm{RuSn}_{0.8} / \mathrm{C}$ ((口) catalizador fresco; $(\square) 1^{\circ}$ reúso y $(\square) 2^{\circ}$ reúso).

Esta disminución podría deberse a la polimerización del furfural bajo las condiciones de reacción. Por tratarse de un soporte de carbón no es viable un tratamiento de calcinación y los oligómeros formados podrían no haber sido eliminados de la superficie por un simple lavado con agua. Un aspecto notable es que la selectividad para alcohol furfurílico mantuvo altos valores durante todas las reutilizaciones.

\section{6.- Conversión catalítica de furfural proveniente de la pirólisis de cáscaras de} semillas de girasol para producir bio-alcohol furfurílico

Como ya se ha desarrollado detalladamente en el Capítulo 1 de esta Tesis, la biomasa lignocelulósica es el recurso de carbono no fósil más económico y abundante que se puede usar para producir productos químicos y combustibles, aplicando procesos que generen menores emisiones de gases de efecto invernadero (Kajaste R., 2014). Las transformaciones bioquímicas de los materiales lignocelulósicos son bastante difíciles de llevar a cabo debido a la resistencia natural de las paredes de las células vegetales a la deconstrucción microbiana y enzimática (Himmel M.E. y col., 2007). En este sentido, se han realizado algunos ensayos preliminares, los cuales se presentarán en el Capítulo 8 (Conclusiones Generales y Perspectivas). Por el contrario, la pirólisis permite transformar rápidamente la biomasa, generando una variedad de 
productos líquidos, gaseosos y sólidos (Lim, C.H. y col, 2016). El líquido, conocido como bio-aceite o bio-oil, es considerado universalmente como una fuente prometedora de combustibles y productos químicos (Bridgewater, A.V., 2012), entre los que se encuentra el furfural (Ioannidou O. y col., 2009).

Las cáscaras de semillas de girasol (Helianthus annuus) constituyen un abundante residuo lignocelulósico de la industria del aceite comestible. En la Planta Piloto de Ingeniería Química (PLAPIQUI) en Bahía Blanca (Buenos Aires, Argentina), el grupo de investigación de la Dra. M.A. Volpe ha realizado un estudio sobre la producción de furfural a partir de dichas cáscaras de girasol, logrando obtener un bioaceite de pirólisis rico en furfural (Casoni A.I. y col., 2015).

El procedimiento utilizado consistió en la utilización de cáscaras de semillas de girasol empleadas directamente, así como también pretratadas. Los pretratamientos se seleccionaron para aumentar el rendimiento de furfural en el bio-oil pirolítico. Se realizaron dos pretratamientos a las cáscaras de semillas, consistentes en lavarlas con soluciones de $\mathrm{H}_{3} \mathrm{PO}_{4}$ al $5 \%$ y $\mathrm{ZnCl}_{2}$ al $5 \%$. Ambas soluciones ácidas originan una despolimerización parcial de holocelulosa, lo cual conduce a un aumento en la concentración de furanos en el correspondiente bio-aceite (Ramirez-Corredores M.M., 2013a; Cao N., Xu Q. y Chen L. F., 1995). Esto da origen a tres tipos de muestras para ser sometidas al proceso de pirólisis: cáscaras sin pretratamiento (S), cáscaras lavadas con ácido (SH) y cáscaras tratadas con solución de cloruro de zinc (SZ).

Las reacciones pirolíticas de $\mathrm{S}$, SH y SZ se llevaron a cabo a $400^{\circ} \mathrm{C}$ en flujo de $\mathrm{N}_{2}$ $\left(200 \mathrm{~cm}^{3} / \mathrm{min}\right)$ utilizando un reactor de flujo descendente de vidrio, provisto de un disco de vidrio poroso en la parte inferior para retener las cáscaras y al mismo tiempo permitir que los vapores puedan salir. Se usaron aproximadamente $3 \mathrm{~g}$ de cáscaras de semilla de girasol en cada reacción. El reactor se colocó en un horno previamente calentado a $400^{\circ} \mathrm{C}$ y los vapores se condensaron, con un baño de agua/hielo, para recoger los bioaceites. Las condiciones experimentales se seleccionaron para lograr el rendimiento máximo de bio-oil (Casoni A.I y col., 2015; Garg R. y Kuumar D., 2016). Los bio-oils de S, SH y SZ se analizaron por cromatografía gaseosa acoplada con espectroscopía de masas y los porcentajes de los principales compuestos en el bio-oil obtenido se presentan en la Tabla 7.9. 
Tabla 7.9. Rendimiento a diferentes productos de pirolisis y composición química de bioaceites $^{\text {a }}$ (Tomada de Casoni A.I. y col., 2018).

\begin{tabular}{|c|c|c|c|}
\hline & $\begin{array}{l}\text { Cáscaras } \\
\text { de semilla } \\
\text { de girasol }\end{array}$ & $\begin{array}{l}\text { Cáscaras de semilla } \\
\text { de girasol tratadas } \\
\text { con } 5 \% \mathrm{ZnCl}_{2}\end{array}$ & $\begin{array}{c}\text { Cáscaras de semilla } \\
\text { de girasol tratadas } \\
\text { con } 5 \% \mathrm{H}_{3} \mathrm{PO}_{4}\end{array}$ \\
\hline Bio-aceite \% en peso & 45 & 39 & 33 \\
\hline Biocarbón \% en peso & 27 & 26 & 31 \\
\hline Gas & 28 & 35 & 36 \\
\hline \multicolumn{4}{|l|}{$\%$ de Compuestos } \\
\hline Ácido acético & 43 & 17 & 15 \\
\hline Furfural & 10 & 24 & 73 \\
\hline 1-Hidroxi-2-propanona & 3 & - & - \\
\hline Levoglucosenona & - & - & 10 \\
\hline Otros $^{b}$ & 44 & 59 & 2 \\
\hline
\end{tabular}

Teniendo en cuenta que el tratamiento con ácido fosfórico condujo a la activación de la celulosa por despolimerización (Ramirez-Corredores M. M., 2013b) y, concomitantemente, a un mayor rendimiento de furfural, este bio-oil fue seleccionado en esta Tesis Doctoral como material de partida para estudiar la performance en cuanto a la hidrogenación de los catalizadores de Ru/C y RuSn $0.4 / C$.

Los ensayos de hidrogenación de la muestra seleccionada se efectuaron a $90^{\circ} \mathrm{C}$ y $1,25 \mathrm{MPa}$ de presión de $\mathrm{H}_{2}$, cargando $0,15 \mathrm{~cm}^{3}$ del bio-oil que fue la cantidad de la que se dispuso para ensayar, $50 \mathrm{~cm}^{3}$ de agua destilada y $85 \mathrm{mg}$ de catalizador. Esta última cantidad se definió buscando mantener la misma relación sustrato/catalizador que la empleada en los ensayos anteriores. En la figura 7.13 se muestran los resultados obtenidos para los dos catalizadores ensayados a 30 minutos de reacción. 


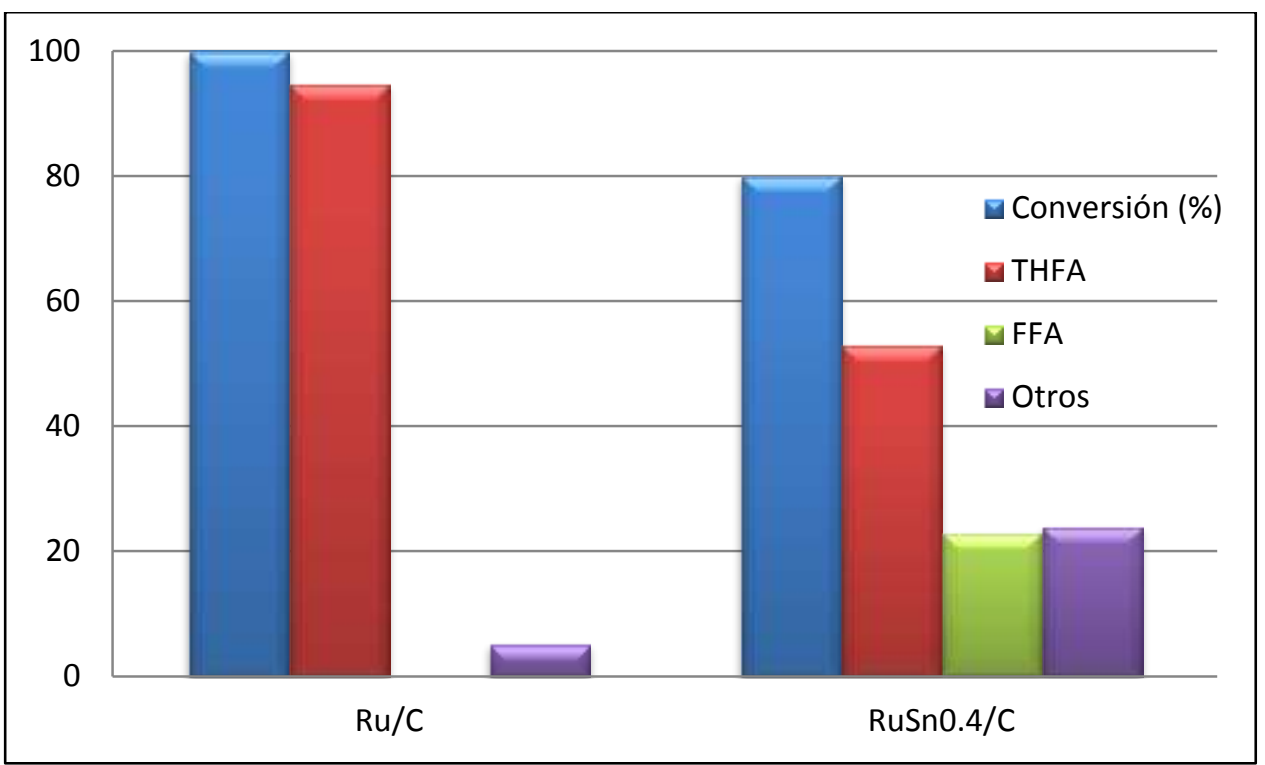

Figura 7.13. Conversión y selectividades obtenidas en la hidrogenación en fase de acuosa del bio-oil (SH).

Puede observarse que el catalizador de Ru monometálico alcanzó 100\% de conversión a los 30 minutos de reacción, obteniéndose casi un 95\% de selectividad a alcohol tetrahidrofurfurílico (THFA). Con el agregado de Sn, el catalizador bimetálico presentó una conversión del $80 \%$ en el mismo tiempo de reacción y se logró alcanzar una selectividad del $23 \%$ a alcohol furfurílico (FFA). 


\section{7.- Conclusiones}

Todos lo catalizadores resultaron activos en la hidrogenación de furfural bajo las condiciones experimentales ensayadas. El sistema $\mathrm{Ru} / \mathrm{C}$ fue el que presentó mayor actividad, obteniéndose una conversión del 94\% luego de 7 hs de reacción. Esto está en relación con el menor tamaño de partículas y la mayor dispersión metálica. Para el mismo tiempo de reacción se obtuvieron conversiones más bajas con el resto de los catalizadores (Ru/A, Ru/Z, Ru/Z-A, Ru/ZP, Ru/ZP-A).

El producto mayoritario al inicio de la reacción fue el alcohol furfurílico (FFA), resultando de la hidrogenación de enlace $\mathrm{C}=\mathrm{O}$. Se obtuvieron selectividades mayores a $90 \%$ para este producto a un $10 \%$ de conversión, en todos los casos ensayados.

Sin embargo, la distribución de productos se modificó notoriamente con el avance de la reacción, obteniéndose una selectividad a FFA menor a $42 \%$ al final de la reacción para el caso de $\mathrm{Ru} / \mathrm{C}$.

Los sistemas fosfatados, Ru/ZP y Ru/ZP-A, fueron los más selectivos a FFA (93 y 95\% respectivamente) hacia el final luego 420 min de reacción. La mayor selectividad a FFA puede estar asociada al tamaño de partícula metálica por un lado y a la acidez del soporte por otro. En partículas grandes y soportes ácidos como los fosfatados, la selectividad a FFA se ve favorecida.

La hidrogenación en fase acuosa (APH) de furfural también se investigó promoviendo el catalizador de Ru/C con el agregado de Sn a través de técnicas QOMS / $M$. Se variaron las relaciones atómicas $\mathrm{Sn} / \mathrm{Ru}$ entre 0,1 y 0,8. La adición de estaño tiene diferentes efectos en el sistema $\mathrm{Ru} / \mathrm{C}$, tanto en términos de conversión como de selectividad, dependiendo de su concentración. Parece haber un compromiso entre la dilución de sitios $\mathrm{Ru}$, activos para la reacción de hidrogenación, y el efecto promotor de Sn. La alta selectividad del alcohol furfurílico lograda con el catalizador $\mathrm{RuSn}_{0.4} / \mathrm{C}$ demostró el prometedor potencial de este sistema en reacciones APH, especialmente teniendo en cuenta que también muestra un alta reactividad al mismo tiempo. La estrecha interacción entre el estaño y rutenio, que conduce a una fase activa bien definida medida por XPS, sería responsable de este comportamiento. 
Se seleccionó un bio-aceite generado a partir de un tratamiento pirolítico de cáscaras de semilla de girasol pretratadas, como material de partida para estudiar la performance en cuanto a la hidrogenación de los catalizadores de Ru/C y RuSn $0.4 / C$. El catalizador de Ru monometálico alcanzó $100 \%$ de conversión a los 30 minutos de reacción, obteniéndose casi un 95\% de selectividad a alcohol tetrahidrofurfurílico (THFA). El catalizador de RuSn 0.4 /C presentó una conversión del $80 \%$ en el mismo tiempo de reacción y se logró alcanzar una selectividad del $23 \%$ a alcohol furfurílico (FFA). 


\section{CAPÍTULO 8}

CONCLUSIONES FINALES Y PERSPECTIVAS A FUTURO 
En el presente capítulo se detallan las conclusiones de este trabajo de Tesis, luego de haber estudiado las reacciones de hidrogenación de diversos sustratos derivados de la biomasa (glucosa, xilosa, celobiosa, trans-2-pentenal y furfural). Además se mencionan las perspectivas de trabajo a llevarse a cabo en el futuro, tendientes a continuar con esta línea de investigación y profundizar los avances alcanzados hasta el presente. 


\section{1.- Conclusiones finales}

La utilización de materias primas renovables ha impulsado en los últimos tiempos el aprovechamiento de la biomasa vegetal como una alternativa válida para la síntesis de derivados con mayor valor agregado, como productos químicos y de química fina.

El objetivo general de esta tesis doctoral ha sido el de generar y transferir conocimientos relacionados al desarrollo racional y a la comprensión del modo de acción de catalizadores sólidos heterogéneos que puedan resultar activos, selectivos y estables en procesos vinculados con las biorrefinerías, como ser la hidrogenación hidrolítica de celulosa con el objeto de generar productos para química fina y energía, en condiciones suaves que sean ambientalmente amigables (empleando agua como solvente y presiones y temperaturas moderadas). Con el fin de cumplir este cometido, se estudió la reacción de hidrogenación en fase acuosa de sustratos provenientes de la degradación de celulosa y hemicelulosa: furfural, glucosa, xilosa y celobiosa, desarrollando metodologías adecuadas para llevar a cabo la reacción propuesta.

Para el desarrollo de esta tesis se utilizaron soportes de carbón activado (C), $\gamma-\mathrm{Al}_{2} \mathrm{O}_{3}(\mathrm{~A})$ y $\mathrm{ZrO}_{2}(\mathrm{Z})$

Los soportes de carbón activado (C) y $\gamma-\mathrm{Al}_{2} \mathrm{O}_{3}(\mathrm{~A})$, de origen comercial, se acondicionaron para ser utilizados en la preparación de los catalizadores para las reacciones propuestas.

Los soportes a base de zirconio, se prepararon por el método de sol-gel. Luego de la calcinación a $600^{\circ} \mathrm{C}$ se evidenció el predominio de fase monoclínica entre fases cristalinas. Estos soportes presentan áreas del orden de los $20-30 \mathrm{~m}^{2} / \mathrm{g}$. Con el objeto de mejorar esta característica se prepararon soportes por deposición de $\mathrm{ZrO}_{2}$ sobre $\gamma-\mathrm{Al}_{2} \mathrm{O}_{3}$ (Z-A) los que presentaron áreas de 170-180 $\mathrm{m}^{2} / \mathrm{g}$. Además, con objeto de mejorar las características ácidas estos soportes fueron modificados con $\mathrm{H}_{3} \mathrm{PO}_{4}(\mathrm{ZP}-\mathrm{A})$. Se observó que el fosfato aumenta la estabilidad térmica del $\mathrm{ZrO}_{2}$.

Todos los sistemas preparados resultaron ser materiales mesoporosos.

En la primera etapa se prepararon catalizadores de Ru sobre carbón variando la proporción del metal desde $0,5 \%$ hasta $3 \%$ en peso. La evaluación de los mismos en la 
reacción de hidrogenación de glucosa en fase acuosa, mostró que el catalizador con mayor contenido metálico presentó conversión prácticamente total y selectividad del $100 \%$ al polialcohol correspondiente (sorbitol). A partir de estos estudios se definió el empleo de 3\% de Ru para la preparación de los demás sistemas catalíticos.

Los soportes con mayor área superficial presentaron mayores valores de dispersión del metal depositado, obteniéndose en todos los casos partículas nanométricas $(1,12-5,70 \mathrm{~nm})$.

Se analizó el efecto de la temperatura de la reacción de hidrogenación de glucosa en fase acuosa lo que permitió determinar un valor para la energía de activación de 30,87 kJ/mol (7,38 Kcal/mol). Se estudió además, el efecto de la presión de $\mathrm{H}_{2}$, determinándose un orden de reacción de 0,5862 para este reactivo, mientras que a partir del estudio de la variación de la concentración inicial de glucosa se estableció un orden de reacción de -1,0105 para el monosacárido.

Se estudió también la estabilidad del catalizador de $\mathrm{Ru}(3 \%) / \mathrm{C}$ en la hidrogenación de glucosa, observando que el valor de velocidad inicial de reacción se mantiene luego de 4 ciclos de uso, aunque la conversión disminuye en cada reciclo. Esto último, sin embargo, puede deberse a la adsorción fuerte de glucosa y/o sorbitol sobre el catalizador, sin que esto implique una desactivación definitiva del mismo por envenenamiento irreversible.

Posteriormente y definidas las condiciones de reacción, se ensayaron los distintos catalizadores monometálicos preparados en la hidrogenación de los monosacáridos glucosa y xilosa, así como del disacárido celobiosa; molécula seleccionada como modelo simple de celulosa, para el estudio del comportamiento de nuestros sistemas catalíticos frente a los polisacáridos.

La actividad en la hidrogenación de glucosa de los catalizadores estudiados resultó altamente dependiente del soporte. Los sistemas soportados sobre alúmina (Ru/ZP-A y Ru/Z-A) alcanzaron mayores conversiones que los catalizadores másicos. La elevada superficie específica y el mayor volumen de poro del soporte ZP-A en particular desempeñan un papel fundamental a la hora de obtener una mejora en la performance catalítica. En todos los casos se obtuvo sorbitol como único producto. 
En la hidrogenación de xilosa el producto mayoritario fue xilitol y se obtuvo una pequeña cantidad de arabinitol en los catalizadores $\mathrm{Ru} / \mathrm{C}, \mathrm{Ru} / \mathrm{Z}$ y $\mathrm{Ru} / \mathrm{Z}-\mathrm{A}$. Ru/ZP-A presentó la mayor conversión (casi 100\%) y selectividad a xilitol (superior a 99\%).

Al analizar las pruebas con celobiosa, se observó que los sitios metálicos de Ru pueden hidrogenar el disacárido a celobitol (3- $\beta$-Dglucopiranosil- D-glucitol). La conversión aumenta en relación al aumento de la dispersión metálica, siendo los sistemas Ru/C, Ru/Z-A y Ru/ZP-A los que presentaron mayores valores de conversión. Sin embargo, la acidez de los soportes en ningún caso fue suficiente para escindir el enlace glicosídico C-O-C del sustrato.

Los sistemas catalíticos se emplearon también en la reacción de hidrogenación de trans-2-pentenal en fase acuosa, en las mismas condiciones definidas para los ensayos con azúcares (en un reactor tipo autoclave (Autoclave Engineers) a 1,25 MPa de presión de $\mathrm{H}_{2}, 90^{\circ} \mathrm{C}$ ). Este compuesto constituye entre otras cosas, un modelo para estudiar el comportamiento catalítico en la hidrogenación de aldehídos $\alpha, \beta$ insaturados. El orden creciente de actividad para los catalizadores monometálicos ensayados fue el siguiente: $\mathrm{Ru} / \mathrm{Z}-\mathrm{A}<\mathrm{Ru} / \mathrm{A}<\mathrm{Ru} / \mathrm{C}<\mathrm{Ru} / \mathrm{ZP}-\mathrm{A}$. Es posible concluir que la actividad de los diversos catalizadores de Ru ensayados depende no solamente de la dispersión de la fase metálica, si no también de las características del soporte. La combinación óptima entre estas características se da para el sistema Ru/ZP-A. En cuanto a la selectividad obtenida, se observa que el producto mayoritario es en todos los casos el aldehído saturado (pentanal).

Con el objeto de obtener mejoras en la actividad catalítica y selectividad al alcohol insataturado (UOL), se prepararon catalizadores de Ru bimetálicos, mediante el agregado de Sn con técnicas QOMS/M sobre el catalizador de Ru/C. Los sistemas bimetálicos así obtenidos se designaron $\mathrm{RuSn}_{\mathrm{y}} / \mathrm{C}$, donde los valores de y $(0,1 ; 0,4$ y 0,8$)$ representa la relación molar Sn/Ru nominal. Después de la adición de Sn, el tamaño medio de partícula aumentó a $2,7 \mathrm{~nm}$ y $2.2 \mathrm{~nm}$ para los catalizadores $\mathrm{RuSn}_{0.4} / \mathrm{C}$ y $\mathrm{RuSn}_{0.8} / \mathrm{C}$, respectivamente. Este aumento en el tamaño de partícula se puede asignar en parte al depósito selectivo de estaño sobre rutenio y no sobre el soporte.

Mediante estudios de XPS realizados a los catalizadores bimetálicos reducidos se determinó la presencia de Ru principalmente en forma metálica, a la vez que se 
encontró la existencia de un efecto electrónico de estaño sobre el rutenio. En cuanto al estado de oxidación del estaño, se observan por XPS dos contribuciones, asignables a Sn (0) y otra a Sn (II, IV). La fracción de estaño metálico es de 20,8\% y 29,9\% para RuSn $_{0.4}$ y RuSn $n_{0.8}$, respectivamente. La existencia de fases RuSn bimetálico (Incluso aleaciones) se podría deducir a partir de esto último.

En los ensayos de hidrogenación de trans-2-pentenal con catalizadores bimetálicos el orden de actividad observado, expresado a través de la velocidad inicial de reacción es: $\mathrm{RuSn}_{0.1}>\mathrm{RuSn}_{0.8}>\mathrm{RuSn}_{0.4} \approx \mathrm{Ru} / \mathrm{C}$. Respecto a la selectividad obtenida con los catalizadores bimetálicos, se observa una mejoría hacia la obtención de UOL. Esto indica que la interacción del sustrato con el catalizadores está influenciado por la presencia de Sn, favoreciendo su aproximación a la superficie metálica a través del enlace $\mathrm{C}=\mathrm{O}$, lo cual favorece el contacto del mismo con el hidrógeno adsorbido.

Otro de los sustratos estudiados en reacciones de hidrogenación con los catalizadores preparados para esta tesis, fue el furfural, aldehído perteneciendo al grupo de los $\alpha, \beta$-insaturados. El sistema Ru/C fue el que presentó mayor actividad, obteniéndose una conversión del $94 \%$ luego de 7 hs de reacción. Esto, en concordancia con los demás estudios presentados, está en relación con el menor tamaño de partículas y la mayor dispersión metálica. Para el mismo tiempo de reacción se obtuvieron conversiones más bajas con el resto de los catalizadores ( $R u / A, R u / Z, R u / Z$ $A, R u / Z P, R u / Z P-A)$. El producto mayoritario al inicio de la reacción fue el alcohol furfurílico (FFA), resultando de la hidrogenación de enlace $C=0$. Se obtuvieron selectividades mayores a $90 \%$ para este producto a un $10 \%$ de conversión, en todos los casos ensayados. Sin embargo, la composición de productos se modificó notoriamente con el avance de la reacción, obteniéndose una selectividad a FFA menor a $42 \%$ al final de la reacción para el caso de $\mathrm{Ru} / \mathrm{C}$.

Los sistemas fosfatados, Ru/ZP y Ru/ZP-A, fueron los más selectivos a FFA (93 y 95\% respectivamente) hacia el final de la reacción. La mayor selectividad a FFA puede estar asociada al tamaño de partícula metálica por un lado y a la acidez del soporte por otro. En partículas grandes y soportes ácidos como los fosfatados, la selectividad a FFA se ve favorecida. 
La hidrogenación en fase acuosa (APH) de furfural también se investigó con los catalizadores bimetálicos RuSn preparados a través de técnicas QOMS / M. La adición de estaño tiene diferentes efectos en el sistema Ru/C, tanto en términos de conversión como de selectividad, dependiendo de su concentración. Parece haber un compromiso entre la dilución de sitios $\mathrm{Ru}$, activos para la reacción de hidrogenación, y el efecto promotor de Sn. Se logró alta selectividad al alcohol furfurílico con el catalizador $\mathrm{RuSn}_{0.4} / \mathrm{C}$ demostrando el prometedor potencial de este sistema en reacciones APH, especialmente teniendo en cuenta que también muestra un alta reactividad al mismo tiempo. La estrecha interacción entre el estaño y rutenio que conduce a una fase activa bien definida, medida por XPS, sería responsable de este comportamiento.

Finalmente se seleccionó un bio-aceite generado a partir de un tratamiento pirolítico de cáscaras de semilla de girasol pretratadas, como material de partida para estudiar la performance en cuanto a la hidrogenación de los catalizadores de Ru/C y $\mathrm{RuSn}_{0.4} / \mathrm{C}$. El catalizador de Ru monometálico alcanzó $100 \%$ de conversión a los 30 minutos de reacción, obteniéndose casi un 95\% de selectividad a alcohol tetrahidrofurfurílico (THFA). El catalizador de $\mathrm{RuSn}_{0.4} / \mathrm{C}$ presentó una conversión del $80 \%$ en el mismo tiempo de reacción y se logró alcanzar una selectividad del $23 \%$ a alcohol furfurílico (FFA).

\section{2.- Perspectivas a futuro}

Como se mencionó al comienzo de esta tesis, los azúcares pueden encontrarse en las plantas, bien como reserva de metabolitos tipo almidón o sacarosa, o bien formando parte de su estructura, como en la lignocelulosa. El primer tipo de azúcares es de fácil accesibilidad y si bien se emplean en la producción de bioetanol, su destino principal es la industria alimentaria. En cambio, los compuestos lignocelulósicos, resultan no comestibles, proviniendo en su mayoría de residuos agrícolas y forestales. Es por ello que se espera que sean el primer objetivo de la química de los recursos de la biomasa. Sin embargo, son más complejos y difíciles de extraer. Una de las estrategias para el tratamiento de la lignocelulosa es su fraccionamiento e hidrólisis que hacen posible realizar un procesado selectivo.

Teniendo esto en cuenta es que surge como propuesta, la posibilidad de encarar estudios profundos tendientes a obtener hidrolizados de celulosa mediante 
tratamientos enzimáticos y a partir de los materiales así obtenidos, emplear catalizadores metálicos buscando obtener productos químicos de valor agregado. Esto se llevará a cabo a partir de los resultados obtenidos en el capítulo 6. 


\section{NOMENCLATURA}

\section{Capítulo 1}

AFEX ammonia fiber explosion (Explosión de fibra con amoniaco)

CB Carbon black

CNT Nanotubos de carbono

C6 y C5 azúcares de 5 y 6 carbonos

FOL alcohol furfurílico

G.P. Grado de polimerización

$\% \mathrm{p} / \mathrm{p} \quad$ Porcentaje peso en peso

QOMS/M Química Organometálica de Superficies sobre Metales

\section{Capítulo 2}

$a$

área ocupada por una molécula de $\mathrm{N}_{2}$ adsorbida $\left(0,162 \mathrm{~nm}^{2}\right)$ (Ec. 2.4)

C

constante relacionada con la energía de adsorción (Ec. 2.1)

d

distancia interplanar del cristal (Ec. 2.5)

$d$

diámetro medio de partícula (nm) (Ec. 2.8, Ec. 2.9, Ec 2.10)

$d_{i}$

intervalo dado de tamaño (nm) (Ec. 2.8)

DRX

Disfracción de rayos $\mathrm{X}$

$E_{b} \quad$ energía cinética del electrón emitido (eV) (Ec. 2.11)

HPLC high performance liquid chromatography

hv $\quad$ energía de excitación (Ec. 2.11)

IUPAC International Union of Pure and Applied Chemists

n número entero que representa el orden de la difracción (Ec. 2.5)

$n_{i} \quad$ número de partículas (Ec. 2.8)

$N_{0} \quad$ número de Avogadro $\left(6,02 \times 10^{23}\right.$ moléculas. gmol $\left.{ }^{-1}\right)($ Ec. 2.4) 
P presión de equilibrio (atm) (Ec. 2.1)

$\mathrm{P}_{0} \quad$ presión de saturación del $\mathrm{N}_{2} \mathrm{a}-196^{\circ} \mathrm{C}$ (atm) (Ec. 2.1)

QOMS/M Química Organometálica de Superficies sobre metales

$\mathrm{S}_{\mathrm{BET}} \quad$ superficie específica $\left(\mathrm{m}^{2} \cdot \mathrm{g}^{-1}\right)($ Ec. 2.4)

SEM Scanning Electron Microscopy

TEM transmission electron microscopy

TGA termogravimetric analysis

TPR temperature programmed reduction

$v \quad$ volumen molar (22400 ml.gmol $\left.{ }^{-1}\right)$ (Ec. 2.4)

V volumen de gas adsorbido en condiciones normales ( 1 atm de presión y $0{ }^{\circ} \mathrm{C}$ ) a la presión parcial $\mathrm{P}$ del adsorbato (Ec. 2.1)

$V_{M} \quad$ volumen de gas requerido para formar una monocapa (Ec. 2.1)

W $\quad$ masa de muestra (g) (Ec. 2.4)

XPS X-ray photoelectron spectroscopy

$\theta \quad$ ángulo de difracción de Bragg (Ec. 2.5)

$\lambda \quad$ longitud de onda radiación $\mathrm{K} \alpha$ del $\mathrm{Cu}(\mathrm{nm})$ (Ec. 2.6)

Ф diámetro de poro

Ф función de trabajo del espectrómetro (Ec. 2.11)

\section{Capítulo 3}
A $\quad \gamma-\mathrm{Al}_{2} \mathrm{O}_{3}$
C Carbón activado
DRX Difracción de rayos $X$
$I_{m} \quad$ intensidad de línea de pico de difractograma para la fase monoclínica (m) de $\mathrm{ZrO}_{2}$ (adimensional) (Ec. 3.1) 


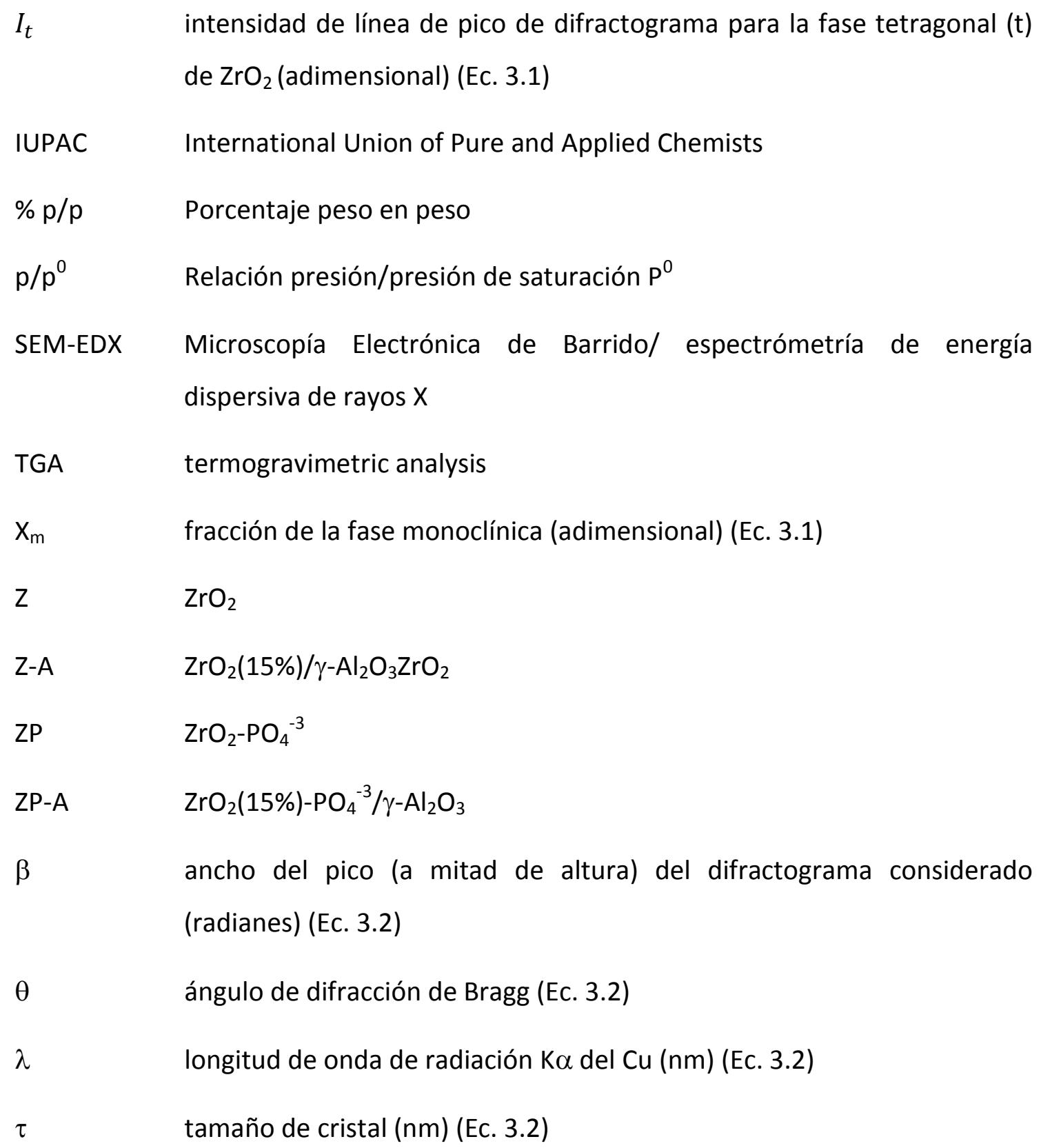

\section{Capítulo 4}

C carbón activado

$\mathrm{Z} \quad \mathrm{ZrO}_{2}$

$\mathrm{Z}-\mathrm{A} \quad \mathrm{ZrO}_{2} / \gamma-\mathrm{Al}_{2} \mathrm{O}_{3}$

$\mathrm{ZP} \quad \mathrm{ZrO}_{2}-\mathrm{PO}_{4}^{-3}$

ZP-A $\quad \mathrm{ZrO}_{2}-\mathrm{PO}_{4}^{-3} / \gamma-\mathrm{Al}_{2} \mathrm{O}_{3}$ 
temperatura $\left({ }^{\circ} \mathrm{C}\right)($ tabla 4.2$)$

M

masa catalizador monometálico (g) (tabla 4.2)

$\mathrm{C}_{\mathrm{i}}$ Concentración inicial de $\mathrm{SnBu}_{4}$ normalizada a $1 \mathrm{~g}$ de $\mathrm{Ru} / \mathrm{C}\left(\mathrm{mmol} \mathrm{L}^{-1}\right)$ (tabla 4.2)

$\mathrm{C}_{\mathrm{f}} \quad$ Concentración final de $\mathrm{SnBu}_{4}$ normalizada a $1 \mathrm{~g}$ de $\mathrm{Ru} / \mathrm{C}\left(\mathrm{mmol} \mathrm{L}{ }^{-1}\right.$ ) (tabla 4.2)

$d_{T E M} \quad$ diámetro medio de partícula $(\mathrm{nm})$

$\mathrm{n}_{\mathrm{i}}$ número de partículas (Ec. 4.1, Ec 4.2, Ec 4.3)

di diámetro de partícula (nm) (Ec. 4.1, Ec 4.2, Ec 4.3)

$D_{R u}$

dispersión de rutenio (\%)

$D_{v a}$

diámetro medio volumétrico $(\mathrm{nm})$

FID

Flame Ionization Detector

$r_{i}$

velocidad inicial de reacción ( $\mathrm{mmoles}_{\mathrm{conv}} \cdot \mathrm{g} \mathrm{Ru}^{-1} \mathrm{~min}^{-1}$ )

SAL

saturated aldehyde

SOL

saturated alcohol

TCD

thermal conductivity detector

TOF

turnover frequency

UAL unsaturated aldehyde

UOL unsaturated alcohol

\section{Capítulo 5}
$\mathrm{APH}$
Aqueous phase hydrogenation
$a_{C}$
Área externa del catalizador por unidad de masa del mismo (Ec. 5.5, Ec.
5.6)
$a_{G}$
Área interfacial por unidad de volumen del reactor (Ec. 5.1) 
$C_{g l u} \quad$ Concentración de glucosa (Ec. 5.12, Ec. 5.14, Ec. 5.15, Ec. 5.16, Ec. 5.17, Ec. 5.18, Ec. 5.19)

$C_{H_{2}} \quad$ Concentración de $\mathrm{H}_{2}$ (mol/L) (Ec. 5.2)

$C_{i} \quad$ Concentración del reactivo en la fase líquida ( $\left.\mathrm{mol} / \mathrm{L}\right)$

$C_{i}^{S} \quad$ Concentración de los reactivos en la superficie del catalizador (Ec. 5.9)

$D_{i}^{e} \quad$ difusividad efectiva de los reactivos en el interior de los poros del catalizador (Ec. 5.9, Ec. 5.11)

$\mathrm{d}_{1} \quad$ Diámetro del agitador (cm) (Ec. 5.8)

$\mathrm{D}_{\mathrm{M}} \quad$ difusividad molecular del reactive $\left(\mathrm{cm}^{2} / \mathrm{s}\right)($ Ec. 5.7$)$

$d_{p} \quad$ Diámetro de partícula del catalizador (cm) (Ec. 5.6, Ec. 5.7)

$\mathrm{d}_{\mathrm{T}} \quad$ Diámetro del interior del tanque (cm) (Ec. 5.8)

$E_{a} \quad$ Energía de activación (Kcal/mol) (Ec. 5.13, Ec. 5.14, Ec. 5.15)

$F_{f} \quad$ Factor de forma (adimensional) (Ec. 5.8)

$H_{H_{2}} \quad$ Constante de Henry para el $\mathrm{H}_{2}$ (mol/L.atm) (Ec. 5.3)

$H_{H_{2}}^{\theta} \quad$ Constante de Henry para el $\mathrm{H}_{2}$ en condiciones estándar (mol/L.atm) (Ec.

$\mathrm{h}_{2} \quad$ Altura del nivel de líquido (cm) (Ec. 5.8)

$k \quad$ Constante de velocidad de reacción (Ec. 5.12, Ec. 5.13, Ec 5.16, Ec. 5.17, Ec. 5.18, Ec. 5.19)

$k_{C} \quad$ Coeficiente de transferencia de materia en la interfase líquido/sólido $(\mathrm{cm} / \mathrm{s})($ Ec. 5.5, Ec. 5.7)

$k_{L} \quad$ Coeficiente de transferencia de materia en la interfase gas-líquido (Ec. 5.1)

L Relación entre el volumen de partícula de catalizador y la superficie externa de la misma (cm) (Ec. 5.9, Ec. 5.10) 
$m \quad$ Orden de reacción de $\mathrm{H}_{2}$ (Ec. 5.12, Ec. 5.14, Ec. 5.15, Ec. 5.16, Ec. 5.17, Ec. 5.18, Ec. 5.19)

$m_{C} \quad$ Masa del catalizador (g) (Ec. 5.5)

$n \quad$ Orden de reacción de glucosa (Ec. 5.12, Ec. 5.14, Ec. 5.15, Ec. 5.16, Ec. 5.17, Ec. 5.18, Ec. 5.19)

$\mathrm{N}$

velocidad de agitación $\left(\mathrm{seg}^{-1}\right)$ (Ec. 5.4, Ec. 5.8)

$P_{H_{2}}$

Presión parcial de hidrógeno en la fase gas (atm) (Ec. 5.2 Ec. 5.12, Ec. 5.14, Ec. 5.15, Ec. 5.16, Ec. 5.17, Ec. 5.18, Ec. 5.19))

Constante de los gases ideales (L atm/K mol) (Ec. 5.13, Ec. 5.14, Ec. 5.15)

$\left(r_{i}\right)_{\text {obs }} \quad$ Velocidad inicial de reacción obtenida experimentalmente (Ec. 5.1, Ec. 5.5, Ec. 5.9)

$r_{p}$

Radio de partícula (Ec. 5.10)

$S_{p}$

Superficie externa de partícula del catalizador (Ec. 5.10)

$S h_{P} \quad$ Número de Sherwood (adimensional) (Ec. 5.7)

$T$

Temperatura (K) (Ec. 5.3, Ec. 5.13, Ec. 5.14, Ec. 5.15)

$T^{\theta}$

Temperatura estándar (K) (Ec. 5.3)

$v$

Viscosidad cinemática de la mezcla de reacción $\left(\mathrm{cm}^{2} / \mathrm{s}\right)($ Ec. 5.7$)$

$V_{p}$

Volumen de partícula de catalizador (Ec. 5.10)

$\% \mathrm{p} / \mathrm{p} \quad$ porcentaje peso en peso

$\propto_{1} \quad$ Relación entre veloc. de reacción observada y máx. veloc. de transferencia en interfase gas/líquido (ec. 5.1)

$\propto_{2} \quad$ Relación entre veloc. de reacción observada y máx. veloc. de transferencia en interfase líquido/sólido (Ec. 5.5)

$\varepsilon \quad$ Energía suministrada al líquido por agitación mecánica $\left(\mathrm{cm}^{2} / \mathrm{s}^{3}\right)($ Ec. 5.7, Ec. 5.8)

$\epsilon_{p} \quad$ Porosidad de la partícula de catalizador (Ec. 5.11) 


$\begin{array}{ll}\mu_{M} & \text { Viscosidad de la mezcla de reacción }(\mathrm{g} /(\mathrm{cm} . \mathrm{s}))(\text { Ec. } 5.7) \\ \rho_{M} & \text { Densidad de la mezcla de reacción }\left(\mathrm{g} / \mathrm{cm}^{3}\right)(\text { Ec. } 5.7) \\ \rho_{p} & \text { Densidad de partículas de catalizador }\left(\mathrm{g} / \mathrm{cm}^{3}\right)(\text { Ec. } 5.6, \text { Ec. } 5.7) \\ \tau & \text { Tortuosidad de la partícula de catalizador (Ec. 5.11) } \\ \Phi & \text { Relación de Weisz-Prater para limitaciones al transporte de materia } \\ & \text { intrapartícula (adimensional) (Ec. 5.9) }\end{array}$

\section{Capítulo 6}

$\mathrm{APH} \quad$ Aqueous phase hydrogenation

$\begin{array}{ll}\mathrm{A} & \gamma-\mathrm{Al}_{2} \mathrm{O}_{3} \\ \mathrm{C} & \text { Carbón activado } \\ \mathrm{D}_{\text {va }} & \text { Diámetro Volumen-área }(\mathrm{nm}) \\ \mathrm{Ea} & \text { Energía de activación aparente } \\ \mathrm{HPLC} & \text { High performance liquid chromatography } \\ \mathrm{Z} & \mathrm{ZrO}_{2} \\ \mathrm{Z}-\mathrm{A} & \mathrm{ZrO}_{2}(15 \%) / \gamma-\mathrm{Al}_{2} \mathrm{O}_{3} \mathrm{ZrO}_{2} \\ \mathrm{ZP} & \mathrm{ZrO}_{2}-\mathrm{PO}_{4}^{-3} \\ \text { ZP-A } & \mathrm{ZrO}_{2}(15 \%)-\mathrm{PO}_{4}^{-3} / \gamma-\mathrm{Al}_{2} \mathrm{O}_{3}\end{array}$

\section{Capítulo 7}
A
$\gamma-\mathrm{Al}_{2} \mathrm{O}_{3}$
$\mathrm{APH} \quad$ Aqueous phase hydrogenation
C Carbón activado
$\mathrm{C}_{\mathrm{FF}}^{0} \quad$ concentración molar inicial de furfural (Ec.7.1)
$\mathrm{C}_{\mathrm{i}}^{\mathrm{t}} \quad$ concentración molar del compuesto i en el tiempo t (Ec. 7.2) 


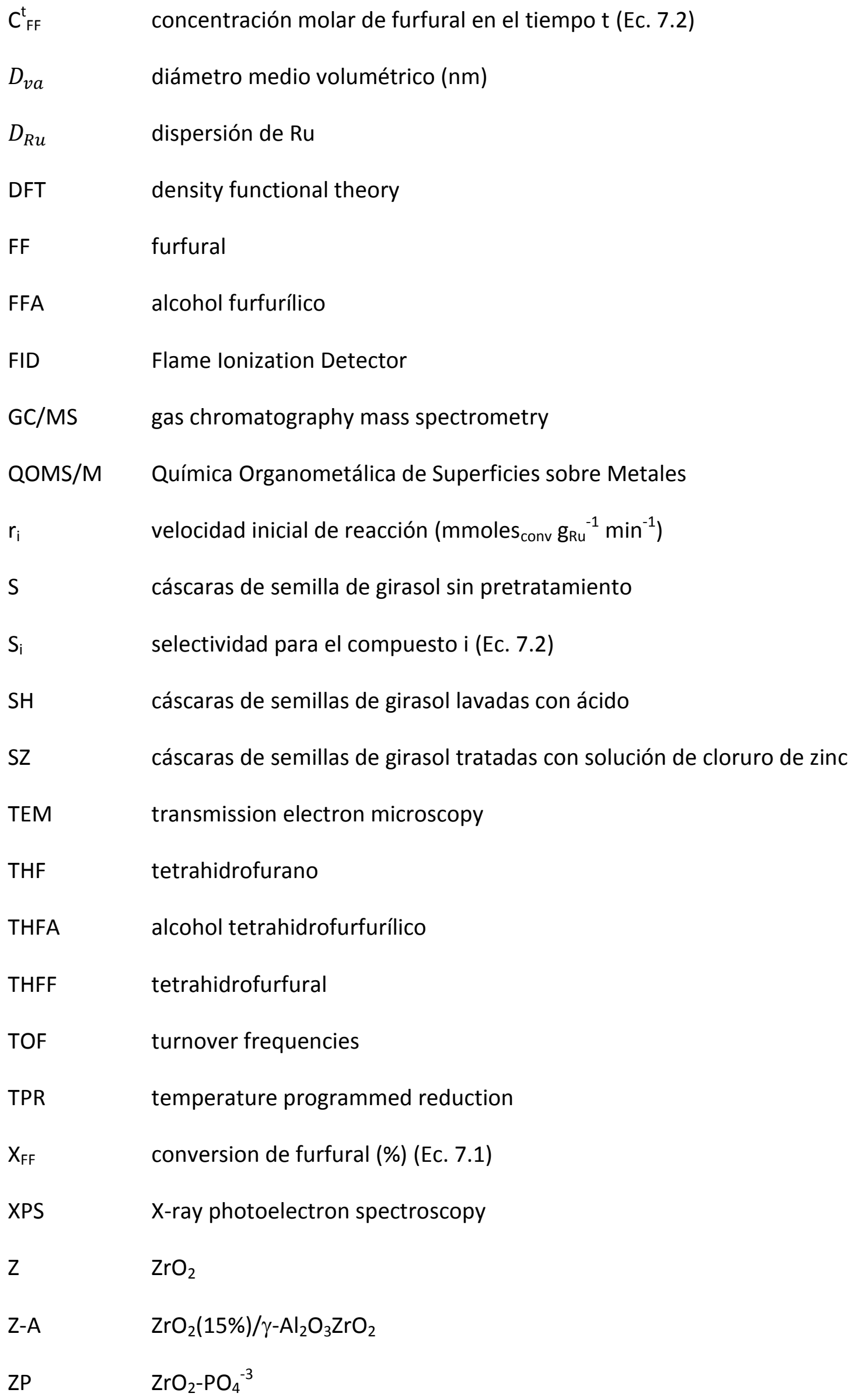


ZP-A $\quad \mathrm{ZrO}_{2}(15 \%)-\mathrm{PO}_{4}^{-3} / \gamma-\mathrm{Al}_{2} \mathrm{O}_{3}$

\section{Capítulo 8}

\begin{tabular}{|c|c|}
\hline A & $\gamma-\mathrm{Al}_{2} \mathrm{O}_{3}$ \\
\hline $\mathrm{APH}$ & Aqueous phase hydrogenation \\
\hline DNS & dinitrosalicylic acid \\
\hline FFA & alcohol furfurílico \\
\hline FPU & Filter Paper Units \\
\hline IUPAC & International Union of Pure and Applied Chemists \\
\hline$k D$ & kiloDalton \\
\hline QOMS/M & Química Organometálica de Superficies sobre Metales \\
\hline THFA & alcohol tetrahidrofurfurílico \\
\hline THFF & tetrahidrofurfural \\
\hline UI & Unidades Internacionales \\
\hline UOL & alcohol insaturado \\
\hline XPS & X-ray photoelectron spectroscopy \\
\hline Z & $\mathrm{ZrO}_{2}$ \\
\hline Z-A & $\mathrm{ZrO}_{2}(15 \%) / \gamma-\mathrm{Al}_{2} \mathrm{O}_{3} \mathrm{ZrO}_{2}$ \\
\hline ZP & $\mathrm{ZrO}_{2}-\mathrm{PO}_{4}^{-3}$ \\
\hline ZP-A & $\mathrm{ZrO}_{2}(15 \%)-\mathrm{PO}_{4}^{-3} / \gamma-\mathrm{Al}_{2} \mathrm{O}_{3}$ \\
\hline
\end{tabular}




\section{BIBLIOGRAFÍA}

- Aboulayt A., Onfroy T., Travert A., Clet G., Maugé F. (2017). Relationship between phosphate structure and acid-base properties of phosphate-modified zirconia - Application to alcohol dehydration. Applied Catalysis A: General, 530, 193-202.

- Akinterinwa O., Khankal R. y Cirino P. C. (2008). Metabolic engineering for bioproduction of sugar alcohols. Current Opinion in Biotechnology, 19 (5), 461467.

- Alexeev O. S. y Gates B. C. (2003). Supported Bimetallic Cluster Catalysts. Industrial \& Engineering Chemistry Research, 42 (8), 1571-1587.

- Alonso D. M., Bond J. Q. y Dumesic J. A. (2010). Catalytic conversion of biomass to biofuels. Green Chemistry, 12, 1493-1513.

- Alonso D. M., Wettstein S. G., Bond J. Q., Root T. W., Dumesic J. A. (2011). Production of biofuels from cellulose and corn stover using alkylphenol solvents. ChemSusChem, 4, 1078-1081.

- Angel G. D. y Benitez J. L. (1994). Ammonia and sulfur poisoning effects on hydrogenation of phenylacetylene over Pd supported catalysts. Journal of Molecular Catalysis, 94 (3), 409-416.

- Annevelink E., de Jong E., Van Ree R., Zwart R. W. R. (2006). First workshop on the possibilities of biorefinery concepts for the industry: Ilevado a cabo en hotel "De Wageningse Berg", Wageningen, the Netherlands (16 June 2006): official minutes.

- Aramendía M. A., Borau V., Jiménez C., Marinas J. M., Ruiz J. R., Urbano F. (2003). Reduction of $\alpha, \beta$-unsaturated aldehydes with basic $\mathrm{MgO} / \mathrm{M}_{2} \mathrm{O}_{3}$ catalysts (M=Al, Ga, In). Applied Catalysis A: General, 249 (1), 1-9.

- Augustine R. L. (1996). Heterogeneous Catalysis for the Synthetic Chemist. New York: M. Dekker. (pp. 161-163). 
- Bachiller-Baeza B., Guerrero-Ruiz A., Wang P., Rodríguez-Ramos I. (2001). Hydrogenation of Citral on Activated Carbon and High-Surface-Area GraphiteSupported Ruthenium Catalysts Modified with Iron. Journal of Catalysis, 204 (2), 450-459.

- Bachiller-Baeza B., Rodríguez-Ramos I., Guerrero-Ruiz A. (2001). Influence of $\mathrm{Mg}$ and $\mathrm{Ce}$ addition to ruthenium based catalysts used in the selective hydrogenation of $\alpha, \beta$-unsaturated aldehydes. Applied Catalysis A: General, 205 (1-2), 227-237.

- Baerlocher C., Mccusker L. B. y Olson D. H. (2007). Atlas of zeolite framework types. Elsevier Science.

- Bailón-García E., Carrasco-Marín F., Pérez-Cadenas A. F., Maldonado-Hodar F. J. (2016). Selective hydrogenation of citral by noble metals supported on carbon xerogels: Catalytic performance and stability. Applied Catalysis A: General, 512, 63-73.

- $\quad$ Bajpai P. K. (1986). Synthesis of mordenite type zeolite. Zeolites, 6 (1), 2-8.

- Bansal R. C., Donnet J. B. y Stoeckli F. (1988). Active carbon. Bansal R. C., Donnet J. B. y Stoeckli F. (1988). Active carbon. New York: Marcel Dekker, INC.

- Barrer, R. M. (1941). Diffusion in and through solids. Cambridge Series of Physical Chemistry (Ed. E. K. Rideal). Cambbridge: Cambridge University Press.

- Bartholomew C. H. y Farrauto R. J. (2005). Fundamentals of Industrial Catalytic Processes, Second Edition. Wiley-Blackwell.

- Basset J. M. y Choplin A. (1983). Surface organometallic chemistry: A new approach to heterogeneous Catalysis. Journal of Molecular Catalysis, 21 (1-3), 95-108.

- Basset J. M., Psaro R., Roberto D., Ugo R. (2009). Modern Surface Organometallic Chemistry, Weinheim: Wiley-VCH Verlag GmbH, (p. 241 y referencias allí citadas). 
- Baudouin D., Candy J. P., Rodemerck U., Krumeich F., Veyre L., Webb P. B., Thieuleux C., Copéret C. (2014). Preparation of Sn-doped 2-3 nm Ni nanoparticles supported on $\mathrm{SiO}_{2}$ via surface organometallic chemistry for low temperature dry reforming catalyst: The effect of tin doping on activity, selectivity and stability. Catalysis Today 235, 237-244.

- Beenackers J. A. W. M., Kuster B. F. M., Van der Baan H. S. (1985). Ionisation and solvation of d-glucose. Carbohydrate Research, 140 (2), 169-183.

- Betancourt P., Rives A., Hubaut R., Scott C. E., Goldwasser J. (1998). A study of the ruthenium-alumina system. Applied Catalysis A: General, 170 (2), 307-314.

- Bos H., Harmsen P. y Annevelink E. (2010). Background information and biorefinery status, potential and Sustainability: Task 2.1.2 Market and Consumers; Carbohydrates.

- Bradley M. K., Robinson J. y Woodruff D. P. (2010). The structure and bonding of furan on Pd (111). Surface Science, 604, (11-12), 920-925.

- Brahme P. H. y Doralswamy L. K. (1976). Modelling of a Slurry Reaction. Hydrogenation of Glucose on Raney Nickel. Industrial \& Engineering Chemistry Process Design and Development, 15 (1), 130-137.

- Bridgewater, A. V. (2012). Review of fast pyrolysis of biomass and product upgrading. Biomass Bioenergy, 38, 68-94.

- Brunauer S., Emmett P. H. y Teller E. (1938). Adsorption of Gases in Multimolecular Layers. Journal of the American Chemical Society, 60 (2), 309319.

- Cai C. M., Zhang T., Kumar R., Wyman C. E. (2014). Integrated furfural production as a renewable fuel and chemical platform from lignocellulosic biomass. Journal of Chemical Technology and Biotechnology, 89 (1), 2-10.

- Candy J. P., Didillon B., Smith E. L., Shay T. B., Basset J. M. (1994). Surface organometallic chemistry on metals: a novel and effective route to customdesigned bimetallic catalysts. Journal of Molecular Catalysis, 86 (1-4), 179-204. 
- Cao N., Xu Q. y Chen L. F. (1995). Acid hydrolysis of cellulose with zinc chloride solutions. Applied Biochemistry and Biotechnology, 51, 21-28.

- Cao Y., Hu J. Ch., Hong Z. S., Deng J. F., Fan K. N. (2002). Characterization of high-surface-area zirconia aerogel synthesized from combined alcohothermal and supercritical fluid drying techniques. Catalalysis Letters., 81 (1-2), 107-112.

- Casoni A. I., Bidegain M., Cubitto M. A., Curvetto N., Volpe M. A. (2015). Pyrolysis of sunflower seed hull for obtaining bio-oils. Bioresource Technology, 177, 406-409.

- Casoni A. I., Hoch P. M., Volpe M. A., Gutierrez V.S. (2018). Catalytic conversion of furfural from pyrolysis of sunflower seed hulls for producing bio-based furfuryl alcohol. Journal of Cleaner Production, 178, 237-246.

- Centi G., Cerrato G., D’Angelo S., Finardi U., Giamello E., Morterra C., Perathoner S. (1996). Catalytic behavior and nature of active sites in copper-onzirconia catalysts for the decomposition of $\mathrm{N}_{2} \mathrm{O}$. Catalysis Today, 27 (1-2), 265270.

- Chang Q., Zhou J., Wang Y., Meng G. (2009). Preparation and characterization of unique zirconia crystals within pores via a sol-gelhydrothermal method, Advanced Powder Technology, 20, 371-374.

- Chaudhari R., Golap R., Eming G., Hoffman H. (1987). Gas-liquid mass transfer in dead end autoclaves. The Canadian Journal of Chemical Engineering, 65, 774751.

- Cherubini F., Jungmeier G., Wellisch M., Willke T., Skiadas I., Van Ree R. (2009). Toward a common classification approach for biorefinery systems. Biofuels, Bioproducts and Biorefining, 3, 534-546.

- Clark J. H., Deswarte F. E. y Farmer T. J. (2009). The integration of green chemistry into future biorefineries. Biofuels, Bioproducts and Biorefining, 3 (1), 72-90.

- Claus P. (1998). Selective hydrogenation of $\alpha, \beta$-unsaturated aldehydes and other $\mathrm{C}=\mathrm{O}$ and $\mathrm{C}=\mathrm{C}$ bonds containing compounds. Topics in Catalysis, 5, 51-62. 
- Climent M. J., Corma A., Iborra S. (2014). Conversion of biomass platform molecules into fuel additives and liquid hydrocarbon fuels. Green Chemistry, 16, 516-547.

- Corma A., Iborra S. y Velty A. (2007). Chemical Routes for the Transformation of Biomass into Chemicals. Chemical Reviews, 107 (6), 2411-2502.

- Crezee E. B., Hoffer B. W., Berger R. J., Makkee M., Kapteijn F., Moulijn J. A. (2003). Three-phase hydrogenation of d-glucose over a carbon supported ruthenium catalyst - Mass transfer and kinetics. Applied Catalysis A: General, 251 (1), 1-17.

- Dandekar A. y Vannice M. A. (1999). Crotonaldehyde Hydrogenation on Pt/TiO and $\mathrm{Ni} / \mathrm{TiO}_{2} \mathrm{SMSI}$ Catalysts. Journal of Catalysis, 183 (2), 344-354.

- De Almeida R. M., Li J., Nederlof C., O’Connor P., Makkee M., Moulijn J. A. (2010). Cellulose Conversion to Isosorbide in Molten Salt hydrate Media. ChemSusChem, 3, 325-328.

- De Jong E., Higson A., Waslh P., Wellisch M. (2011). Biobased Chemicals - Value added products from biorefineries. IEA Bioenergy - Task 42. Disponible en: https://www.researchgate.net/publication/262048753_Bio-

Based_Chemicals_Value_Added_Products_From_Biorefineries

- Déchamp N., Gamez A., Perrard A., Gallezot P. (1995). Kinetics of glucose hydrogenation in a trickle-bed reactor. Catalysis Today, 24 (1-2), 29-34.

- Delbecq F. y Sautet P. (1995). Competitive $C=C$ and $C=0$ Adsorption of $\alpha-\beta$ Unsaturated Aldehydes on Pt and Pd Surfaces in Relation with the Selectivity of Hydrogenation Reactions: A Theoretical Approach. Journal of Catalysis, 152 (2), 217-236.

- Delbecq F. y Sautet P. (2003). Influence of Sn additives on the selectivity of hydrogenation of $\alpha$ - $\beta$-unsaturated aldehydes with Pt catalysts: a density functional study of molecular adsorption. Journal of Catalysis, 220 (1), 115-126. 
- Deng W., Tan X., Fang W., Zhang Q., Wang Y. (2009). Conversion of Cellulose into Sorbitol over Carbon Nanotube-Supported Ruthenium Catalyst. Catalysis Letters, 133, 167-174.

- $\quad$ Ding L. N., Wang A. Q., Zheng M. Y., Zhang T. (2010). Selective Transformation of Cellulose into Sorbitol by Using a Bifunctional Nickel Phosphide Catalyst. ChemsusChem, 3 (7), 818-821.

- Döbereiner J. W. (1832). Ueber die medicinische und chemischeAnwendung und die vortheilhafteDarstellung der Ameisensäure. Annalen der Pharmacie, 3 (2), 141-146.

- Dutta S., De S., Saha B., Alam M. I. (2012). Advances in conversion of hemicellulosic biomass to furfural and upgrading to biofuels. Catalysis Science \& Technology, 2, 2025-2036.

- Englisch M., Ranade V. S. y Lercher J. A. (1997). Liquid phase hydrogenation of crotonaldehyde over Pt/SiO 2 catalysts. Applied Catalysis A: General, 163 (1-2), 111-122.

- Fan L. T., Gharpuray M. M., Lee Y. H. (1987). Cellulose Hydrolysis. Berlin: Springer-Verlag.

- Faraldos M. y Goberna C. (2002), Técnicas de análisis y caracterización de materiales. Madrid: Consejo Superior de Investigaciones Científicas.

- Fenouillot F., Rousseau A., Colomines G., Saint-Loup R., Pascault J. P. (2010). Polymers from renewable 1,4:3,6-dianhydrohexitols (isosorbide, isomannide and isoidide): A review. Progress in Polymer Science, 35 (5), 578-622.

- Ferretti O. A. y Casella M. L. (1995). Latin American Applied Research, 25, 125.

- Ferretti O. A. y Casella M. L. (2009). Controlled preparation of heterogeneous catalysts. En: M. Basset, R. Psaro, D. Roberto, R. Ugo (Eds.), Modern Surface Organometallic Chemistry (pp. 239-291). Weinheim: Wiley-VCH Verlag GmbH.

- Frainier L. J. y Fineberg H. (1981). Preparation of furfuryl alcohol from furfural US Patent 4,302,397. 
- Fukuoka A. y Dhepe P. L. (2006). Catalytic Conversion of Cellulose into Sugar Alcohols. Angewandte Chemie International Edition, 45 (31), 5161-5163.

- Gallezot P., Giroir-Fendler A. y Richard P. (1981). En Pascoe W. (Ed.), Catalysis of Organic Reactions. New York.

- Gallezot P. y Richard R. (1998). Selective Hydrogenation of $\alpha, \beta$-Unsaturated Aldehydes. Catalysis Reviews - Science \& Engineering, 40 (1-2), 81-126.

- Gallezot P. (2008). Catalytic conversion of biomass: challenges and issues. ChemSusChem, 1, 734-737.

- Galvagno S., Capannelli G., Neri G., Donato A., Pietropaolo R. (1991). Hydrogenation of cinnamaldehyde over Ru/C catalysts: effect of Ru particle size. Journal of Molecular Catalysis, 64 (2), 237-246.

- Galvagno S., Milone C., Donate A., Neri G., Pietropaolo R. (1993). Influence of metal particle size in the hydrogenation of citral over Ru/C. Catalysis Letters, 18 (4), 349-355.

- Galvagno S., Milone C., Neri G., Donato A., Pietropaolo R. (1993). Hydrogenation of cinnamaldehyde and citral over Ru supported catalysts. Studies in Surface Science and Catalysis, 78, 163-170.

- Garg R. y Kuumar D. (2016). Pyrolysis of babool seeds (Acacia nilotica) in a fixed bed reactor and bio-oil characterization. Renewable Energy, 96, 167-171.

- Ghose T. K. (1987). Measurement of cellulase activities. Pure and Applied Chemistry, 59 (2), 257-268.

- Gomez Silva C. y Faria J. L. (2009). Anatase vs. rutile efficiency on the photocatalytic degradation of clofibric acid under near UV to visible irradiation. Photochemical \& PhotobiologicalSciences, 8 (5), 705-711.

- Gregg S. J. y Sing K. S. W. (1982). Adsorption, Surface Area and Porosity. London: Academic Press. 
- Gröger H. y Hummel W. (2014). Combining the "two worlds" of chemocatalysis and biocatalysis towards multi-step one-pot processes in aqueous media. Current Opinion in Chemical Biology, 19, 171-179.

- Guerrero-Ruiz A., Badenes P. y Rodríguez-Ramos I. (1998). Study of some factors affecting the Ru and Pt dispersions over high surface area graphitesupported catalysts. Applied Catalysis A: General, 173 (2), 313-321.

- Guha S. K., Kobayashi H., Fukuoka A.; M. Crocker (Ed.). (2010). Thermochemical Conversion of Biomass to Liquid Fuels and Chemicals. (pp. 344-364). Cambridge: Royal Society of Chemistry.

- Guo Z., Xiao C., Maligal-Ganesh R. V., Zhou L., Goh T. W., Li X., Tesfagaber D., Thiel A., Huang W. (2014). Pt Nanoclusters Confined within Metal - Organic Framework Cavities for Chemoselective Cinnamaldehyde Hydrogenation. ACS Catalysis, 4 (5), 1340-1348.

- Hall M., Bausal P., Lee J. H., Realff M. J., Bommarius A. S. (2011). Biological pretreatment of cellulose: Enhancing enzymatic hydrolysis rate using cellulosebinding domains from cellulases. Bioresource Technology, 102 (3), 2910-2915.

- Handjani S., Marceau E., Blanchard J., Krafft J. M., Che M., Mäki-Arvela P., Kumar N., Wärnå J., Murzin D. Y. (2011). Influence of the support composition and acidity on the catalytic properties of mesoporous SBA-15, Al-SBA-15, and $\mathrm{Al}_{2} \mathrm{O}_{3}$-supported $\mathrm{Pt}$ catalysts for cinnamaldehyde hydrogenation. Journal of Catalysis, 282 (1), 228-236.

- Heikkila H., Alen R., Kauko S., Lindroos M., Nurmi J., Sarmala P., Tylli M. (1999). Method of producing polyols from arabinoxylan-containing material. EP Patent 1002782.

- Heikkila H., Koivikko H., Ravanko V., Alen R., Nurmi J., Ojamo H., Haimi P., Tylli M. (2002). Process for the production of xilitol. WO Patent 2002088155.

- Hernandez Enríquez J. M., Cortez Lajas, L. A., García Alamilla R., Castillo Mares A., Sandoval Robles G., García Serrano L. A. (2009). Synthesis and characterization of mesoporous and nano-crystalline phosphate zirconium oxides. Journal of Alloys and Compounds, 483, 425-428. 
- Himmel M. E., Ding S. Y., Johnson D. K., Adney W. S., Nimlos M. R., Brady J. W., Foust T. D. (2007). Biomass recalcitrance: engineering plants and enzymes for biofuels production. Science, 315, 804-807.

- Hoffer B. W., Crezee E., Devred F., Mooijman P. R. M., Sloof W. G., Kooyman P. J., van Langeveld A. D., Kaptejn F., Moulijn J. A. (2003). The role of the active phase of Raney-type $\mathrm{Ni}$ catalysts in the selective hydrogenation of d-glucose to d-sorbitol. Applied Catalysis A: General, 253 (2), 437-452.

- Holladay J. E., White J. F., Bozell J. J., Johnson D. (2007). Top Value Added Chemicals From Biomass - Volume II - Results of Screening for Potential Candidates from Biorefinery Lignin. United States.

- Huber G. W., Cortright R. D. y Dumesic J. A. (2004). Renewable Alkanes by Aqueous-Phase Reforming of Biomass-Derived Oxygenates. Angewandte Chemie International Edition, 43 (12), 1549-1551.

- Huber G. W., Iborra S. y Corma A. (2006). Synthesis of Transportation Fuels from Biomass: Chemistry, Catalysts, and Engineering. Chemical Reviews, 106 (9), 4044-4098.

- Hughes S., Gibbons W., Moser B., Rich J. (2013). Sustainable multipurpose biorefineries for third-generation biofuels and value-added co-products. En: Fang Z (Ed.), Biofuels - Economy, Environment and Sustainability. (pp. 245-262). InTech.

- Humblot F., Didillon D., Lepeltier F., Candy J. P., Corker J., Clause O., Bayard F., Basset J. M. (1998). Surface Organometallic Chemistry on Metals: Formation of a Stable $: \mathrm{Sn}\left(\mathrm{n}-\mathrm{C}_{4} \mathrm{H}_{9}\right)$ Fragment as a Precursor of Surface Alloy Obtained by Stepwise Hydrogenolysis of $\mathrm{Sn}\left(\mathrm{n}-\mathrm{C}_{4} \mathrm{H}_{9}\right)_{4}$ on a Platinum Particle Supported on Silica. Journal of the American Chemical Society, 120, 137-146.

- Ide M. S., Hao B., Neurock M., Davis R. J. (2012). Mechanistic Insights on the Hydrogenation of $\alpha, \beta$-Unsaturated Ketones and Aldehydes to Unsaturated Alcohols over Metal Catalysts. ACS Catalysis, 2 (4), 671-683. 
- Ignatyev, I. A., Van Doorslaer C., Mertens P. G. N., Binnemans K., De Vos D. E. (2010). Reductive Splitting of Cellulose in the Ionic Liquid 1-Butyl-3Methylimidazolium Chloride. ChemSusChem, 3 (1), 91-96.

- Ikeda Y., Sakaihori Keiichi T., Tomishige K., Fujimoto K. (2000). Promoting effect of phosphoric acid on zirconia catalysts in selective synthesis of dimethyl carbonate from methanol and carbon dioxide. Catalysis Letters, 66 (1-2), 59-62.

- Industry Experts (2014). Xylitol. Polyol/Sugar Alcohol Sweetener. A Global Market Overview. Disponible en: https://www.marketresearch.com/product/ sample-8164119.pdf

- Ioannidou O. y Zabaniotou A. (2007). Agricultural residues as precursors for activated carbon production - A review. Renewable and Sustainable Energy Reviews, 11 (9), 1966-2005.

- Ioannidou O., Zabaniotou A., Antonakou E. V., Papazisi K. M., Lappas A. A., Athanassiou C. (2009). Investigating the potential for energy, fuel, materials and chemicals production from corn residues (cobs and stalks) by non-catalytic and catalytic pyrolysis in two reactor configurations. Renewable \& Sustainable Energy Reviews, 13, 750-762.

- Jaworski M. A., Lick I. D., Siria G. J., Casella M. L. (2014). $\mathrm{ZrO}_{2}$-modified $\mathrm{Al}_{2} \mathrm{O}_{3}$ supported $\mathrm{PdCu}$ catalysts for the water denitrification reaction. Applied Catalysis B: Environmental, 156-157, 53-61.

- Jones A. y Mc Nicol B. (1986). Temperature Programmed Reduction for Solid Material Characterization. New York: Marcel Dekker, Inc.

- Kajaste R. (2014). Chemicals from biomass - managing greenhouse gas emissions in biorefinery production chains - a review. Journal of Cleaner Production, 75, 1-10.

- Kamm B., Gruber P. R., Kamm M. (2005). Biorefineries-Industrial Processes and Products: Status Quo and Future Directions. Wiley-VCH.

- Kamm B. y Kamm M. (2004). Principles of biorefineries. Applied Microbiology and Biotechnology, 64, 137-145. 
- Kijeński J., Winiarek P., Paryjczak T., Lewicki A., Mikołajska A. (2002). Platinum deposited on monolayer supports in selective hydrogenation of furfural to furfuryl alcohol. Applied Catalysis A: General, 233 (1-2), 171-182.

- King D., Inderwildi O., Williams A., Hagan A. (2010) The future of industrial biorefineries. World Economic Forum, Ginebra, Suiza.

- Klimova T., Rojas M. L., Castillo P., Cuevas R., Ramírez J. (1998). Characterization of $\mathrm{Al}_{2} \mathrm{O}_{3}-\mathrm{ZrO}_{2}$ mixed oxide catalytic supports prepared by the sol-gel method. Microporous and Mesoporous Materials, 20 (1-4), 293-306.

- Kobayashi H., Ito Y., Komanoya T., Hosaka Y., Dhepe P. L., Kasai K., Hara K., Fukuoka A. (2011). Synthesis of sugar alcohols by hydrolytic hydrogenation of cellulose over supported metal catalysts. Green Chemistry, 13, 326-333.

- Kobayashi H., Komanoya T., Guha S.K., Hara K., Fukuoka A. (2011). Conversion of cellulose into renewable chemicals by supported metal catalysis. Applied Catalysis A: General 409-410, 13-20.

- Kohno S. y Yamatsu I. (1971). Preparation of xylitol. US Patent 3558725.

- Kondo, T. S. (2005). Hydrogen bonds in cellulose and cellulose derivatives. En: Dumitriu S. (Ed.), Polysaccharides: Structural Diversity and Functional Versatility 2da. ed. (pp. 69-98). New York: Marcel Dekker.

- Kusserow B., Schimpf S. y Claus P. (2003). Hydrogenation of Glucose to Sorbitol over Nickel and Ruthenium Catalysts. Advanced Synthesis \& Catalysis, 345 (1-2), 289-299.

- Lashdaf M., Krause A., Lindblad M., Tiitta M., Venalainen T. (2003). Behaviour of palladium and ruthenium catalysts on alumina and silica prepared by gas and liquid phase deposition in cinnamaldehyde hydrogenation. Applied Catalysis A: General, 241 (1-2), 65-75.

- Lazaridis P. A., Karakoulia S., Delimitis A., Coman S. M., Parvulescu V. I., Triantafyllidis K. S. (2015). D-Glucose hydrogenation/hydrogenolysis reactions on noble metal (Ru, Pt)/activated carbon supported catalysts. Catalysis Today, 257 (2), 281-290. 
- Lee J., Kim Y. T. y Huber G. W. (2014). Aqueous-phase hydrogenation and hydrodeoxygenation of biomass-derived oxygenates with bimetallic catalysts. Green Chemistry, 16, 708-718.

- Lee J., Xu Y. y Huber G. W. High-throughput screening of monometallic catalysts for aqueous-phase hydrogenation of biomass-derived oxygenates. (2013). Applied Catalysis B: Environmental, 140-141, 98-107.

- Lefebvre F., Candy J. P. y Basset J. M. (1999). En: Braunstein P., Oro L. A. y Raithby P. R. (eds.), Metal Clusters in Chemistry (p. 782). Weinheim: Wiley VCH Verlag $\mathrm{GmbH}$.

- Li H., Chu D., Liu J., Qiao M., Dai W., Li H. (2008). A Novel RutheniumPhosphorus Amorphous Alloy Catalyst for Maltose Hydrogenation to Maltitol. Advanced Synthesis \& Catalysis, 350 (6), 829-836.

- Li H., Li H. y Deng J. F. (2002). Glucose hydrogenation over Ni$\mathrm{B} / \mathrm{SiO}_{2}$ amorphous alloy catalyst and the promoting effect of metal dopants. Catalysis Today, 74 (1-2), 53-63.

- $\quad$ Li H., Luo H., Zhuang L., Dai W., Qiao M. (2003). Liquid phase hydrogenation of furfural to furfuryl alcohol over the Fe-promoted Ni-B amorphous alloy catalysts. Journal of Molecular Catalysis A: Chemical, 203 (1-2), 267-275.

- $\quad$ Li H. X., Wang W. J. y Deng J. F. (2000). Glucose hydrogenation to sorbitol over a skeletal Ni-P amorphous alloy catalyst (Raney Ni-P). Journal of Catalysis, 191 (1), 257-260.

- Li N., Tompsett G. A., Zhang T., Shi J., Wyman C. E., Huber G. W. (2011). Renewable gasoline from aqueous phase hydrodeoxygenation of aqueous sugar solutions prepared by hydrolysis of maple wood. Green Chemistry, 13, 91101.

- Liaw B., Chiang S., Chen S., Chen Y. (2008). Preparation and catalysis of amorphous $\mathrm{CoNiB}$ and polymer-stabilized CoNiB catalysts for hydrogenation of unsaturated aldehydes. Applied Catalysis A: General, 346 (1-2), 179-188. 
- Lieske H. y Völter J. (1984). State of tin in $\mathrm{Pt}-\mathrm{SnAl}_{2} \mathrm{O}_{3}$ reforming catalysts investigated by TPR and chemisorptions. Journal of Catalysis, 90 (1), 96-105.

- $\quad$ Lim C. H., Mohammed I. Y., Abakr Y. A., Kazi F. K., Yusup S., Lam H. L. (2016). Novel input-output prediction approach for biomass pyrolysis. Journal of Cleaner Production, 136, 51-61.

- Liu Z., Tan X., Li J., Lv C. (2013). Easy synthesis of bimetal PtFe-containing ordered mesoporous carbons and their use as catalysts for selective cinnamaldehyde hydrogenation. New Journal of Chemistry, 37, 1350-1357.

- $\quad$ Luo C., Wang S. y Liu H. (2007). Cellulose Conversion into Polyols Catalyzed by Reversibly Formed Acids and Supported Ruthenium Clusters in Hot Water. Angewandte Chemie International Edition, 46 (40), 7636-7639.

- Mäki-Arvela P., Salmi T., Holmbom B., Willför S., Murzin D. Y. (2011). Synthesis of sugars by hydrolysis of hemicelluloses. A review. Chemical Reviews, 111, 5638-5666.

- Makinen K. K. (1992). Dietary prevention of dental caries by xylitol clinical beffectiveness and safety. The Journal of Applied Nutrition, 44, 16-28.

- Makkee M., Kieboom A. P. G., Van Bekkum H. (1985). Hydrogenation of dfructose and d-fructose/d-glucose mixtures. Carbohydrate Research, 138, 225236.

- Mamman A. S. (2008). Furfural: Hemicellulose/xylose-derived biochemical. Biofuels, Bioproducts and Biorefining, 2, 438-454.

- Mao H., Chen C., Liao X. P., Shi B. (2011). Catalytic hydrogenation of quinoline over recyclable palladium nanoparticles supported on tannin grafted collagen fibers. Journal of Molecular Catalysis A: Chemical, 341, 51-56.

- Margitfalvi J., Borbath I., Hegeds M., Tompos A. (2002). Preparation of new type of $\mathrm{Sn}-\mathrm{Pt} / \mathrm{SiO}_{2}$ catalysts for carbonyl activation. Applied Catalysis A: General, 229 (1-2), 35-49. 
- Margitfalvi J., Hegedüs M., Göbölös S., Kern-Tálas E. , Szedlacsek P., Szabó S., Nagy F. (1984). Proceedings of the 8th International Congress on Catalysis, Berin, Germany, 4 p. 903.

- Marijuan de Santiago L. (1988). Cinética de adsorción de compuestos fenólicos en disolución acuosa sobre carbón activo: determinación de los coeficientes de difusión interna. (Tesis Doctoral). Universidad Complutense de Madrid.

- Marinelli T., Nabuurs S., Ponec V. (1995). Activity and Selectivity in the Reactions of Substituted $\alpha, \beta$-Unsaturated Aldehydes. Journal of Catalysis, 151 (2), 431-438.

- Materials Design, Application Note Phase Transitions in ZrO2 (2009).

- Meille V., Pestre N., Fongarland P., de Bellefon C. (2004). Gas/Liquid Mass Transfer in Small Laboratory Batch Reactors: Comparison of Methods. Ind. Eng. Chem. Res., 2004, 42 (43), pp. 924-927.

- Menon V. y Rao M. (2012). Trends in bioconversion of lignocellulose: Biofuels, platform chemicals \& biorefinery concept. Progress in Energy and Combustion Science, 38 (4), 522-550.

- Merat N., Godawa C. y Gaset A. (1990). High selective production of tetrahydrofurfuryl alcohol: Catalytic hydrogenation of furfural and furfuryl alcohol. Journal of Chemical Technology and Biotechnology, 48 (2), 145-159.

- Mercadante L., Neri G., Milone C., Donato A., Galvagno S. (1996). Hydrogenation of $\alpha, \beta$-unsaturated aldehydes over $\mathrm{Ru} / \mathrm{Al}_{2} \mathrm{O}_{3}$ catalysts. Journal of Molecular Catalysis A: Chemical, 105 (3), 93-102.

- Merlo A. B., Machado B. F., Vetere V., Faria J. L., Casella M. L. (2010). PtSn/SiO 2 catalysts prepared by surface controlled reactions for the selective hydrogenation of cinnamaldehyde. Applied Catalysis A: General, 383, 43-49.

- Merlo A. B., Vetere V., Ruggera J., Casella M. (2009). Bimetallic PtSn catalyst for the selective hydrogenation of furfural to furfuryl alcohol in liquid-phase. Catalysis Communications, 10, 1665-1669. 
- Mikkola J. P., Vainio H., Salmi T., Sjöholm R., Ollonqvist T., Väyrynen J. (2000). Deactivation kinetics of Mo-supported Raney Ni catalyst in the hydrogenation of xylose to xylitol. Applied Catalysis A: General, 196, 143-155.

- Miller G. L. (1959). Use of Dinitrosalicylic Acid Reagent for Determination of Reducing Sugar. Analytical Chemistry, 31 (3), 426-428.

- Milone C., Ingoglia R., Tropeano M. L., Neria G., Galvagno S. (2003). First example of selective hydrogenation of unconstrained $\alpha, \beta$-unsaturated ketone to $\alpha, \beta$-unsaturated alcohol by molecular hydrogen. Chemical Communications, 7, 868-869.

- Mironenko R. M., Belskaya O. B., Gulyaeva T. Y., Nizovskii A. I., Kalinkin A. V., Bukhtiyarov V. I., Lavrenov A. V., Likholobov V. A. (2015). Effect of the nature of carbon support on the formation of active sites in $\mathrm{Pd} / \mathrm{C}$ and $\mathrm{Ru} / \mathrm{C}$ catalysts for hydrogenation of furfural. Catalysis Today, 249, 145-152.

- Mishra D. K., Dabbawala A. A. y Hwang J. S. (2013)a. Poly (styrene-codivinylbenzene) amine functionalized polymer supported ruthenium nanoparticles catalyst active in hydrogenation of xylose. Catalysis Communications, 41, 52-55.

- Mishra D. K., Dabbawala A. A. y Hwang J. S. (2013)b. Ruthenium nanoparticles supported on zeolite $Y$ as an efficient catalyst for selective hydrogenation of xylose to xylitol.Journal of Molecular Catalysis A: Chemical, 376, 63-70.

- Mishra D. K., Dabbawala A. A., Park J. J., Jhung S. H., Hwang J. S. (2014). Selective hydrogenation of $d$-glucose to d-sorbitol over HY zeolitesupported ruthenium nanoparticles catalysts. Catalysis Today, 232, 99-107.

- Mojet B. L., Miller J. T., Ramaker D. E., Koningsberger D. C. (1999). A New Model Describing the Metal-Support Interaction in Noble Metal Catalysts. Journal of Catalysis, 186 (2), 373-386.

- Monson P. A. (2012). Understanding adsorption/desorption hysteresis for fluids in mesoporous materials using simple molecular models and classical density functional theory. Microporous Mesoporous Mater, 160, 47-66. 
- Musci J. J., Merlo A. B. y Casella M. L. (2017). Aqueous phase hydrogenation of furfural using carbon-supported Ru and RuSn catalysts. Catalysis Today, 296, 43-50.

- Nagaraja B. M., Kumar V., Shasikala V., Padmasri A., Sreedhar B., David Raju B., Rama Rao K. S. (2003). A highly efficient $\mathrm{Cu} / \mathrm{MgO}$ catalyst for vapour phase hydrogenation of furfural to furfuryl alcohol. Catalysis Commununications, 4 (6), 287-293.

- Negahdar L., Delidovich I. y Palkovits R. (2016). Aqueous-phase hydrolysis of cellulose and hemicelluloses over molecular acidic catalysts: Insights into the kinetics and reaction mechanism. Applied Catalysis B: Environmental, 184, 285298.

- Negoi A., Triantafyllidis K., Parvulescu V. I., Coman S. M. (2014). The hydrolytic hydrogenation of cellulose to sorbitol over $M(R u, I r, P d, R h)-B E A-z e o l i t e$ catalysts. Catalysis Today, 223, 122-128.

- Neri G., Bonaccorsi L., Mercadante L., Galvagno S. (1997). Kinetic Analysis of Cinnamaldehyde Hydrogenation over Alumina-Supported Ruthenium Catalysts. Industrial \& Engineering Chemistry Research, 36, 3554-3562.

- Neri G., Mercadante L., Milone C., Pietropaolo R., Galvagno S. (1996). Hydrogenation of citral and cinnamaldehyde over bimetallic Ru$\mathrm{Me} / \mathrm{Al}_{2} \mathrm{O}_{3}$ catalysts. Journal of Molecular Catalysis A: Chemical, 108 (1), 41-50.

- Nitta Y., Ueno K. y Imanaka T. (1989). Selective hydrogenation of $\alpha \beta$ unsaturated aldehydes on cobalt-silica catalysts obtained from cobalt chrysotile. Applied Catalysis, 56 (1), 9-22.

- Niu Y., Wang H., Zhu X., Song Z., Xie X., Liu X., Han J., Ge Q. (2014). Ru supported on zirconia-modified SBA-15 for selective conversion of cellobiose to hexitols. Microporous and Mesoporous Materials, 198, 215-222.

- Octave S. y Thomas D. (2009). Biorefinery: Toward an industrial metabolism. Biochimie, 91 (6), 659-64. 
- O’Driscoll Á., Leahy J. J. y Curtin T. (2017). The influence of metal selection on catalyst activity for the liquid phase hydrogenation of furfural to furfuryl alcohol. Catalysis Today, 279 (2), 194-201.

- Olinger P. M., Pepper T. (2001), en: L. O. Nabors (Ed.), Alternative Sweetners, Marcel Dekker, New York, Basel, pp. 335-365.

- Patel M. (2006). Medium and Long-term Opportunities and Risks of the Biotechnological Production of Bulk Chemicals from Renewable Resources. The Brew Project. Utrecht University, Utrecht, The Netherlands.

- Perego C. y Villa P. (1997). Catalyst preparation methods. Catalysis Today,34, 281-305.

- Perrard A., Gallezot P., Joly J. P., Durand R., Baljou C., Coq B., Trens P. (2007). Highly efficient metal catalysts supported on activated carbon cloths: A catalytic application for the hydrogenation of d-glucose to d-sorbitol. Applied Catalysis A: General, 331, 100-104.

- Pham T. N., Samikannu A., Rautio A.R., Juhasz K. L., Konya Z., Wärnå J., Kordas K., Mikkola J.P. (2016). Catalytic Hydrogenation of d-Xylose Over Ru Decorated Carbon Foam Catalyst in a SpinChem Rotating Bed Reactor. Topics in Catalysis, 59 (13-14), 1165-1177.

- Ramachandran P. y Chaudhari R. (1983). Three phase catalytic reactors. New York: Gordon and Breach Science.

- Ramaker D. E., de Graaf J., van Veen J. A. R., Koningsberger D. C. (2001). Nature of the Metal-Support Interaction in Supported Pt Catalysts: Shift in Pt Valence Orbital Energy and Charge Rearrangement. Journal of Catalysis, 203 (1), 7-17.

- Ramírez-Corredores, M. M. (2013)a. The role of catalysis for the sustainable production of biofuels and biochemicals. En: Triantafyllidis K. S., Lappas A. A., Stocker M. (Eds.), Pathways and Mechanisms of Fast Pyrolysis: Impact on Catalyst Research, vol. 6 (p. 166). Amsterdam: Elsevier.

- Ramírez-Corredores, M. M. (2013)b. The role of catalysis for the sustainable production of biofuels and biochemicals. En: Triantafyllidis K. S., Lappas A. A., 
Stocker M. (Eds.), Pathways and Mechanisms of Fast Pyrolysis: Impact on Catalyst Research (p. 186). Amsterdam: Elsevier.

- Rao R. S., Baker R. T. K. y Vannice M. A. (1999). Furfural hydrogenation over carbon-supported copper. Catalysis Letters, 60 (1-2), 51-57.

- Rao R. S., Dandekar A., Baker R. T. K., Vannice M. A. (1997). J. Properties of Copper Chromite Catalysts in Hydrogenation Reactions. Journal of Catalysis, $171(2), 406-419$.

- Rao R. S., Gallagher J., Fish S., Prakasham R. S. (2012). Overview on Commercial Production of Xylitol, Economic Analysis and Market Trends. En: da Silva S., Chandel A. (Eds.). D-Xylitol Fermentative Production, Application and Commercialization (pp. 291-306). Berlin Heidelberg: Springer.

- Resasco D. E., Faria J., Sitthisa S., Prasomsri T., Ruiz M. P. (2011). Furfurals as chemical platform for biofuel production. En: Kubička D. y Kubičkova I. (Eds.), Heterogeneous catalysis in biomass to chemicals and fuels. Kerala, India: Research Signpost.

- Rinaldi R. y Schüth F. (2009). Acid Hydrolysis of Cellulose as the Entry Point into Biorefinery Schemes. ChemSusChem, 2 (12), 1096-1107.

- Rodiansono, Astuti M. D., Santoso U. P., Shimazu S., (2015). Hydrogenation of Biomass-derived Furfural Over Highly Dispersed-Aluminium Hydroxide Supported Ni-Sn(3.0) Alloy Catalysts. Procedia Chemistry, 16, 531-539.

- Rodriguez J. A., Jirsak T., Chaturvedi S., Hrbek J. (1998). Surface Chemistry of $\mathrm{SO}_{2}$ on $\mathrm{Sn}$ and $\mathrm{Sn} / \mathrm{Pt}(111)$ Alloys: Effects of Metal-Metal Bonding on Reactivity toward Sulfur. Journal of the American Chemical Society, 120 (43), 1114911157.

- Rodríguez Reinoso F. (2009), Retos Actuales en la Síntesis y Aplicación de Carbones Activados. Plenaria 3, $1^{\circ}$ Simposio sobre Adsorción, Adsorbentes y sus Aplicaciones, SAASA.

- Rojas H., Borda G., Rosas D., Martínez J. J., Reyes P. (2008). Hydrogenation of furfural on ir/nb2o5 catalyst study kinetic. Dyna, 155, 115-122. 
- Ruppert A. M., Weinberg K. y Palkovits R. (2012). Hydrogenolysis Goes Bio: From Carbohydrates and Sugar Alcohols to Platform Chemicals. Angewandte Chemie International Edition, 51 (11), 2564-2601.

- SábadaZubiri I. (2012). Catalizadores para biorrefinería obtención de furfural y su transformación a productos de condensación aldólica. (Tesis Doctoral). Instituto de Catálisis y Petroquímica (CSIC).

- Sander R., 1999, version 3. Compilation of Henry's Law Constants for Inorganic and Organic Species of Potential Importance in Environmental Chemistry.

- Sano Y., Yamaguchi N. y Adachi T. (1974). Mass Transfer Coefficients for Suspended Particles in Agitated Vessels and Bubble Columns. Journal of Chemical Engineering of Japan, 7, 255-261.

- Santori G. F., Casella M. L., Siri G. J., Adúriz H. R., Ferretti O. A. (2000). Hydrogenation of crotonaldehyde on $\mathrm{Pt} / \mathrm{SiO}_{2}$ catalysts modified with tin added via surface organometallic chemistry on metals techniques. Applied Catalysis A: General, 197 (1), 141-149.

- Santori G. F., Moglioni A. G., Vetere V., Moltrasio Iglesias G. Y., Casella M. L., Ferretti O. A. (2004). Hydrogenation of aromatic ketones with Pt- and Snmodified Pt catalysts. Applied Catalysis A: General, 269 (1-2), 215-223.

- Saparrat M. C. N., Estevez J. M., Troncozo M. I., Arambarri A. M., Balatti P. A. (2010). In-vitro depolymerization of Scutia buxifolia leaf-litter by a dominant Ascomycota Ciliochorella sp. International Biodeterioration \& Biodegradation, $64,262-266$.

- Sarkar A. y Pramanik P. (2009). Synthesis of mesoporous niobium oxophosphate using niobium tartrate precursor by soft templating method. Microporous Mesoporous Materials, 117, 580-85.

- Seo, G. y Chon, H. (1981). Hydrogenation of furfural over copper-containing catalysts. Journal of Catalysis, 67 (2), 424-429. 
- Seok Whang H., Seok Choi M., Lim J., Kim C., Heo I., Chang T. S., Lee H. (2017). Enhanced activity and durability of Ru catalyst dispersed on zirconia for dry reforming of methane. Catalysis Today, 293-294, 122-128.

- Serrano-Ruiz J., López-Cudero A., Solla-Gullón J., Sepúlveda-Escribano A., Aldaz A., Rodríguez-Reinoso F. (2008). Hydrogenation of $\alpha, b$ unsaturated aldehydes over polycrystalline, (111) and (100) preferentially oriented Pt nanoparticles supported on carbon. Journal of Catalysis, 253 (1), 159-166.

- Serrano-Ruiz J. C., Luque R. y Sepúlveda-Escribano A. (2011). Transformations of biomass-derived platform molecules: from high added-value chemicals to fuelsvia aqueous-phase processing. Chemical Society Reviews, 40, 5266-5281.

- $\quad$ Sing K. S. W., Everett D. H., Haul R. A. W., Moscou L., Pierotti R. A., Rouquérol J., Siemieniewska T. (1985).Reporting physisorption data for gas/solid systems with special rederence to the determination of surface area and porosity. Pure and Applied Chemistry, 57 (4), 603-619.

- Siri G. J., Ramallo-López J. M., Casella M. L., Fierro J. L. G., Requejo F. G., Ferretti O. A. (2005). XPS and EXAFS study of supported PtSn catalysts obtained by surface organometallic chemistry on metals: Application to the isobutane dehydrogenation. Applied Catalysis A: General, 278 (2), 239-249.

- Sitthisa S., Na W. y Resasco D. E. (2011). Selective conversion of furfural to methylfuran over silica-supported NiFe bimetallic catalysts. Journal of Catalysis, 284 (1), 90-101.

- Sitthisa S., Sooknoi T., Ma Y., Balbuena P. B., Resasco D. E. (2011). Kinetics and mechanism of hydrogenation of furfural on $\mathrm{Cu} / \mathrm{SiO}_{2}$ catalysts. Journal of Catalysis, 277 (1), 1-13.

- Skoog, D. A. y West, D. M. (2001). Análisis Instrumental. Madrid: Mc Graw Hill.

- Srinivasan R., Watkins T. R., Hubbard C. R., Davis B. H. (1995). Sulfated Zirconia Catalysts. The Crystal Phases and Their Transformations. Chemistry of Materials, 7 (4), 725-730.

- Stakheev A. Yu., Zhang Y., Ivanov A. V., Baeva G. N., Ramaker D. E., Koningsberger D. C. (2007). Separation of Geometric and Electronic Effects of 
the Support on the $\mathrm{CO}$ and $\mathrm{H} 2$ Chemisorption Properties of Supported $\mathrm{Pt}$ Particles: The Effect of Ionicity in Modified Alumina Supports. The Journal of Physical Chemistry C, 111 (10), 3938-3948.

- Steffan M., Lucas M., Brandner A., Wollny M., Oldenburg N., Claus P. (2007). Selective Hydrogenation of Citral in an Organic Solvent, in a lonic Liquid, and in Substance. Chemical Engineering \& Technology, 30 (4), 481-486.

- Stenhouse J. (1840). Über das sogenannte künstliche Ameisenöl. Justus Liebigs Annalen der Chemie, 35 (3), 301-304.

- Stoeckli F. (1990). Microporous carbons and their characterization: The present state of the art. Carbon, 28, 1-6.

- Su D. (2017). Advanced electron microscopy characterization of nanomaterials for catalysis. (2017). Green Energy \& Environment, 2 (2), 70-83.

- Tanabe K. (1985). Surface and catalytic properties of $\mathrm{ZrO}_{2}$. Materials Chemistry and Physics, 13 (3-4), 347-364.

- Tangchupong N., Khaodee W., Jongsomjit B., Laosiripojana N., Praserthdam P., Assabumrungrat S. (2010). Effect of calcination temperature on characteristics of sulfated zirconia and its application as catalyst for isosynthesis. Fuel Processing Technology 91 (1), 121-126.

- Tathod A. P. y Dhepe P. L. (2015). Efficient method for the conversion of agricultural waste into sugar alcohols over supported bimetallic catalysts. Bioresource Technology, 178, 36-44.

- Thommes M. y Cychosz K. A. (2014). Physical adsorption characterization of nanoporous materials: progress and challenges. Adsorption, 20 (2-3), 233-250.

- Thommes M., M., Kaneko, K., Neimark, A. V., Olivier, J. P., Rodriguez Reinoso, F., Rouquerol, J. y Sing, K. S. W. (2015). Physisorption of gases, with special reference to the evaluation of surface area and pore size distribution (IUPAC Technical Report). Pure and Applied Chemistry, 87 (9-10), 1051-1069.

- Tidahy H. L., Siffert S., Wyrwalski F., Lamonier J. F. Aboukaïs A. (2007). Catalytic activity of copper and palladium based catalysts for toluene total oxidation. Catalysis Today, 119 (1-4), 317-320. 
- Tolón Becerra A., Lastra Bravo X., Piñero Contreras F. J., Fernández Montero S. (2011). European Union energy policy for sustainable development, Cambio Climático, Riesgos Nat. y Tecnológicos en el Context. Desarro. 61-100.

- Toraya H., Yoshimura M. y Somiya S. (1984). Calibration curve for quantitative analysis of the monoclinic-tetragonal ZrO2 system by X-ray diffraction. Journal of the American Ceramic Society, 67 (6), 119-121.

- $\quad$ Torres G. C., Ledesma S. D., Jablonski E. L., De Miguel S. R., Scelza O. A. (1999). Hydrogenation of carvone on $\mathrm{Pt}-\mathrm{Sn} / \mathrm{Al}_{2} \mathrm{O}_{3}$ catalysts. Catalysis Today, 48 (1-4), $65-72$.

- Travers C., Bournonville J. P. y Martino G. (1984). Proceedings of the 8th International Congress on Catalysis, Berlin, Germany, p. 891.

- Van Gorpa K., Boerman E., Cavenaghi C. V., Berben P. H. (1999). Catalytic hydrogenation of fine chemicals: sorbitol production. Catalysis Today, 52 (2-3), 349-361.

- Vilcocq L., Cabiac A., Especel C., Guillon E., Duprez D. (2013). Transformation of Sorbitol to Biofuels by Heterogeneous Catalysis: Chemical and Industrial Considerations. Oil \& Gas Science and Technology, 68 (5), 841-860.

- Vilella I. M. J., de Miguel S. R., Salinas-Martínez de Lecea C., Linares-Solano A., Scelza O. A. (2005). Catalytic performance in citral hydrogenation and characterization of PtSn catalysts supported on activated carbon felt and powder. Applied Catalysis A: General, 281, 247-258.

- Von Arx, M. Mallat T. y Baiker A. (1999). Unprecedented selectivity behaviour in the hydrogenation of an $\alpha, \beta$-unsaturated ketone: hydrogenation of ketoisophorone over alumina-supported Pt and Pd. Journal of Molecular Catalysis A: Chemical, 148 (1-2), 275-283.

- Wagner C. D. (1989). SRD-20 X-ray Photoelectron Spectroscopy Database. (version 1.0). Gaithersburg, MD: National Institute of Standards and Technology (NIST). 
- Wang S. G., Vorotnikov V. y Vlachos D. G. (2915). Coverage-Induced Conformational Effects on Activity and Selectivity: Hydrogenation and Decarbonylation of Furfural on Pd (111). ACS Catalysis, 5 (1), 104-112.

- Werpy T., y Petersen, G. (2004) Top Value Added Chemicals from Biomass: Volume I - Results of Screening for Potential Candidates from Sugars and Synthesis Gas. United States.

- Wettstein S. G., Alonso D. M., Gu E. I., Dumesic J. A. (2012). A roadmap for conversion of lignocellulosic biomass to chemicals and fuels. Current Opinion in Chemical Engineering, 1, 218-224.

- Wettstein S. G., Bond J. Q., Alonso D. M., Pham H. N., Datye A. K., Dumesic J. A. (2012). RuSn bimetallic catalysts for selective hydrogenation of levulinic acid to Y-valerolactone. Applied Catalysis B: Environmental, 117-118, 321-329.

- Wisniak J., Hershkowitz M., Leibowitz R., Stein S. (1974). Hydrogenation of Xylose to Xylitol. Industrial \& Engineering Chemistry Product Research and Development, 13 (1), 75-79.

- Wisniak J. y Simon R. (1979). Hydrogenation of Glucose, Fructose, and Their Mixtures. Industrial \& Engineering Chemistry Product Research and Development, 18 (1), 50-57.

- Wu J., Shen Y., Liu C., Wang H., Geng C., Zhang Z. (2005). Vapor phase hydrogenation of furfural to furfuryl alcohol over environmentally friendly $\mathrm{Cu}$ $\mathrm{Ca} / \mathrm{SiO}_{2}$ catalyst. Catalysis Communications, 6 (9), 633-637.

- Wyman C. E., Decker S. R., Himmel M. E., Brady J. W., Skopec C. E., Viikari L., en: S. Dumitriu (Ed.), Hydrolysis of Cellulose and Hemicellulose, Marcel Dekker, Inc., New York, 2004, pp. 995-1033.

- Yadav M., Mishra D. K. y Hwang J. (2012). Catalytic hydrogenation of xylose to xylitol using ruthenium catalyst on $\mathrm{NiO}$ modified $\mathrm{TiO}_{2}$ support. Applied Catalysis A: General, 425-426, 110-116.

- Yamaguchi T. (1994). Application of $\mathrm{ZrO}_{2}$ as a catalyst and a catalyst support. Catalysis Today, 20, 199-217. 
- Yermakov Y. I., Kuznetsov B. N. y Zakharov V. A.; Catalysis By Supported Complexes, (1981), Elsevier, Amsterdam.

- Yoon E.Y. (2001). A Conformational Study of Oligosaccharides Investigated by Tandem Mass Spectrometry and Molecular Modeling. Bulletin of the Korean Chemical Society, 22 (3), 293-297.

- Yoshida S., Yamashita H., Funabiki T., Yonezawa T. (1984). Catalysis by amorphous metal alloys. Part 1. - Hydrogenation of olefins over amorphous $\mathrm{Ni}$ $\mathrm{P}$ and Ni-B alloys. Journal of the Chemical Society, Faraday Transactions 1: Physical Chemistry in Condensed Phases, 80, 1435-1446.

- Yuan Q., Zhang D., van Haandel L., Ye F., Xue T., Hensen E. J. M., Guan Y. (2015). Selective liquid phase hydrogenation of furfural to furfuryl alcohol by Ru/ZrMOFs. Journal of Molecular Catalysis A: Chemical, 406, 58-64.

- Zeitsch K. L. (2000). The chemistry and technology of furfural and its many byproducts. Elsevier Science.

- Zhang C., Lai Q. y Holles J. H. (2017). Bimetallic overlayer catalysts with high selectivity and reactivity for furfural hydrogenation. Catalysis Communications, $89,77-80$.

- Zhang H. P. y Lynd L. R. (2004). Toward an aggregated understanding of enzymatic hydrolysis of cellulose: Non complexed cellulase systems. Biotechnology and Bioengineering, 88 (7), 797-824.

- Zhang J., Li J. B., Wu S. B. y Ying Liu. (2013) Advances in the Catalytic Production and Utilization of Sorbitol. Industrial \& Engineering Chemistry Research, 52, 11799-11815.

- Zhang J., Lin L., Zhang J., Shi J. (2011). Efficient conversion of d-glucose into dsorbitol over MCM-41 supported Ru catalyst prepared by a formaldehyde reduction process. Carbohydrate Research, 346 (11), 1327-1332.

- Zhang X., Durndell L. J., Isaacs M. A., Parlett C. M. A., Lee A. F., Wilson K. (2016). Platinum-Catalyzed Aqueous-Phase Hydrogenation of d-Glucose to d-Sorbitol. ACS Catalysis, 6 (11), 7409-7417. 
- Zhao H., Kwak J. H., Wang Y., Franz J. A., White J. M., Holladay J. E. (2006). Effects of Crystallinity on Dilute Acid Hydrolysis of Cellulose by Cellulose BallMilling Study. Energy \& Fuels, 20 (2), 807-811.

- Zheng H. Y., Zhua Y. L., Teng B. T., Bai Z. Q., Zhang C. H., Xiang H. W., Li Y. W. (2006). Towards understanding the reaction pathway in vapour phase hydrogenation of furfural to 2-methylfuran. Journal of Molecular Catalysis A: Chemical, 246 (1-2), 18-23.

- Zhu Y. y Zaera F. (2914). Selectivity in the catalytic hydrogenation of cinnamaldehyde promoted by $\mathrm{Pt} / \mathrm{SiO} 2$ as a function of metal nanoparticle size. Catalysis Science \& Technology, 4, 955-962. 